NASA Technical Memorandum 104797

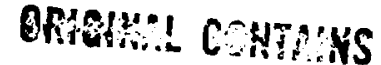

CELER HEUTIRATIBIS

\title{
Cratering and Penetration Experiments in Teflon Targets at Velocities from 1 to $7 \mathrm{~km} / \mathrm{s}$
}

Friedrich Hörz

Mark Cintala

Ronald P. Bernhard

Frank Cardenas

William Davidson

Gerald Haynes

Thomas H. See

Jerry Winkler

Jeffrey Knight

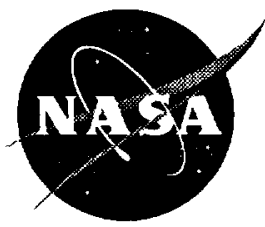





\begin{abstract}
Approximately $20 \mathrm{~m}^{2}$ of protective thermal blankets, largely composed of teflon, were retrieved from the Long Duration Exposure Facility (LDEF) after the spacecraft had spent $\sim 5.7$ years in space. Examination of these blankets revealed that they contained thousands of hypervelocity impact features ranging from micron-sized craters to penetration holes several millimeters in diameter. We conducted impact experiments in an effort to reproduce such features and to -- hopefully -- understand the relationships between projectile size and the resulting crater or penetration-hole diameter over a wide range of impact velocity. Such relationships are needed to derive the size and mass frequency distribution and flux of natural and man-made particles in low-Earth orbit.

Powder propellant and light-gas guns were used to launch soda-lime glass spheres of $3.175 \mathrm{~mm}\left(1 / 8^{\prime \prime}\right)$ nominal diameter $\left(D_{p}\right)$ into pure Teflon ${ }^{\mathrm{FEP}}$ targets at velocities ranging from 1 to $7 \mathrm{~km} / \mathrm{s}$. Target thickness (T) was varied over more than three orders of magnitude from infinite halfspace targets $\left(D_{p} / T<0.1\right)$ to very thin films $\left(\mathrm{D}_{\mathrm{p}} / \mathrm{T}>100\right)$.

Cratering and penetration of massive teflon targets is dominated by brittle failure and the development of extensive spall zones at the target's front and, if penetrated, the target's rear side. Mass removal by spallation at the back side of teflon targets may be so severe that the absolute penetration-hole diameter $\left(D_{h}\right)$ can become larger than that of a standard crater $\left(D_{c}\right)$ at relative target thicknesses of $D_{p} / T$ $=0.6-0.9$. The crater diameter in infinite halfspace teflon targets increases - - at otherwise constant impact conditions -- with encounter velocity by a factor of $\mathrm{V} 0.44$. In contrast, the penetration-hole size in very thin foils $\left(D_{p} / T>50\right)$ is essentially unaffected by impact velocity. Penetrations at target thicknesses intermediate to these extremes will scale with variable exponents of $V$. Our experimental matrix is sufficiently systematic and complete, up to $7 \mathrm{~km} / \mathrm{s}$, to make reasonable recommendations for the velocityscaling of teflon craters and penetrations. We specifically suggest that cratering behavior and associated equations apply to all impacts in which the shock-pulse duration of the projectile $\left(t_{p}\right)$ is shorter than that of the target $\left(t_{t}\right)$. We also demonstrate that each penetration hole from space-retrieved surfaces may be assigned a unique projectile size, provided an impact velocity is known or assumed. This calibration seems superior to the traditional ballistic-limit approach.
\end{abstract}





\section{TABLE OF CONTENT}

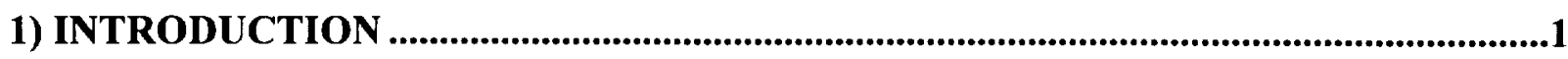

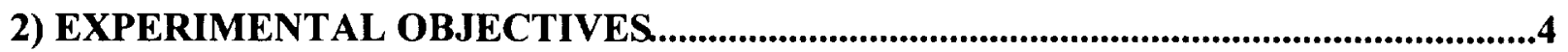

3) EXPERIMENTAL PROCEDURES .................................................................................5

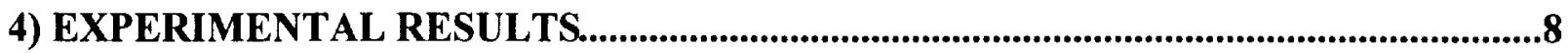

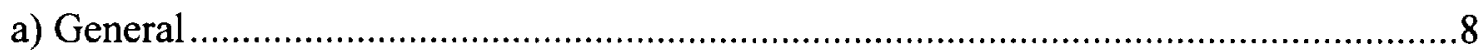

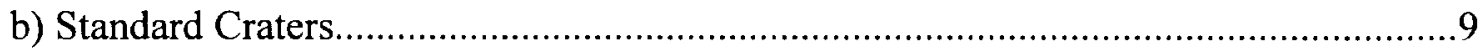

c) Penetration-holes: Morphologic Elements and Evolution .......................................12

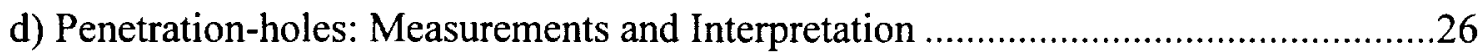

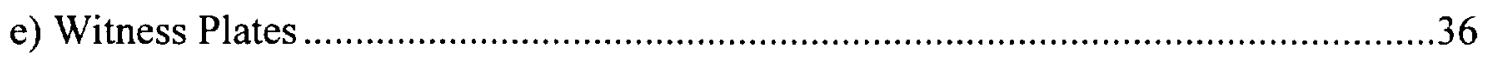

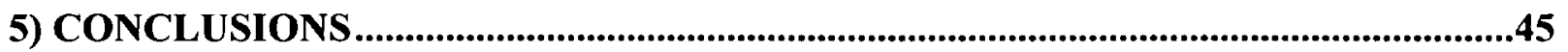

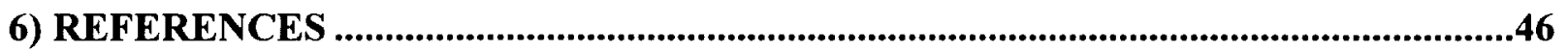

7) APPENDIX .................................................................................................................................49

8) TABLES OF EXPERIMENTAL CONDITIONS AND RESULTS............................A143 



\section{1) INTRODUCTION}

A detailed understanding of impacts into both massive and relatively thin targets is needed to characterize the hypervelocity particle environment in low-Earth orbit (LEO) from the analysis of space-exposed surfaces (e.g., Levine, 1992, 1993; McDonnell, 1992; Flury, 1993). In addition, flight instruments are being developed that aim at measuring the trajectories of individual particles prior to decelerating them in such a fashion that their residues may be returned to Earth for analysis of mineralogic constituents, chemical compositions, isotopic characteristics and organic molecules (CDCF, 1990). Current techniques under development for both the trajectory measurement and capture objectives envision utilizing the penetration of thin foils. The methods and objectives of such instrument developments overlap with cratering and penetration studies of long-standing military interest, and especially with the more recent developments of hypervelocity collisional shields for the protection of spacecraft in Earth orbit (e.g., Anderson, 1990, 1993; Flury, 1993).

The mass-frequency distribution of hypervelocity particles in LEO has a steep mass index, typical of comminution products (e.g., Grun et al., 1985, Kessler, 1993). In practice, this entails that for each penetrative event in a space-exposed membrane of thickness $T$, there must be numerous, relatively small hypervelocity craters of depth $\mathrm{P}<<\mathrm{T}$. Consequently, the common thread among many of the above developments is the desire to better understand the transition from genuine cratering to penetration processes in a wide variety of target materials and for any specific set of initial impact conditions. Obviously, small and large impact events are relative terms in the above context. Conceptually, it matters little whether the projectile diameter $\left(D_{p}\right)$ or target thickness $(\mathrm{T})$ is varied to predict whether the collisional outcome will be a cratering or penetration event. This leads to an experimental matrix that was employed throughout this work and that is conceptually illustrated in Figure 1.

A projectile of constant diameter $\left(D_{p}\right)$ and of constant impact velocity $(V)$ is allowed to encounter targets of systematically decreasing thickness $\mathrm{T}$. The normalized projectile diameter $\left(D_{p} / T\right)$ will then lead to a variety of collisional outcomes. Very massive targets sustain a fully grown or standard crater of diameter $\left(\mathrm{D}_{\mathrm{c}}\right)$ and depth $\mathrm{P}$. The ballistic limit -- in our definition -marks the transition from such infinite halfspace targets to those of finite thickness; the latter will be perforated and will possess penetration holes of diameter $D_{h}$. Target thickness at the exact ballistic limit $\left(\mathrm{T}_{\mathrm{BL}}\right)$ will ideally sustain the full cratering event and be characterized by a penetration of size $D_{h}=0$. All collisions at $T<T_{B L}$ will result in the physical penetration of the target. We define marginal penetrations as those events that are characterized by $D_{h}<D_{p}$; the latter condition is unique for massive targets which are subtly thinner than $\mathrm{T}_{\mathrm{BL}}$. As the target thickness progressively decreases, the penetration-hole sizes will rapidly increase, approaching crater dimensions (i.e., $\mathrm{D}_{\mathrm{h}} \cong \mathrm{D}_{\mathrm{c}}$; Hörz et al., 1994). As $\mathrm{T}$ continues to decrease, typically at $\mathrm{T}<$ $\mathrm{D}_{\mathrm{p}}$, the hole size will again gradually begin to decrease. Eventually, at extremely thin foils, the condition of $D_{h}=D_{p}$ is reached.

Figure 1 reveals an experimental matrix that was designed to yield empirical relationships of $D_{c}, D_{h}, T$ and $D_{p}$. These relationships are crucial in permitting the extraction of projectile dimensions from individual craters $\left(D_{c}\right)$ and penetration holes $\left(D_{h}\right)$ in retrieved space-exposed surfaces of thickness T (e.g., Warren et al., 1989; Humes, 1992; McDonnell and Sullivan, 1992; 
Coombs et al., 1993). Conversely, the resulting crater or penetration-hole size may be predicted from the knowledge of $D_{p}$ and $T$, at otherwise constant impact conditions.

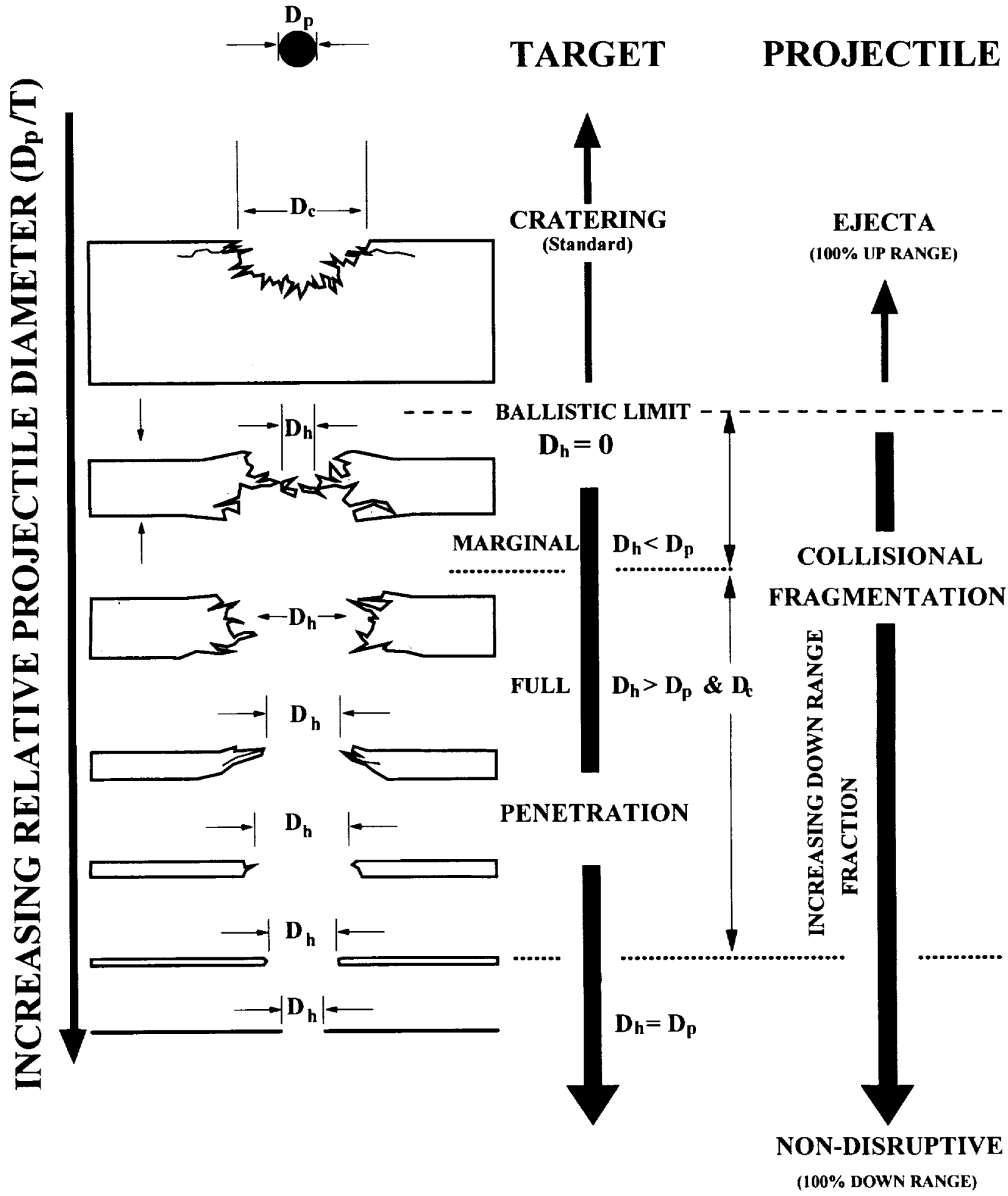

Figure 1. Conceptual illustration of diverse collisional outcomes that result when a model impactor encounters targets of widely variable thickness (T). This illustration includes our empirical findings that teflon yields in a largely brittle fashion. This figure also serves to define some of the terminology used throughout this report. Note especially our definitions of ballistic limit and marginal penetrations, and that diameter $D_{c}$ is always measured at the target surface, whereas $D_{h}$ may be measured anywhere within the target; penetrations of massive targets may be characterized by measurement of $D_{c}$ and/or $D_{h}$. 
Observations related to the fate of the impactor are of interest to a number of studies as well, such as the size or energy distribution of projectile fragments and their geometric dispersion, the onset of melting and vaporization, or the mass-fraction of the initial projectile that will reach a collector substrate located behind a penetrated target. Such interests and observations largely pertain to the contemplated analysis of projectile residue in the context of capture cells (see CDCF, 1990). Is the projectile residue concentrated in specific areas? Under what conditions can one expect solid fragments, melts or vapors? Clearly, such observations are also important for the development of collisional shields, because they directly relate to the spatial redistribution and deposition of the impactor's initial kinetic energy. Obviously, all projectile material is being ejected uprange during hypervelocity cratering, while as thinner and thinner targets are encountered, successively larger mass fractions of projectile and target will continue downrange. Ultimately, a condition is reached where the foil thickness is too thin to collisionally fracture the projectile and where an essentially undeformed impactor continues on its initial trajectory, at practically uninhibited velocity. This condition is of critical interest for trajectory sensors in future flight experiments that will monitor the magnitude and location of impact triggered plasma, or that may measure the change in polarization of PVDF films (CDCF, 1990).

Relatively thin films $\left(D_{p} / T>10\right)$ recently became of interest to collisional shield development (Cour-Palais and Crews, 1990). Such targets are sufficiently massive to cause substantial collisional fragmentation of many projectiles as demonstrated by the investigation of thermal blankets from the Solar Maximum Satellite (McKay et al., 1986 and as postulated by Hörz et al., 1986). Any number of such thin targets may be stacked to efficiently decelerate or annihilate the impactor, because successive, multiple collisions with large numbers of target elements will incrementally raise the projectile's entropy to cause melting, or even vaporization. Deliberate compromises between the degree of projectile fragmentation, heating, deceleration and dispersion will have to be made when selecting the number, thickness and separation distances of individual target elements for multiple-foil capture devices (e.g., Hörz et al., 1986; CDCF, 1990) or for collisional bumpers and shields (Cour-Palais and Crews, 1990; Hörz et al., 1993; Christiansen and Kerr, 1993).

This report describes cratering and penetration experiments in teflon targets consistent with Figure 1 and the objectives described above. Teflon is frequently used as a thermal protective material. Specifically, teflon-based thermal blankets occupied $\sim 20 \mathrm{~m}^{2}$ of surface area that was exposed for $\sim 5.7$ years on board the Long Duration Exposure Facility (LDEF). Approximately 700 penetration holes $>300 \mu \mathrm{m}$ in diameter were observed and documented by See et al. (1990), combined with literally thousands of relatively small craters. The pure teflon targets utilized in the present study are not exact duplicates of the thermal-blanket materials used by the UltraHeavy Cosmic-Ray Nuclei Experiment (O'Sullivan et al, 1992) on LDEF. The LDEF blankets were composites, consisting of a space-facing, $\sim 125 \mu \mathrm{m}$ thick teflon layer, that possessed a vapor-deposited metal mirror ( $\mathrm{Ag}$ and Inconel $\sim 0.1 \mu \mathrm{m}$ thick) on the backside, which, in turn, was backed by an organic binder and thermal protective paint (Chemglaze), yielding a total blanket thickness of 175-190 $\mu \mathrm{m}$ (O'Sullivan et al., 1992, Allbrooks and Atkinson, 1992). Some impact experiments with LDEF thermal blankets were conducted by Schneider et al. (1993). However, these experiments were largely conducted to reproduce some peculiar delaminations which were observed on the space-exposed blankets (e.g., See et al., 1990), rather than to extract projectile size from the measurement of hole dimensions. 
The purpose of this report is to document the experimental conditions, products and findings of $\sim 90$ impact experiments in more detail than is possible in traditional journal articles. This document will hopefully stimulate and support hydrocode computer simulations, a powerful tool necessary to scale somewhat limited laboratory capabilities (i.e., velocity) to those occurring in Earth orbit. Verification of such hydrocodes requires that experimental products be duplicated with high fidelity, before extrapolating with confidence to unknown conditions. Extensive photo-documentation of the experimental craters, penetrations and witness plates is often the best way for the reader to develop a sense of these rather complex structures that are not easily described in qualitative terms, much less by quantitative measurement(s) within the scope of this study.

\section{2) EXPERIMENTAL OBJECTIVES}

Consistent with Figure 1, we employed targets that ranged from infinite halfspace geometries to ultra-thin foils. Massive targets were machined from a single piece of $\sim 8 \mathrm{~cm}$ in diameter Teflon FEP round stock, while targets thinner than $800 \mu \mathrm{m}$ were cut from commercial sheet-stock that came as thin as $6 \mu \mathrm{m}$. The following objectives were pursued:

Establish the ballistic-limit thickness $\left(T_{B L}\right)$ of teflon where $D_{h}=0$ - An experimental sequence typically started by generating a standard crater in an infinite halfspace target, and then proceed to the $D_{p} / T=0.5$ and 1.0 cases. Depending on the results, subsequent thicknesses were adjusted, in small thickness increments, by two criteria that bracketed $T_{\mathrm{BL}}$. The first of these criteria is the onset of bulging or spallation of the target's rear surface, which preceded actual perforation (i.e., occurs at $\mathrm{T}>\mathrm{T}_{\mathrm{BL}}$ ), while the second criteria was the onset of physical penetration, which mandated subtly thinner targets than $\mathrm{T}_{\mathrm{BL}}$ (i.e., $\mathrm{T}<\mathrm{T}_{\mathrm{BL}}$ ). Penetration holes very close to the ballistic limit have dimensions $D_{h}<D_{p}$. Hörz et al. (1994) demonstrated that a series of such marginal penetration holes may be used to extrapolate to the condition of $\mathrm{D}_{\mathrm{h}}=0$, thereby yielding an exact ballistic limit thickness.

Establish the target thickness where $D_{h}<D_{c}$ - Penetration holes in massive targets typically approach the diameter of standard craters (i.e., $\mathrm{D}_{\mathrm{h}} \cong \mathrm{D}_{\mathrm{c}}$ ), and are best interpreted as representing truncated cratering events (Hörz et al., 1994). Genuine penetration formulas seem to apply only for the condition $D_{h}<D_{c}$ and for target thicknesses much thinner (typically by a factor of 2-3) than the ballistic-limit thickness (i.e., at $\mathrm{T} \ll \mathrm{T}_{\mathrm{BL}}$ ). Thus, the condition of $\mathrm{D}_{\mathrm{h}}<\mathrm{D}_{\mathrm{c}}$ delineates the transition from cratering to penetration equations when interpreting projectile sizes from penetration holes.

Establish the target thickness that yields the condition $D_{h}=D_{p}-$ Experiments with successively thinner targets aimed at monitoring the gradual decrease of $\mathrm{D}_{\mathrm{h}}$ until the condition of $\mathrm{D}_{\mathrm{h}}=\mathrm{D}_{\mathrm{p}}$ was reached (see Figure 1). When this important threshold condition occurs, the projectile dimensions may be directly equated to the measured penetration hole(s). The conditions for non-disruptive penetrations at still thinner foils (Figure 1) were not part of this study. 
Determine the size distribution, geometric dispersion and physical state of projectile fragments during penetration of thick and thin targets - Such an objective serves to evaluate the ability of locating and analyzing the remnants of collisionally disrupted projectiles that will be produced by capture cells. Selection of appropriate foils depends on an understanding of projectile disruption as a function of foil thickness. For these reasons each experiment employed a witness plate -- at some known standoff distance (L) -- located behind the target. Note that the debris cloud consists of both projectile fragments and debris dislodged from the target, and that the cumulative mass of the target debris frequently exceeds that of the projectile (Pietkutowsky, 1990; Stilp et al., 1990; Hörz et al., 1994).

Evaluate the effects of impact velocity - We conducted penetration experiments at variable target thicknesses, consistent with Figure 1, with average impact velocities of 2.3, 4.0, 6.0, 6.3 and $7.0 \mathrm{~km} / \mathrm{s}$. While each of the individual series included a cratering experiment, an additional $\sim 20$ craters were generated at relatively narrow velocity intervals between 1 and $7 \mathrm{~km} / \mathrm{s}$. These $\sim 90$ experiments form an excellent experimental basis for the velocity scaling of craters and penetrations in teflon targets.

\section{3) EXPERIMENTAL PROCEDURES}

All experiments were carried out at the Experimental Impact Laboratory, SN4, NASA-JSC, Houston, Texas. The Vertical Impact Facility, a powder-propellant gun equipped with a $7.2 \mathrm{~mm}$ diameter bore barrel, was used for all velocities $<3 \mathrm{~km} / \mathrm{s}$. Two essentially identical, light-gas guns of $5 \mathrm{~mm}$ bore were used for all experiments utilizing velocities $>3 \mathrm{~km} / \mathrm{s}$. All projectile velocities were determined by the occultation of LED-IR lasers-photodiodes arrays. Three such velocity stations are attached to the free-flight chamber (beyond the sabot stripper) of the vertical gun (i.e., responding only to the in-flight projectile); agreement between the three stations are typically within $0.2 \%$ of each other. Four identical velocity stations are installed along the freeflight chambers of both light-gas guns, but in front of the sabot stripper. In addition, both lightgas guns employ photodiodes that pick up the light flashes upon (a) impact of the sabot at the sabot separator and (b) impact of the projectile with the actual target, which is $\sim 8 \mathrm{~m}$ down-range from the muzzle. One of the light-gas guns is also equipped with devices that monitor impactproduced plasma; these charge sensors were used in many, but not all, experiments as additional velocity sensors. The internal consistency between all three types of velocity sensors utilized on the two light-gas guns is $<2 \%$, and typically $<1 \%$.

Spherical soda-lime glass projectiles were utilized as reasonable analogs to natural silicate impactors, the particles of major interest in this study. Projectiles were individually hand-picked under the binocular microscope to eliminate flawed specimen that possessed either surface chips, internal bubbles and/or cracks. Such flawed spheres do not tend to survive launch at high velocities and often generate excessively large data scatter, including non-reproducible penetration and fragmentation results.

All target $>1 \mathrm{~mm}$ in thicknesses were machined to specifications from a single piece of teflon round stock and precisely measured prior to conducting an experiment; specimen of $\mathrm{T}<1 \mathrm{~mm}$ were cut from commercially available sheet stock. The disc-shaped targets were mounted in circular clamping devices, $\sim 7.5 \mathrm{~cm}$ inside diameter. The witness plates were mounted a known 
standoff distance (between $12-13 \mathrm{~cm}$, depending on absolute target thickness) from the target's rear surface. The $\sim 29 \mathrm{~cm}$ square witness plates were fabricated from aluminum 1100 (annealed), either $7.3 \mathrm{~mm}\left(1 / 4^{\prime \prime}\right)$ or $3.17 \mathrm{~mm}\left(1 / 8^{\prime \prime}\right)$ thick, depending on expected fragmentation products. All witness plates were blued with water-based lay-out ink, which was found to vastly improve recognition of subtle witness-plate features compared to bare, metallic aluminum plates. In contrast to most any paint, the ink neither peels nor spalls, nor does it measurably affect the plate's surface properties.

A minimum of two observers independently performed the dimensional measurements. Craters and penetration holes in teflon are characterized by spall zones and rather fuzzy, exceptionally unsharp crater outlines and diameters as detailed in Figure 2. The spall diameter on the front $\left(D_{s}\right)$ or back side $\left(D_{b}\right)$ was defined as the average extent of mass removal. Approximately 4-6 diameter measurements of this substantially scalloped demarcation line were averaged to obtain $D_{s}$ and $D_{b}$. Crater diameter $\left(D_{c}\right)$ is defined as the intercept between the original target surface and the crater cavity. This definition is maintained in this study to be consistent with measurements by others in metals and non-metallic targets (e.g., See et al., 1990). Unfortunately, spallation of the front surfaces totally destroyed this intercept. Consequently, one is forced to extrapolate this intercept by extending and projecting the cavity walls onto the initial target surface. In general, this involves some operator judgment, and even more so if the cavity walls are as poorly defined as with the teflon targets. Even experienced observers can differ in the definition of this cavity shape, or its intercept with the original target surface; measurements of $D_{c}$ in teflon targets can vary by as much as $\sim 15 \%$ among individuals. Reconciliation sessions with additional individuals were almost routine, rarely focusing on the actual measurement, but on interpreting and defining pertinent criteria to objectively delineate the morphological element of interest. In addition, hole diameters were frequently best estimates, especially in the more massive targets, because their frayed and ragged nature severely limited the utility of mechanical tools, such as a caliper, to reach into the hole for a precise and objective measurement. Hole diameters $\left(D_{h}\right.$, measured at the narrowest spot at some arbitrary target depth), based on multiple caliper readings, varied by as much as $10 \%$ among individuals. However, measurement precision varies with the absolute target thickness, with the largest uncertainties $(\sim 10 \%)$ occurring with the more massive targets (i.e., $\mathrm{D}_{\mathrm{p}} / \mathrm{T}<1$ ). Measurements associated with thin targets $\left(\mathrm{D}_{\mathrm{p}} / \mathrm{T}>10\right)$, on the other hand, will be as precise as those in metal targets (i.e., $<2 \%$ discrepancy among observers).

The above descriptions and Figure 2 serve to illustrate that many of the target features were difficult to quantify. It is even more difficult (and was totally beyond the scope of this effort) to extract quantitative information from the complex debris-spray patterns on the witness plates. Extensive photo-documentation was determined to be the best method of conveying to the reader some realistic sense for first-order morphologies and trends, as well as for detailed and subtle features that characterize the debris clouds of penetrated targets. The ejecta cloud originating from the target's front surface was not monitored.

Throughout this report, many individual photographs were combined into photographic plates to illustrate specific trends. However, such plates may not be assembled and reproduced without loss of detail and spatial resolution. Consequently, the Appendix contains, in systematic fashion, photographs of each individual experiment at the best optical resolution available. Even these reproductions suffer from substantial degradation relative to the original photographs, and even more so relative to the actual experimental products, especially the witness plates. 


\section{4) EXPERIMENTAL RESULTS}

\section{A) General}

The initial impact conditions and major results for all individual experiments are listed in Table 1, which groups related experiments by impact velocity. Within the different experimental series, individual experiments are ranked in the order of decreasing target thickness, except for the crater series, which lists the experiments in the order of increasing projectile velocity. Some cratering shots are listed twice within Table 1, because they are integral parts of both the cratering and penetration series. Note that the Appendix exactly duplicates Table 1 in the sequencing of experiments; chronological laboratory experiment number is the sole identifier for each test. This presentation by topic enables relative efficient comparison of many related experiments, yet it may make the search for any individual test somewhat cumbersome for the casual reader. To facilitate the latter, we provide Table 2, which lists all experiments in numerical order, together with the nominal impact velocity and relative target thicknesses $\left(D_{p} / T\right)$. Table 2 should permit efficient cross referencing with Table 1, and in rapidly locating individual experiments within the Appendix.

Photographic documentation of teflon turned out to be difficult, due to the material's relatively dull and non-reflective, white surfaces. In addition, most craters were too large to be conveniently photographed by Scanning Electron Microscope (SEM) methods that -- under special provisions -- provide a minimum magnification of $10 \mathrm{X}$ in our instrument; this rules out most features $>1 \mathrm{~cm}$ in diameter. In addition, substantial charging could not be avoided for features $<1 \mathrm{~cm}$ in diameter, as the highly irregular and somewhat fuzzy crater interiors could not be homogeneously coated with vapor-deposited carbon or other conducting material. The optical photographs benefited from thinly dusting the targets with a highly diluted paint using a fine airbrush applicator, which allowed the paint to soak into many of the cracks to provided some contrast between the damaged and undamaged areas (the undamaged areas were wiped clean while the paint was still wet). This procedure was used for all optical photography of the penetration experiments. However, the best method was very recently developed and involves dye-penetrant (in spray form) that is typically used in the detection and visualization of hair-line cracks and other flaws during quality control inspections. This dye-penetrant was used to document the crater cross-sections. Unfortunately, it could not be used on the previously painted specimen, because the paint had long dried and could not be dissolved and removed quantitatively from the highly irregular surfaces, especially the long cracks, etc.

Each of the photographic plates present a number of individual experiments to essentially identical scales; yet this scale can vary considerably from plate to plate. Note that a single crosssection does not necessarily reflect the exact average dimensions listed in Table 1. Nevertheless, the approximate dimensions for an individual frame within a given photographic plate may be derived from the thinnest films depicted, because the condition of $D_{p} \cong D_{h} \cong 3.175 \mathrm{~mm}$ is approximated at $\mathrm{D}_{\mathrm{p}} / \mathrm{T}>20$. Generally, the front and rear views of a target, at any given velocity, are of the same scale. All cross-section plates contain the case of $\mathrm{D}_{\mathrm{p}} / \mathrm{T} \cong 1$ (i.e., $\mathrm{T} \cong 3.175 \mathrm{~mm}$ ), which can be used as an internal standard from plate to plate. Unless otherwise noted, all witness plates were $29 \mathrm{~cm}$ on a side. 

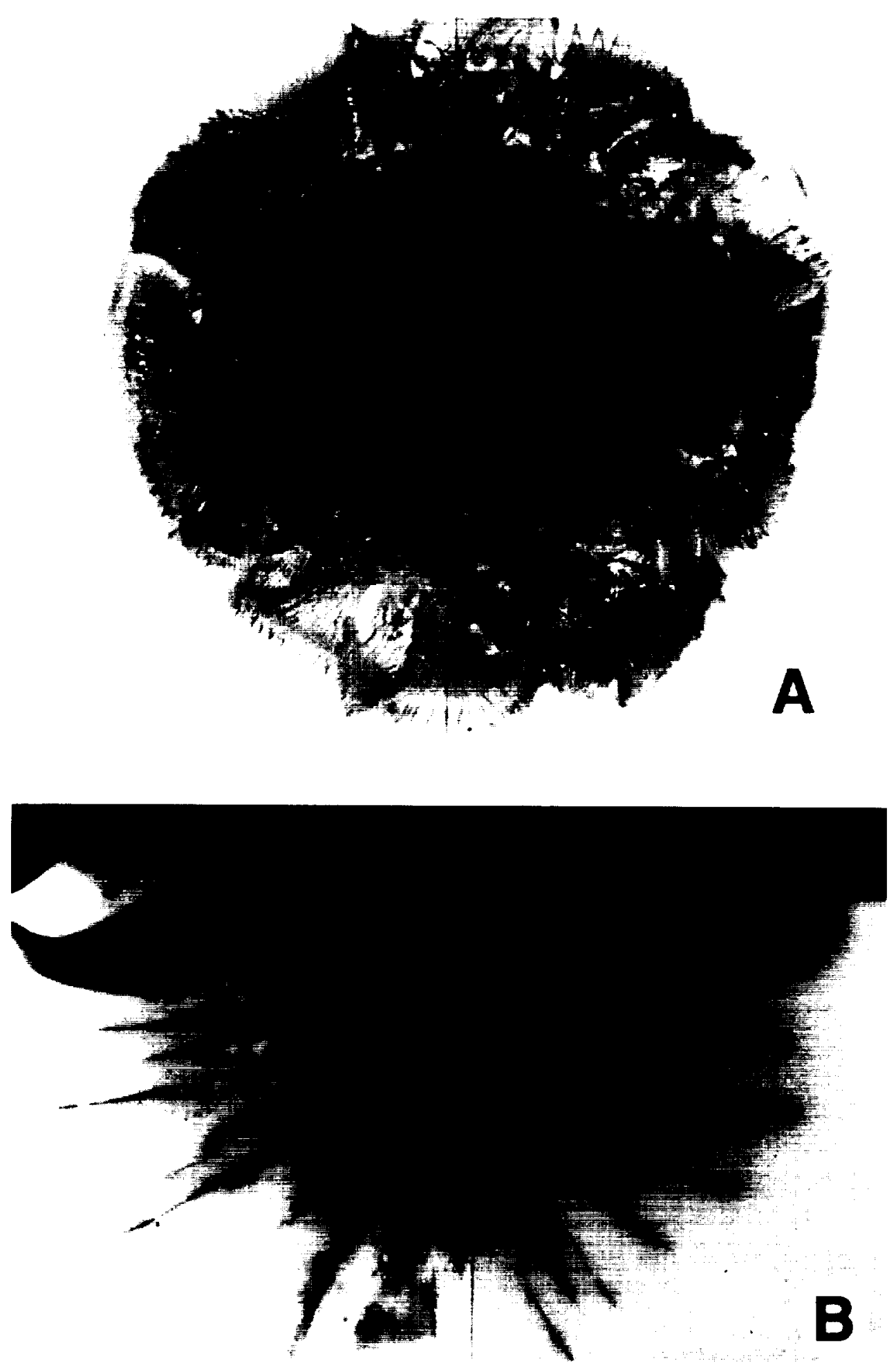

Figure 2. Typical crater produced in teflon by a $3.175 \mathrm{~mm}$ diameter soda-lime glass at $6 \mathrm{~km} / \mathrm{s}$. (a) Plan view and (b) Crosssection. Note the presence of the somewhat scalloped spall zone and the highly irregular, frayed crater interior, which make the qualitative distinction between a crater diameter $\left(D_{c}\right)$ and spall diameter $\left(D_{S}\right)$ relatively easy. However, exact measurements for $D_{c}$ are somewhat operator dependent. 


\section{B) Standard Craters}

Before addressing the penetration behavior of teflon, we first describe the standard craters in infinite halfspace targets and how they evolve as a function of velocity. Figure 3 a presents select craters in plan view, while Figure $3 \mathrm{~b}$ presents the corresponding cross-sections. Note the brittle behavior of teflon and the difficulties encountered in defining the actual crater diameter at the initial target surface. The entire crater interior is characterized by numerous tears and wedgeshaped promontories that lead to a highly frayed, diffuse crater interior. The transition from the crater cavity to the relatively smooth spall zones is gradual and lacks a distinct, sharp boundary. The subtle change in slope from that characterizing the spall zone to that typical for the steep crater walls is taken to represent the crater diameter $D_{c}$.

A concentric, highly scalloped fracture marks the outer boundary of the spall zone; scalloping develops at the intercept of this concentric fracture with a pronounced system of radial cracks. The cross-sections in Figure $3 \mathrm{~b}$ also reveal pervasive, radial fracturing at depth, and a distinct lack of largely concentric fractures. As can be seen in Figure 3b, the entire crater cavity is surrounded by an extensive radial-fracture system extending on the order of a crater radius. Individual fractures are fairly equally spaced around the periphery of the crater, and the number of cracks seems relatively invariant, regardless of impact velocity. On the other hand, the crater bottoms become increasingly more frayed with increasing velocity. The partially dislodged materials in the crater interiors is relatively equant, if not blocky at velocities $<3 \mathrm{~km} / \mathrm{s}$, becoming increasingly more elongate/fibrous and frayed at velocities $>4 \mathrm{~km} / \mathrm{s}$.

The absence of prominent concentric fractures within teflon differs from classic brittle materials, such as dense crystalline rocks (e.g., Gault et al., 1968; Hörz, 1973; Lange and Ahrens, 1986) or glass (e.g., Cour-Palais, 1987; Schneider et al., 1990). Such silicate materials develop pronounced, hemispherical fracture systems in addition to radial fracture systems. Compared to the glass impacts of Schneider et al., the fracture density within teflon is very modest. Some of the wedge-shaped promontories in the cavity interiors obviously emanate from the target volume between neighboring, radial cracks. Their ends or tips are frequently frayed and bent, and always somewhat thinned, suggesting that modest plastic deformation may have occurred. However, we have not observed melting and associated flow in any teflon targets at $D_{p} / T<1$. On the other hand, thin targets show evidence of melting and thickening, forming a penetration-hole lip at $\mathrm{D}_{\mathrm{p}} / \mathrm{T}>50$. In summary, the macroscopic failure mode of massive teflon targets seems to be somewhat intermediate between truly brittle and ductile materials.

The dark areas within the cross-sections of the low-velocity experiments $(<3 \mathrm{~km} / \mathrm{s})$ of Figure $3 \mathrm{~b}$ represent the glass projectile. The glass projectile is almost entirely preserved at $1.04 \mathrm{~km} / \mathrm{s}$, but becomes increasingly fragmented as velocity increases to $3 \mathrm{~km} / \mathrm{s}$; we are uncertain what happens to the projectile at encounter velocities $>3 \mathrm{~km} / \mathrm{s}$. Occasionally, we observed small projectile fragments at higher velocities, usually wedged into some radial cracks; the vast majority of the impactor's mass must have been ejected. On two occasions (at $\sim 6 \mathrm{~km} / \mathrm{s}$ ) we observed melt beads in the crater cavity immediately following the experiment. Unfortunately, these beads were jarred loose and lost during the cross-sectioning process, which includes the use of sawing, milling and polishing equipment. Undoubtedly, our teflon craters retained only small amounts of projectile residue, when compared to similar experiments in aluminum targets (Bernhard et al., 1994). 

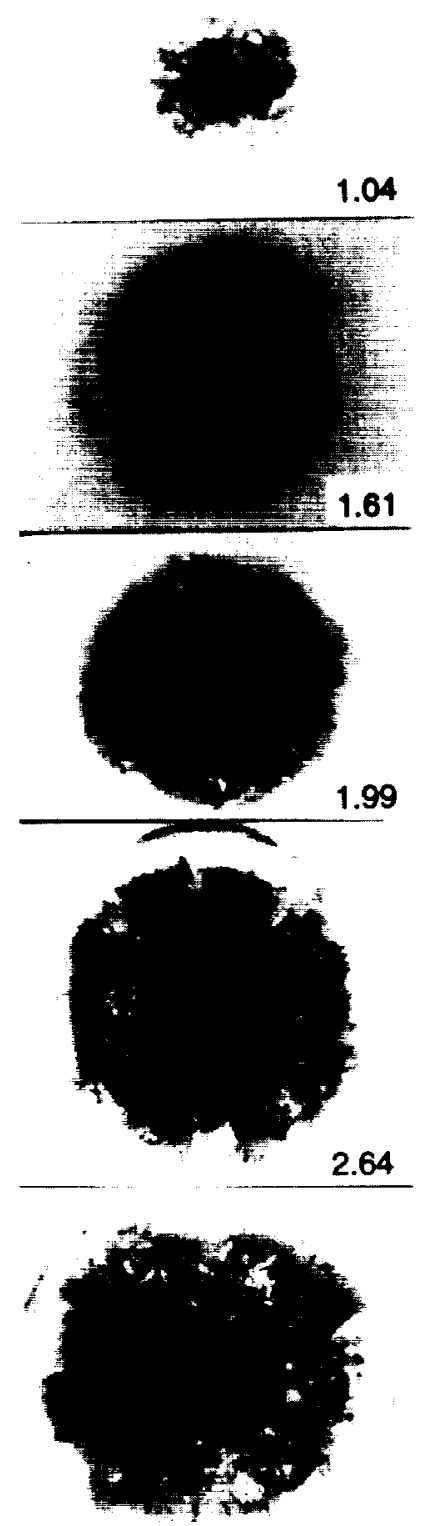

3.02

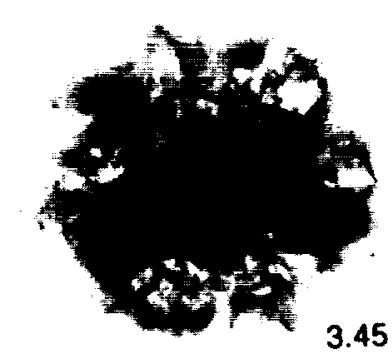

3.45

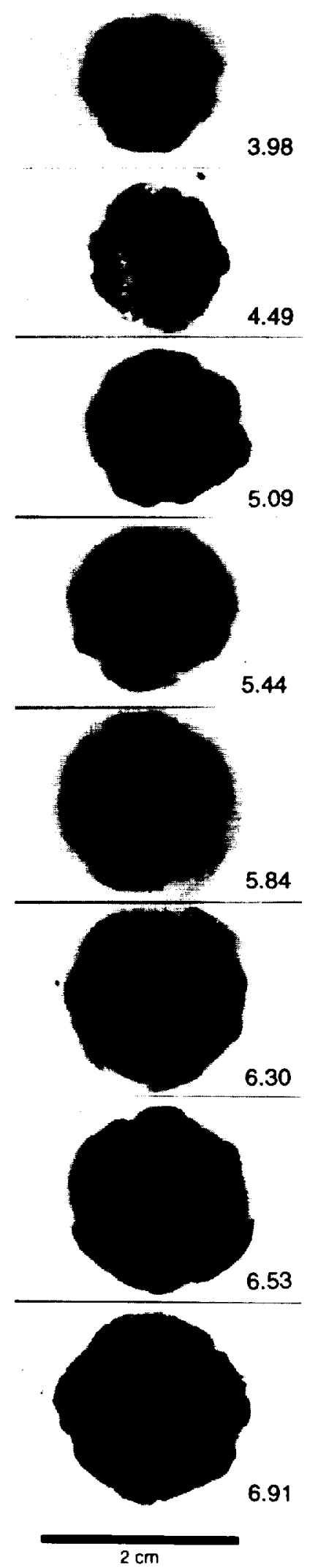

Figure 3a. Plan view of craters produced in Teflon FEP targets by $3.175 \mathrm{~mm}$ diameter soda-lime glass projectiles at various velocities (lower right-hand corner) from $\sim 1$ to $7 \mathrm{~km} / \mathrm{s}$. Observe the crater cavity as opposed to the associated spall zone. Also note the different scales for the left- and right-hand columns. 

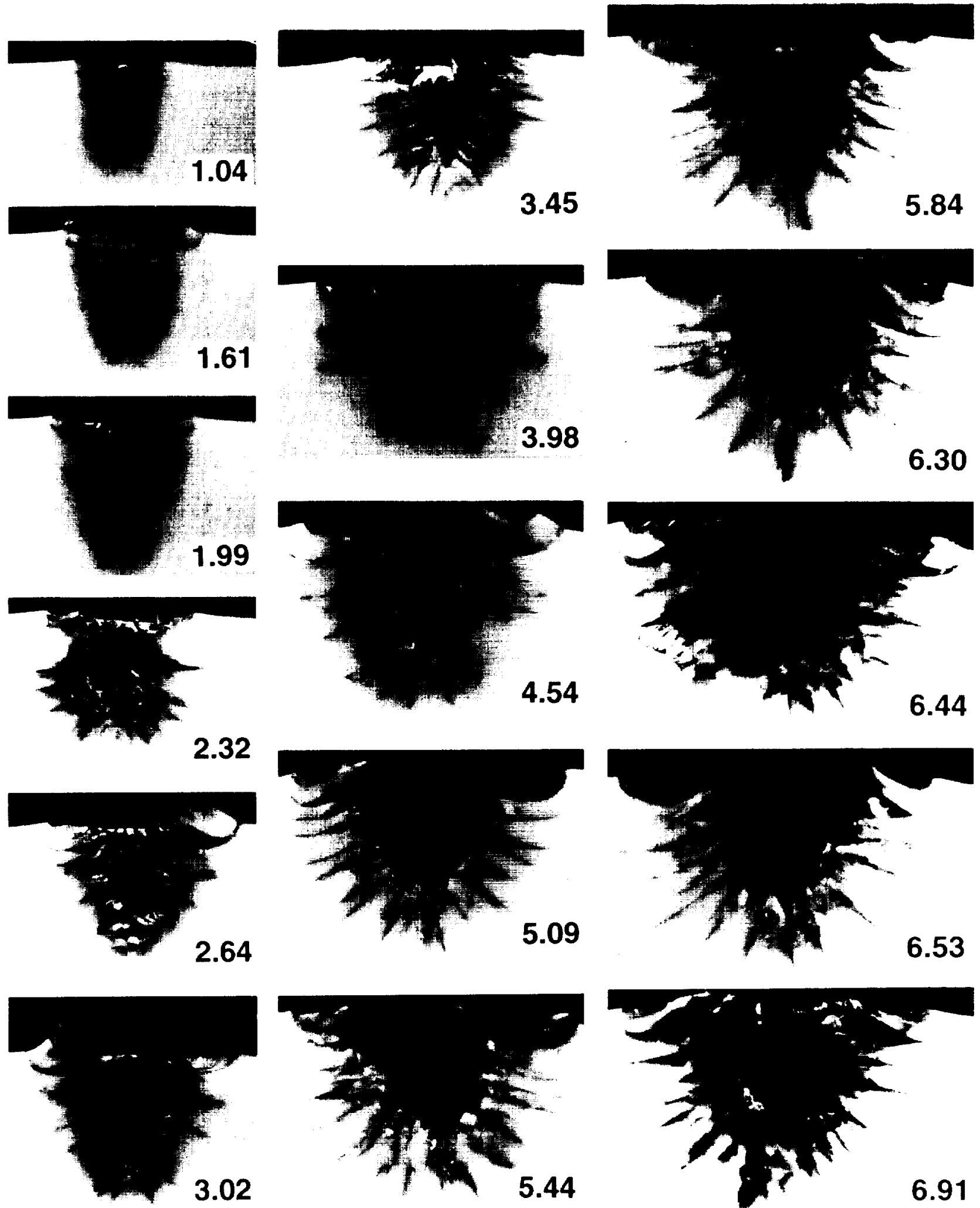

Figure 3b. Cross-sections of craters in teflon targets produced by $3.175 \mathrm{~mm}$ diameter soda-lime glass spheres at various velocities (lower right-hand corner) from $1-7 \mathrm{~km} / \mathrm{s}$. Note the production of a significant radial fracture system surrounding the craters at all velocities, and the relatively deep structures produced at $<3 \mathrm{~km} / \mathrm{s}$. Dark areas at crater bottoms in the $<3 \mathrm{~km} / \mathrm{s}$ shots are projectile remnants. Scales are only approximately the same from frame to frame; Table 1 contains detailed dimensional measurements (see text for additional discussion). 
Figures 2 and 3 illustrate some of the problems alluded to earlier in obtaining various precise crater dimension measurements. Indeed, it is unclear whether or not a well defined crater cavity bounded by crisp and sharp surfaces, as implied by such measurements, even exists in teflon. This is also the reason why we refrained from measuring crater depth. However, even though no quantitative depth measurements were obtained, examination of Figure $3 \mathrm{~b}$ clearly shows that the relative depth of the low-velocity $(<3 \mathrm{~km} / \mathrm{s})$ craters is distinctly larger, compared to those of the experiments at $>5 \mathrm{~km} / \mathrm{s}$, consistent with the relatively efficient penetration of low-velocity impactors (e.g., Stilp et al., 1990; Christiansen, 1992; Schmidt et al., 1994).

The diameter measurements $\left(D_{c}\right)$ of all craters are illustrated in Figure 4, together with the front-spall diameters $\left(D_{S}\right)$. A least-square fit through the crater diameter data yields a velocity exponent of $\mathrm{V}^{0.44}$. Also plotted for comparison in Figure 4 are the results of Watts et al. (1993), who compared and summarized a number of different cratering formalisms to derive a general cratering equation. The agreement of our observations with Watts et al. (1993) is fair, yet much of the discrepancy may relate to the difficulties in defining and measuring the surface diameter of the crater cavities. We will continue our collaborations with Watts et al. and -- hopefully -resolve some of these discrepancies.

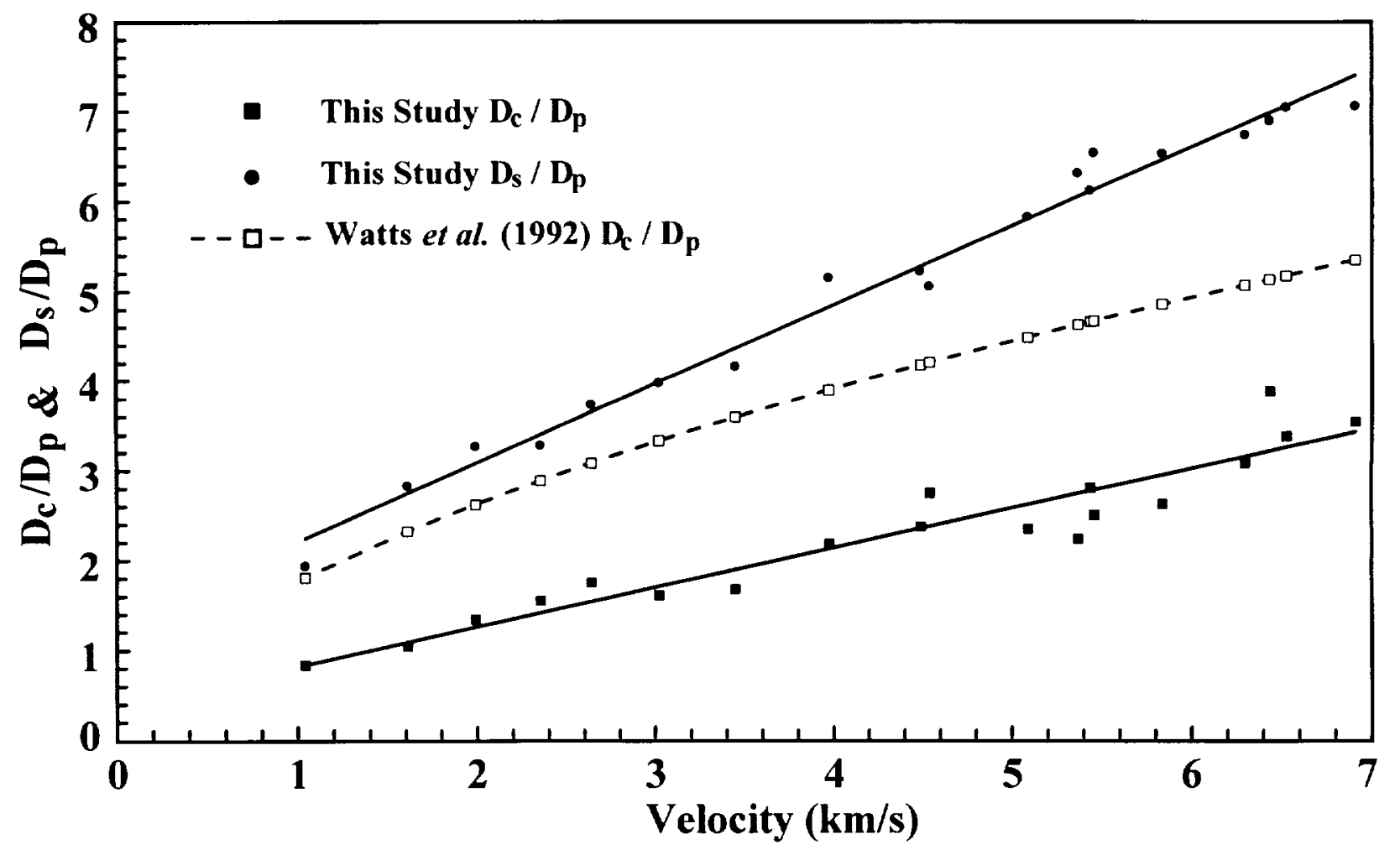

Figure 4. The relationship between crater diameters $\left(D_{c}\right)$ and front spall zones $\left(D_{S}\right)$ in teflon targets as a function of impact velocity. Dashed line represents crater diameters $\left(D_{\mathcal{C}}\right)$ based on Watts et al. (1993).

\section{C) Penetration Holes: Morphologic Elements and Their Evolution}

Figures 5-7 illustrate the cratering and penetration-hole morphologies for teflon targets of vastly different thicknesses, each plate representing a given velocity. Figures $5 \mathrm{a}-5 \mathrm{~h}$ show the front and back sides of select targets, while Figures 6 presents the corresponding cross-sections. The latter plates are limited to only the relatively massive targets, because thin targets are not 
very informative in cross-section. Figure 7 presents generic details of the spallation process on the target's back side.

The most important, first-order result of these penetration experiments relates to the systematic dependence of hole diameter on target thickness. Penetrations in massive targets have dimensions typical for cratering events, with $D_{h}$ systematically decreasing as $T$ decreases (Figures 5 and 6). The end-member condition of $D_{h}=D_{p}$ is generally reached at $D_{p} / T>50$ (i.e., at very thin foils thicknesses). As expected, and illustrated in Figures 5-7, another first-order observation is that the low-velocity experiments produced smaller diameter craters and penetration-holes than did the high-velocity impacts. We have measured these dimensional relationships and will present and discuss the results below. The remainder of this section is devoted to the qualitative description of some morphologic elements, and their evolution as a function of $T$ and/or encounter velocity.

Note the pronounced spallation phenomena on both the front and rear sides of teflon targets. The exit-side spall zone $\left(D_{b}\right)$ typically possess a larger radius than the corresponding front-side spall $\left(D_{s}\right)$, except for the marginal penetration of the most massive targets. Spall zones on the target's front surface of these massive targets have dimensions and morphologies akin to the spall zones of the standard crater(s) in teflon (e.g., compare Figures 3, 5 and 6), analogous to the rim and lip morphologies of craters and penetrations in ductile aluminum targets (Hörz et al., 1994). As $T$ decreases, the relative width of this spall zone $\left(D_{s} / D_{h}\right)$ decreases, becoming essentially negligible at $\mathrm{D}_{\mathrm{p}} / \mathrm{T}>10$. Again, this behavior is analogous to that of the relative lip width $\left(D_{1} / D_{h}\right)$ for aluminum penetrations. The spallation phenomena on the rear side follows similar trends and decreases in relative width $\left(D_{b} / D_{h}\right)$ with decreasing $T$. In addition, when $D_{S}$ and $D_{b}$ distinctly differ in diameter, the larger diameter is always found on the back side $\left(\mathrm{D}_{\mathrm{b}}\right.$; see crosssections in Figure 6, but remember that these cross-sections may not truthfully reflect the true average dimensions in every case). At $D_{p} / T>5$, and especially for $D_{p} / T>10$ it becomes difficult to distinguish the target's front side from that of the rear, because $D_{s}$ and $D_{b}$ are virtually identical, as are other morphologic elements of such spall zones. Essentially no spall zones are discernible as the condition of $D_{h}=D_{p}$ is approached, and, as mentioned above, the edges of the penetration holes in the very thin targets are increasingly molten and thickened to form distinct lips (see Appendix).

The substantial fraying described from crater bottoms and walls is evident in most penetrated targets as well, especially in the more massive targets. Note that none of the infinite halfspace targets (Figure $3 b$ ), or those that were penetrated (Figure 6) display obvious hemispherical, shelllike fracture systems in cross-section, nor conspicuous concentric fracture systems at the target's front or rear surfaces. Such fracture systems seem to be more prominent in truly brittle glass targets (e.g., Schneider et al., 1990).

New fracture systems, relative to the cratering case, develop at the target's back side as soon as the teflon targets begin to bulge (Figure 7). One set of fractures is essentially parallel to the target's back surface; these fractures appear to be caused be the rarefaction wave (e.g., Gehring, 1970). A second, and ultimately dominant fracture system is of a distinctly conical shape; this system controls the detailed geometry of the total volume/mass of material displaced at the target's rear. This conical system emanates from the radial fracture system surrounding the standard crater that was described above (Figure $3 \mathrm{~b}$ ). The cratering-related fracture system is 


\section{Soda-Lime Glass $\rightarrow$ Teflon $(2.3 \mathrm{~km} / \mathrm{s})$}

\section{$D p / T$}
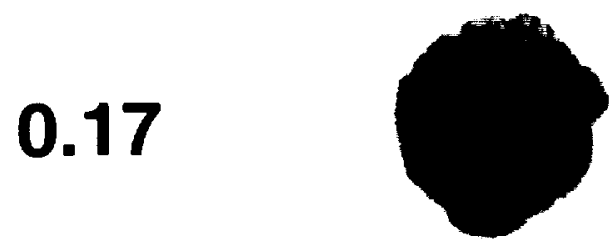

0.25
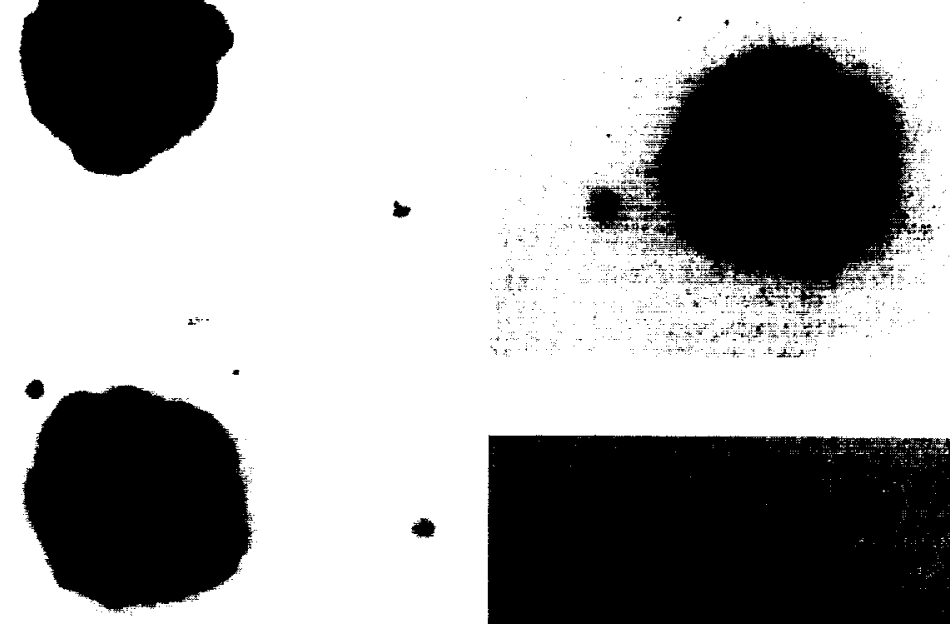

0.33
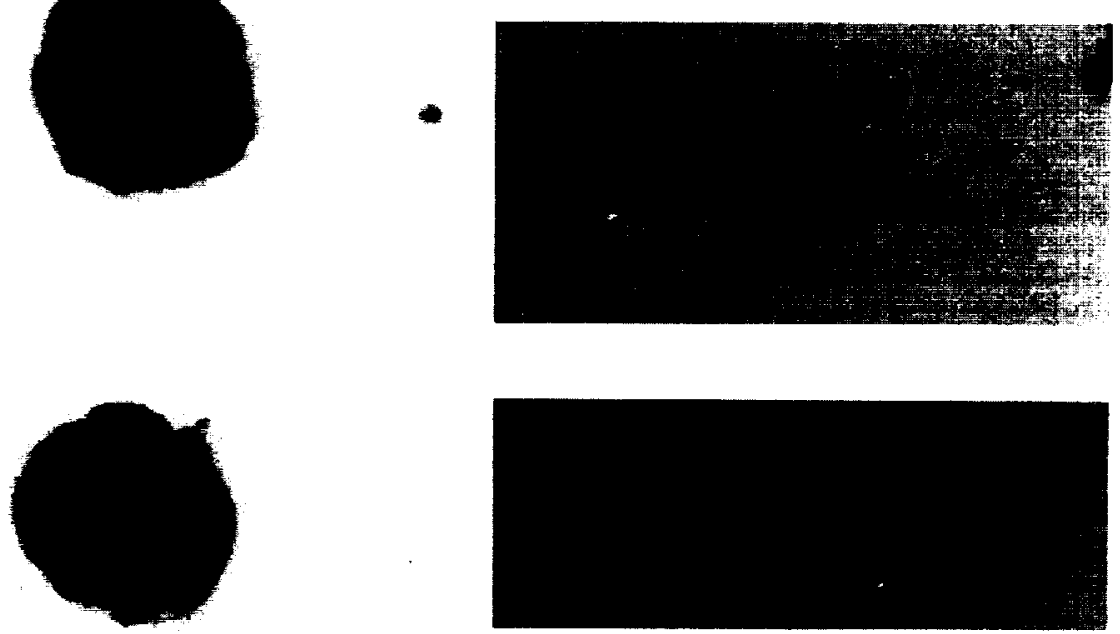

3.90

6.35
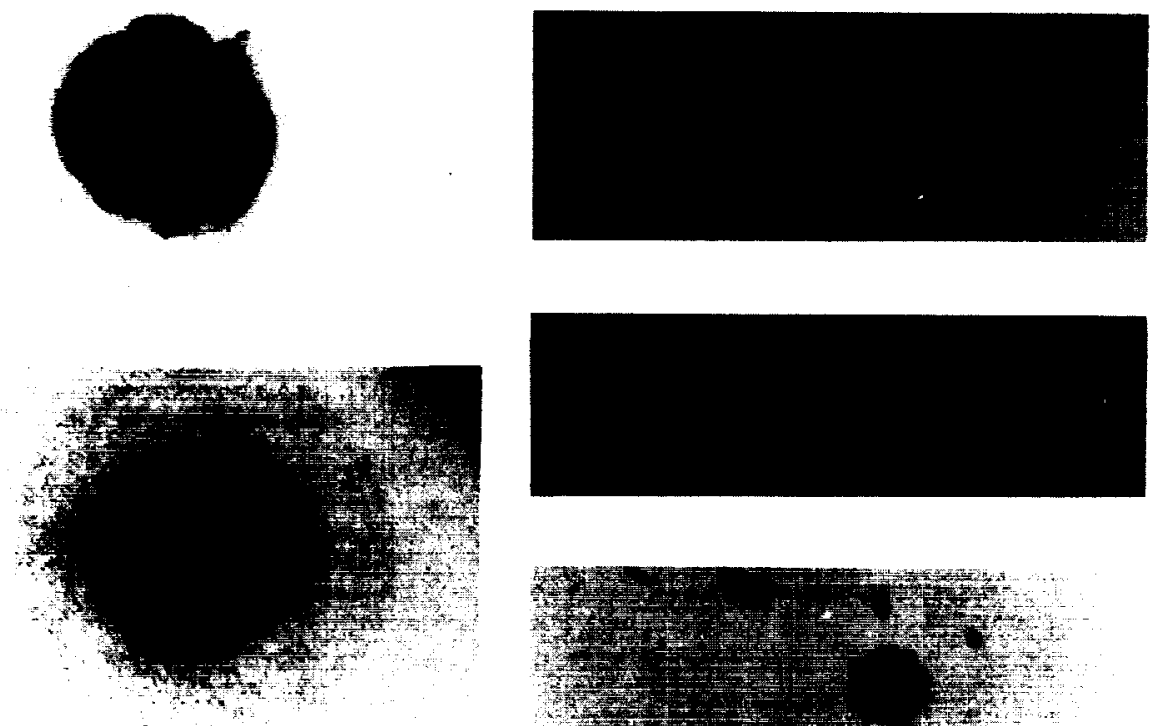

12.7

0.67

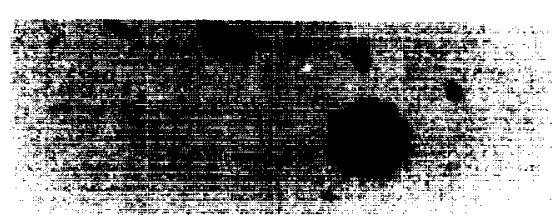

Figure 5a. Entrance-side of cratering and penetration experiments in teflon targets of variable thickness $(T)$ that were impacted by $3.175 \mathrm{~mm}$ diameter $\left(D_{p}\right)$ soda-lime glass projectiles with an average encounter velocity of $2.3 \mathrm{~km} / \mathrm{s}$. 


\section{Soda-Lime Glass $\rightarrow$ Teflon $(2.3 \mathrm{~km} / \mathrm{s})$}

\section{$\mathrm{Dp} / \mathrm{T}$}

0.33
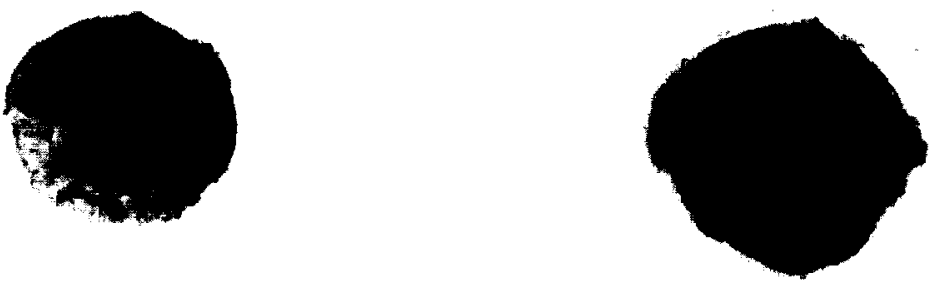

1.00

0.49
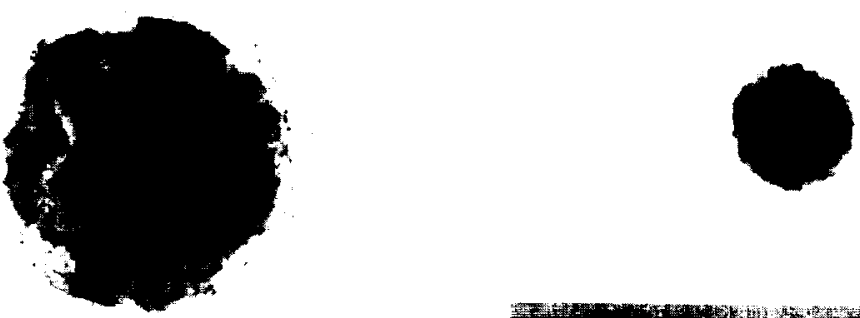

3.90

0.67
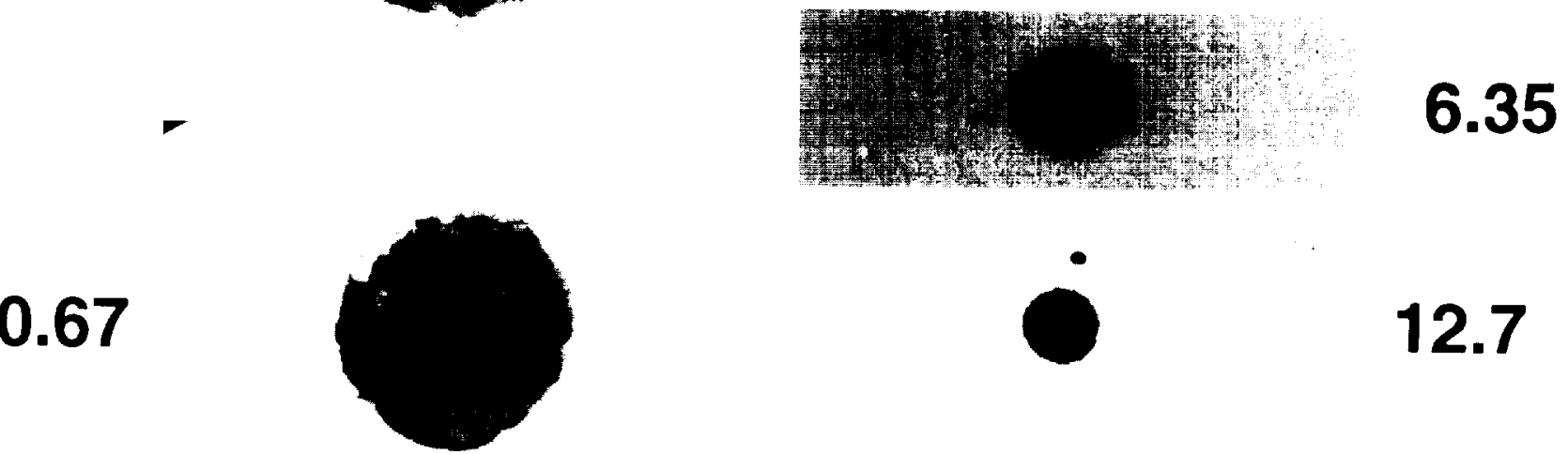

6.35

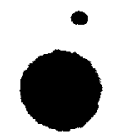

12.7

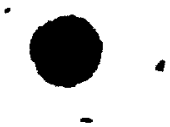

31.7

Figure 5b. Exit-side of cratering and penetration experiments into teflon targets of variable thickness (T) that were impacted by $3.175 \mathrm{~mm}$ diameter $\left(\mathrm{D}_{\mathrm{p}}\right)$ soda-lime glass projectiles with an average encounter velocity of $2.3 \mathrm{~km} / \mathrm{s}$. 


\section{Soda-Lime Glass $\rightarrow$ Teflon $(4 \mathrm{~km} / \mathrm{s})$}

\section{$\mathrm{Dp} / \mathrm{T}$}

0.12
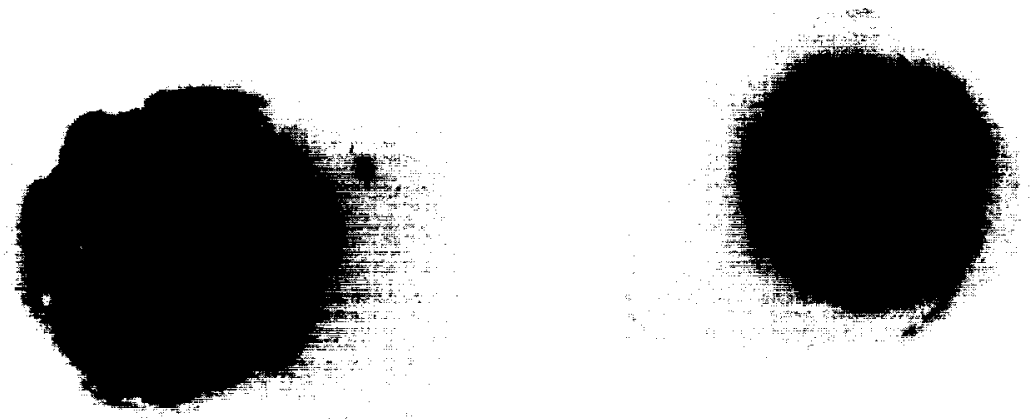

0.63
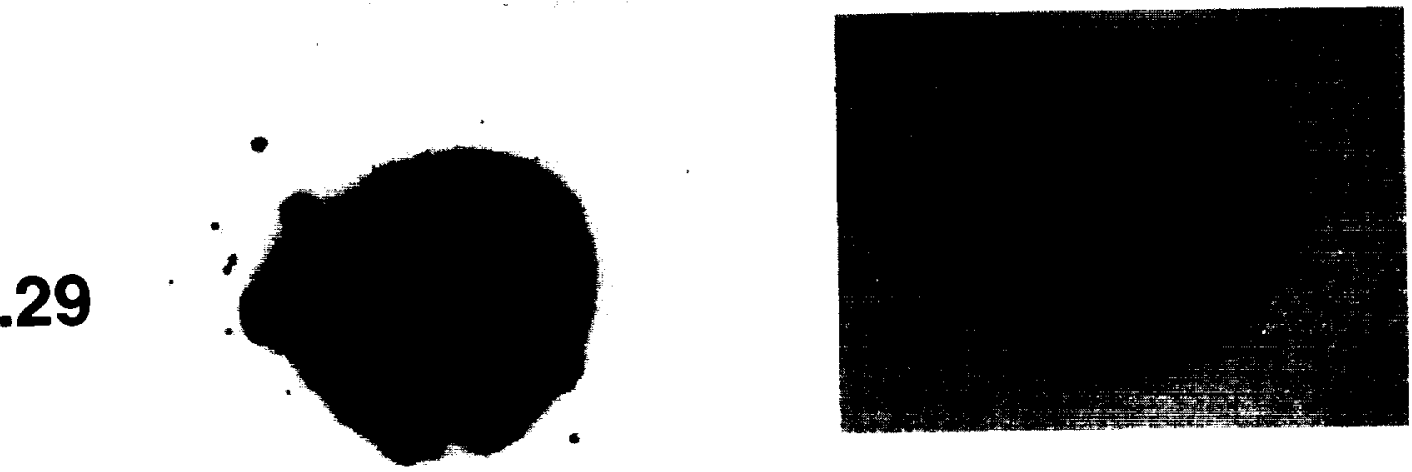

1.09
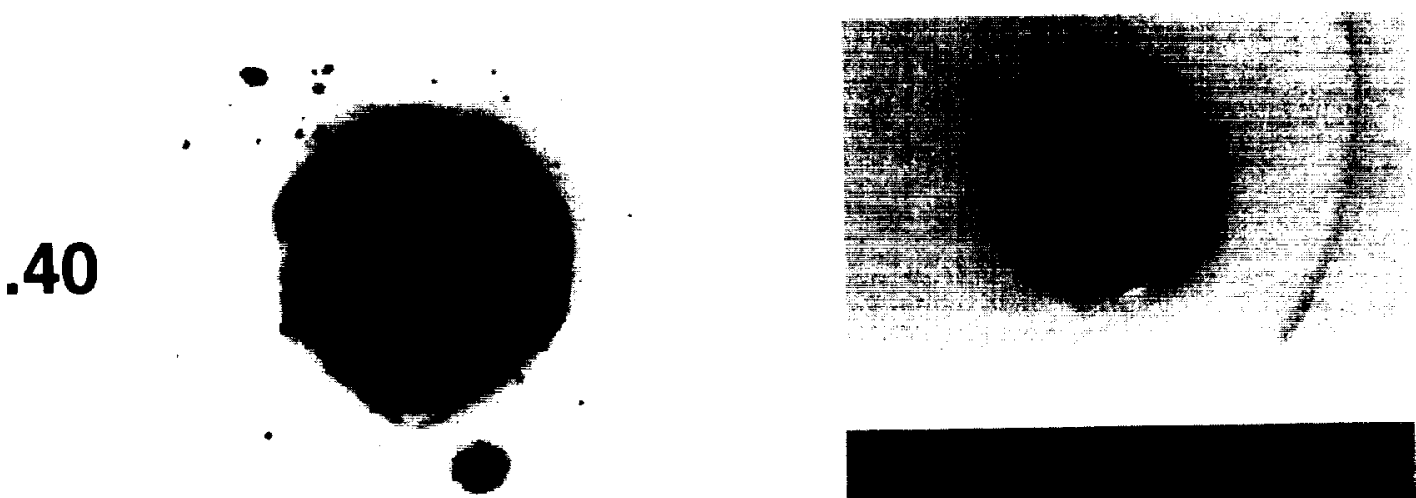

1.57

.40
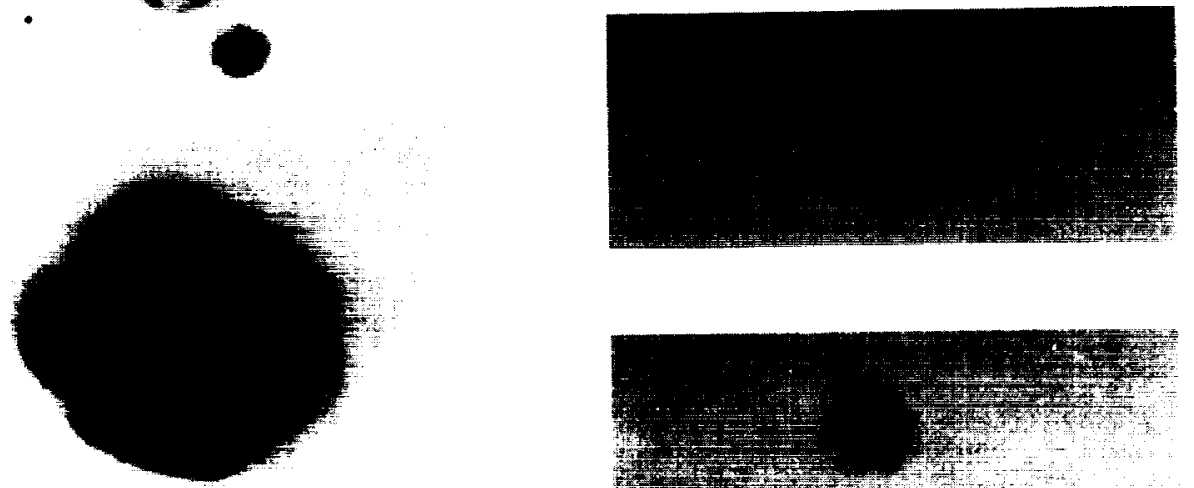

6.35
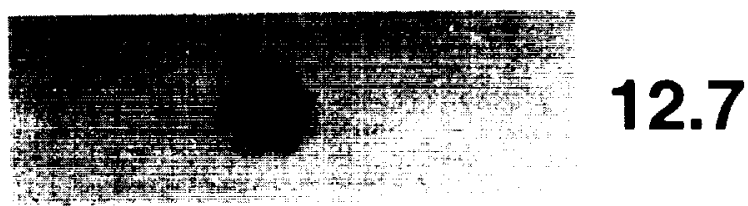

Figure 5c. Entrance-side view of cratering and penetration experiments in teflon targets of variable thickness (T) that were impacted by $3.175 \mathrm{~mm}$ diameter $\left(D_{p}\right)$ soda-lime glass projectiles with an average encounter velocity of $4.0 \mathrm{~km} / \mathrm{s}$. 


\section{Soda-Lime Glass $\rightarrow$ Teflon $(4 \mathrm{~km} / \mathrm{s})$}

\section{$\mathrm{Dp} / \mathrm{T}$

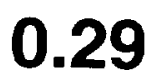

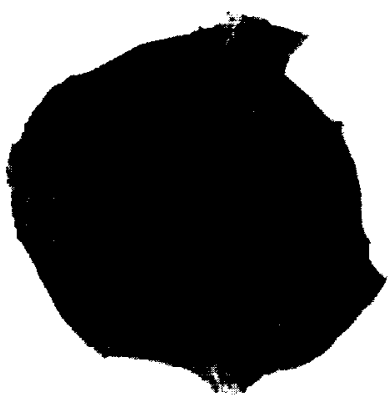

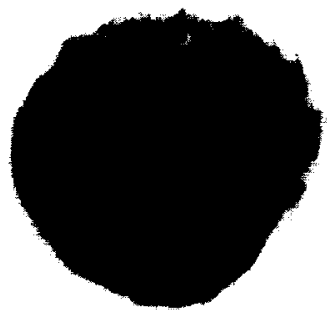

0.63
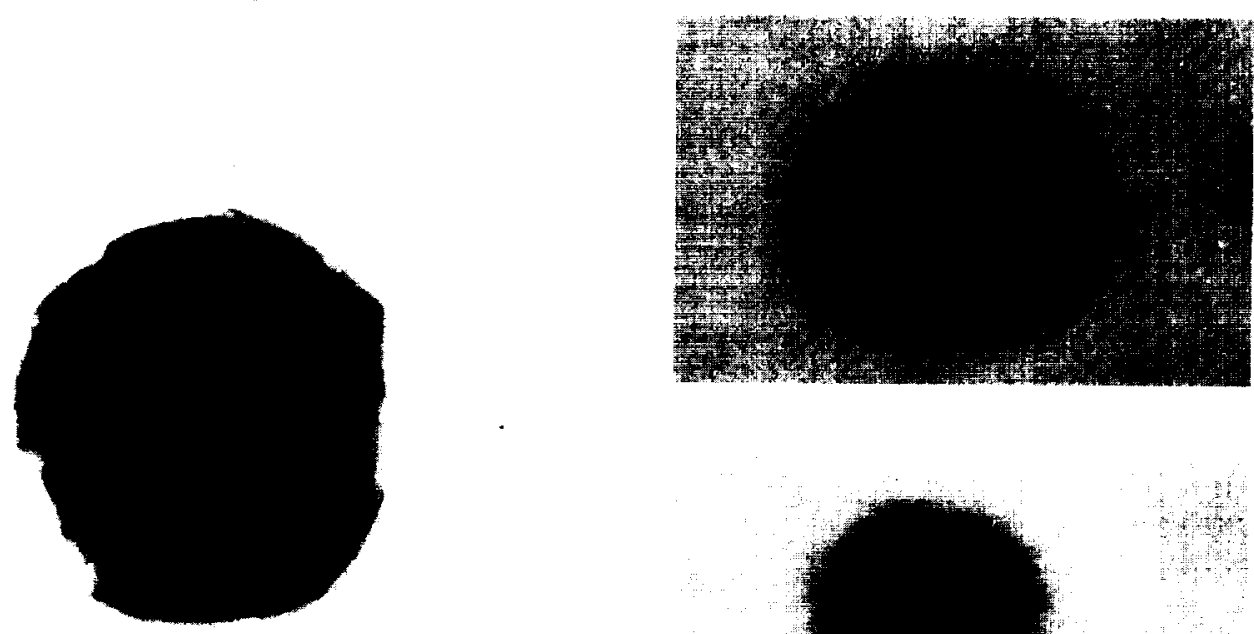

1.09
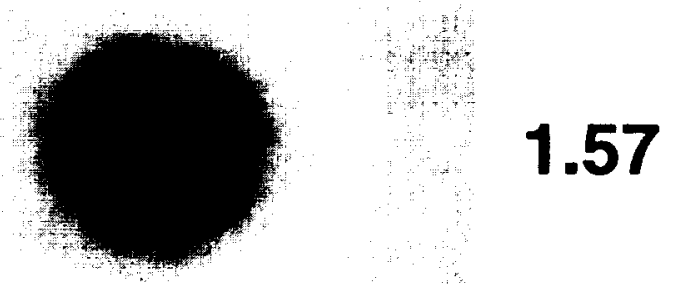

.40
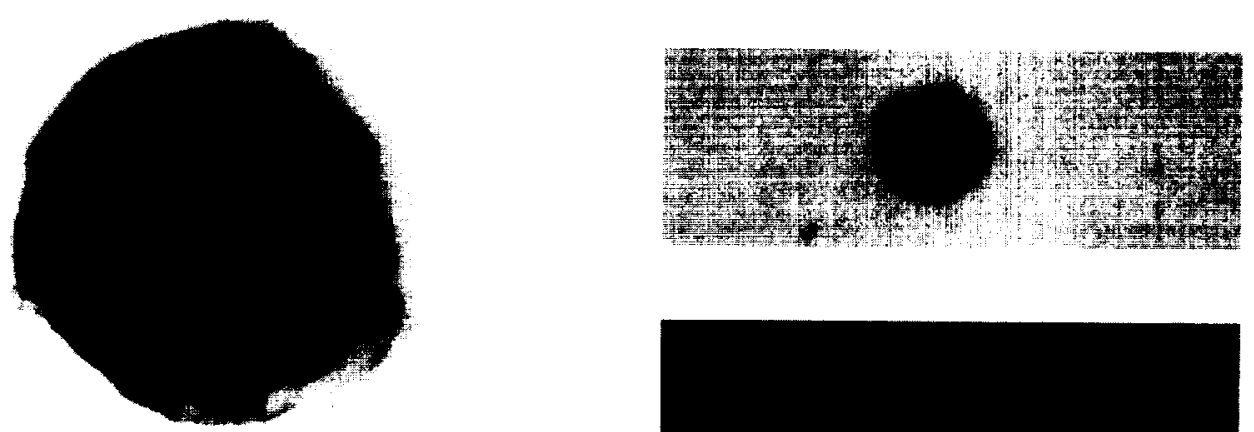

6.35

12.7

Figure 5d. Exit-side views of cratering and penetration experiments into teflon targets of variable thickness (T) that were impacted by $3.175 \mathrm{~mm}$ diameter $\left(D_{p}\right)$ soda-lime glass projectiles with an average encounter velocity of $4.0 \mathrm{~km} / \mathrm{s}$. 


\section{Front Side}

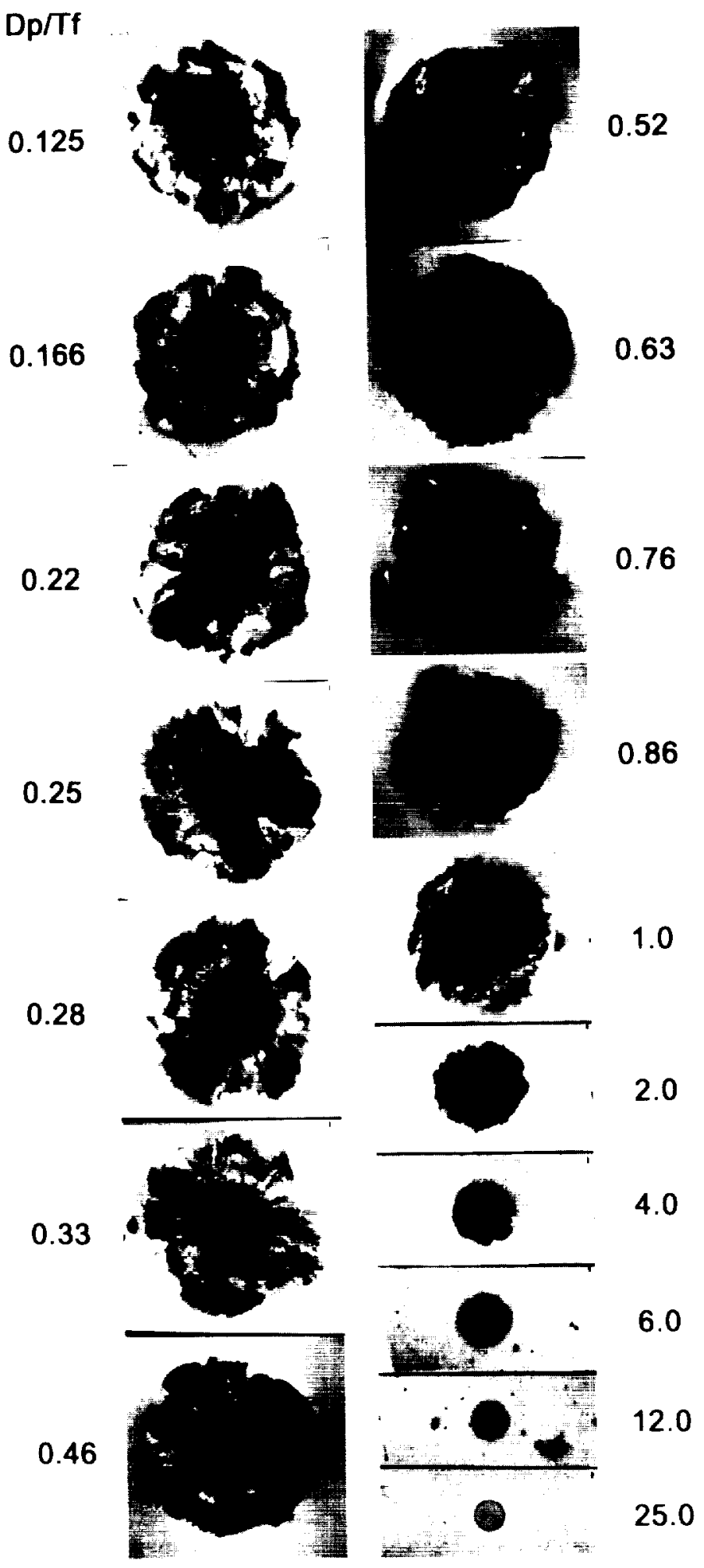

Figure 5e. Entrance-side view of cratering and penetration experiments in teflon targets of variable thickness (T) that were impacted by $3.175 \mathrm{~mm}$ diameter $\left(D_{p}\right)$ soda-lime glass projectiles with an average encounter velocity of $6.3 \mathrm{~km} / \mathrm{s}$. 


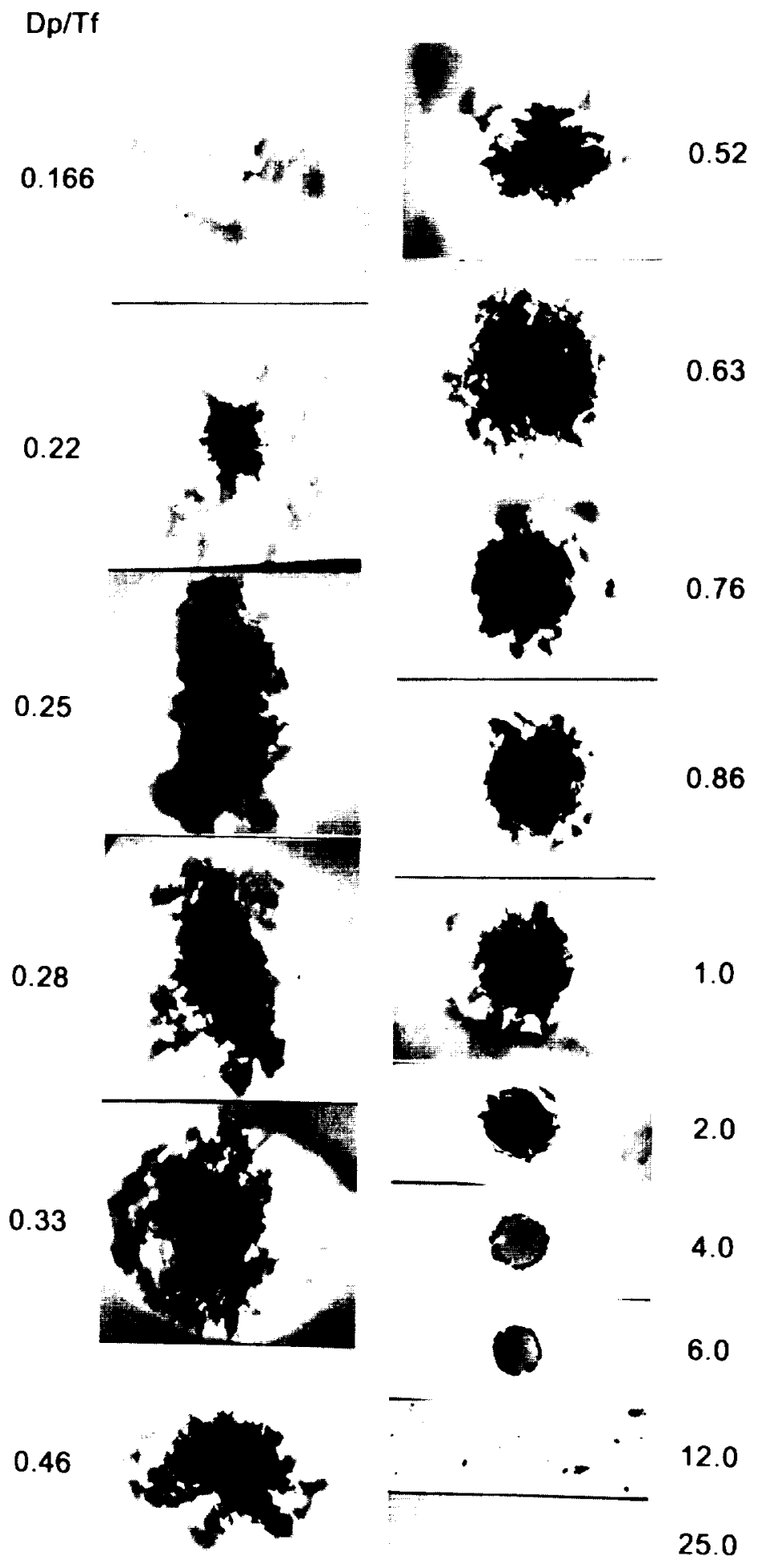

Figure 5f. Exit-side views of cratering and penetration experiments into teflon targets of variable thickness ( $T$ ) that were impacted by $3.175 \mathrm{~mm}$ diameter $\left(D_{p}\right)$ soda-lime glass projectiles with an average encounter velocity of $6.3 \mathrm{~km} / \mathrm{s}$. 


\section{Soda-Lime Glass $\rightarrow$ Teflon $(7 \mathrm{~km} / \mathrm{s})$}

\section{$\mathrm{Dp} / \mathrm{T}$}
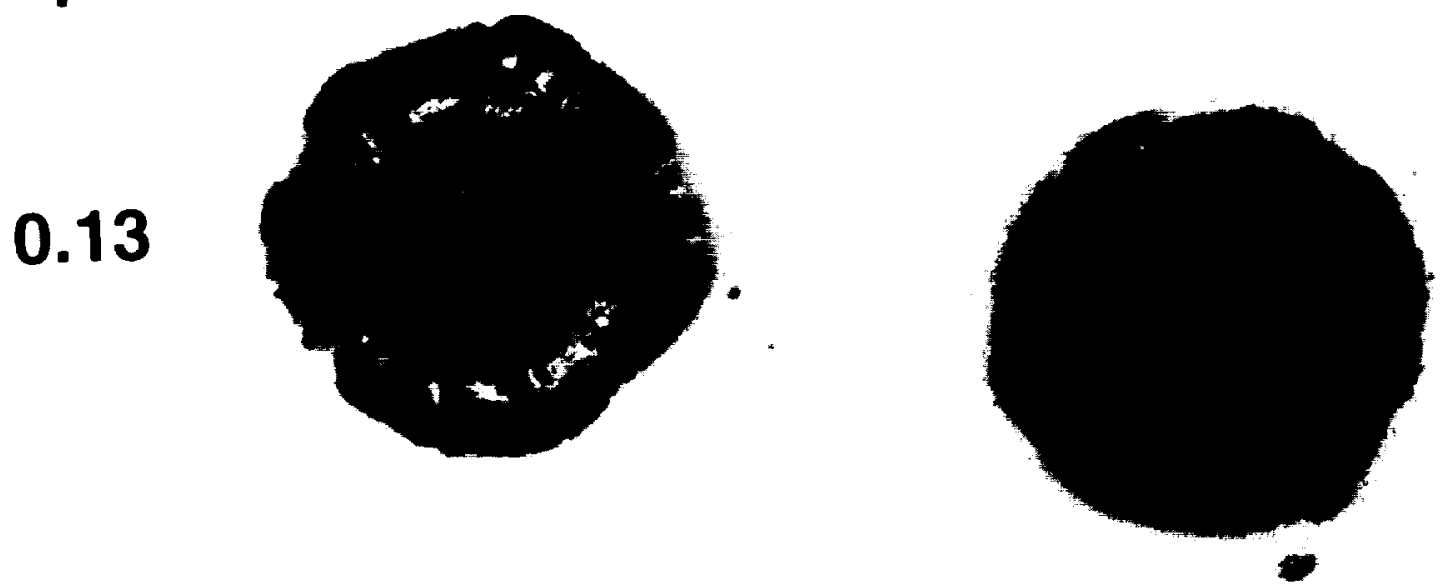

0.50
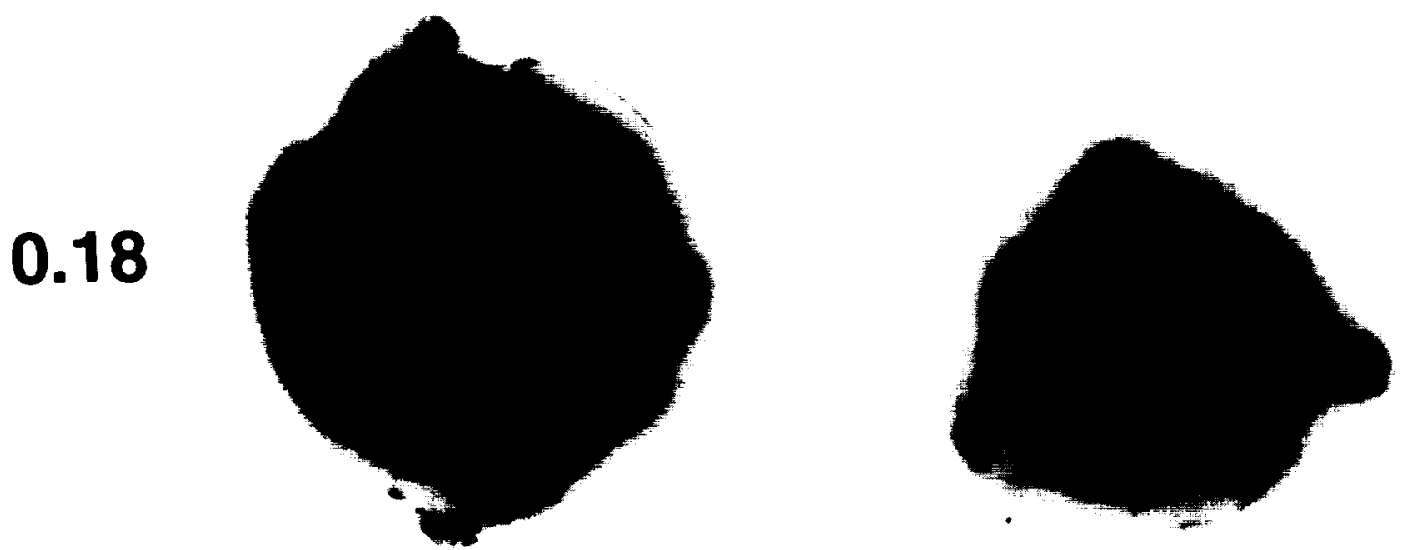

0.98

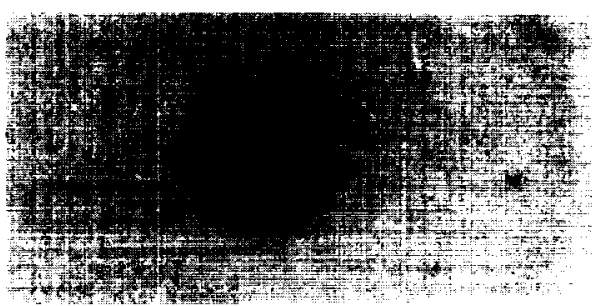

6.35

0.25
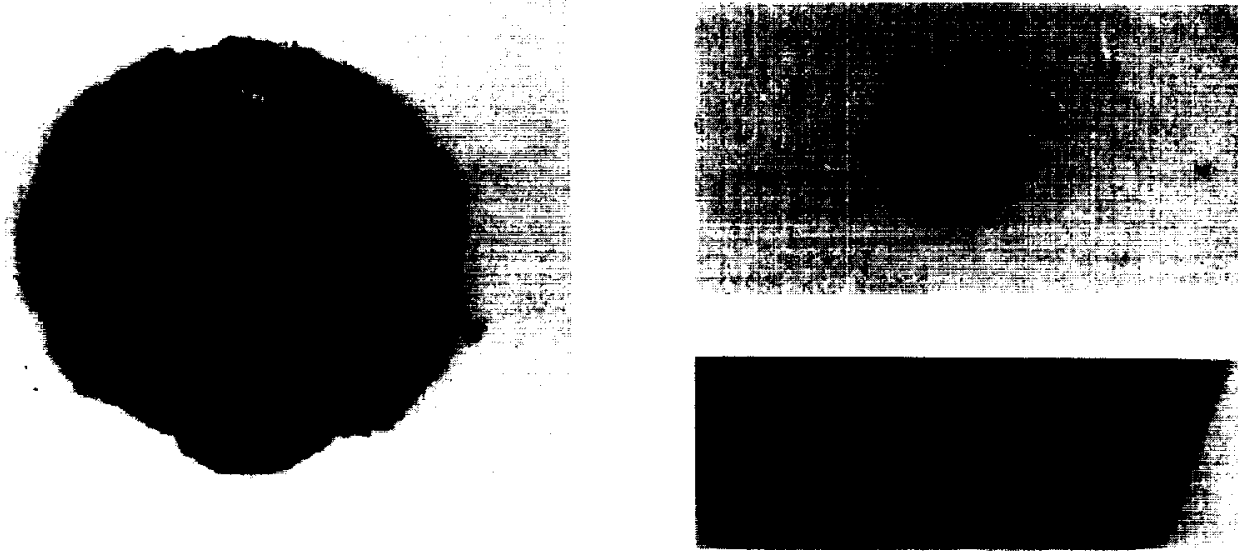

\section{9}

Figure 5g. Entrance-side view of cratering and penetration experiments in teflon targets of variable thickness (T) that were impacted by $3.175 \mathrm{~mm}$ diameter $\left(D_{p}\right)$ soda-lime glass projectiles with an average encounter velocity of $7.0 \mathrm{~km} / \mathrm{s}$. 


\section{Soda-Lime Glass $\rightarrow$ Teflon $(7 \mathrm{~km} / \mathrm{s})$}

\section{$\mathrm{Dp} / \mathrm{T}$ \\ 0.18}

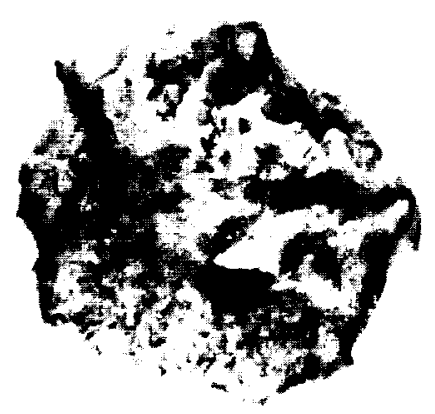

0.25

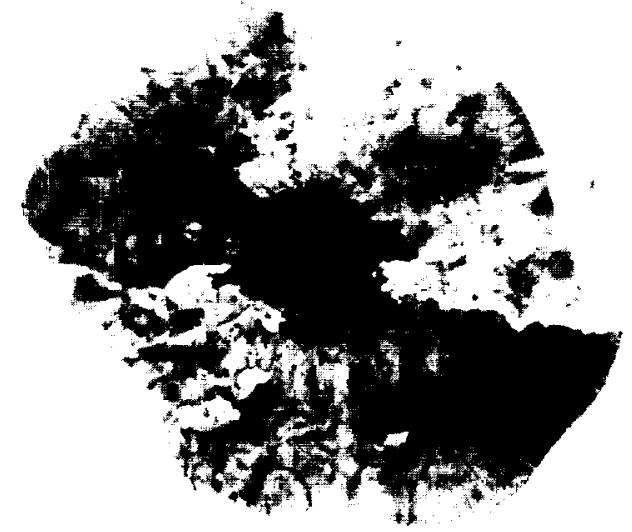

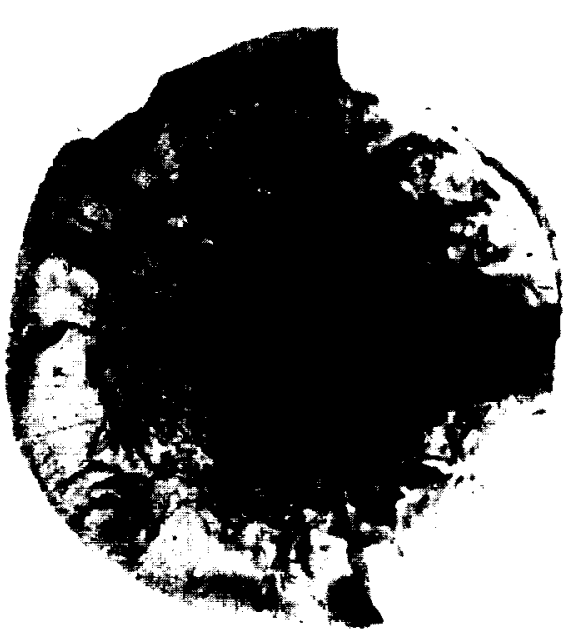

0.50

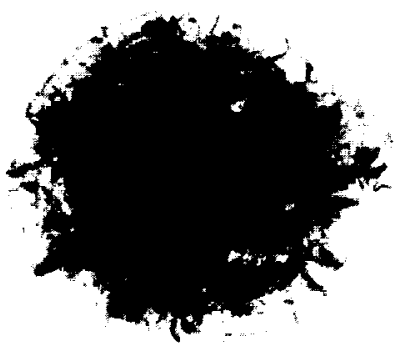

0.90

Figure 5h. Exit-side views of cratering and penetration experiments into teflon targets of variable thickness (T) that were impacted by $3.175 \mathrm{~mm}$ diameter $\left(D_{p}\right)$ soda-lime glass projectiles with an average encounter velocity of $7.0 \mathrm{~km} / \mathrm{s}$. 


\section{Soda-Lime Glass $\rightarrow$ Teflon $(2.3 \mathrm{~km} / \mathrm{s})$}

\section{$\mathrm{Dp} / \mathrm{T}$}

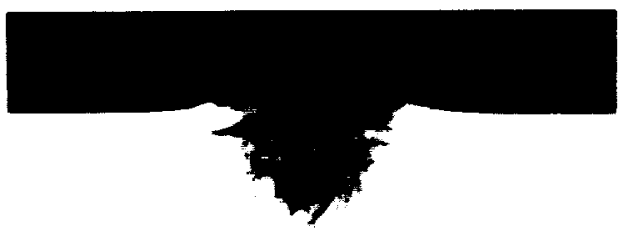

0.17
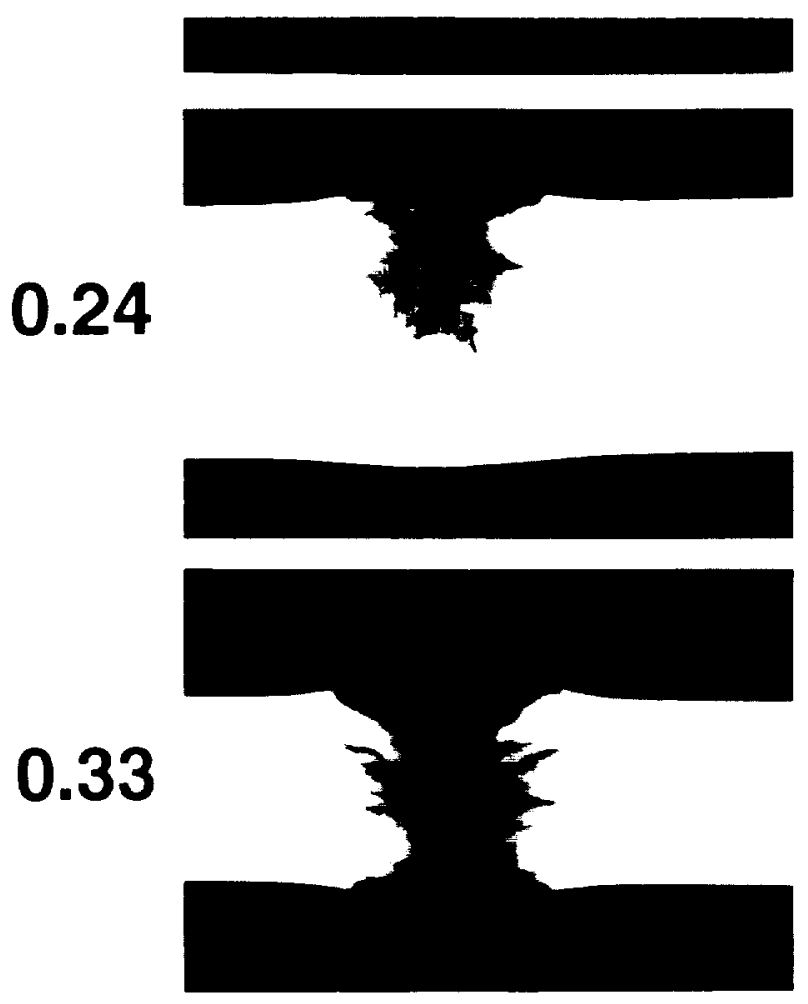
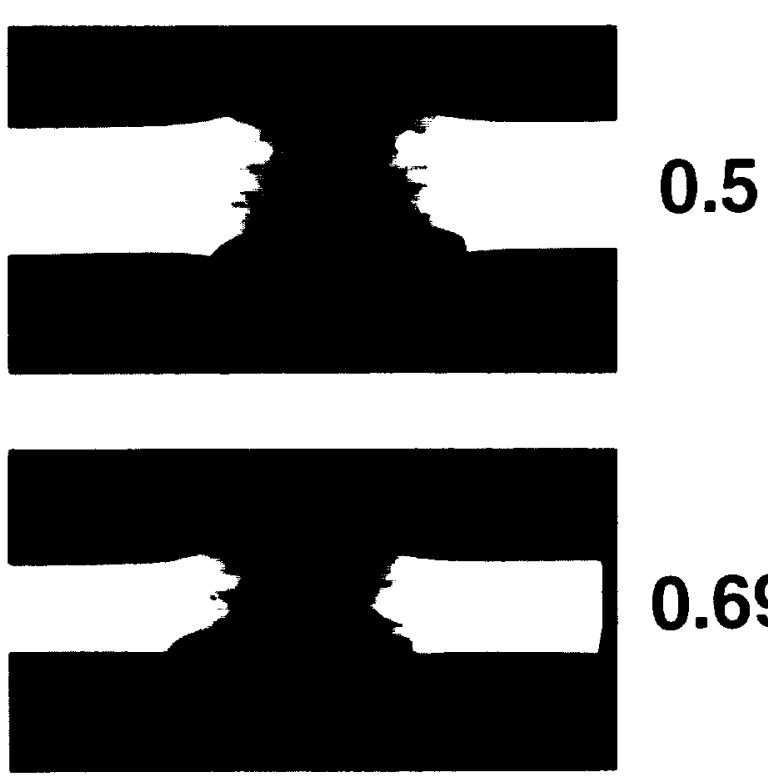

0.69
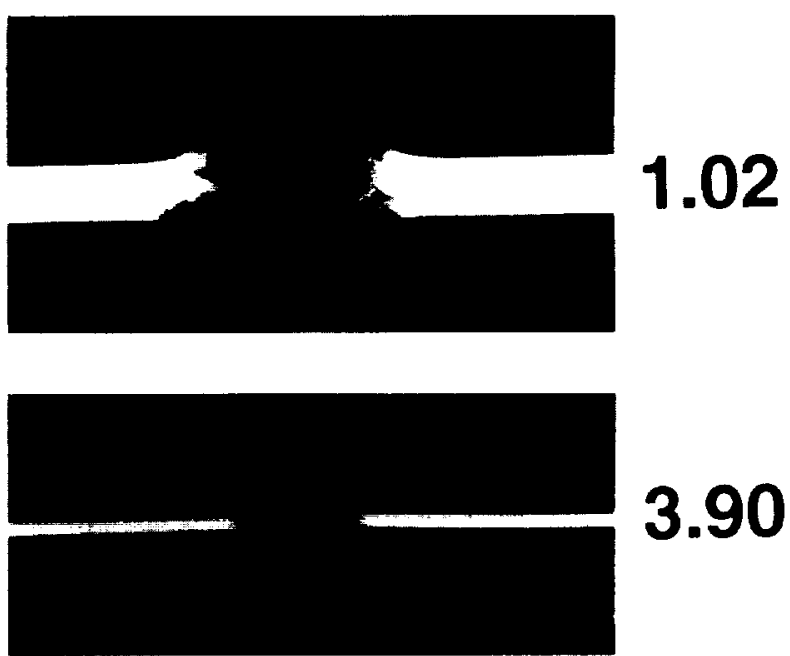

Figure 6a. Cross-sections of cratering and penetration events in teflon targets of variable thickness (T) that were impacted by $3.175 \mathrm{~mm}$ diameter soda-lime glass projectiles at a nominal impact velocity of $2.3 \mathrm{~km} / \mathrm{s}$. Note the case were $D_{p} / T \sim 1$ in each plate of Figure 6 (i.e., $\mathrm{T} \sim 3.175 \mathrm{~mm}$ ), which can be used as an internal scale. 


\section{Soda-Lime Glass $\rightarrow$ Teflon $(4 \mathrm{~km} / \mathrm{s})$}
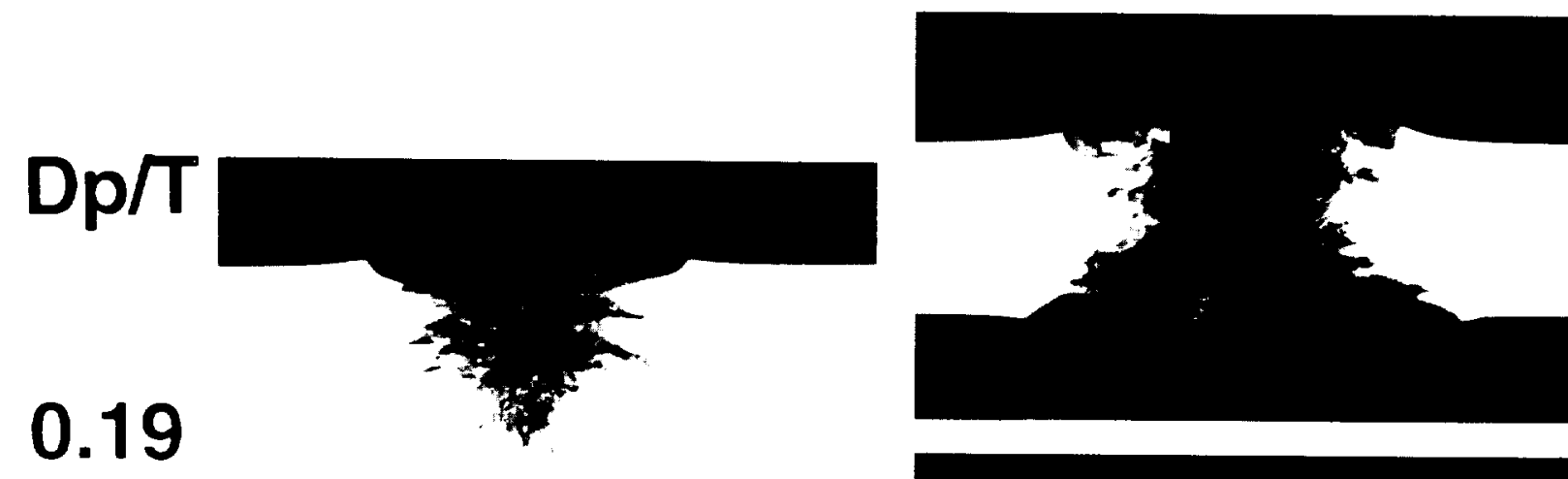

0.40
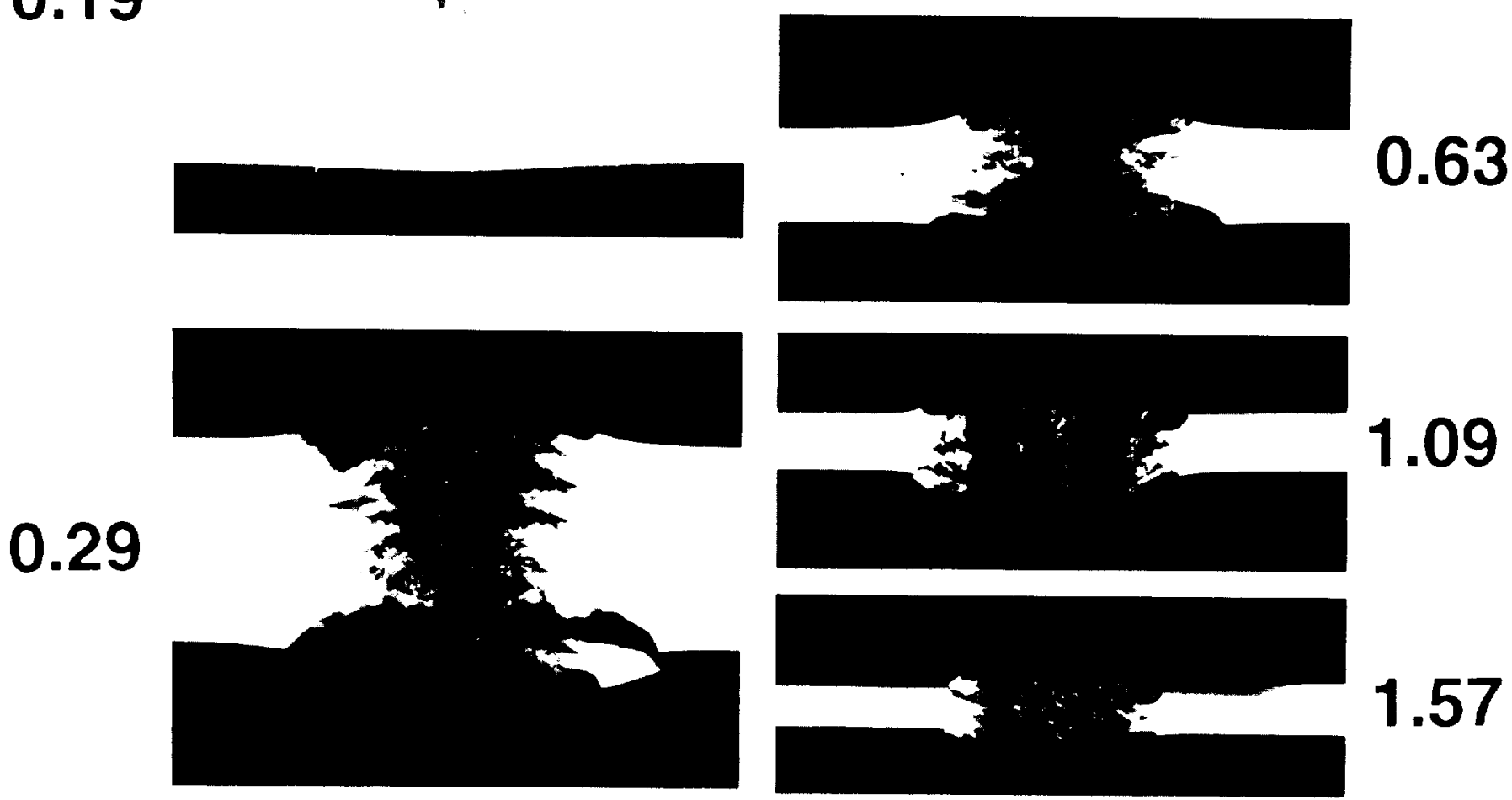

1.09

1.57

Figure 6b. Cross-sections of cratering and penetration events in teflon targets of variable thickness (T) that were impacted by $3.175 \mathrm{~mm}$ diameter soda-lime glass projectiles at a nominal impact velocity of $4.0 \mathrm{~km} / \mathrm{s}$. 


\section{Soda Lime Glass Into Teflon}

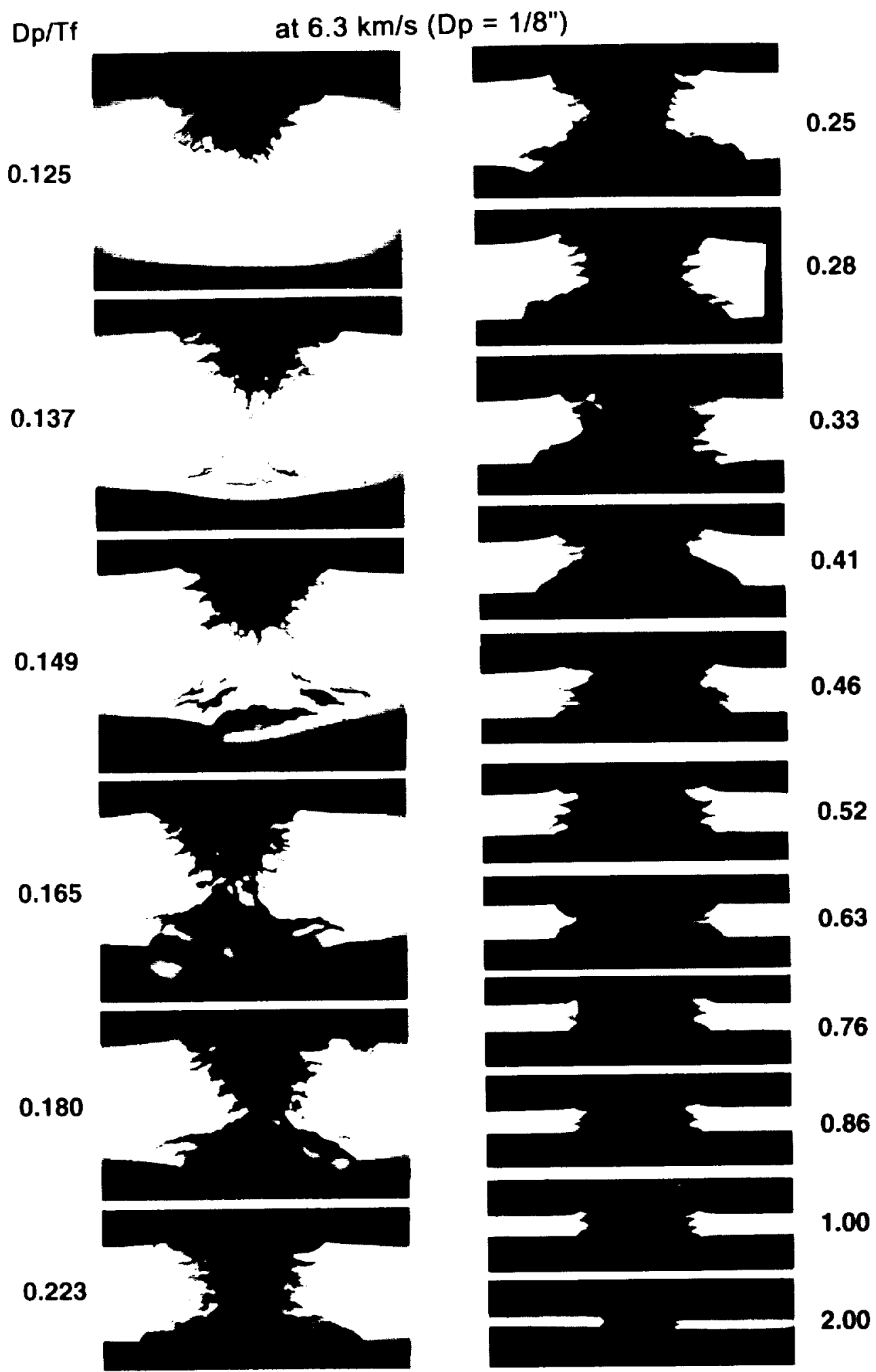

Figure 6c. Cross-sections of cratering and penetration events in teflon targets of variable thickness (T) that were impacted by $3.175 \mathrm{~mm}$ diameter soda-lime glass projectiles at a nominal impact velocity of $6.3 \mathrm{~km} / \mathrm{s}$. 


\section{Soda-Lime Glass $\rightarrow$ Teflon $(7 \mathrm{~km} / \mathrm{s})$}
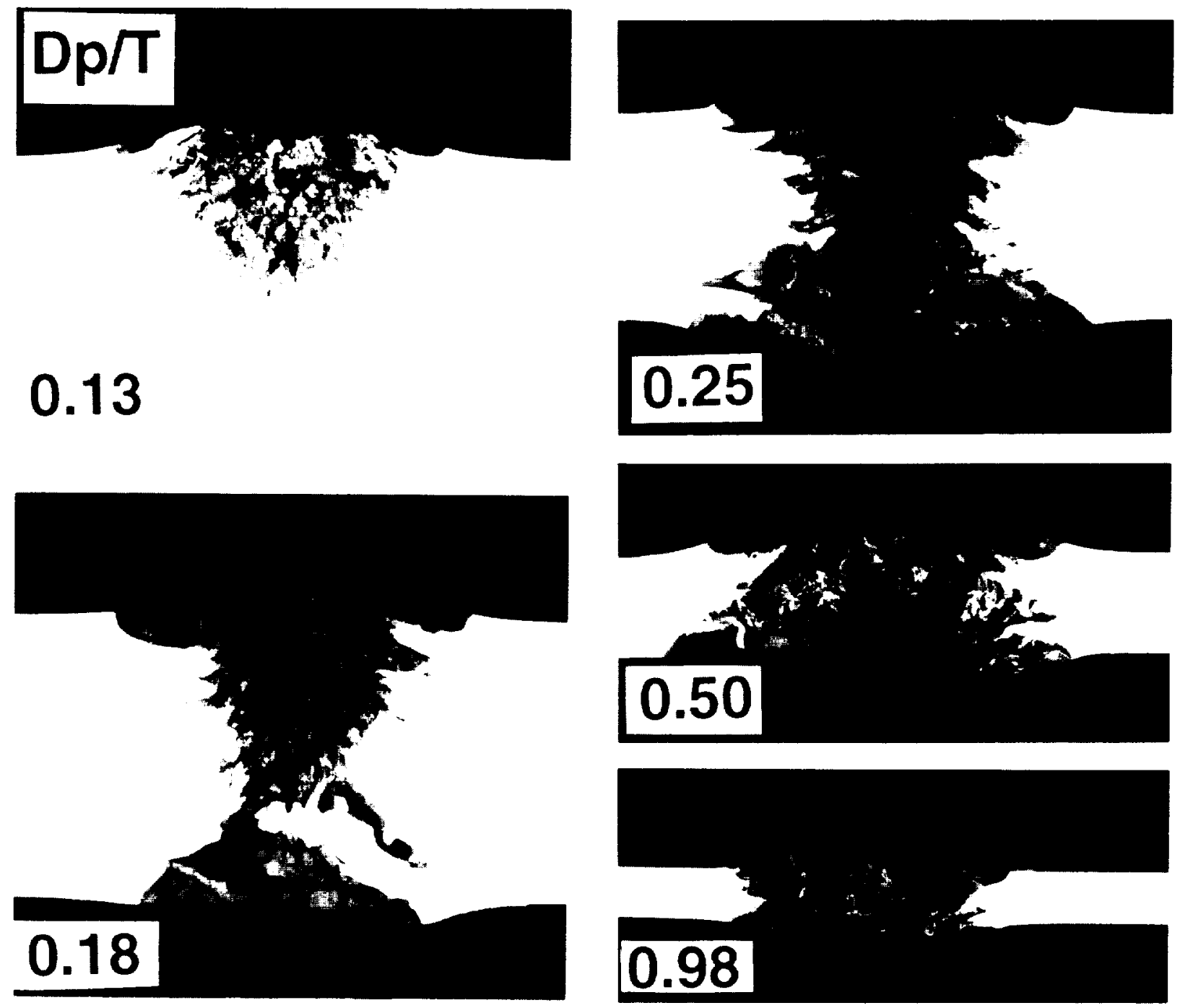

Figure 6d. Cross-sections of cratering and penetration events in teflon targets of variable thickness $(T)$ that were impacted by $3.175 \mathrm{~mm}$ diameter soda-lime glass projectiles at a nominal impact velocity of $7.0 \mathrm{~km} / \mathrm{s}$. 
being utilized, and substantially amplified by the rarefaction wave. As the ballistic limit is approached, these radial/conical fractures connect from the crater bottom to the target's back surface to become the macroscopic failure surface along which rear spallation takes place and ceases. Figures 6 and 7 also illustrate how this cratering related fracture system affects the radial extent, and especially the depth of the rear spall zone. As T decreases, rear-surface spallation tends to occur along fractures that intercept the crater profile at increasingly higher stratigraphic levels, exhibiting an increasingly larger cone angle along the macroscopic failure surface. At some specific $D_{p} / T$ this cone-angle becomes so large that it intercepts the target's front side at a radial range larger than that typical for crater diameter. This gives rise to the unusual situation where $D_{h}$ can become measurably larger than an associated standard crater (i.e., $D_{c}<D_{h}$; see Figure 7). For ductile materials (i.e., aluminum), we also found that the rims associated with the penetration of massive targets may be larger than the rims associated with the standard craters in the same material (e.g., Hörz et al., 1994). However, we never observed the case were $\mathrm{D}_{\mathrm{h}}>\mathrm{D}_{\mathrm{c}}$ in ductile materials. $D_{h}>D_{c}$ may well be the general case for brittle targets, considering the pervasive fracture systems associated with craters in glass (Schneider et al., 1990).

The qualitative observations offered during discussion of Figures 5-7 attest to the fact that a wide diversity of morphological phenomena are being produced during the penetration of teflon targets. These morphologic characteristics, without exception, are part of a remarkable continuum that strongly depends on $\mathrm{T}$, at otherwise identical impact conditions. This continuum is bound by the standard crater in infinite halfspace targets on one end, and by the ultra-thin foil that yields the condition of $D_{h}=D_{p}$ on the other. The various morphological elements seem to develop gradually, and in an exceptionally systematic, predictable fashion as $\mathrm{T}$ changes. Specifically, $D_{h}$ and $D_{S}$ are so systematically dependent on $T$ that reliable criteria emerge which permit the reconstruction of typical projectile dimensions from measured $D_{h}$ or $D_{s}$ and known foil-thickness (T), for a given impact velocity. Similar systematic behavior was found for cratering and penetration processes in aluminum 1100 (Hörz et al., 1994), as well as in lead, inconel, aluminum 6061 and other metal targets we have experimented with.

\section{D) Penetration-Holes: Measurements and Interpretations}

Figure 8 presents the detailed diameter measurements for craters $\left(D_{c}\right)$, penetration holes $\left(D_{h}\right)$, front-surface spalls $\left(D_{s}\right)$ and back-surface spalls $\left(D_{b}\right)$ plotted as a function of the relative projectile dimensions $\left(D_{p} / T\right)$, for each of the five experimental velocities. Note that $D_{c}$ can be smaller than the associated $D_{h}$ in some cases, and that the relative width of the front spall zone $\left(\mathrm{D}_{\mathrm{S}} / \mathrm{D}_{\mathrm{h}}\right)$ is readily apparent for massive targets, yet decreases with decreasing $\mathrm{T}$. As noted above, $\mathrm{D}_{\mathrm{b}}$ in massive targets can easily be a factor of two times larger than the associated $\mathrm{D}_{\mathrm{c}}$, and $\mathrm{D}_{\mathrm{b}}>$ $\mathrm{D}_{\mathrm{s}}$ in most cases (i.e., over a considerable range in $\mathrm{D}_{\mathrm{p}} / \mathrm{T}$ ). The measurement of the spall diameters at $D_{p} / T>5$ is not terribly informative, and $D_{h}$ becomes the dominant and only criterion to characterize a given penetration. The condition of $\mathrm{D}_{h}=\mathrm{D}_{\mathrm{p}}$ is approximated at $\mathrm{D}_{\mathrm{p}} / \mathrm{T}$ $>50$. Having summarized the cratering behavior in Figure 4, we construct a curve through all penetration-hole data in Figure 9.

We consider $D_{c}$ and $D_{h}$ to be the primary measurements for estimating projectile sizes from space-retrieved impacts, the reason why we concentrate on these two measurements in Figure 9. Craters are represented by a horizontal line in this portrayal, because their $D_{c} / D_{p}$ ratio remains 
thickness (e.g., Pailer and Grun, 1980; Carey et al., 1985; Herrmann and Wilbeck, 1987; McDonnell and Sullivan, 1992). All other perforations in a given target must be the result of larger or more energetic impactors, yet specific dimensions or energies beyond the threshold values may not be specified. As a result, entire populations of penetration holes may be represented by a single, cumulative datum only. The approach illustrated in Figure 11 permits interpretation of individual penetration holes and associated size-frequency distributions of impactors, akin to crater populations.

Figure 11 places the characterization of individual penetration holes in teflon, and their associated projectile dimensions, on par with the extraction of impactor dimensions from diameter and/or depth measurements of individual craters (Hörz et al., 1990, 1993, 1994; Tanner et al., 1993). The dynamic behavior of hypervelocity particles in LEO is sufficiently known such that the population of penetration holes on space-exposed surfaces (e.g., LDEF) may be interpreted via reasonably constrained, mean encounter velocities of natural (e.g., Zook, 1992) and man-made (Kessler, 1993) particles.

We note from Figures 9-11 that only rare and exceptionally large impact events will approach the condition of $D_{h}=D_{p}$ for the case of the LDEF thermal blankets (Hörz et al., 1993). Assuming (conservatively) that this is the case for $D_{p} / T=50$, one calculates for the $\sim 200 \mu \mathrm{m}$ thick LDEF blankets a hole diameter of $D_{h}=1 \mathrm{~cm}=D_{p}$, independent of impact velocity. The largest hole observed on LDEF was only $\sim 3 \mathrm{~mm}$ in diameter (See et al., 1990). Returning to Figure 11 , this corresponds to a $D_{h} / T \sim 15$. The vast majority of penetration holes in the LDEF blankets have scaled diameters of $D_{h} / T<5$. Similar considerations apply to most other surfaces retrieved from space, such as Solar Max materials (Warren et al., 1989). These observations underscore the need for detailed laboratory simulations, such as the current teflon experiments, because most LEO penetrations may neither be interpreted as craters, nor as having dimensions that directly resemble those of the impactor (Hörz et al., 1993).

For completeness of the dimensional measurements, Figure 12 summarizes the relative widths of the front $\left(D_{s}\right)$ and rear spalls $\left(D_{b}\right)$, normalized to $D_{h}$, and plots them as a function of relative projectile size $\left(D_{p} / T\right)$. $D_{s}$ is readily twice $D_{h}$ for massive targets, while $D_{b}$ is larger still. Substantial data scatter is prominent for massive targets. Similar observations were made with the relative rim widths in aluminum targets (Hörz et al., 1994). Close inspection of Figure 12 reveals that low-velocity impacts $(2.3 \mathrm{~km} / \mathrm{s})$ tend to consistently develop larger spall zones, for any given $T$, than the $>6 \mathrm{~km} / \mathrm{s}$ events. Thus, the relative spall diameter $\left(D_{s} / D_{h}\right)$ may be related to the impact velocity. However, this is not corroborated by the standard craters (Figure 4). Obviously, Figure 12 is characterized by substantial scatter, and best fit (polynomial) lines through the data for any given velocity may cross and overlap each other. Therefore, we are unclear as to the detailed velocity dependence of the relative spall dimensions and suggest that they are not a reliable measure of the impact velocity.

We realize that Figures 8-12 strongly relate to the investigation of collisional hazards in LEO, and to the shielding of spacecraft or military targets by passive bumper systems. The calibration curves illustrated in Figure 11 may be used with a known $\mathrm{D}_{\mathrm{p}} / \mathrm{T}$ ratio and an assumed velocity to predict $D_{h}$ with confidence. 
massive targets, as postulated for all conditions of $t_{p}<t_{t}$. Note that the large hole diameters decrease to the approximate crater dimensions at $D_{p} / T$ values that are close to the $T_{c p}$ arrow in Figure 9, and that $D_{s}$ and $D_{c}$ only decrease for smaller target thicknesses (i.e., when $t_{p}>t_{t}$ ). We take this as evidence that the condition of $t_{p}=t_{t}$ may be a most useful criterion to distinguish between crater-like structures and genuine penetration holes. Ideally, the $\mathrm{T}_{\mathrm{cp}}$ line in Figure 10 coincides with, and defines the condition of $\mathrm{D}_{\mathrm{c}}>\mathrm{D}_{\mathrm{h}}$.

Extrapolation of the experimental data to velocities $>10 \mathrm{~km} / \mathrm{s}$ in Figure 10 was performed by taking the standard crater diameter and extrapolating to a desired velocity, and by assuming that this diameter, after normalization to typical impactor dimensions $\left(D_{c} / D_{p}\right)$, is constant at all conditions of $t_{p}<t_{t}$. The other major assumption in Figure 10 is that the condition of $D_{h}=D_{p}$ be met at $D_{p} / T=100$, regardless of velocity. The actual curves from the $T_{c p}$ intercept to the $D_{h}=$ $D_{p}$ case are largely intuitive, yet represent reasonably constrained interpolations that parallel the trends of the experimental data at lower velocities. There is little doubt that a more rigorous treatment of the experimental data and their extrapolation to higher impact velocities is warranted. Figure 10 may provide the conceptual framework for such extrapolations.

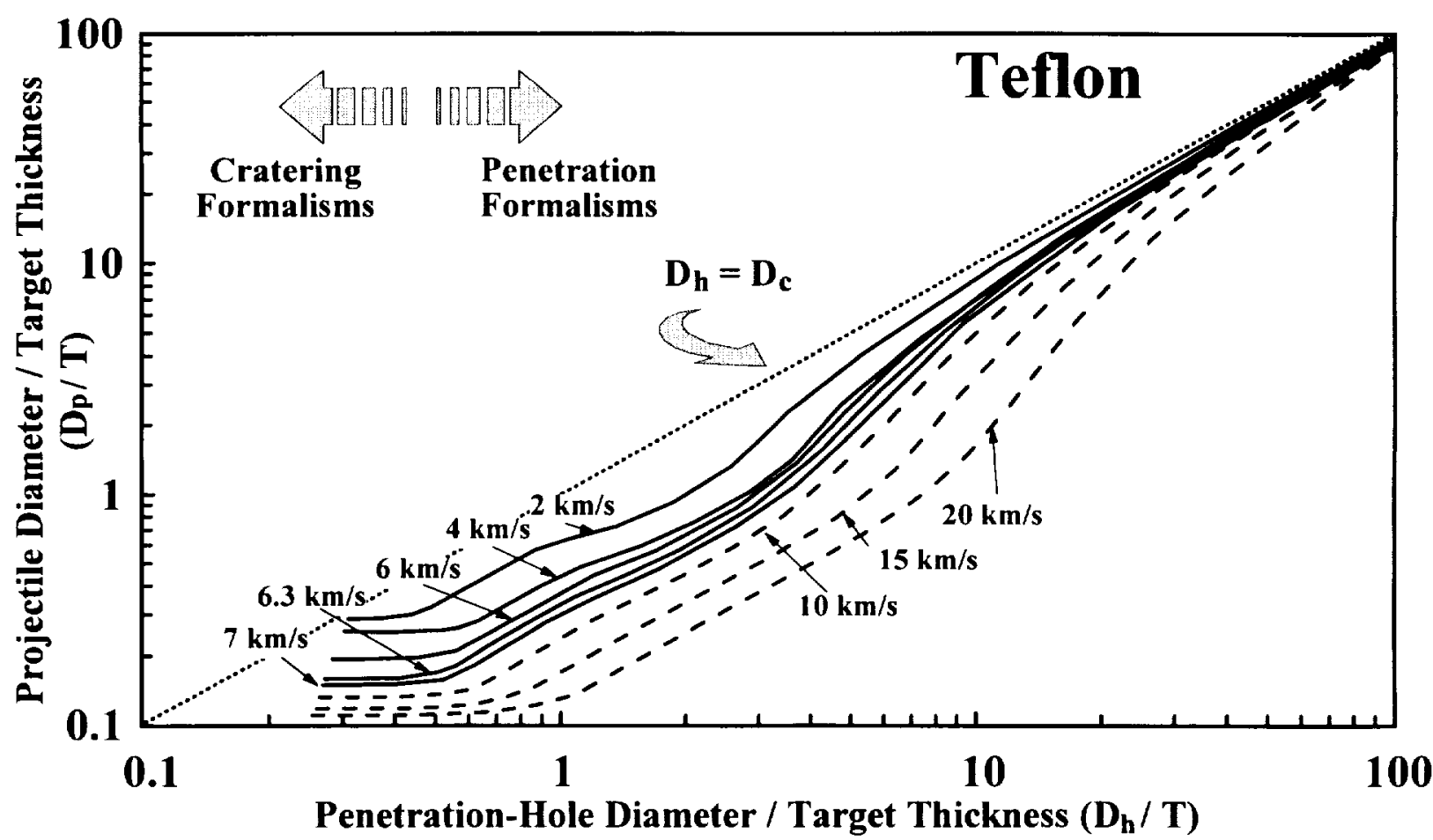

Figure 11. Calibration curves to solve for projectile dimensions $\left(D_{p}\right)$ from the measurements of penetration-hole size $\left(D_{h}\right)$ and thickness ( $T$ ) of teflon targets using glass projectiles of density $2.4 \mathrm{~g} / \mathrm{cm}^{3}$ and assumed model velocities.

Figure 11 summarizes the data in yet a different way, but in a fashion that seems most suitable to the data's intended application, which is to determine an unknown projectile diameter from the easily obtainable measurements of $\mathrm{D}_{\mathrm{h}}$ and $\mathrm{T}$ on space-exposed surfaces. In principal, this portrayal yields unique $\mathrm{D}_{\mathrm{p}} / \mathrm{T}$ values, and thus, specific projectile dimensions for any individual penetration hole, provided an impact velocity is known or assumed. This represents substantial progress over traditional capabilities that are rooted in ballistic-limit considerations, which solve for the minimum particle size (or energy) that is capable of penetrating a given target 
The $\mathrm{T}_{\mathrm{cp}}$ line in Figures 9 and 10 delineates the target thickness where the shock-pulse durations within the projectile $\left(t_{p}\right)$ and target $\left(t_{t}\right)$ are exactly equal. The shorter of the two pulses defines the duration of the compressive phase of the impact event. The $T_{c p}$ line in Figure 10 is based on equation-of-state data by Marsh (1980) for quartz glass and teflon, and follows the computational method of Cintala (1992) for their extrapolation to cosmic velocities. All impacts to the left of this line are characterized by $t_{p}<t_{t}$. This relationship is reversed in thin targets, where $t_{p}>t_{t}$. As argued on the basis of aluminum penetrations (Hörz et al., 1994), this condition delineates the real termination of cratering phenomena at the target's front surface. The condition $t_{p}>t_{t}$ produces material flows of increasingly smaller radial extend at the front surface of progressively thinner targets. Therefore, we propose that diameter $D_{c}$ become the practical measurement of choice for all conditions of $t_{p}<t_{t}$.

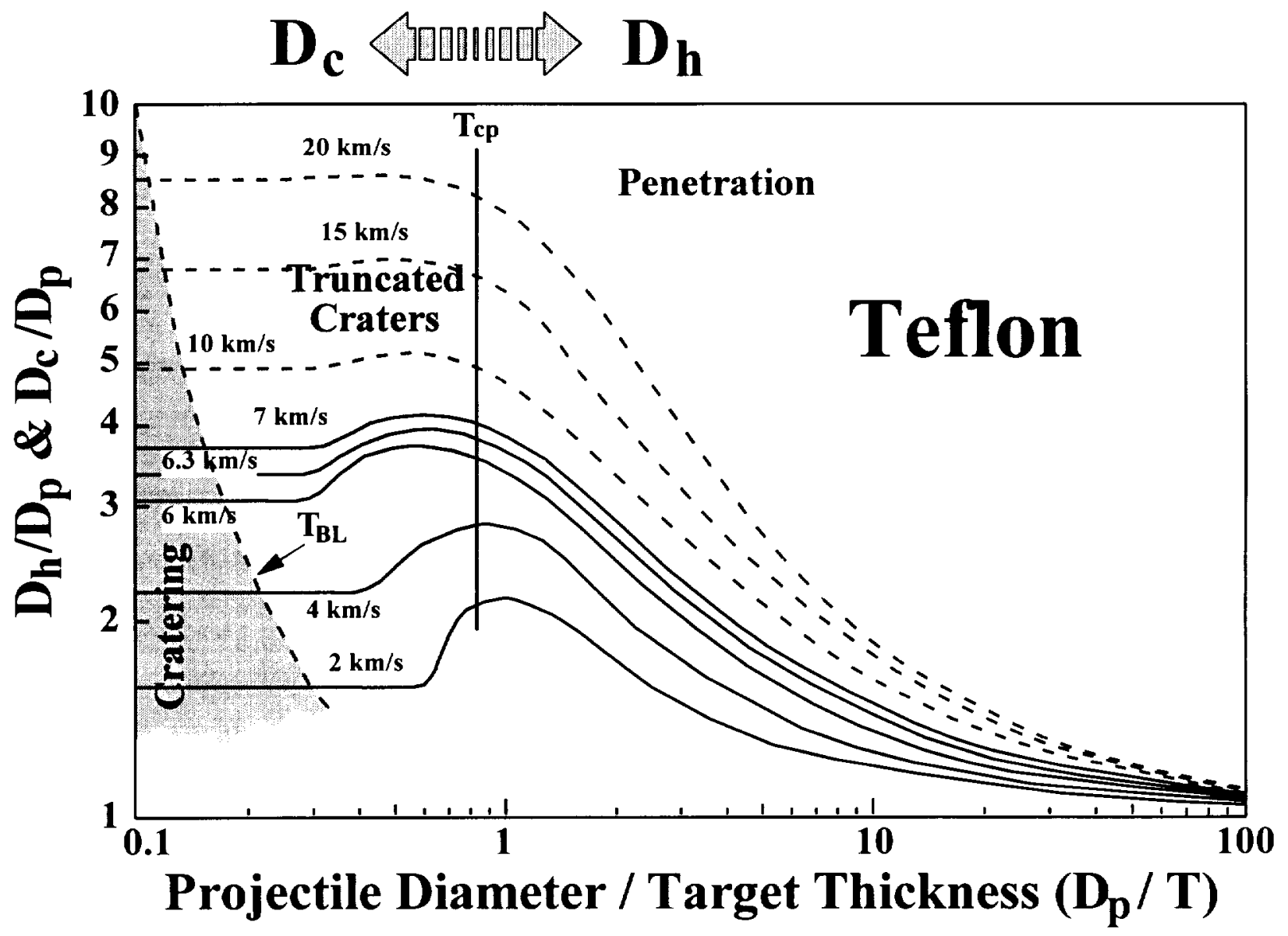

Figure 10. Summary comparison of the velocity dependence of crater dimensions and penetration-hole sizes in teflon targets, combined with the proposed extrapolation of the experimental data to higher velocities. For a detailed discussion and derivation of the diverse criteria, see text.

The $T_{c p}$ arrows in Figure 9 indicate the condition were $t_{p}=t_{t}$, with the corresponding $D_{p} / T$ value given in parentheses. Unfortunately, the extra-large penetration holes in teflon, caused by spallation processes from the rear, prevent the detailed tracking of the actual $D_{c}$ in massive teflon targets, especially at low velocities. The experimental data suggest that the oversized penetration holes become less prominent with increasing velocity, and the $>6 \mathrm{~km} / \mathrm{s}$ experiments closely conform to the idea of a relatively constant crater diameter for craters and penetrations in 
consequence, the parameter of interest to obtain projectile dimensions from such penetrations is $D_{c}$ at the original target surface, rather than $D_{h}$ at some target depth. The range in $D_{p} / T$ over which these conditions apply is substantially beyond the ballistic limit, typically approaching the condition of $D_{p} / T=1$. Very generally, $D_{c}$ remains the preferred and diagnostic measurement for all penetrations that possess rim morphologies or spall-zones, at the target front side, which closely resemble that of the standard crater. Such structures are best characterized by $D_{c}$ and associated cratering equations when estimating projectile dimensions, as detailed by Hörz et al. (1994).

As previously mentioned, teflon targets, and possibly many brittle materials, may develop penetration holes that are noticeably larger than $D_{c}$ of a corresponding standard crater. As illustrated in Figures 8 and 9 , this condition is predominantly a function of $D_{p} / T$, yet one that is also dependent on velocity. It is obviously more pronounced at low velocities and decreases in magnitude with increasing encounter velocity, and may completely vanish at collisional velocities typical for LEO particles ( $>10 \mathrm{~km} / \mathrm{s}$ ). Generally, $\mathrm{D}_{\mathrm{p}} / \mathrm{T} \cong 1$ must be reached to produce hole dimensions which truly represent the condition of $\mathrm{D}_{\mathrm{h}}=\mathrm{D}_{\mathrm{c}}$.

Penetration-hole behavior in teflon targets of $\mathrm{D}_{\mathrm{p}} / \mathrm{T}>1$ is akin to that of aluminum and many other materials (e.g., Carey et al., 1985; Hermann and Wilbeck, 1987). However, none of the previous reports, except the aluminum experiments by Hörz et al. (1994), tested targets as thin as $\mathrm{D}_{\mathrm{p}} / \mathrm{T}>100$. Note that the condition of $\mathrm{D}_{\mathrm{p}} / \mathrm{T}=10$ yields penetration holes in teflon $\sim 50 \%$ larger than $D_{p}$. From Figure 9, we also conclude that the condition of $D_{p} / D_{h}=1$ is reached, for most practical purposes, at $D_{p} / T>50$. This condition is virtually independent of impact velocity, and represents a very important result to which we will return later.

To illustrate the velocity dependent trends we replot the data from Figure 9 in Figure 10, yet we display only one measurement, either $\mathrm{D}_{\mathrm{c}}$ or $\mathrm{D}_{\mathrm{h}}$, at any given $\mathrm{D}_{\mathrm{p}} / \mathrm{T}$. The intent is to display that measurement which appears most suitable in characterizing the projectile dimensions for any arbitrary target thickness. Obviously, cratering processes and measurement of $D_{c}$ apply to the thickest targets, whereas $\mathrm{D}_{\mathrm{h}}$, and some penetration formalism, apply to the thin targets. Therefore, the purpose of Figure 10 becomes one of making practical suggestions of what dimensions to measure, as a minimum, on perforated, space-exposed teflon surfaces.

The experimental observations verify the strong velocity dependence of cratering and penetration phenomena in massive targets, typically of $D_{p} / T<1$. In contrast, projectile velocity seems to be of little consequence in producing a hole approximately the size of the impactor at $\mathrm{D}_{\mathrm{p}} / \mathrm{T}>50$. Therefore, we reach the important conclusion that relative dimensions $\left(\mathrm{D}_{\mathrm{p}} / \mathrm{T}\right.$ or $\left.\mathrm{D}_{\mathrm{h}} / \mathrm{T}\right)$ alone are important considerations in the velocity-scaling of penetration phenomena.

Interpretation of Figure 10 and extrapolation of the experimental data to higher velocities is based on a number of assumptions, first detailed by Hörz et al. (1994) for aluminum targets. Extrapolation to velocities $>10 \mathrm{~km} / \mathrm{s}$ exclusively relies on experiments conducted at velocities $>6$ $\mathrm{km} / \mathrm{s}$, because the experiments at $4 \mathrm{~km} / \mathrm{s}$, and especially at $2.3 \mathrm{~km} / \mathrm{s}$ are unsuitable to describe the hydrodynamic behavior of teflon (or any other material) at higher velocities (e.g., Schmidt et al., 1993). In Figure 10 the ballistic-limit thickness $\left(T_{\mathrm{BL}}\right)$ of the $>6 \mathrm{~km} / \mathrm{s}$ experiments is extrapolated to the higher impact velocities (i.e., 10,15 and $20 \mathrm{~km} / \mathrm{s}$ ). By definition, all targets to the left of this line will constitute infinite halfspace targets and will not be physically penetrated at any given velocity. Such targets will sustain full-fledged cratering events characterized by some specific $\mathrm{D}_{\mathrm{c}}$, which scales with $\mathrm{V}^{0.44}$. 
This condition will be approached asymptotically by all penetration holes of dimensions $D_{h} \ll D_{c}$ and especially by those of $D_{h}<$ $D_{p}$ (off scale in Figure 9; see Table 1). In practice, $T_{\mathrm{BL}}$ was obtained relatively quickly by varying $T$ in sufficiently small increments to produce at least one bulged or spalled target that was not physically perforated, one marginal penetration $\left(D_{h}<D_{p}\right)$, and several substantial penetrations of $D_{h}<D_{c}$. Some of these latter penetration may have resulted in rather large holes that seem to have substantially overshot the ballistic limit, yet all holes where $D_{h}<D_{c}$ are useful in determining the general shape of the $D_{h}$-curve, and its extrapolation to $D_{h}=0$ at $\mathrm{T}_{\mathrm{BL}}$ in Figure 9.

Returning to Figure 8, the parameter $D_{h}$ increases dramatically over a narrow interval of $D_{p} / T$, while $D_{c}$ stays relatively constant. As discussed with the analogue aluminum experiments (Hörz et al., 1994), penetrations in massive targets must be viewed, to first order, as craters that had their bottoms truncated. This truncation occurs at increasingly higher stratigraphic levels -- measured from the crater bottom -- as $\mathrm{T}$ decreases.

As a

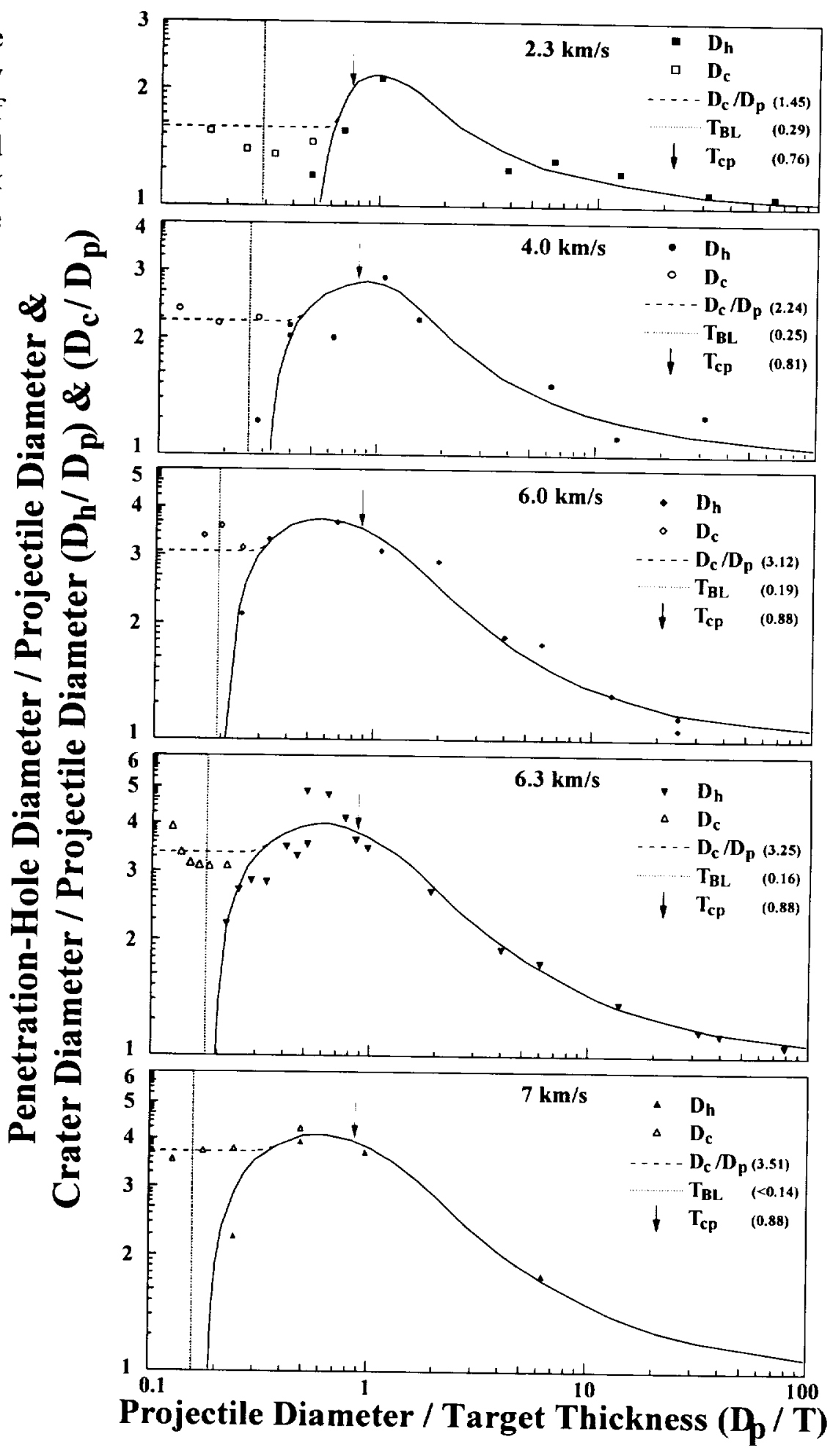

Figure 9. Plot depicting only the $D_{c}$ and $D_{h}$ measurements which are the most pertinent for the interpretation of unknown, space-produced impacts and other features, such as the ballistic limit. Numbers in parenthesis reflect normalized crater diameters $\left(D_{c} / D_{p}\right)$ or specific $\mathrm{D}_{\mathrm{p}} / \mathrm{T}$ values for the ballistic limit $\left(\mathrm{T}_{\mathrm{BL}}\right)$ and the transition from cratering to penetration $\left(\mathrm{T}_{\mathrm{cp}}\right)$. 

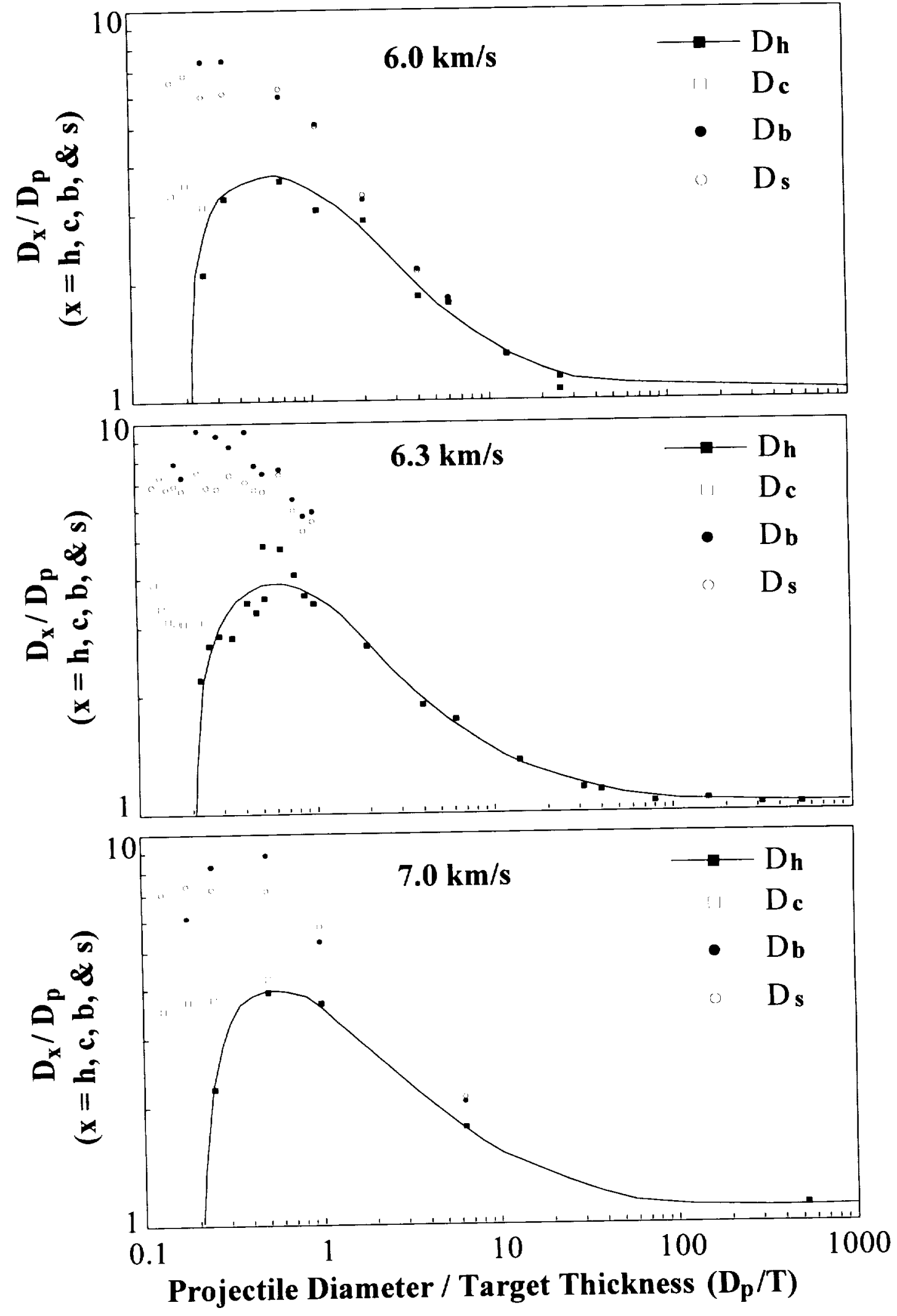

Figure 8. (continued) 
constant, regardless of $T$, for any given velocity. The average $D_{c} / D_{p}$ ratio is given in brackets for each of the five experimental series. The rapidly steepening slope -- for massive targets -- of the $D_{h}$ curve in Figures 8 and 9 is largely influenced by $D_{h}=0$, our definition for the ballistic limit ( $\mathrm{T}_{\mathrm{BL}}$; vertical line in Figure 9), which intercepts the $\mathrm{D}_{\mathrm{p}} / \mathrm{T}$ axis at $\mathrm{T}_{\mathrm{BL}}$ (given in parenthesis).

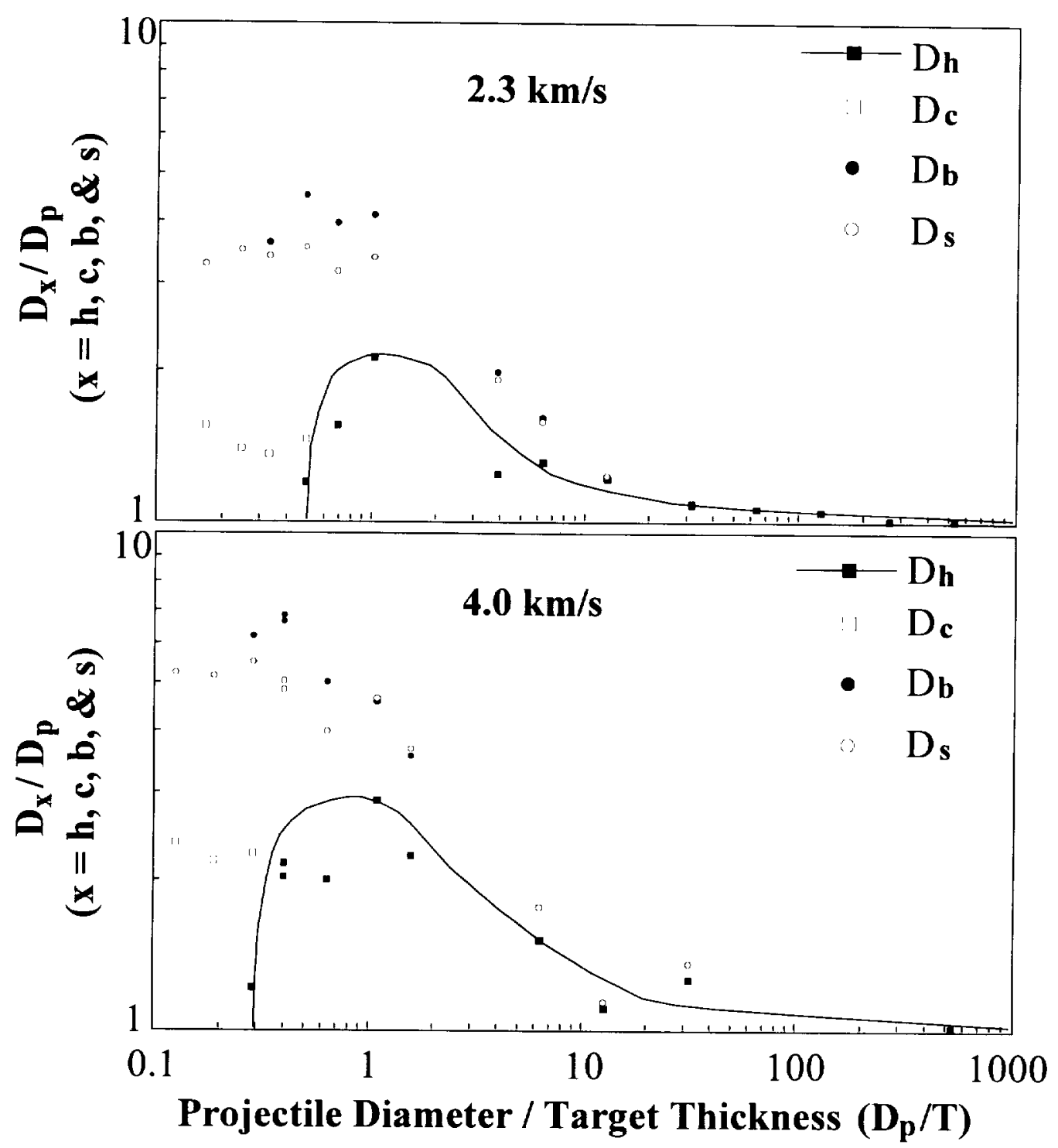

Figure 8. Dimensional measurements of craters and penetrations in teflon targets of variable thickness ( $T$ ) employing $3.175 \mathrm{~mm}$ diameter soda-lime glass projectiles at velocities from $2-7 \mathrm{~km} / \mathrm{s}$. The solid line reflects the behavior of only the penetration holes $\left(D_{h}\right)$. Note that the diameters of the spall zones at the front- $\left(D_{s}\right)$ and back-surfaces $\left(D_{b}\right)$ are substantially larger than the associated crater $\left(D_{c}\right)$ and penetrationhole diameters $\left(D_{h}\right)$. Also note that $D_{c}$ is smaller than $D_{h}$ over a select $D_{p} / T$ range, and that this effect seems to diminish with increasing velocity. 

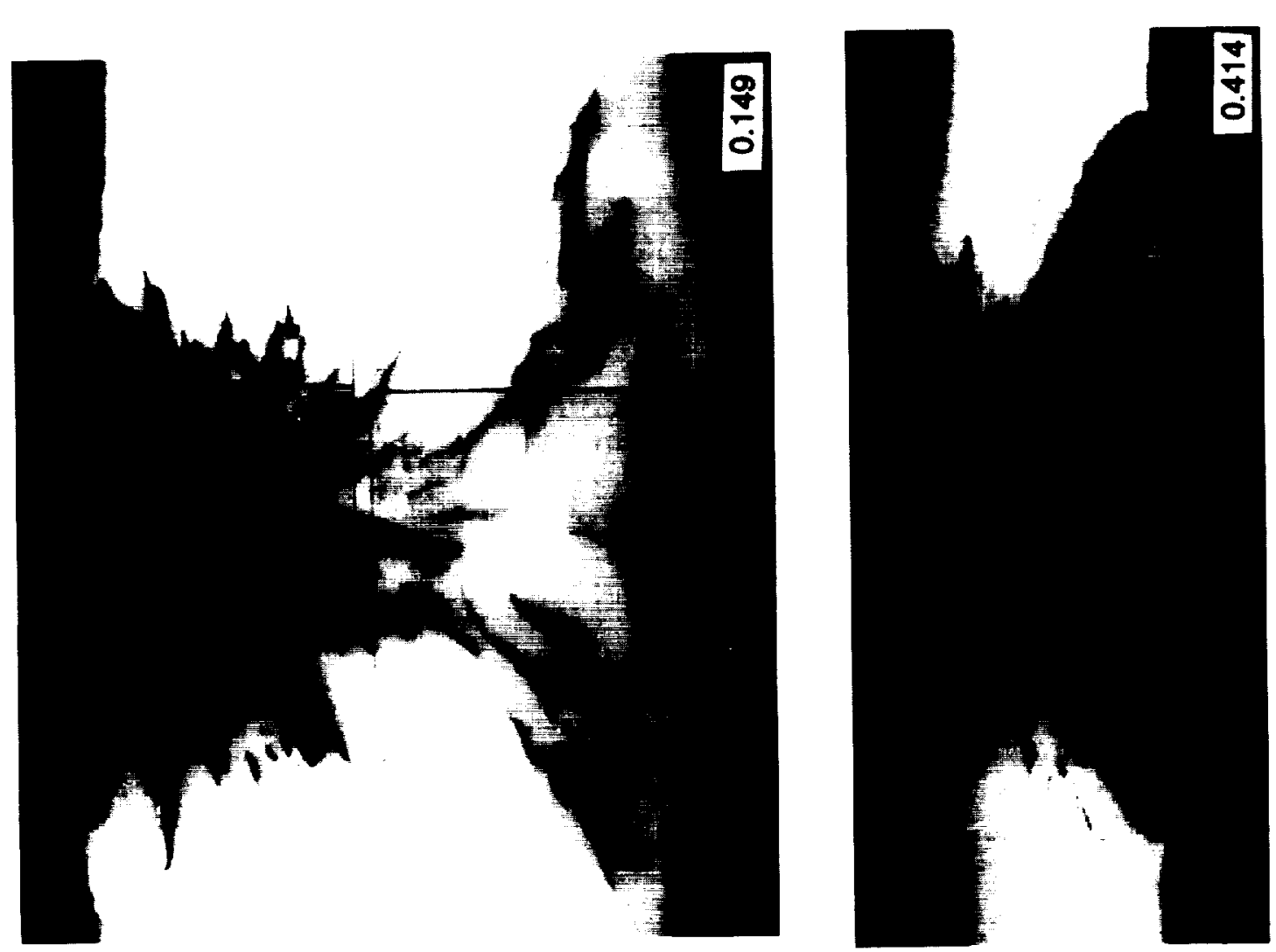

覀垔 \% 管览 ot 5 政

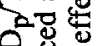
के 들 흠 政 해을 昰员 을 它 政是 柁 焉导 政 呈员星 总宫言

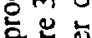
政 등 要 额㝴 䟢志 它员.
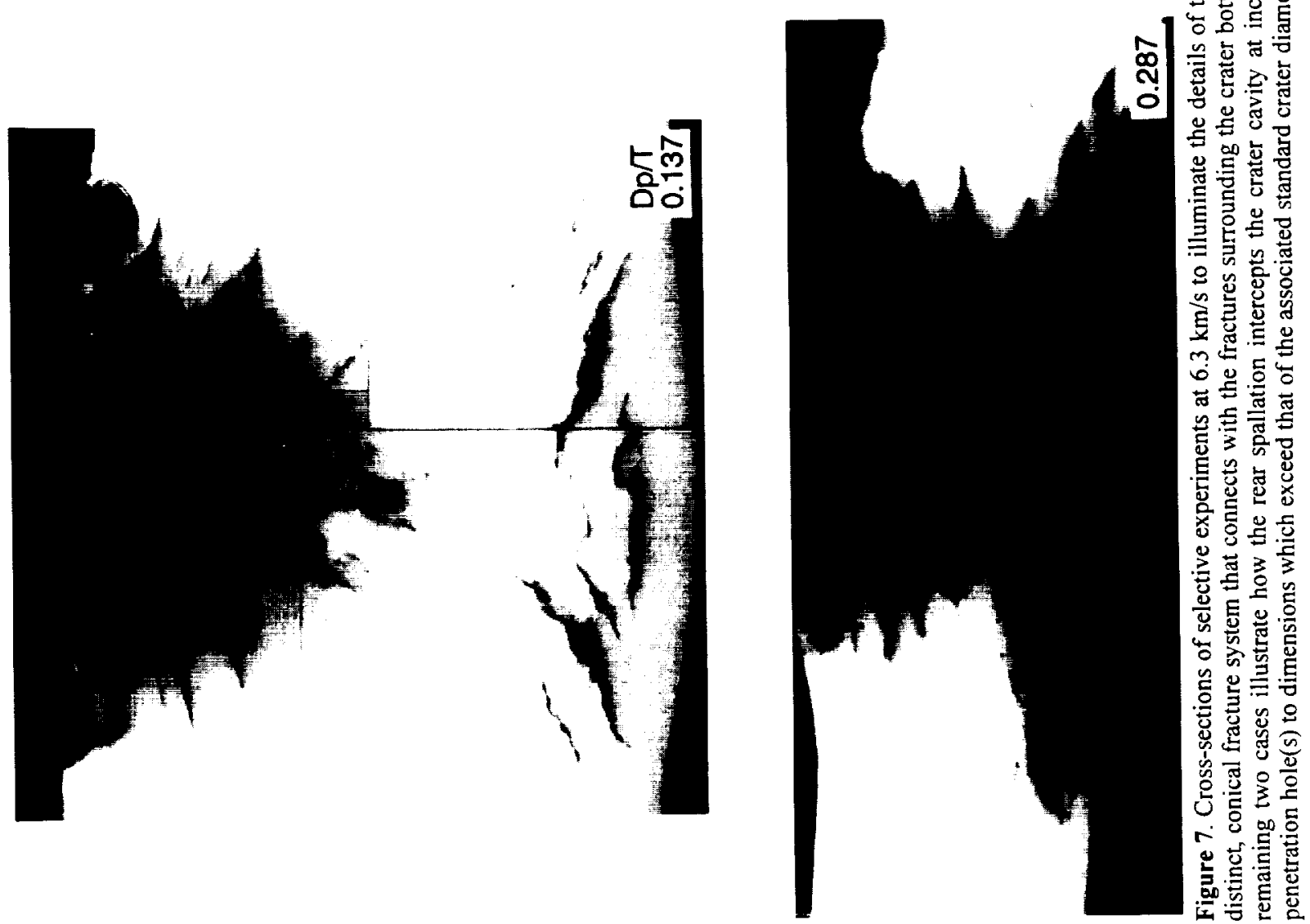


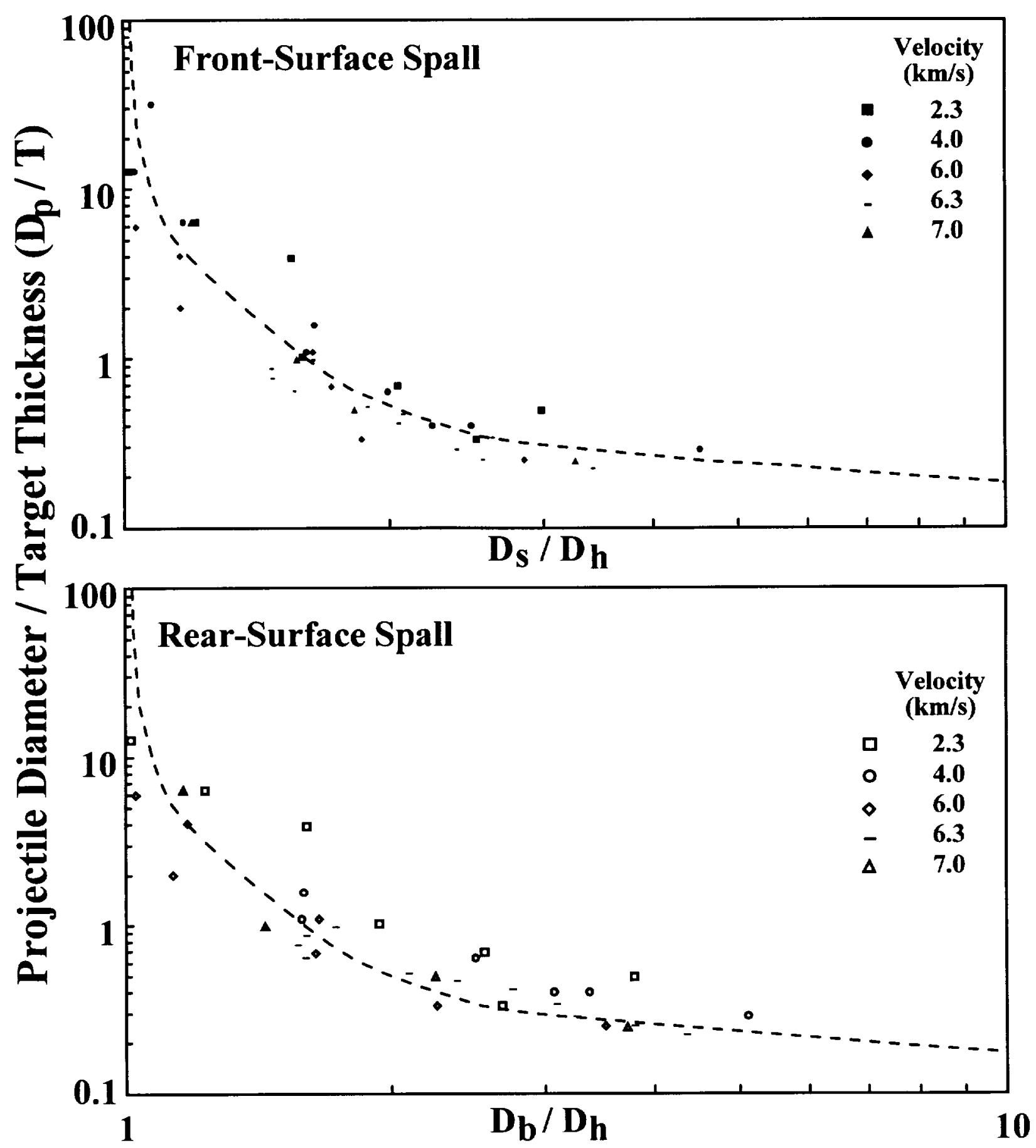

Figure 12. Relative size of the spall zones, normalized to penetration-hole diameter, at the target's front $\left(D_{S}\right)$ and rear surfaces $\left(D_{b}\right)$ as a function of relative projectile size and target thickness $\left(D_{p} / T\right)$. Note the substantial data scatter in this plot, which is real and inherent in the spallation process. Although difierences between low- and high-velocity experiments seem to exists, the results are not sufficiently reproducible to derive quantitative relationships and inferences. 


\section{E) Witness Plates}

Witness plates were exposed during all penetration experiments to monitor the debris plume emanating from the target, although it was known that quantitative analysis of these highly complex spray patterns would exceed the scope of the present study. Nevertheless, we present some qualitative observations and comments regarding these witness plates. The descriptions to follow will benefit from frequent consultation of the high-resolution photographs contained within the Appendix, because substantial and important details degraded or were altogether lost during reproduction of Figure 13. In addition, frequent consultation of the cross-sections in Figure 6 is recommended in order to develop some sense for the volume or mass that was displaced from the target, both in an absolute and relative sense. Unless otherwise noted, all witness-plate photographs contained in Figure 13 and the Appendix portray the entire witness plate. All witness plates ( $29 \mathrm{~cm}$ square) were at a standard standoff distance (L) of $\sim 12 \mathrm{~cm}$. Thus, plume dispersion angles as large as $110^{\circ}$ were accessible. Undoubtedly, some fragments could have, and did disperse wider than the witness plate, yet their total mass cannot be significant (e.g., Pietkutowksy, 1990).

Distinction between target debris and projectile fragments responsible for specific witnessplates craters and damage, a major aspect of the descriptions to follow, is very difficult in these experiments, unlike the witness plates from aluminum experiments (Hörz et al., 1994). Nevertheless, one can make inferences about the distribution of target and projectile debris for the teflon penetrations as well, because of the continuum nature of the general, morphologic trends that are sensitively related to the target thickness.

Figure 13a contains the $2.3 \mathrm{~km} / \mathrm{s}$ experiments. Starting with the most massive targets, no visible damage of the witness plate occurred until $\mathrm{D}_{\mathrm{p}} / T=0.33$ was reached, where a few, large (several millimeters in size) spall fragments barely dented the witness plate. Such large, relatively low-velocity fragments dominate until some powdery deposits appear at $D_{p} / T>0.6$. This powder consists of finely crushed projectile material. Maximum peak stress in the projectile is $\sim 14 \mathrm{Gpa}$ at $2.3 \mathrm{~km} / \mathrm{s}$, well below the melting point of soda-lime glass, yet sufficient to cause thorough disruption. This projectile dust is irregularly distributed on the witness plates, yet seems to concentrate within narrow streaks, many of which exhibit distinctive gradients in the amount of total mass deposited. The streaks appear to emanate from local depressions and concentrations of projectile material, suggesting that individual, large, highly disaggregated fragments were dispersed.

At target thicknesses where this projectile dust appears, the large, low-velocity target fragments had given way to smaller target debris of increasingly higher velocities, capable of forming relatively deep gauges and craters with raised rims. All well developed witness-plate craters at $\mathrm{D}_{\mathrm{p}} / \mathrm{T}<1.0$ are derived from the target, and their aerial distribution is highly irregular. As $\mathrm{T}$ decreases, differentiation between projectile fragments and target debris becomes difficult, if not impractical. However, the overall spray patterns tended to exhibit progressively more organized and concentric geometries, especially within the central portions of the debris cloud (at $\mathrm{D}_{\mathrm{p}} / \mathrm{T} \cong 1$; Figures $13 \mathrm{~b}-13 \mathrm{e}$ ). Centro-symmetric geometries are highly pronounced, if not dominant for still thinner targets, where a distinctly bimodal crater distribution begins to form, which is clearly discernible at $\mathrm{D}_{\mathrm{p}} / \mathrm{T}=4$. Material forming the central portions of the debris plume has a tightly confined dispersion angle, possessing a stunningly sharp contact with the outer portions of the overall debris cloud; this phenomenon is more pronounced at higher impact 

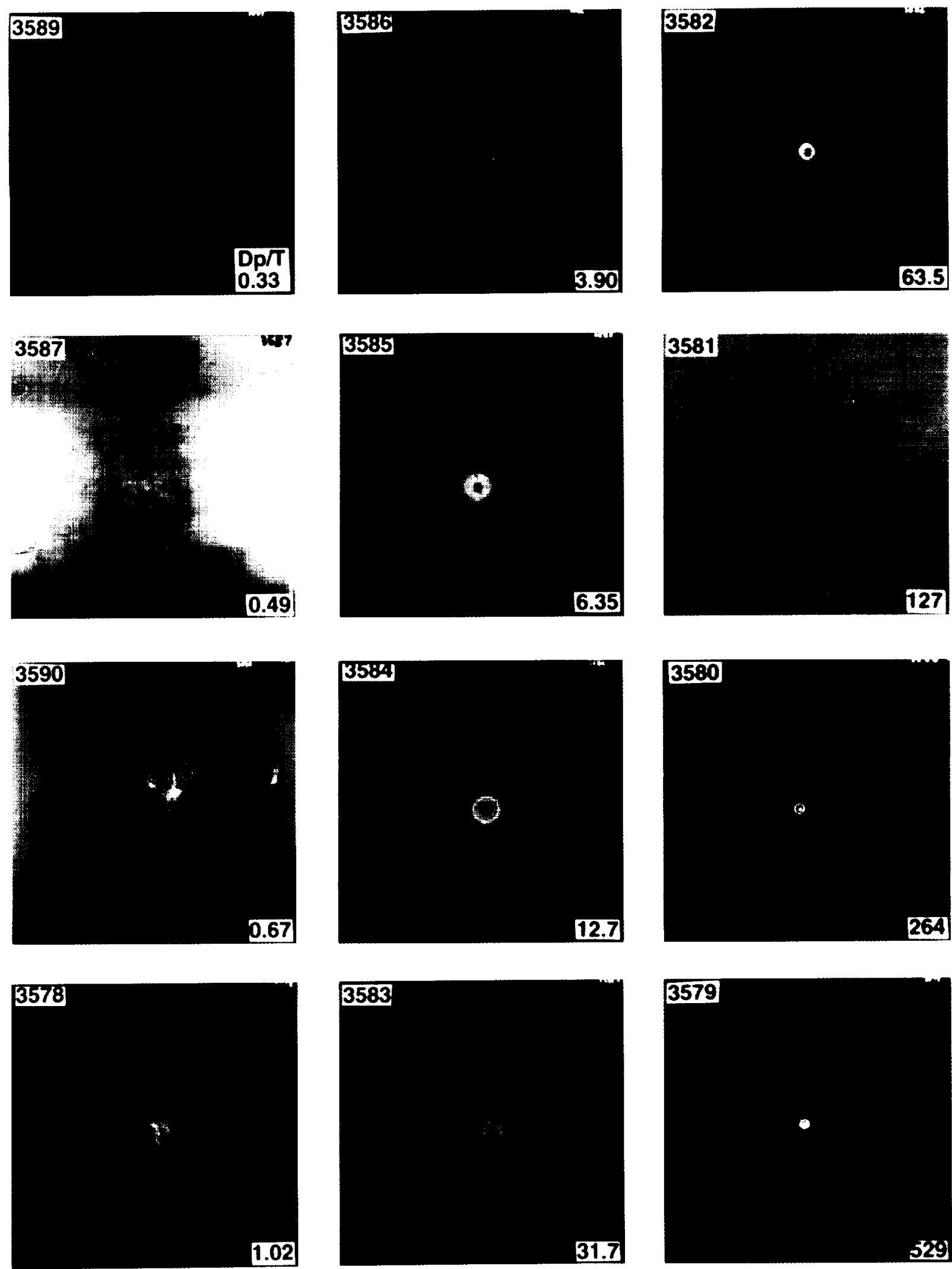

Figure 13a. Witness-plate spray patterns for penetrations of teflon targets of thickness $(T)$ by soda-lime glass projectiles 3.175 $\mathrm{mm}$ in diameter at a nominal velocity of $2.3 \mathrm{~km} / \mathrm{s}$ (numbers in upper left refer to experiment number, while the numbers in the lower right-hand corner refer to $\mathrm{D}_{\mathrm{p}} / \mathrm{T}$ ). Individual witness plate are $\sim 29 \mathrm{~cm}$ square. Experiment 3581 is to the same scale, although the witness plate was smaller than the normal $29 \mathrm{~cm}$ on a side. 


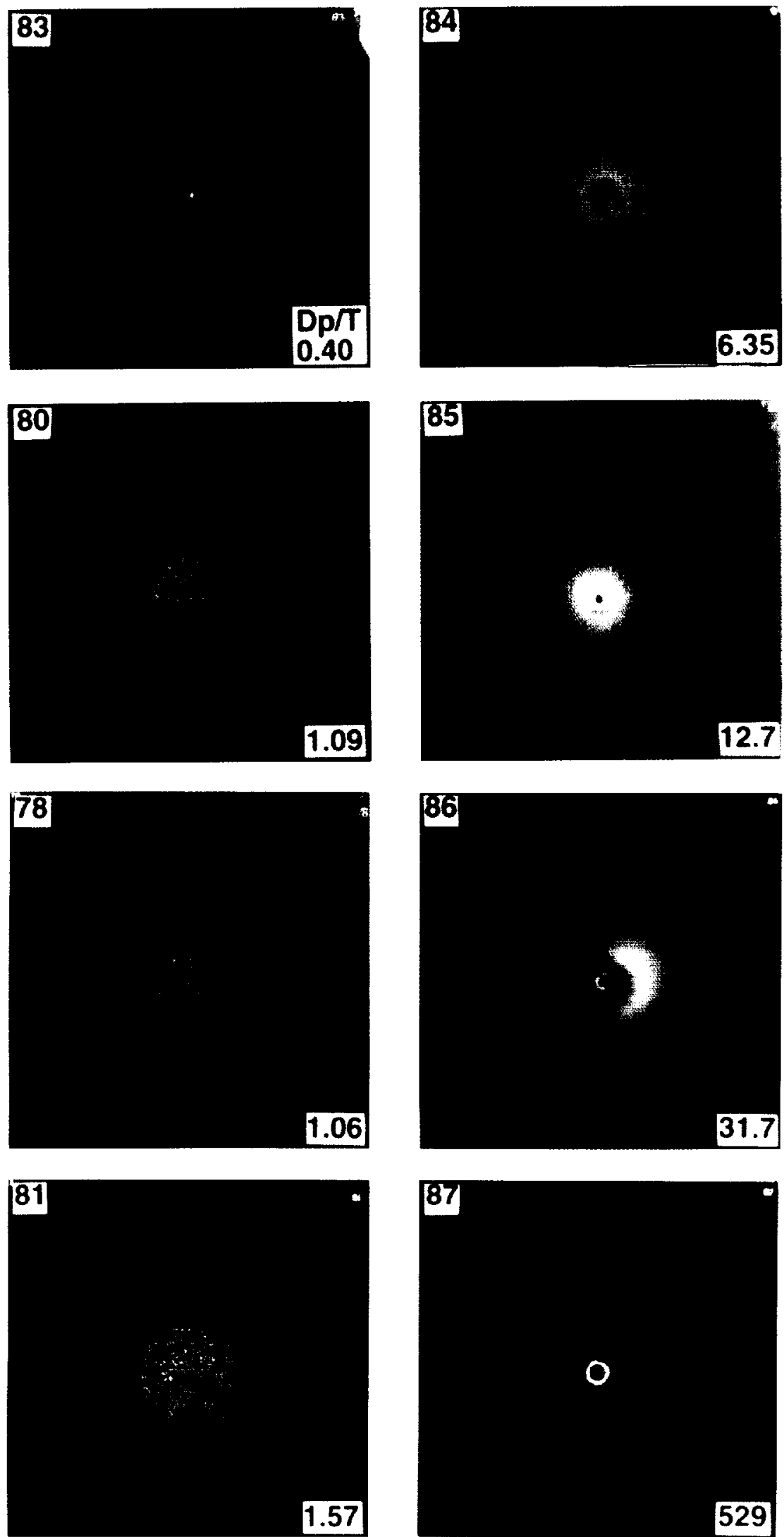

Figure 13b. Witness-plate spray patterns for teflon penetrations at a nominal projectile velocity of $4 \mathrm{~km} / \mathrm{s}$. 


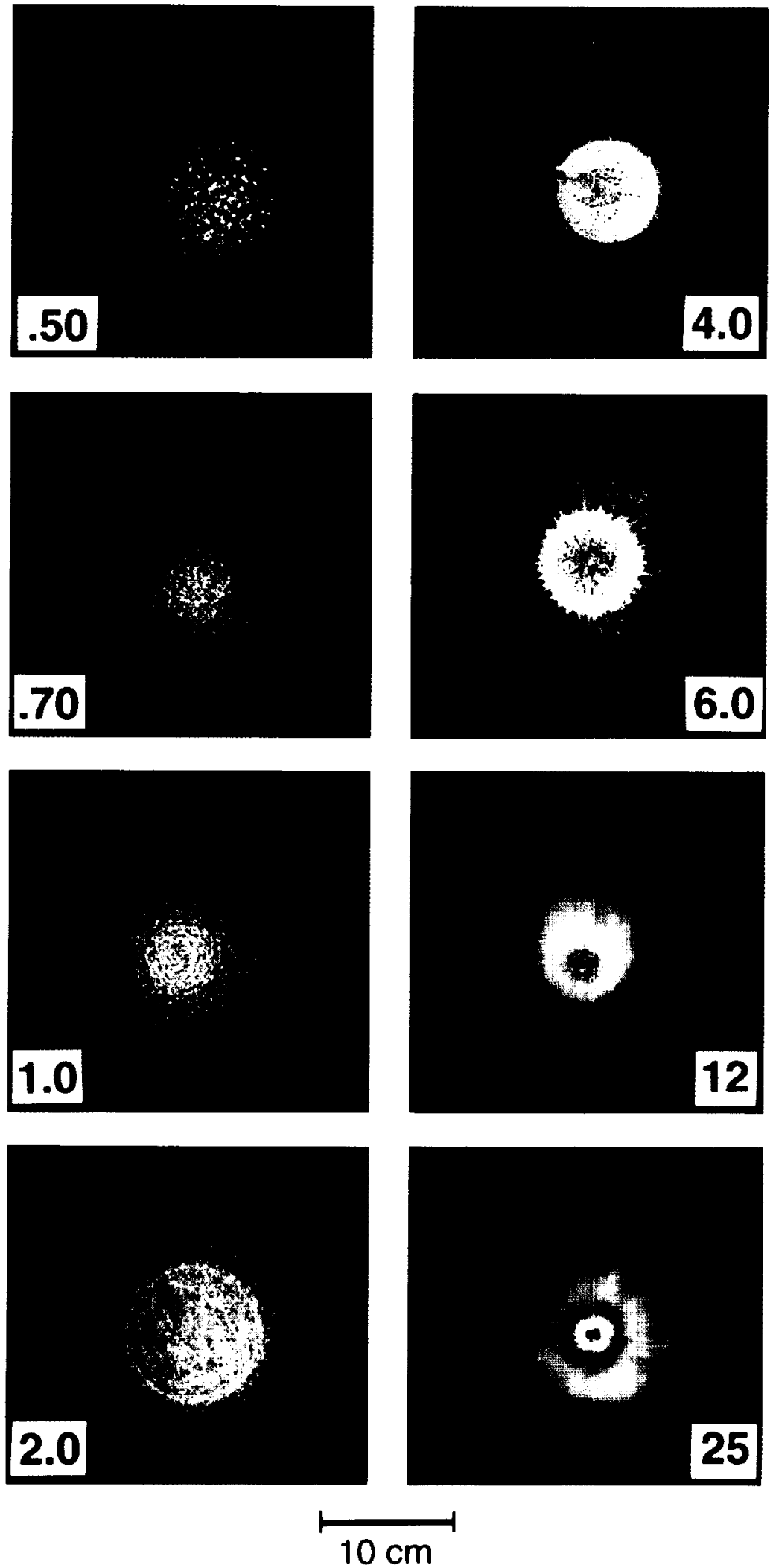

Figure 13c. Witness-plate spray patterns for teflon penetrations at a nominal projectile velocity of $6 \mathrm{~km} / \mathrm{s}$. 



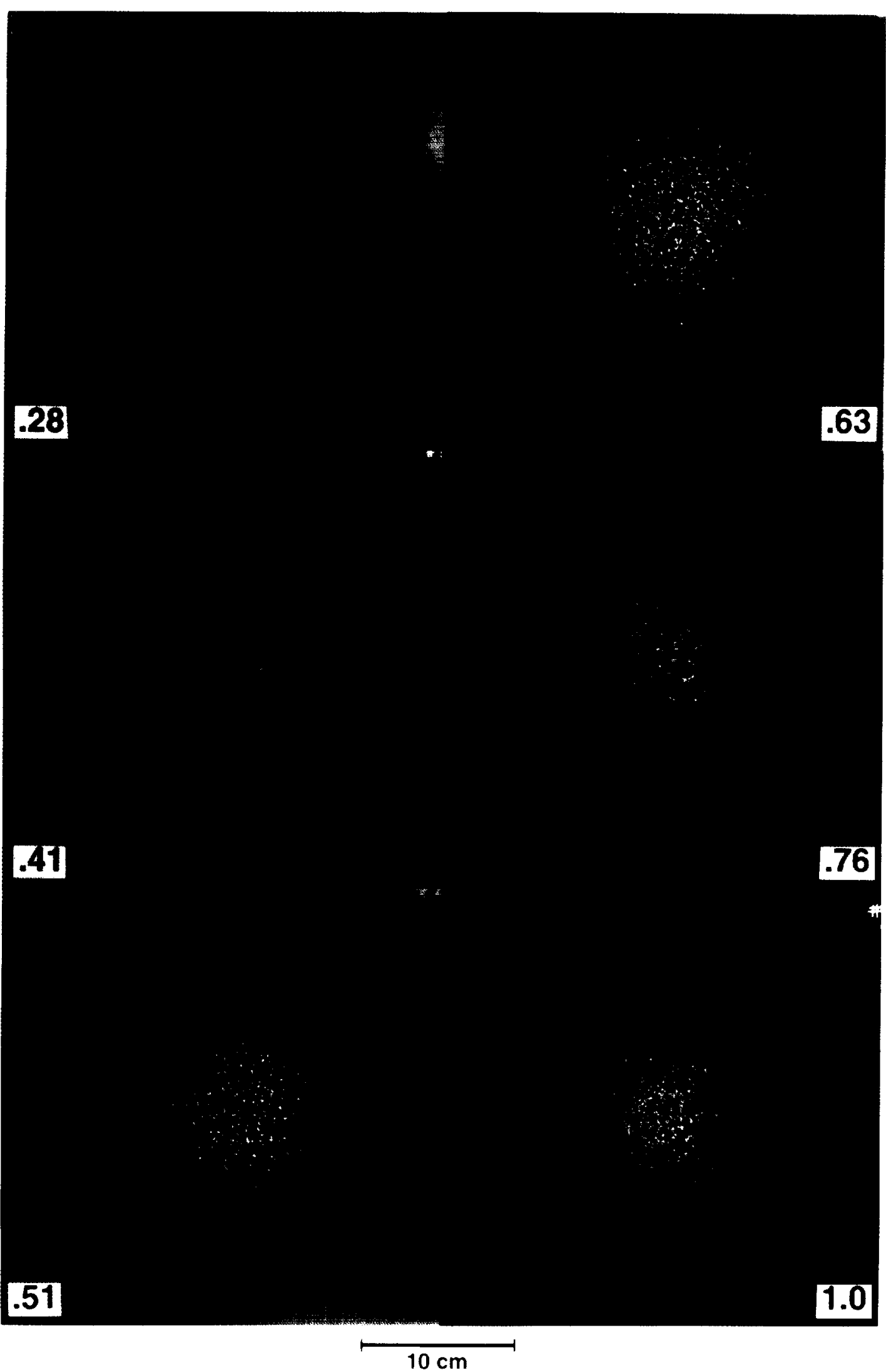

Figure 13d. Witness-plate spray patterns for teflon penetrations at a nominal projectile velocity of $6.3 \mathrm{~km} / \mathrm{s}$. 

Soda Lime Glass $\rightarrow$ Teflon

$D_{p}=3.175 \mathrm{~mm} \quad V=6.3 \mathrm{~km} / \mathrm{s}$

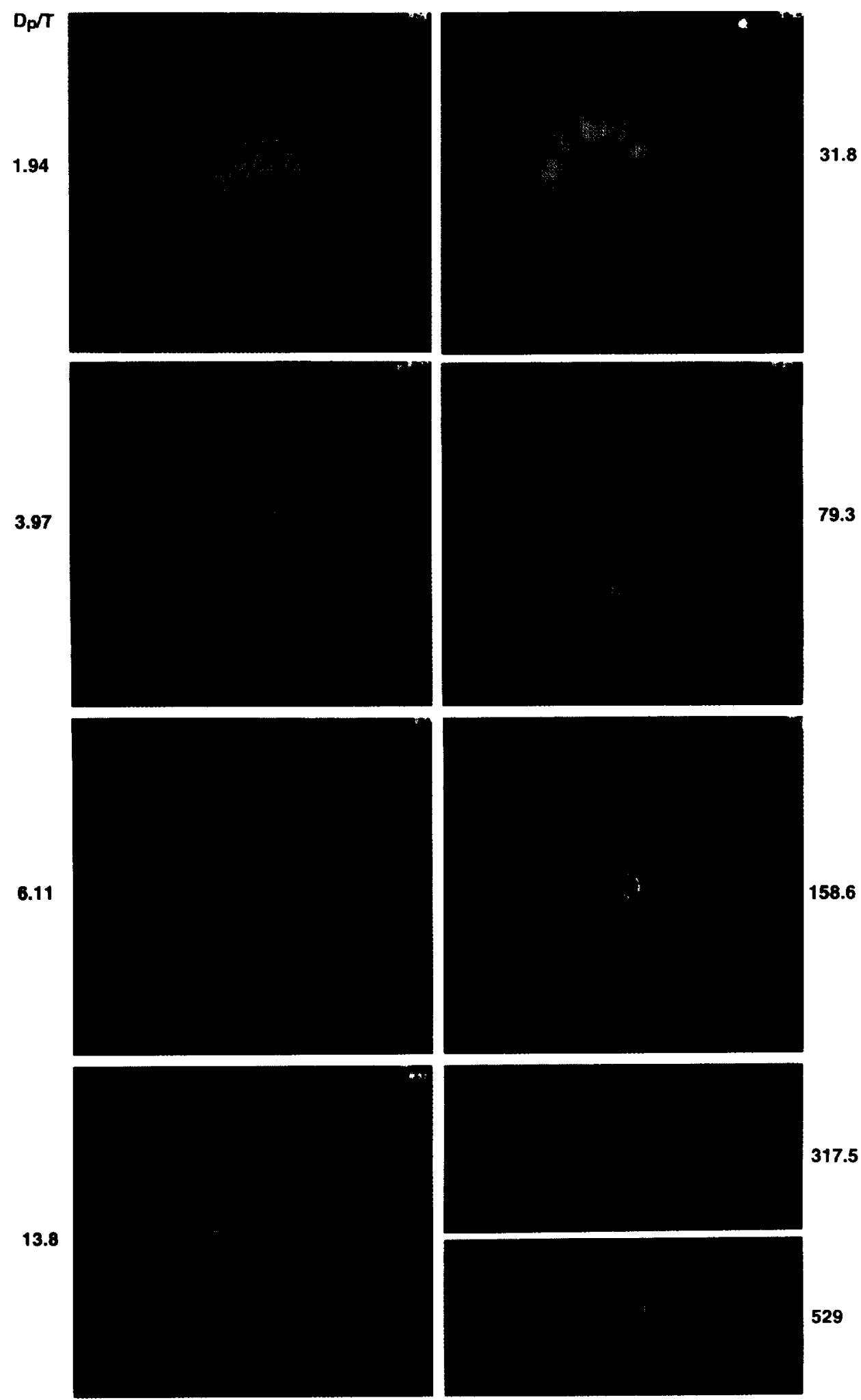

Figure 13d. (continued) 



\section{Soda-Lime Glass $\rightarrow$ Teflon $(7 \mathrm{~km} / \mathrm{s})$}
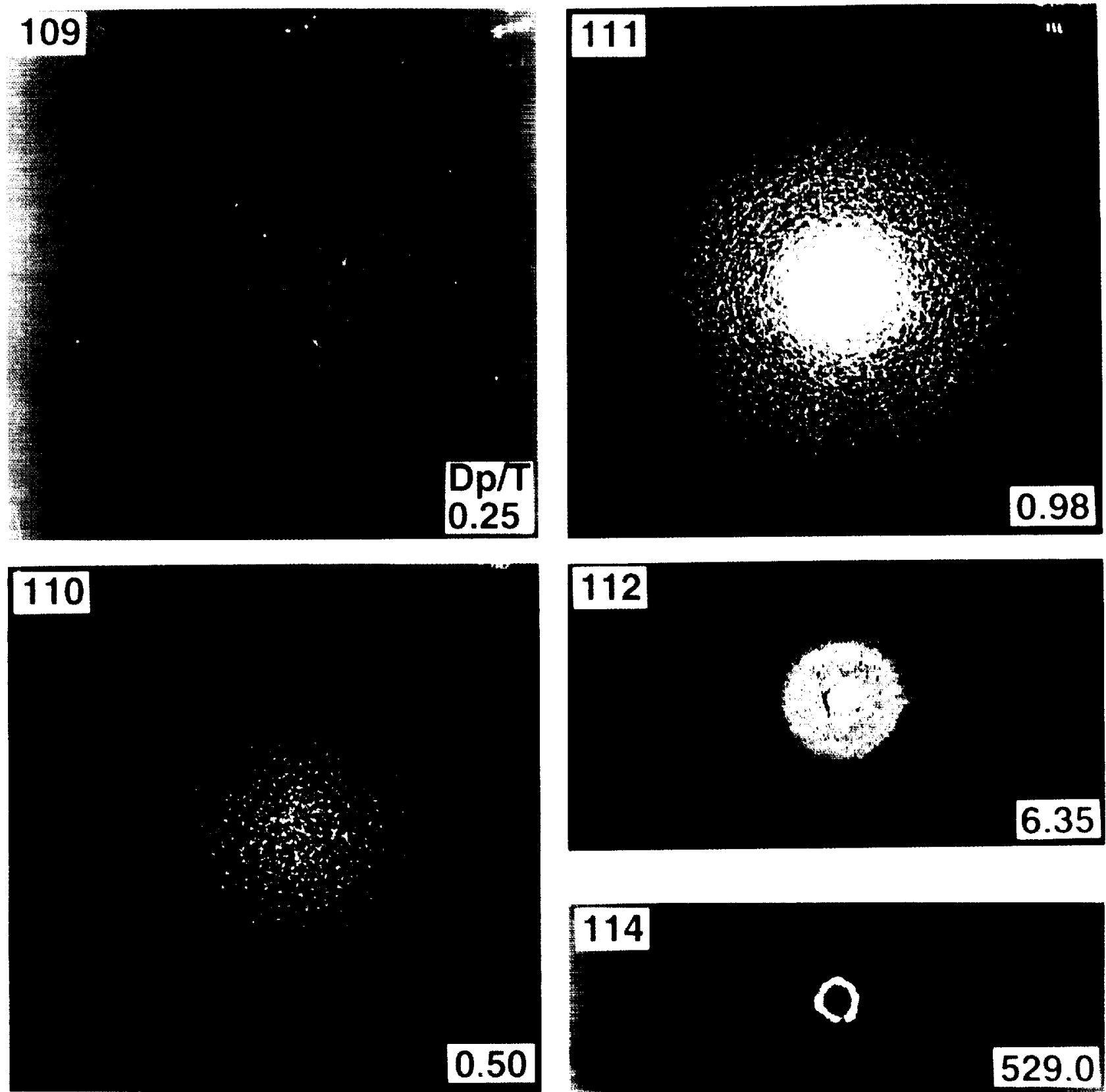

Figure 13e. Witness-plate spray patterns for teflon penetrations at a nominal projectile velocity of $7 \mathrm{~km} / \mathrm{s}$. 

velocities. As $\mathrm{T}$ decreases, the diameter of the central portion shrinks. Undoubtedly, for thin targets (i.e., $\mathrm{D}_{\mathrm{p}} / \mathrm{T}$ conditions ranging from 4 to 12) this sharply bounded central halo is dominated by projectile fragments. Analogous separation of projectile fragments and target debris was observed in our earlier aluminum experiments (Hörz et al., 1994). These observations confirm the fact that the projectile species are concentrated within the central portions of the debris cloud and are less widely dispersed than the target-generated debris (Pietkutowsky, 1990,1993; Hörz et al., 1994). However, we have no quantitative information on how much, if any, target debris resides within this central halo of the witness plate and/or central portion of the debris cloud.

Figure $13 \mathrm{~b}$ presents the witness plates for the $4 \mathrm{~km} / \mathrm{s}$ series. Note that two essentially identical cases, $\mathrm{D}_{\mathrm{p}} / \mathrm{T}=1.06$ and 1.09 , are illustrated to demonstrate the excellent reproducibility of these fairly complex spray patterns. The principle difference between the $4 \mathrm{~km} / \mathrm{s}$ and $2.3 \mathrm{~km} / \mathrm{s}$ series is a substantially wider distribution of all debris, yet specifically of the impactor for any given value of $T$. The central, white dot in the $D_{p} / T=0.40$ experiment represents the first sign of the projectile powder at $4 \mathrm{~km} / \mathrm{s}$, even though substantial penetration holes were generated at thicker targets (e.g., $\mathrm{D}_{\mathrm{p}} / \mathrm{T}=0.29$ case in Figure $6 \mathrm{~d}$ ). By the time the first sign of projectile residue appears in the $4 \mathrm{~km} / \mathrm{s}$ series, the target debris has already dispersed over almost the entire witness plate, is generally more fine-grained compared to the $2.3 \mathrm{~km} / \mathrm{s}$ case, and possessed sufficient velocity to form discrete and fairly distinct witness-plate craters. Projectile fragments and target debris become difficult to distinguish at $\mathrm{D}_{\mathrm{p}} / \mathrm{T}$ conditions $>0.5$, and essentially impossible by $\mathrm{D}_{\mathrm{p}} / \mathrm{T} \cong 1$ in Figure $13 \mathrm{~b}$. In analogy to the low-velocity shots (Figure 13a) and the earlier aluminum experiments (Hörz et al., 1994), we are confident that the majority of the projectile resides within a central, well-defined dispersion cone that possesses a distinct boundary with the associated target debris. Note the distinctly radial appearance of the spray pattern at $D_{p} / T=31.7$, where material was deposited rather than removed. These deposits most likely represent molten target material, analogous to the aluminum experiments (Hörz et al., 1994). In addition, note that a few large fragments occupy the very center of the spray patterns at $\mathrm{D}_{\mathrm{p}} / \mathrm{T}>1$. These fragments tend to overlap and progressively coagulate with decreasing $\mathrm{T}$ to form a central cluster of particles at $\mathrm{D}_{\mathrm{p}} / \mathrm{T}>6$, and ultimately a coherent and continuous central depression in the $\mathrm{D}_{\mathrm{p}} / \mathrm{T}=31.7$ experiment. This depression will increasingly resemble a bona fide crater, albeit with a hummocky, irregular interior surface, reflecting the heterogeneous mass distribution of a fragmented impactor, which is still evident at $\mathrm{D}_{\mathrm{p}} / \mathrm{T}=529$.

Only a few experiments were conducted at $6 \mathrm{~km} / \mathrm{s}$, and the associated spray patterns (Figure $13 \mathrm{c}$ ) are very similar to those of the $6.3 \mathrm{~km} / \mathrm{s}$ series (Figure 13d); both velocity series will be discussed together with emphasis on the $6.3 \mathrm{~km} / \mathrm{s}$ series. Figures $13 \mathrm{c}$ and $13 \mathrm{~d}$, at comparable velocities, also serve to illustrate how reproducible these debris clouds are, despite their obvious complexity, and how systematically and sensitively they depend on $\mathrm{T}$.

Referring to Figure $13 \mathrm{~d}$, note the irregularly shaped, shallow indentations caused by lowvelocity target debris at $\mathrm{D}_{\mathrm{p}} / \mathrm{T}=0.28$. The relatively modest damage on the witness plate belies the substantial mass that was displaced form the target (Figure 6c). We did not observe the powdered projectile materials at this velocity (nor at $6 \mathrm{~km} / \mathrm{s}$ ), or any signs of melted projectile akin to our aluminum targets at $\mathrm{D}_{\mathrm{p}} / \mathrm{T}<0.6$ (Hörz et al., 1994). Peak stress in the glass impactor at $6.3 \mathrm{~km} / \mathrm{s}$ is $\sim 47 \mathrm{GPa}$, sufficient to melt the impactor. However, we do see some molten material, arranged in a roughly concentric fashion at $\mathrm{D}_{\mathrm{p}} / \mathrm{T}>0.7$, but we do not know whether 
this is projectile or target melt. Results of the aluminum experiments (Hörz et al., 1994) suggests this molten material to be projectile, occurring as melt stringers which tend to connect neighboring craters, both comprising an increasingly larger part of the concentric, web-like geometry (Lange et al., 1986). Note how the irregular crater distributions at $\mathrm{D}_{\mathrm{p}} / \mathrm{T}<0.5$ are gradually assuming a more organized, centro-symmetric geometry as $\mathrm{D}_{\mathrm{p}} / \mathrm{T}$ approaches 1 ; at $\mathrm{D}_{\mathrm{p}} / \mathrm{T}$ $>1$ these centro-symmetric morphologies dominate all spray patterns within the high-velocity experiments. Especially note the pronounced central halo at $\mathrm{D}_{\mathrm{p}} / \mathrm{T} \cong 4$ and the sharp contacts with the peripheral target debris. Furthermore, note the pronounced central cluster of the larger projectile fragments and how they progressively coagulate into a central depression, becoming sufficient to physically penetrate the thin $(3.175 \mathrm{~mm})$ witness plate. At $\mathrm{D}_{\mathrm{p}} / \mathrm{T}>10$ projectile mass totally dominates the displaced target mass, based on simple volumetric grounds, and thus, most major witness-plate features must reflect impactor fragments. These witness-plate features clearly develop and evolve from features that began to appear for somewhat thicker targets. This gradual evolution leads us to propose that the central portion of the bulk cloud is totally dominated by projectile melts or fragments, completely analogous to penetrated aluminum targets (Hörz et al., 1994).

Experiments at $D_{p} / T \cong 4$ and 6 in Figure $13 \mathrm{c}$ and $13 \mathrm{~d}$ are very similar and seem to reveal especially good information about the fragmented impactor. They are characterized by large projectile fragments that are somewhat irregularly distributed at $6 \mathrm{~km} / \mathrm{s}$ (Figure 13c), but which form a more organized, central cluster at $6.3 \mathrm{~km} / \mathrm{s}$ (Figure 13d). It is these fragments which are responsible for the witness-plate penetrations at $\mathrm{D}_{\mathrm{p}} / \mathrm{T} \cong 6$. These massive fragments contrast with much more fine-grained material that forms the overall central halo; it seems that the projectile-size distribution is distinctly bimodal. Earlier we noted that the projectile powder for the more massive targets is very fine-grained, and that larger and fewer fragments combine to form the central clusters and depressions at $D_{p} / T>4$. Therefore, we conclude that impactorfragment size distribution is systematically related to $D_{p} / T$. Small projectile fragments result from penetrations of massive targets and large fragments occur for thin targets, with distinctly bimodal size distributions at intermediate target thicknesses.

The $\mathrm{D}_{\mathrm{p}} / \mathrm{T}=4$ case (Figure $13 \mathrm{c}$ and $13 \mathrm{~d}$ ) reveals a small, but distinctly radial component to the debris pattern, which ultimately totally dominates the periphery of the spray patterns for thin targets. There is a distinct transition from the predominantly concentric patterns at $D_{p} / T=4$ to one largely dominated by the radial spray patterns at $D_{p} / T>10$. Note the complete absence of any radial components at $D_{p} / T=2$, and the relatively short $(1-4 \mathrm{~cm}$ in length), radial streaks at $D_{p} / T=4$ just outside the central halo. These radial streaks become more pronounced at $D_{p} / T=$ 6 , and ultimately are the dominant witness-plate features at $D_{\mathrm{p}} / \mathrm{T}>10$. These streaks occur at radial ranges that used to be occupied by craters, implying that the absolute dispersion angle remained constant. Identical radial features were observed with the earlier aluminum experiments (Hörz et al., 1994), where we could demonstrate that the streaks represent molten aluminum. From the aluminum experiments we concluded that the onset of radial streaks reflected the phase transition from predominantly solid to molten target materials; we believe this to be the case for the teflon targets as well. The appearance of radial streaks merely indicates that molten material that was previously ejected uprange, as part of the cratering process, is now exiting the target's rear side and moving downrange. No radial morphologies are observed in the $2.3 \mathrm{~km} / \mathrm{s}$ series (Figure 13a), because no target melts were produced. 
Figure 13e displays the $7 \mathrm{~km} / \mathrm{s}$ series. Again, note the irregular, shallow indentations on the witness plate at $\mathrm{D}_{\mathrm{p}} / \mathrm{T}=0.25$ and the difficulty in differentiating projectile from target materials for increasingly thinner targets. All observations offered for the $6.3 \mathrm{~km} / \mathrm{s}$ series (above) apply to the $7 \mathrm{~km} / \mathrm{s}$ as well, and are consistent with the above conclusions.

In summary, we could demonstrate that witness-plate spray patterns are very sensitively and systematically related to the relative target and projectile dimensions (i.e., to $\mathrm{D}_{\mathrm{p}} / \mathrm{T}$ ). While velocity is also important, it seems to be of secondary significance. For instance, compare the cases of $D_{p} / T \cong 0.5,4.0$, and 30.0 from all experimental series/velocities (Figure 13a-13e) and note the similar witness-plate patterns for any given $D_{p} / T$ condition. The lack of substantial velocity dependence in these spray patterns is somewhat surprising, yet similar results are being found in ongoing penetration studies of aluminum targets at different velocities.

\section{5) CONCLUSION}

Teflon FEP targets which varied over three orders of magnitude in thickness were impacted by soda-lime glass spheres of constant diameter $(3.175 \mathrm{~mm})$ at encounter velocities of $\sim 2.3,4.0,6.0$, 6.3 and $7 \mathrm{~km} / \mathrm{s}$. The resulting craters and penetration holes form a morphologic continuum that is sensitively related to the relative dimensions of the impactor and target $\left(D_{p} / T\right)$. Impactor sizes may be reconstructed from individual crater or penetration-hole measurements in teflon targets of any arbitrary thickness, and it is possible to interpret each individual penetration hole in a manner analogous to individual impact craters. Nevertheless, the present approach still mandates an independent velocity measurement or an assumption regarding encounter velocity. Neither craters nor penetrations in teflon -- or other materials investigated to date -- seem to possess postmortem morphologic elements that depend sensitively and systematically on encounter speed at $\mathrm{V}>6 \mathrm{~km} / \mathrm{s}$.

In addition, we propose that the relative shock-pulse duration be used to delineate the transition from catering to penetration phenomena when extracting projectile dimensions from space-exposed surfaces; this transition does not occur at the ballistic limit, as has been assumed by most workers in the past. Instead, we suggest that cratering formalisms apply to all conditions of $t_{p}<t_{t}$, and that penetration equations be used only when $t_{p}>t_{t}$. Using this concept we make specific proposals for the dimensional scaling of craters and penetration holes at impact velocities beyond those accessible in the laboratory, resulting in calibration curves that solve for projectile dimensions from impacts into teflon targets of arbitrary thickness, and at essentially arbitrary velocities up to $20 \mathrm{~km} / \mathrm{s}$.

The effects of projectile density and shape were not addressed in this work, yet their significance is recognized (e.g., Watts et al., 1993). Additional experiments in teflon targets using variable projectile densities and shapes seem warranted to provide additional insights into the interpretation of craters and penetrations that were produced under poorly constrained conditions, reflecting our limited understanding of the hypervelocity particle environment in LEO. The technology exists to measure the velocity of individual particles in space, and to subsequently decelerate them for capture and return to Earth in a form suitable for compositional analysis and identification of component materials and associated densities, and possibly (CDCF, 1990). Clearly, such in situ investigations are needed for a more quantitative understanding of the hypervelocity environment in LEO. 


\section{6) REFERENCES}

Allbrooks, M.A. and Atkinson, D. (1992) The Magnitude if Impact Damage on LDEF Materials, NASA Contractor Report $188258,85 \mathrm{pp}$.

Anderson, C.E. (1990) Hypervelocity Impact, Proc. of the 1989 Symposium, San Antonio, TX., Int. J. Impact Engng. 10., $635 \mathrm{p}$.

Anderson, C.E. (1993) Hypervelocity Impact, Proc. of the 1992 Symposium, Austin, TX., Int. J. Impact Engng., 14., $891 \mathrm{p}$.

Bernhard, R.P., See, T.H. and Hörz, F. Impact Craters at $1-7 \mathrm{~km} / \mathrm{s}$ in Aluminum 1100 Targets (in preparation).

Carey, W.C., McDonnell, J.A.M. and Dixon, D.G. (1985) An Empirical Penetration Equation for Thin Metallic Films Used in Capture Cell Techniques, in Properties and Interactions of Interplanetary Dust, R.H. Giese and P. Lamy, eds., Reidel, Dordrecht, p.131-136.

CDCF (1990), Cosmic Dust Collection Facility: Scientific Objectives and Programmatic Relations, CDCF Working Group Report, F. Hörz, ed., NASA TM 102169, 14 p.

Cintala, M.J. (1992) Impact-Induced Thermal Effects in the Lunar and Mercurian Regoliths, $J$. Geophys. Res., 97, p. 947-973.

Coombs, C.R., Watts, A.J., Wagner, J.D. and Atkinson, D.(1993), LDEF Data: Comparison with Existing Models, in LDEF - 69 Months in Space: Second Post-Retrieval Symposium, NASA CP 3194, p. 619-664.

Cour-Palais, B. G. (1987) Hypervelocity Impacts in Metals, Glass, and Composites, Int. J. Impact Engng., 5, p. 681-692.

Cour-Palais, B.G. and Crews, J.L. (1990) A Multi-Shock Concept for Spacecraft Shielding, Int. J. Impact Engng., 10, p. 135-146

Christiansen, E. L. (1993) Design and Performance Equations for Advanced Meteoroid and Debris Shields, Int. J. Impact Engng., 14, p. 145-156.

Christiansen, E.L. and Kerr, J.H. (1993) Mesh Double-Bumper Shield: a Low-Weight Alternative for Spacecraft Meteoroid and Orbital Debris Protection, Int. J. Impact Engng. 14, p. $169-180$.

Flury, W. ed. (1993) Proc. First European Conference on Space Debris, European Space Agency, Paris, ESA SD-01, $741 \mathrm{pp}$.

Gehring, J.W. (1970) Theory of Impact on Thin Targets and Shields and Correlation with Experiment, in High Velocity Impact Phenomena, Kinslow, R. ed., Academic Press, p. 105156.

Grun, E., Zook, H.A., Fectig, H. and Giese, R.H. (1985), Collisional Balance of the Meteoritic Complex, Icarus, 62, p. 244-272.

Herrmann, W. and Wilbeck, J. (1986) Review of Hypervelocity Penetration Theories, Sandia National Laboratories Report, SAND -86-1884C, $29 \mathrm{p}$.

Hörz, F., Cintala, M.J. and See, T.H. (1986) Hypervelocity Particle Capture: Some Considerations Regarding Suitable Target Media, Lunar and Planetary Institute Technical Report, F. Hörz., ed., LPI TR-86-05, p. 58-60.

Hörz, F. , Cintala, M.J., Bernhard, R.P. and See, T.H. (1993) Dimensionally Scaled Experiments to Extract Projectile Sizes from Space-Exposed Surfaces, Int. J. Impact Engng. 14, p. 347358. 
Hörz, F., Cintala, M.J., Bernhard, R. and See, T.H. (1994) Dimensionally Scaled Penetration Experiments: Aluminum Targets and Glass Projectiles $50 \mu \mathrm{m}$ to $3.2 \mathrm{~mm}$ in Diameter, Int. J. Impact Engng., 15, in press.

Humes, D.H. (1992) Large Craters on the Meteoroid and Debris Impact Experiment, in $L D E F$ 69 Months in Space: First-Post Retrieval Symposium, NASA CP 3134, p. 399-418.

Kessler, D.E. (1993) Origin of Orbital Debris on LDEF's Trailing Surfaces, in LDEF - 69 Months in Space: Second Post-Retrieval Symposium, NASA CP 3194, p.585-594

Lange, G.S., Eigner, S., Igenbergs, I., Jessberger, E.K., Kuczera, H., Maas, D., Sutton, S., Weishaupt, U. and Zinner, E. (1986) Ion Microprobe Sensitivities and Their Application to Multi-element Analysis of LDEF Impact Residues (abstract), Lunar Planet. Sciences XVII, Abstracts, Lunar Planetary Institute, Houston, p. 456-457.

Levine, A.E. (1992) LDEF - 69 Months in Space, First Post-Retrieval Symposium, NASA Conference Publication, CP 3134, 1705 pp.

Levine, A.E. (1993) LDEF - 69 Months in Space, Second Post-Retrieval Symposium, NASA Conference Publication, CP 3194, 1572 pp.

McDonnell, J.A.M. ed.(1992) Hypervelocity Impacts in Space, University of Kent, Canterbury, U.K., $288 \mathrm{pp}$.

McDonnell, J.A.M. and Sullivan, K. (1992) Hypervelocity Impacts on Space Detectors: Decoding the Projectile Parameters, in Hypervelocity Impacts in Space, University of Kent, Canterbury, U.K., p. 39-47.

McKay, D.S., Rietmeijer, F.J.M., Schramm, L.S., Barrett, R.A., Zook. H.A. and Blanford, G.E. (1986) The Solar Maximum Satellite Capture Cell: Impact Features and Orbital Debris and Meteoritic Projectile Materials, in Lunar and Planetary Institute Technical Report, LPI TR 86-05, F. Hörz., ed., p. 72-75.

O'Sullivan, D., Thompson, A., Bosch, J., Keegan, R., Wenzel, K.P., Smit, A. and Domingo, C. (1992) The LDEF Ultra-Heavy Cosmic Ray Experiment, in LDEF - 69 Months in Space: First Post-Retrieval Symposium, NASA CP 3134, p. 367-376.

Pietkutowsky, A.J. (1990) A Simple Dynamic Model for the Formation of Debris Clouds, Int. $J$. Impact Engng., 10, p. 453-472.

Schmidt, R.M., Housen, K.R., Pietkutowsky, A.J. and Poormon, K.L. (1994) Cadmium Simulation of Orbital Debris Shield Performance to Scaled Velocities of $18 \mathrm{~km} / \mathrm{s}, J$. Spacecraft and Rockets, in press.

Schneider, E., Stilp, A., Bureo, R. and Lambert, M. (1990) Micrometeoritic and Space Debris Simulation for Columbus Hull Components, Int. J. Impact Engng., 10, p. 499-508.

Schneider, E., Stilp, A., Rott, M., Levadou, F. and Schwehm, G. (1993) Hypervelocity Impact Simulation Experiments on LDEF-Foils, Int. J. Impact Engng., 14, p. 631-636.

See, T.H., Allbrooks, M.K., Atkinson, D.R., Simon, C.R. and Zolensky, M.E. (1990) Meteoroid and Debris Impact Features Documented on the Long Duration Exposure Facility, NASA JSC Report \# 24608, 561 pp.

Stilp, A.J., Hohler, V., Schneider, E., and Weber, K. (1990) Debris Cloud Expansion Studies, Int. J. Impact Engng., 10, p. 543-554.

Warren, J.L., Zook, H.A, Allton, J.H., Clanton, U.S., Dardano, C.B., Holder, J.A., Marlow, R.R., Schultz, R.A., Watts, L.A., and Wentworth, S.J. (1989) The Detection and Observation of 
Meteoroid and Space Debris Impact Features on the Solar Maximum Satellite, Proc. Lunar Planet. Sci. Conf., 19th, p. 641-657.

Watts, A., Atkinson, D. and Rieco, S. (1993) Dimensional Scaling for Impact Cratering and Perforation, NASA JSC Contractor Report, NCR 188259, $170 \mathrm{pp}$.

Zook, H.A. (1992) Deriving the Velocity Distribution of Meteoroids from the Measured Meteoroid Impact Directionality on the Various LDEF Surfaces, in LDEF - 69 Months in Space: First Post-Retrieval Symposium, NASA CP 3194, p. 569-580. 



\section{DETAILED PHOTO DOCUMENTATION OF IMPACT EXPERIMENTS INTO TEFLON TARGETS}

\section{LEGEND:}

$$
\begin{aligned}
& \mathbf{S L}=\text { Soda lime glass } \\
& \mathbf{D}_{\mathbf{p}}=\text { Projectile diameter } \\
& \mathbf{V}=\text { Impact Speed } \\
& \mathbf{T}=\text { Target thickness }
\end{aligned}
$$

Scale: Absolute or relative target thickness is given in the legend of each plate; crosssections and plan-views are to the same scale. All witness plates are $29 \mathrm{~cm}$ square. Note that quantitative, dimensional measurements of craters and penetration holes are given in Table 1.

\section{EXPERIMENT IDENTIFICATION:}

Each experiment is uniquely identified with a laboratory shot number. The latter identifies the chronological sequence with which the experiments were conducted with each of the three different guns that were employed in this work:

Shot Numbers 11-114: New 5 mm Light-Gas Gun

Shot Numbers 428-1316: Old 5 mm Light-Gas Gun

Shot Numbers $>3000$ : Powder Propellant, Vertical Impact Facility

\section{ORGANIZATION OF APPENDIX:}

This appendix is organized by experimental topic and exactly duplicates the sequence of experiments as listed in Table 1. For the purpose of comparison, we deemed it useful to organize the photodocumentation by the two variables of prime interest, impact velocity and target thickness. Table 2 lists all of the experiments in numerical order and serves as cross-reference to locate any experiment by shot number.

Cratering events are typically captured with a plan-view of the target's front side (forward facing) and a cross-sectional view through the target. Penetrations typically portray the target's front (forward facing) and back-sides (rearward facing) and a cross section; the latter is not very informative for very thin targets and was omitted for targets were $D_{p} / T>10$. Penetration experiments are also characterized by witness-plate photographs; the latter were omitted for very massive targets, where there was no penetration and, subsequently, no damage to the witness plates.

Some judgment had to be exercised in determining when to switch from optical-microscope scales to that of a Scanning Electron Microscope (SEM) for the portrayal of high-resolution details. The time-consuming nature of the SEM limited the high-resolution SEM photography to representative views only. 

PROJECTILE: Soda Lime

$\mathrm{D}_{\mathrm{p}}=3175 \mu \mathrm{m}$

$\mathrm{V}=1.04 \mathrm{~km} / \mathrm{s}$

\section{TARGET: Teflon}

$\mathrm{T}=14351 \mu \mathrm{m}$

FRONT

\section{CROSS-SECTION}
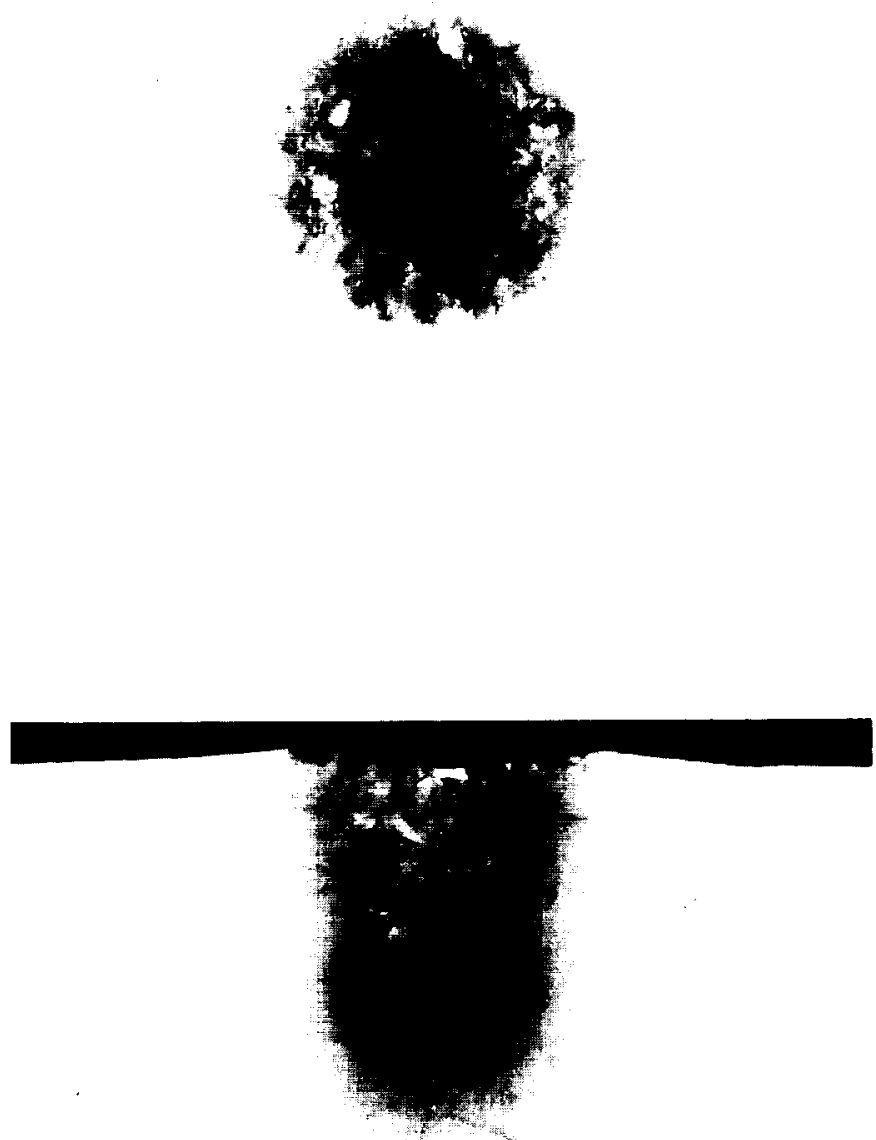
PROJECTILE: Soda Lime

$$
\begin{aligned}
\mathrm{D}_{\mathrm{p}} & =3175 \mu \mathrm{m} \\
\mathrm{V} & =1.61 \mathrm{~km} / \mathrm{s}
\end{aligned}
$$

TARGET: Teflon

$\mathrm{T}=15850 \mu \mathrm{m}$

FRONT

CROSS-SECTION

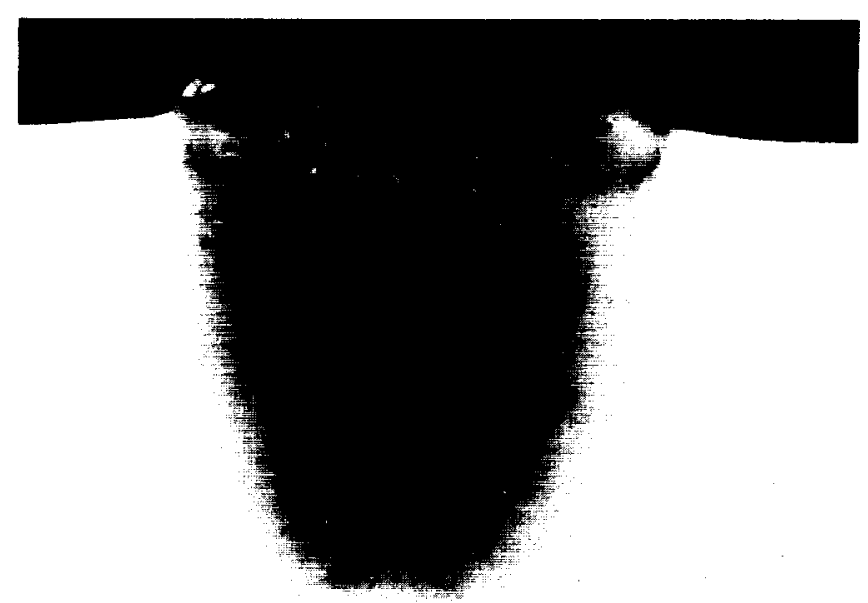


PROJECTILE: Soda Lime

$\mathrm{D}_{\mathrm{p}}=3175 \mu \mathrm{m}$

$\mathrm{V}=1.99 \mathrm{~km} / \mathrm{s}$

TARGET: Teflon

$\mathrm{T}=20890 \mu \mathrm{m}$

FRONT

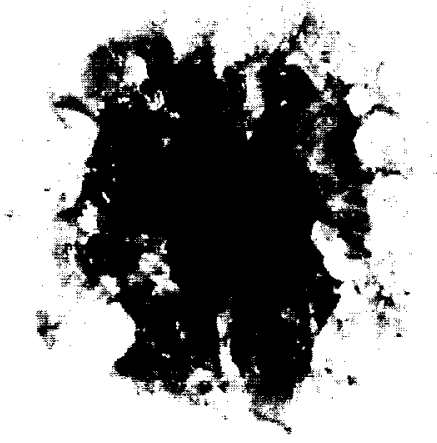

CROSS-SECTION

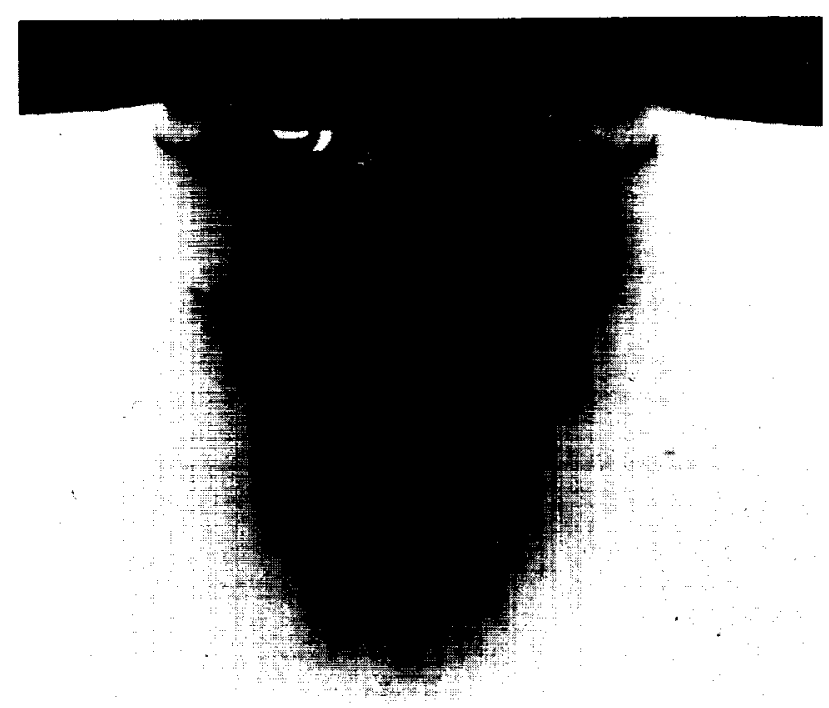


PROJECTILE: Soda Lime

$$
\begin{aligned}
\mathrm{D}_{\mathrm{p}} & =3175 \mu \mathrm{m} \\
\mathrm{V} & =2.35 \mathrm{~km} / \mathrm{s}
\end{aligned}
$$

TARGET: Teflon

$\mathrm{T}=19020 \mu \mathrm{m}$

FRONT

CROSS-SECTION
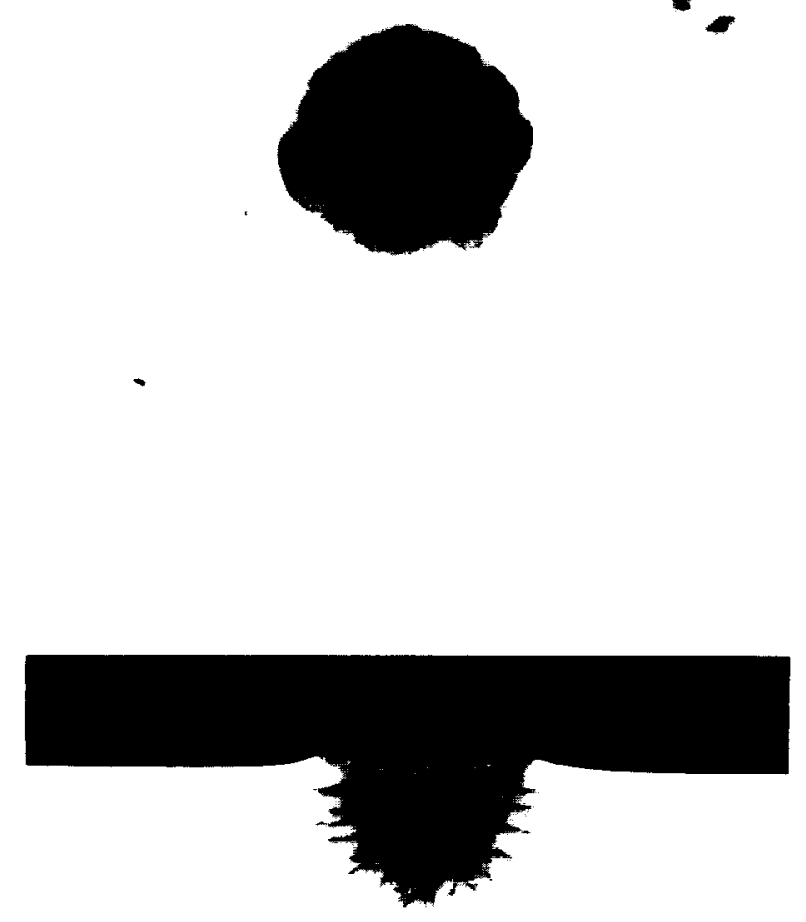

$-$ 
PROJECTILE: Soda Lime

$$
\begin{aligned}
\mathrm{D}_{\mathrm{p}} & =3175 \mu \mathrm{m} \\
\mathrm{V} & =2.64 \mathrm{~km} / \mathrm{s}
\end{aligned}
$$

TARGET: Teflon

$$
\mathrm{T}=25400 \mu \mathrm{m}
$$

FRONT

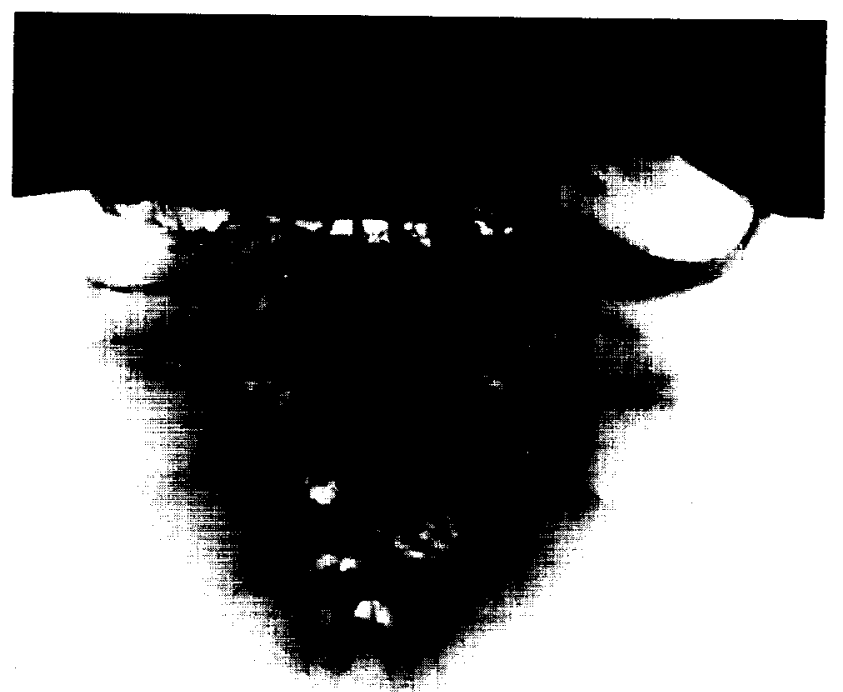


PROJECTILE: Soda Lime

$$
\begin{aligned}
\mathrm{D}_{\mathrm{p}} & =3175 \mu \mathrm{m} \\
\mathrm{V} & =3.02 \mathrm{~km} / \mathrm{s}
\end{aligned}
$$

TARGET: Teflon

$\mathrm{T}=19355 \mu \mathrm{m}$

FRONT

CROSS-SECTION
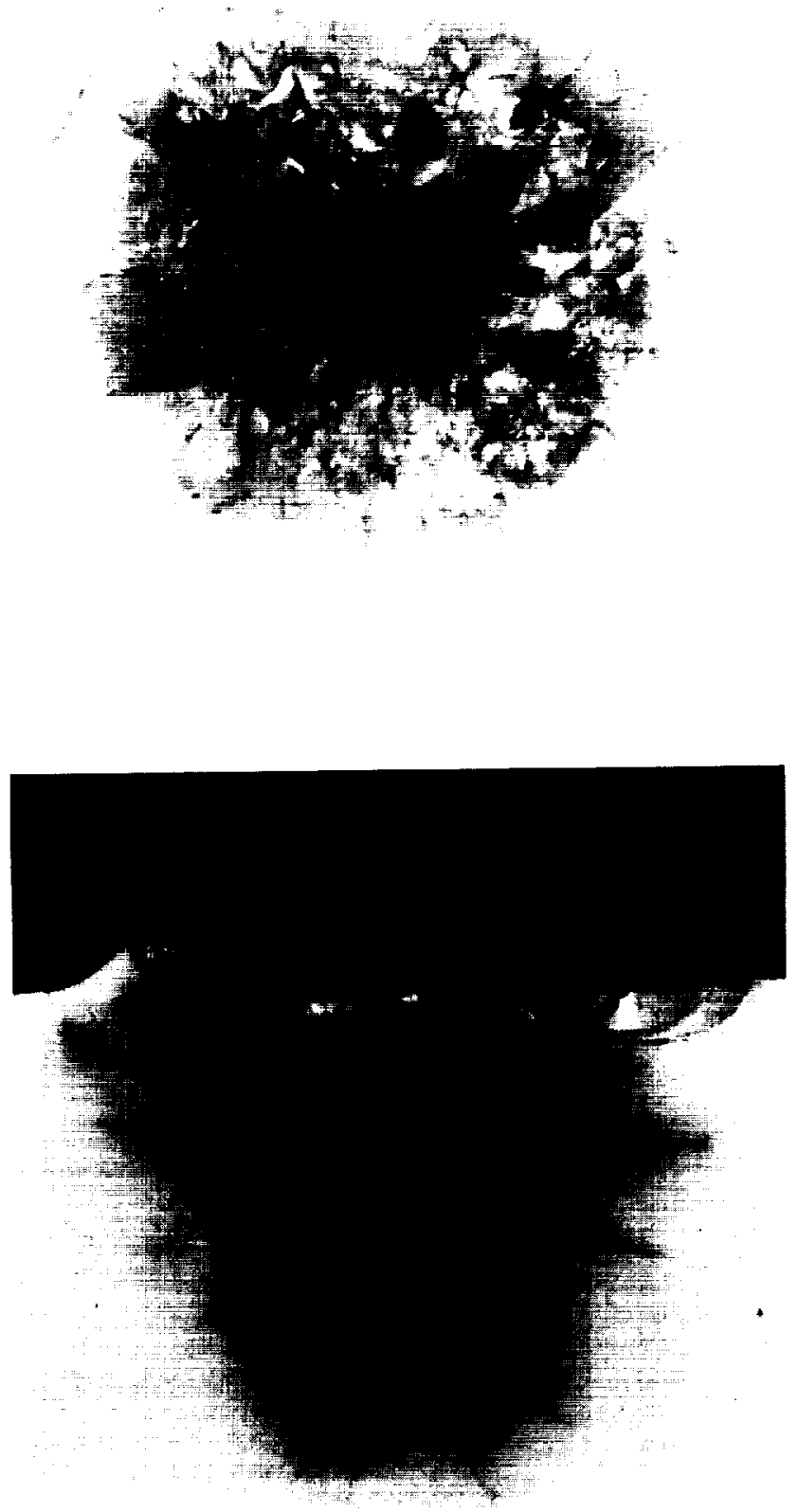
PROJECTILE: Soda Lime

$$
\begin{aligned}
\mathrm{D}_{\mathrm{p}} & =3175 \mu \mathrm{m} \\
\mathrm{V} & =3.45 \mathrm{~km} / \mathrm{s}
\end{aligned}
$$

TARGET: Teflon

$\mathrm{T}=26512 \mu \mathrm{m}$

FRONT

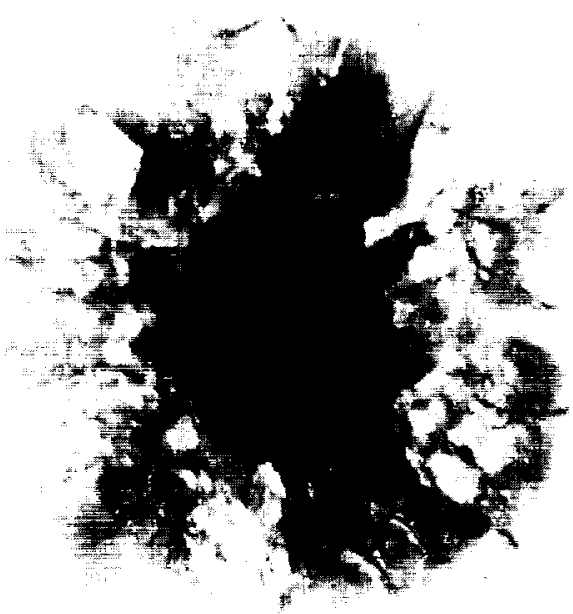

CROSS-SECTION

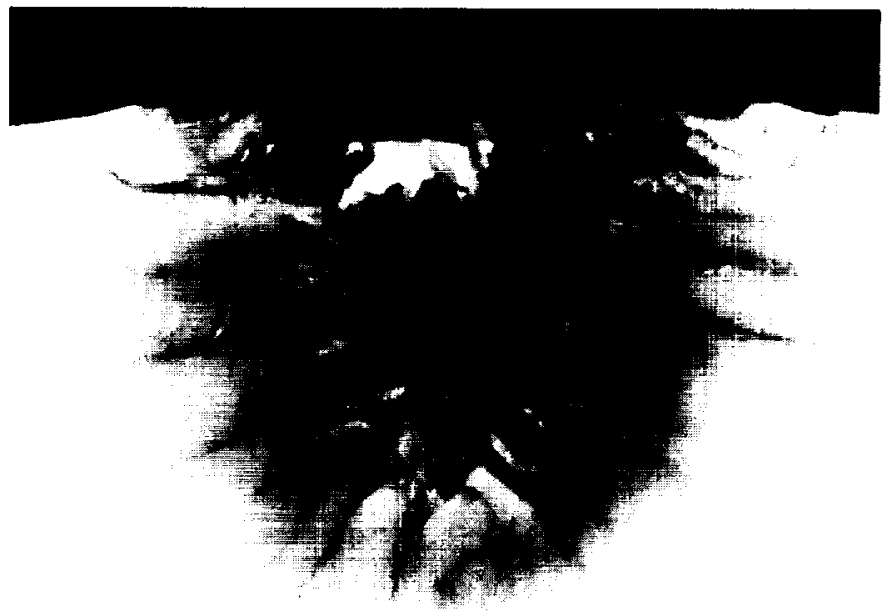




\section{PROJECTILE: Soda Lime}

$$
\begin{aligned}
\mathrm{D}_{\mathrm{p}} & =3175 \mu \mathrm{m} \\
\mathrm{V} & =3.98 \mathrm{~km} / \mathrm{s}
\end{aligned}
$$

\section{TARGET: Teflon}

$$
\mathrm{T}=16850 \mu \mathrm{m}
$$

FRONT

CROSS-SECTION
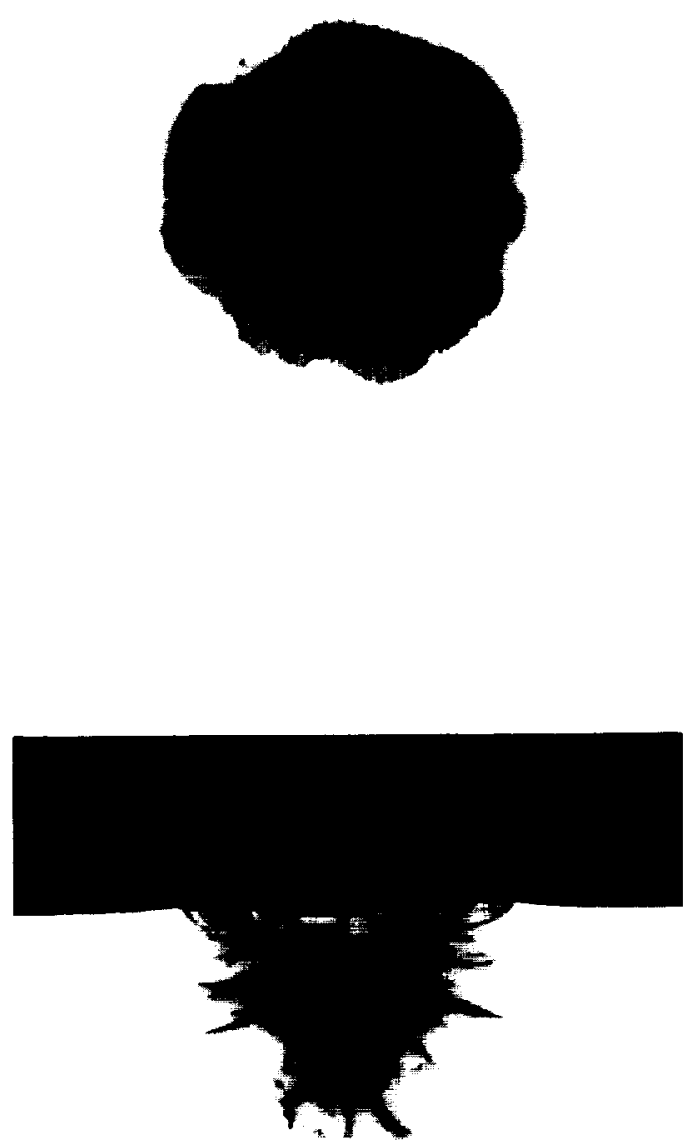
PROJECTILE: Soda Lime

$\mathrm{D}_{\mathrm{p}}=3175 \mu \mathrm{m}$

$\mathrm{V}=4.49 \mathrm{~km} / \mathrm{s}$

TARGET: Teflon

$\mathrm{T}=24400 \mu \mathrm{m}$

CROSS-SECTION
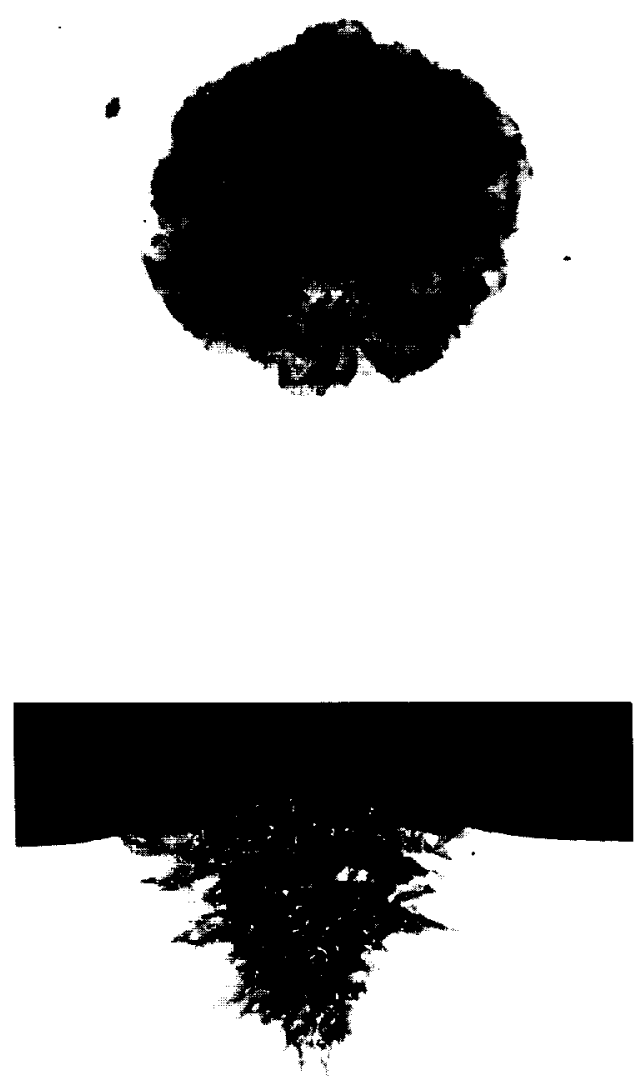
PROJECTILE: Soda Lime

$$
\begin{aligned}
\mathrm{D}_{\mathrm{p}} & =3175 \mu \mathrm{m} \\
\mathrm{V} & =4.54 \mathrm{~km} / \mathrm{s}
\end{aligned}
$$

TARGET: Teflon

$$
\mathrm{T}=19010 \mu \mathrm{m}
$$

FRONT

\section{CROSS-SECTION}

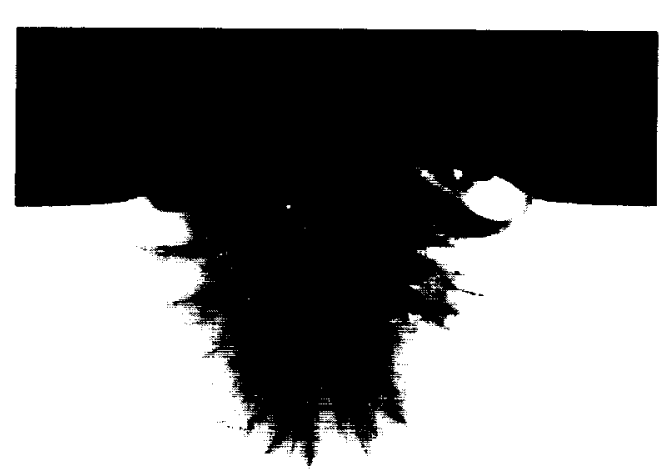

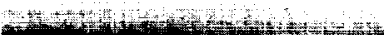

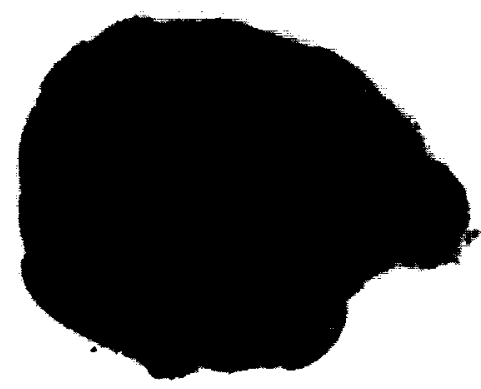


PROJECTILE: Soda Lime

$$
\begin{aligned}
\mathrm{D}_{\mathrm{p}} & =3175 \mu \mathrm{m} \\
\mathrm{V} & =5.09 \mathrm{~km} / \mathrm{s}
\end{aligned}
$$

TARGET: Teflon

$\mathrm{T}=19152 \mu \mathrm{m}$

\section{FRONT}

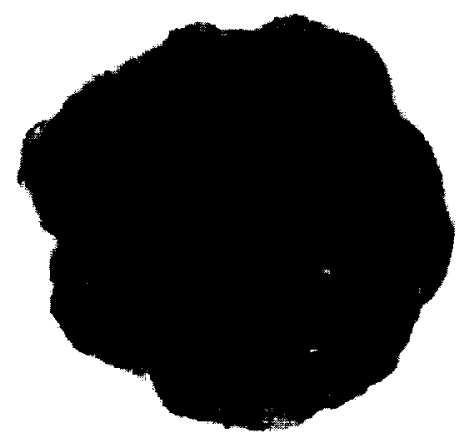

CROSS-SECTION

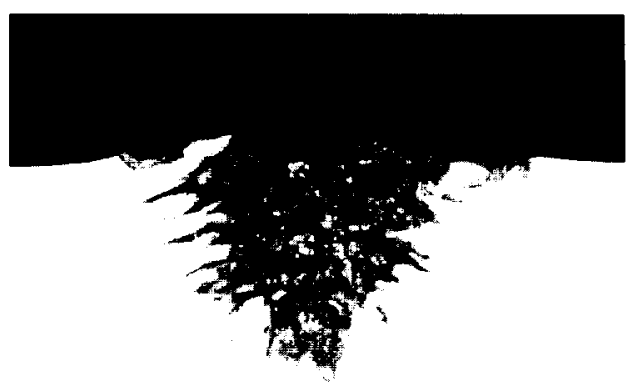


PROJECTILE: Soda Lime

$$
\begin{aligned}
\mathrm{D}_{\mathrm{p}} & =3175 \mu \mathrm{m} \\
\mathrm{V} & =5.37 \mathrm{~km} / \mathrm{s}
\end{aligned}
$$

TARGET: Teflon

$$
\mathrm{T}=26710 \mu \mathrm{m}
$$

\section{FRONT}

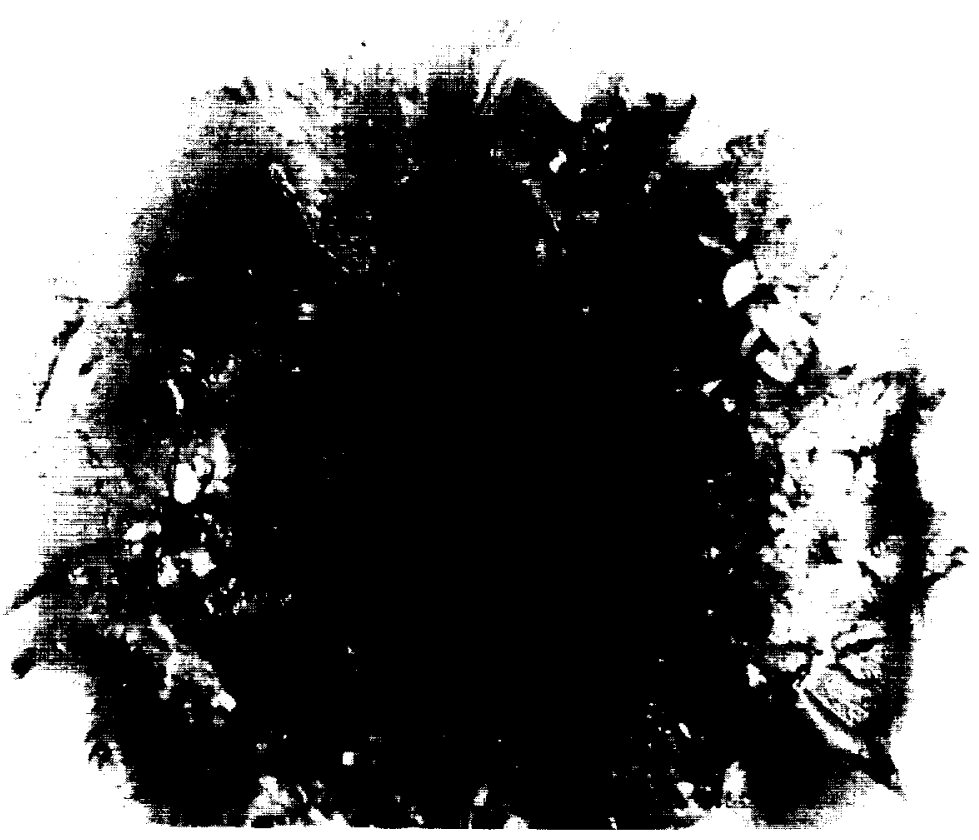

CROSS-SECTION 
PROJECTILE: Soda Lime

$$
\begin{aligned}
\mathrm{D}_{\mathrm{p}} & =3175 \mu \mathrm{m} \\
\mathrm{V} & =5.44 \mathrm{~km} / \mathrm{s}
\end{aligned}
$$

TARGET: Teflon

$$
\mathrm{T}=19020 \mu \mathrm{m}
$$

\section{FRONT}

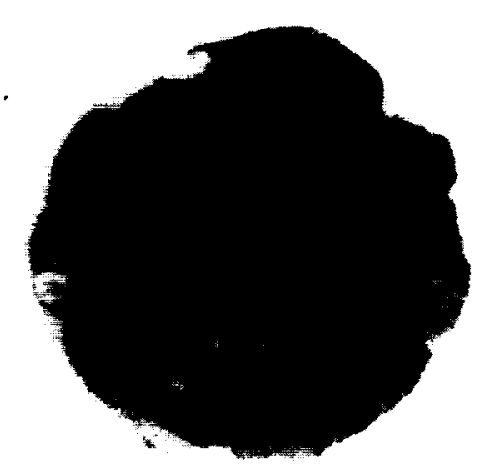

CROSS-SECTION

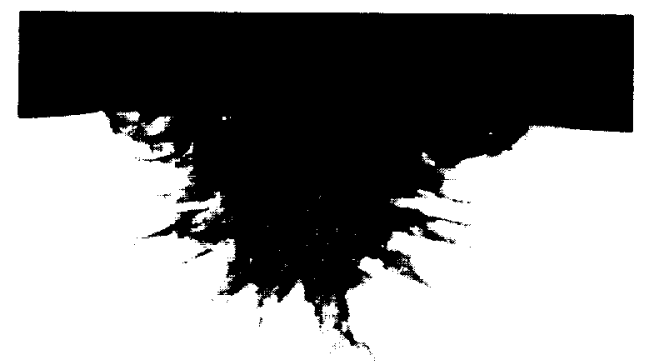


PROJECTILE: Soda Lime

$$
\begin{aligned}
\mathrm{D}_{\mathrm{p}} & =3175 \mu \mathrm{m} \\
\mathrm{V} & =5.46 \mathrm{~km} / \mathrm{s}
\end{aligned}
$$

TARGET: Teflon $\mathrm{T}=25146 \mu \mathrm{m}$

FRONT

\section{CROSS-SECTION}
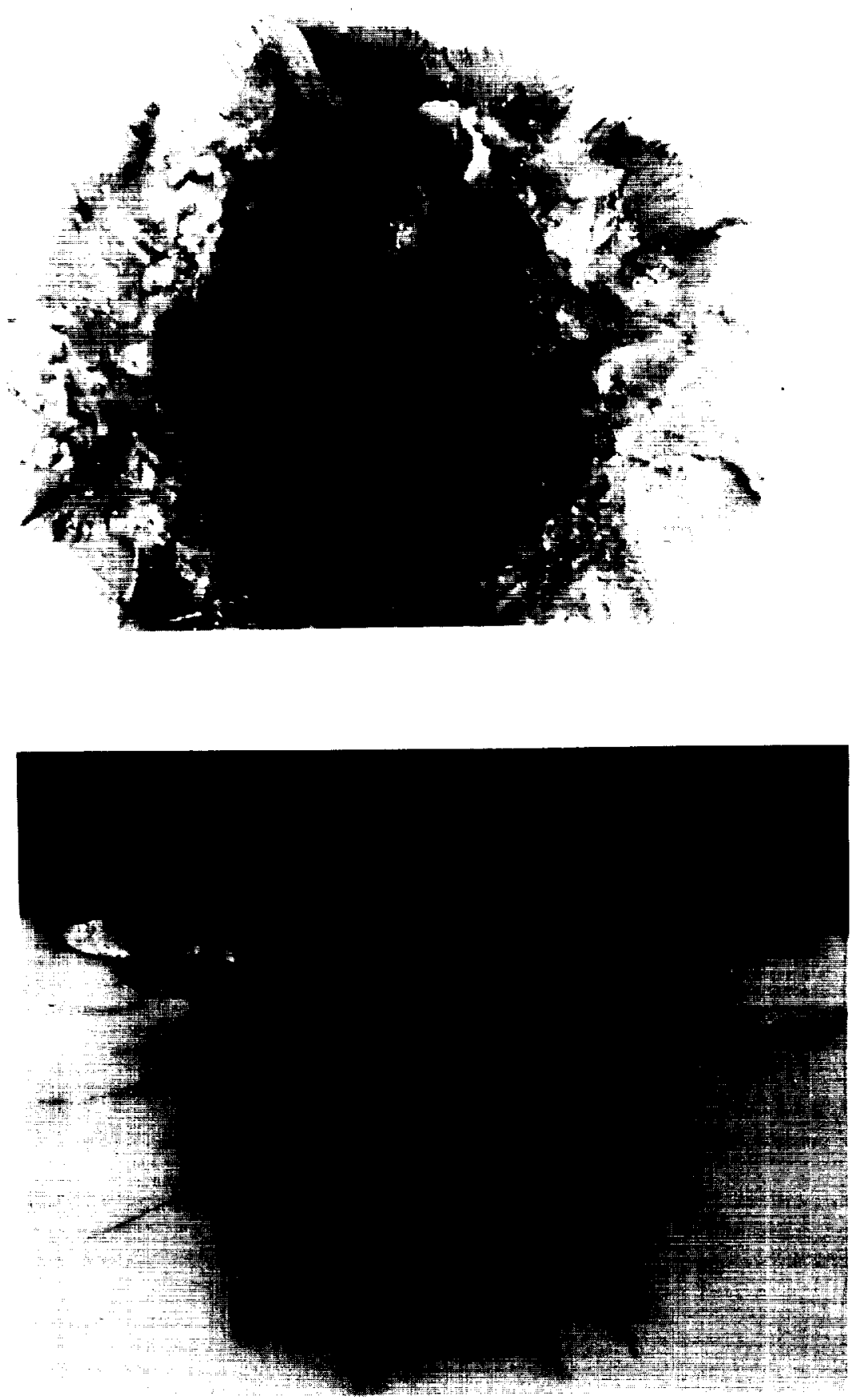
PROJECTILE: Soda Lime

$$
\begin{aligned}
\mathrm{D}_{\mathrm{p}} & =3175 \mu \mathrm{m} \\
\mathrm{V} & =5.84 \mathrm{~km} / \mathrm{s}
\end{aligned}
$$

\section{TARGET: Teflon}

$\mathrm{T}=18959 \mu \mathrm{m}$

FRONT

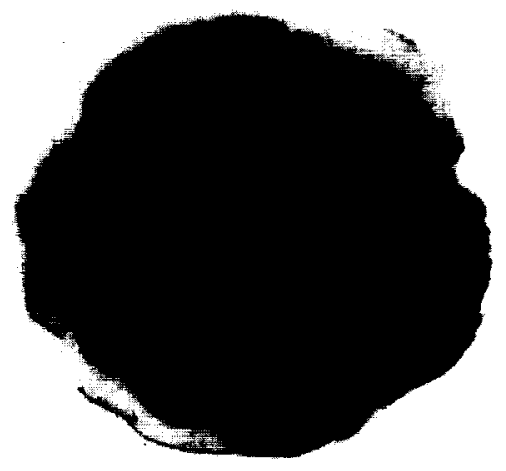

CROSS-SECTION

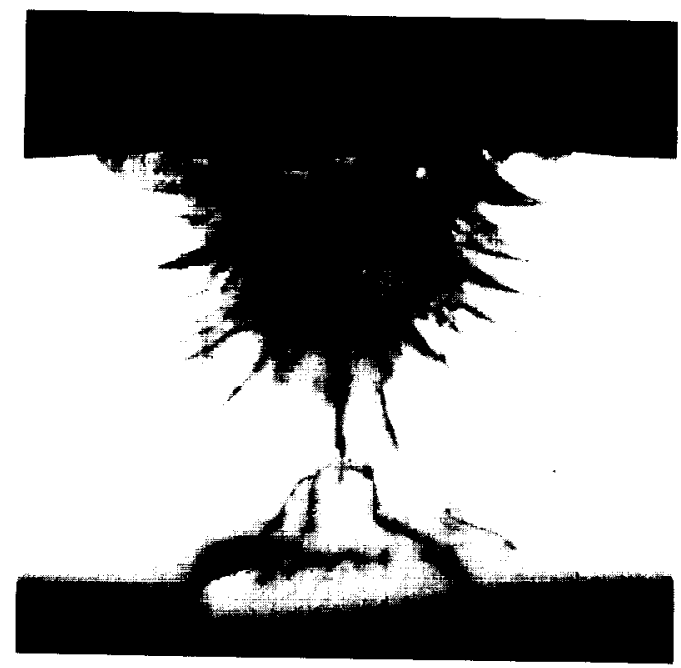


PROJECTILE: Soda Lime

$D_{p}=3175 \mu \mathrm{m}$

$\mathrm{V}=6.12 \mathrm{~km} / \mathrm{s}$

TARGET: Teflon

$\mathrm{T}=19050 \mu \mathrm{m}$

FRONT

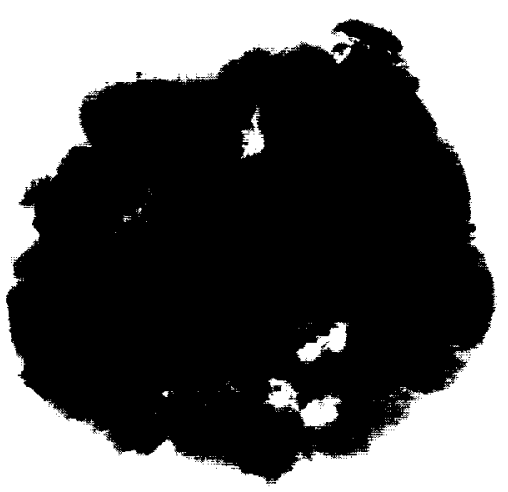

CROSS-SECTION 
PROJECTILE: Soda Lime

$$
\begin{aligned}
\mathrm{D}_{\mathrm{p}} & =3175 \mu \mathrm{m} \\
\mathrm{V} & =6.30 \mathrm{~km} / \mathrm{s}
\end{aligned}
$$

\section{TARGET: Teflon}

$$
\mathrm{T}=25600 \mu \mathrm{m}
$$

\section{FRONT}

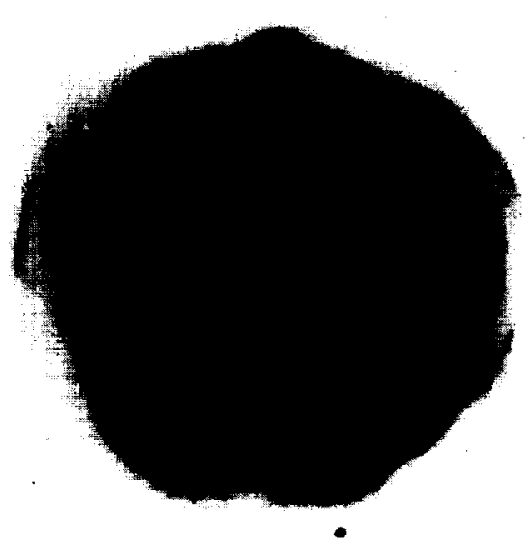

\section{CROSS-SECTION}

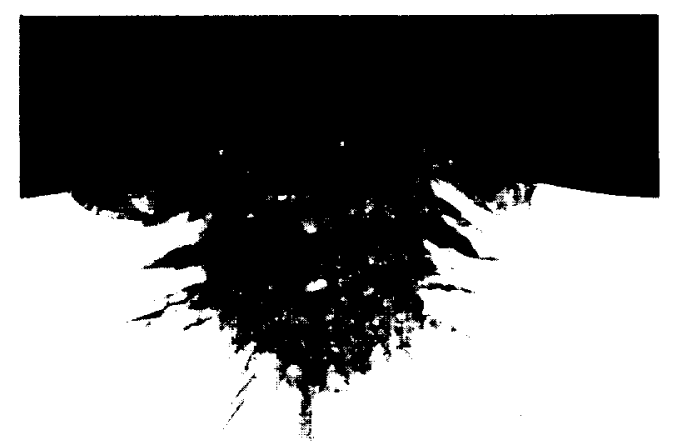


PROJECTILE: Soda Lime

$$
\begin{aligned}
\mathrm{D}_{\mathrm{p}} & =3175 \mu \mathrm{m} \\
\mathrm{V} & =6.44 \mathrm{~km} / \mathrm{s}
\end{aligned}
$$

TARGET: Teflon

$\mathrm{T}=25550 \mu \mathrm{m}$

\section{FRONT}

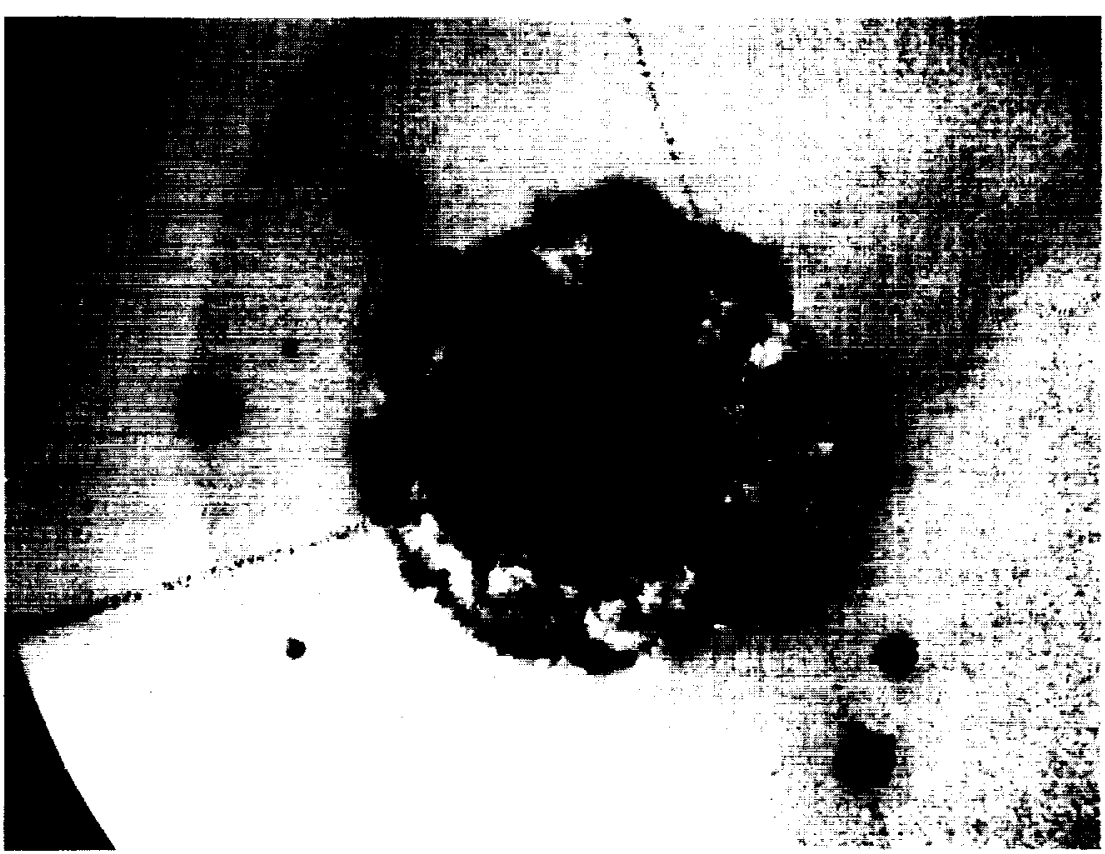

CROSS-SECTION
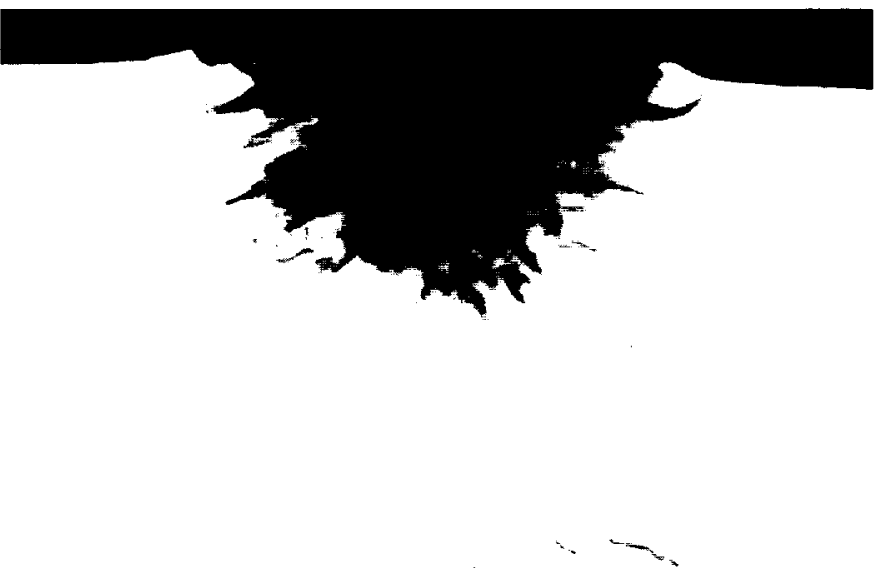
PROJECTILE: Soda Lime

$\mathrm{D}_{\mathrm{p}}=3175 \mu \mathrm{m}$

$\mathrm{V}=6.53 \mathrm{~km} / \mathrm{s}$

TARGET: Teflon

$\mathrm{T}=24190 \mu \mathrm{m}$

FRONT

CROSS-SECTION
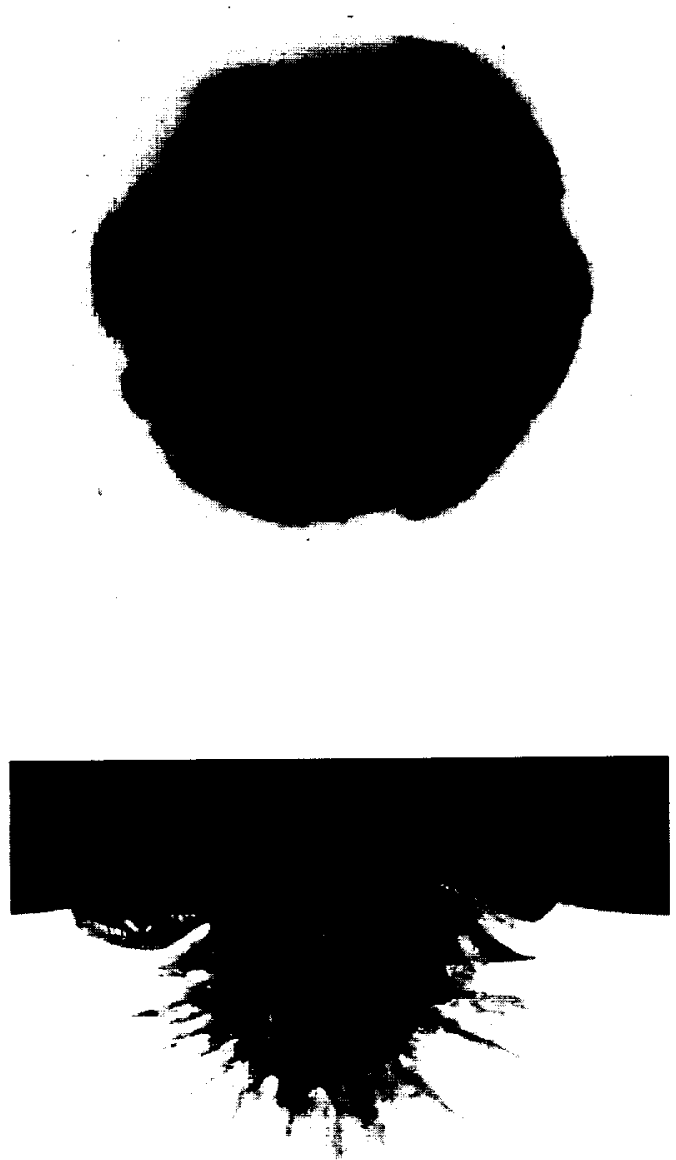
PROJECTILE: Soda Lime

$$
\begin{aligned}
\mathrm{D}_{\mathrm{p}} & =3175 \mu \mathrm{m} \\
\mathrm{V} & =6.91 \mathrm{~km} / \mathrm{s}
\end{aligned}
$$

TARGET: Teflon

$\mathrm{T}=24790 \mu \mathrm{m}$

\section{FRONT}

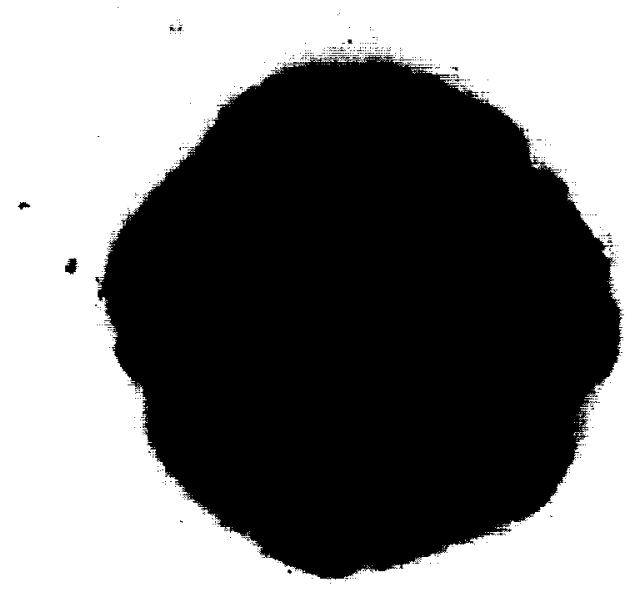

CROSS-SECTION

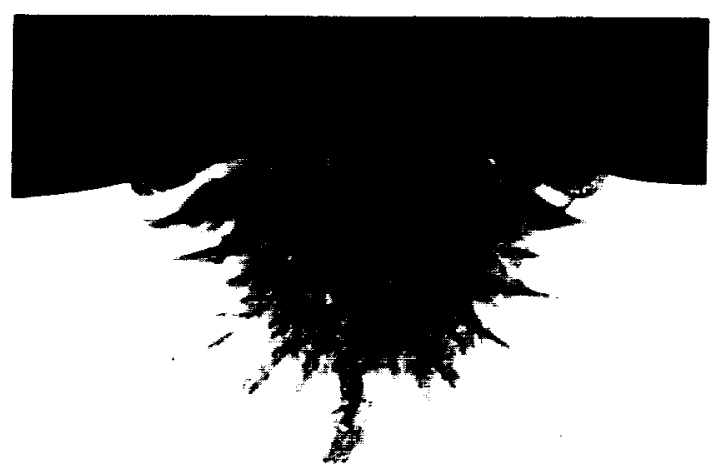


PROJECTILE: SL

$$
\begin{aligned}
D_{p} & =3175 \mu \mathrm{m} \\
V & =2.32 \mathrm{~km} / \mathrm{s}
\end{aligned}
$$

TARGET: Teflon

$$
\begin{aligned}
\mathrm{T} & =12920 \mu \mathrm{m} \\
\mathrm{D}_{\mathrm{p}} / \mathrm{T} & =0.25
\end{aligned}
$$

FRONT

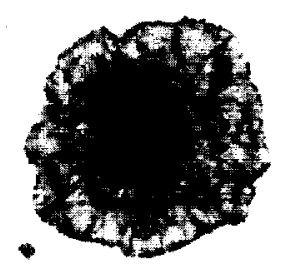

REAR
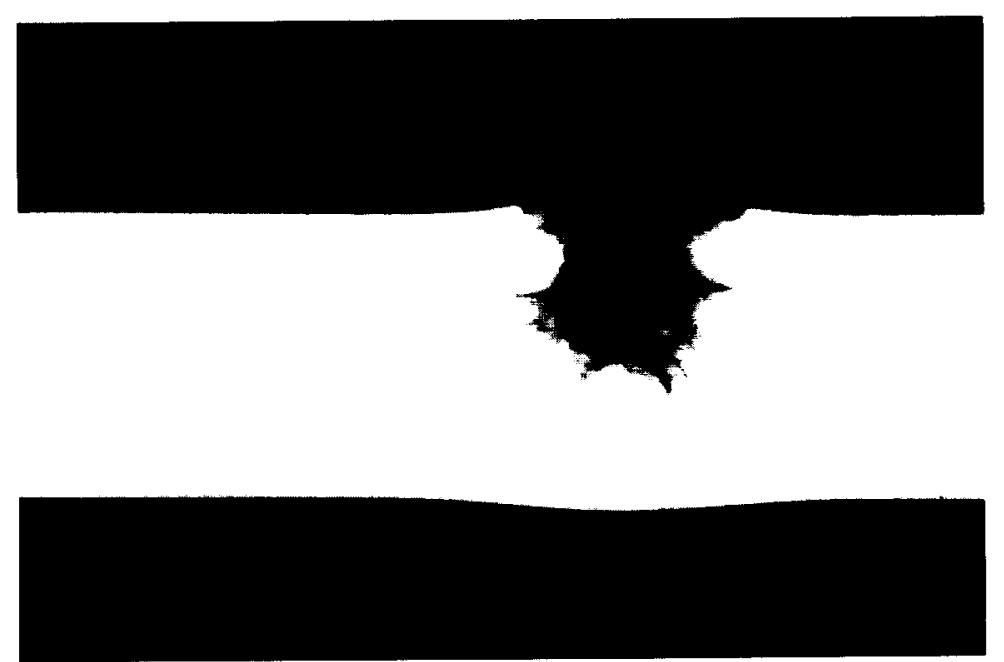
SHOT \# 3589

PROJECTILE: SL

$\begin{aligned} D_{p} & =3175 \mu \mathrm{m} \\ V & =2.38 \mathrm{~km} / \mathrm{s}\end{aligned}$

TARGET: Teflon

$\mathrm{T}=9580 \mu \mathrm{m}$

$\mathrm{D}_{\mathrm{p}} / \mathrm{T}=0.33$

FRONT

REAR

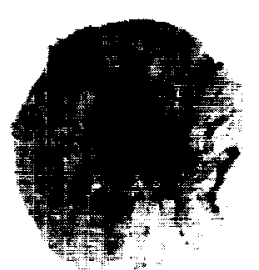

CROSS-SECTION

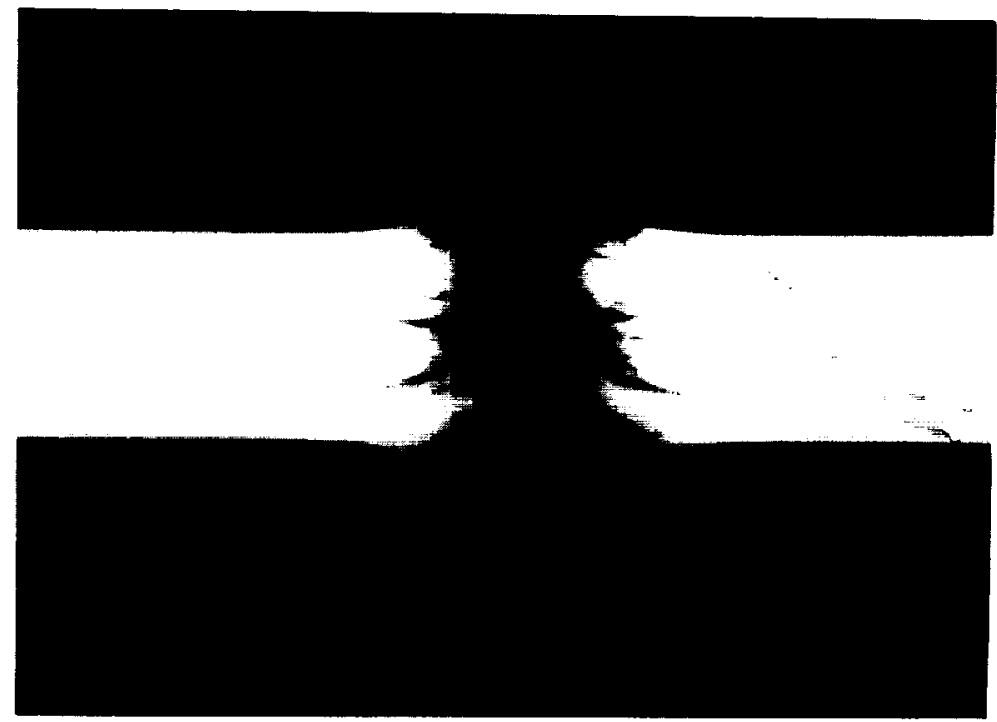


SHOT \# 3589 



\section{SHOT \# 3588}

PROJECTILE: Soda Lime

$\begin{aligned} \mathrm{D}_{\mathrm{p}} & =3175 \mu \mathrm{m} \\ \mathrm{V} & =2.31 \mathrm{~km} / \mathrm{s}\end{aligned}$

TARGET: Teflon

$\mathrm{T}=6770 \mu \mathrm{m}$

$\mathrm{D}_{\mathrm{p}} / \mathrm{T}=0.47$

FRONT

REAR

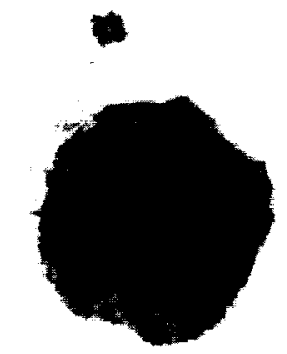

CROSS-SECTION
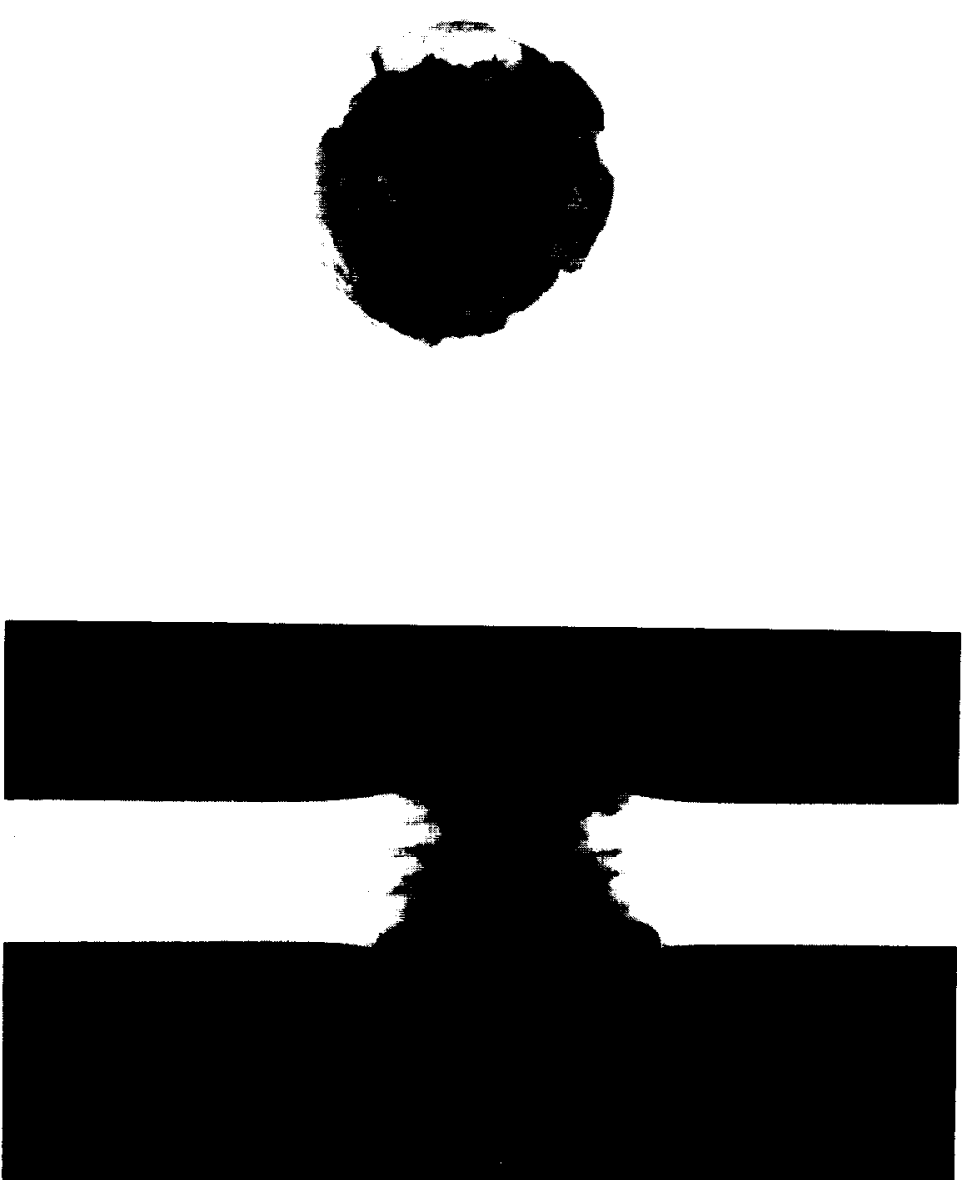

SHOT \# 3588 



\section{SHOT \# 3587}

PROJECTILE: SL

$$
\begin{aligned}
D_{p} & =3175 \mu \mathrm{m} \\
V & =2.34 \mathrm{~km} / \mathrm{s}
\end{aligned}
$$

\section{TARGET: Teflon}

$$
\begin{aligned}
\mathrm{T} & =6450 \mu \mathrm{m} \\
\mathrm{D}_{\mathrm{p}} / \mathrm{T} & =0.49
\end{aligned}
$$

FRONT

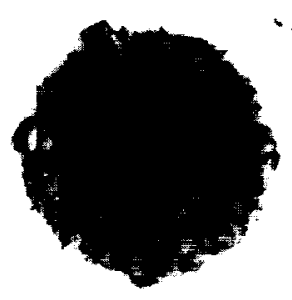

REAR

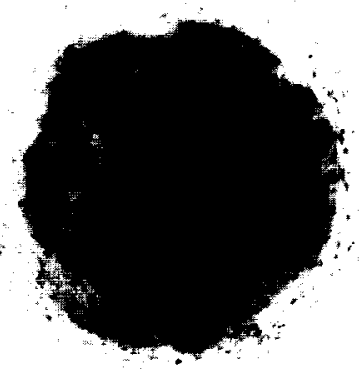

\section{CROSS-SECTION}

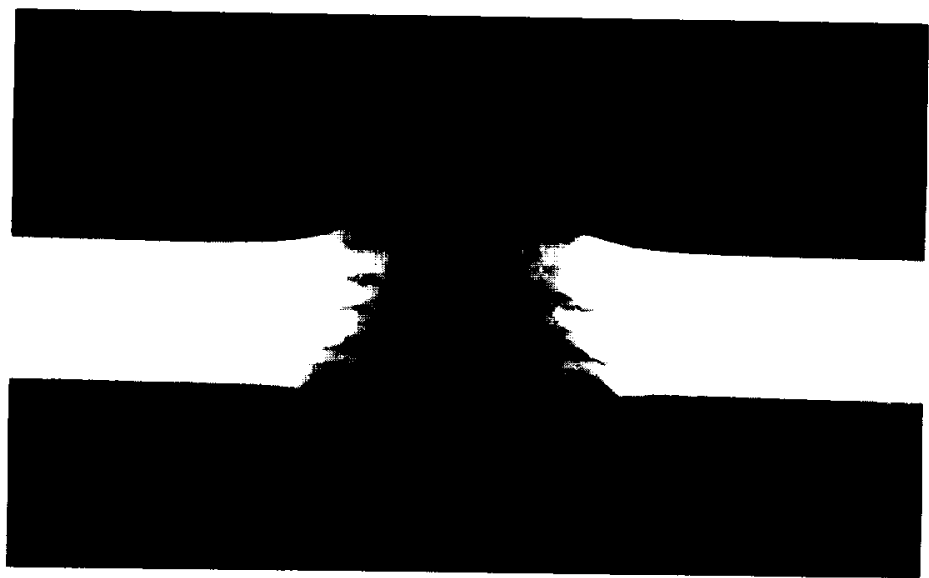



SHOT \# 3587

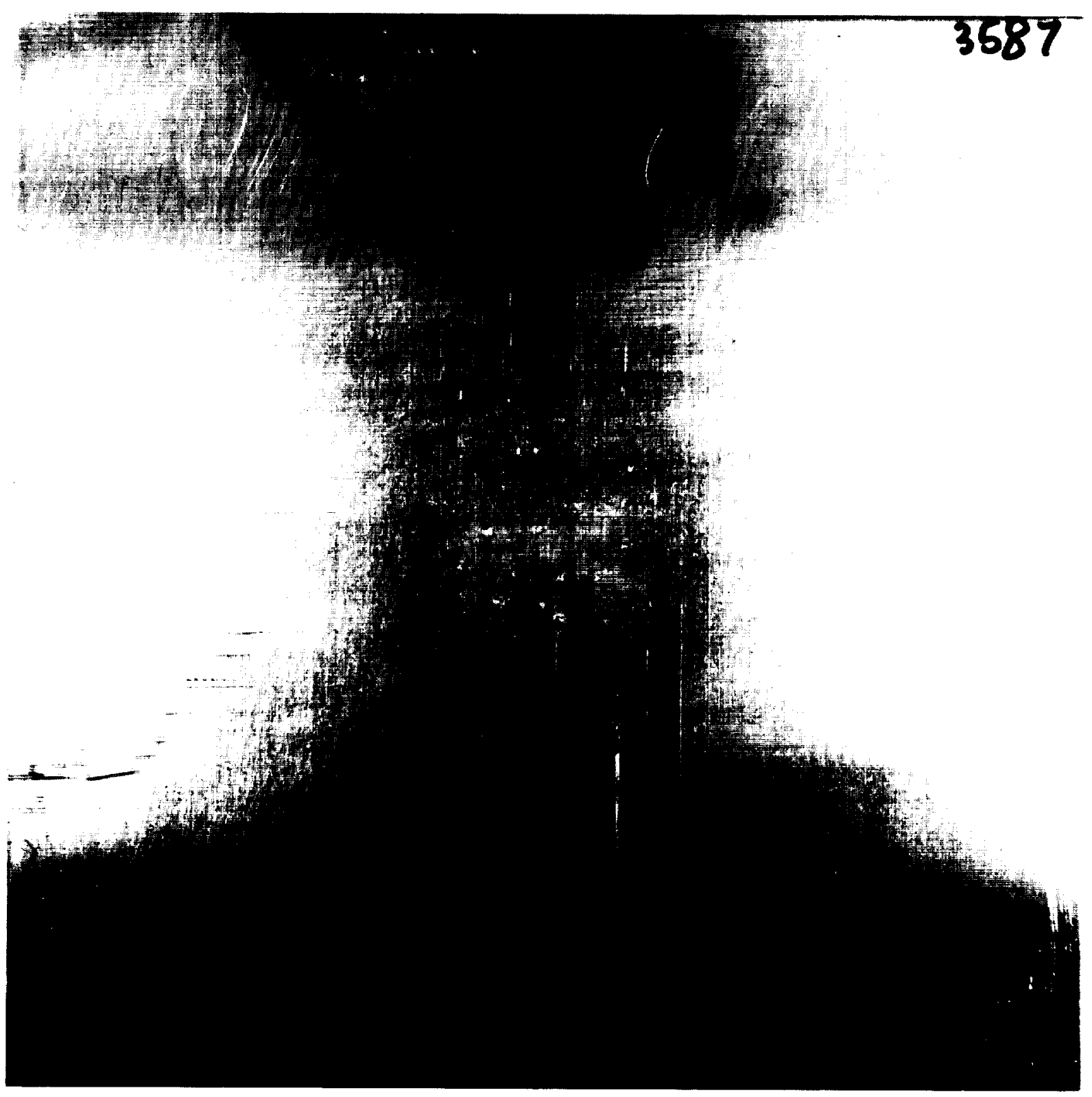



SHOT \# 3590

PROJECTILE: SL

$$
\begin{aligned}
\mathrm{D}_{\mathrm{p}} & =3175 \mu \mathrm{m} \\
\mathrm{V} & =2.44 \mathrm{~km} / \mathrm{s}
\end{aligned}
$$

TARGET: Teflon

$$
\begin{aligned}
\mathrm{T} & =4610 \mu \mathrm{m} \\
\mathrm{D}_{\mathrm{p}} / \mathrm{T} & =0.69
\end{aligned}
$$
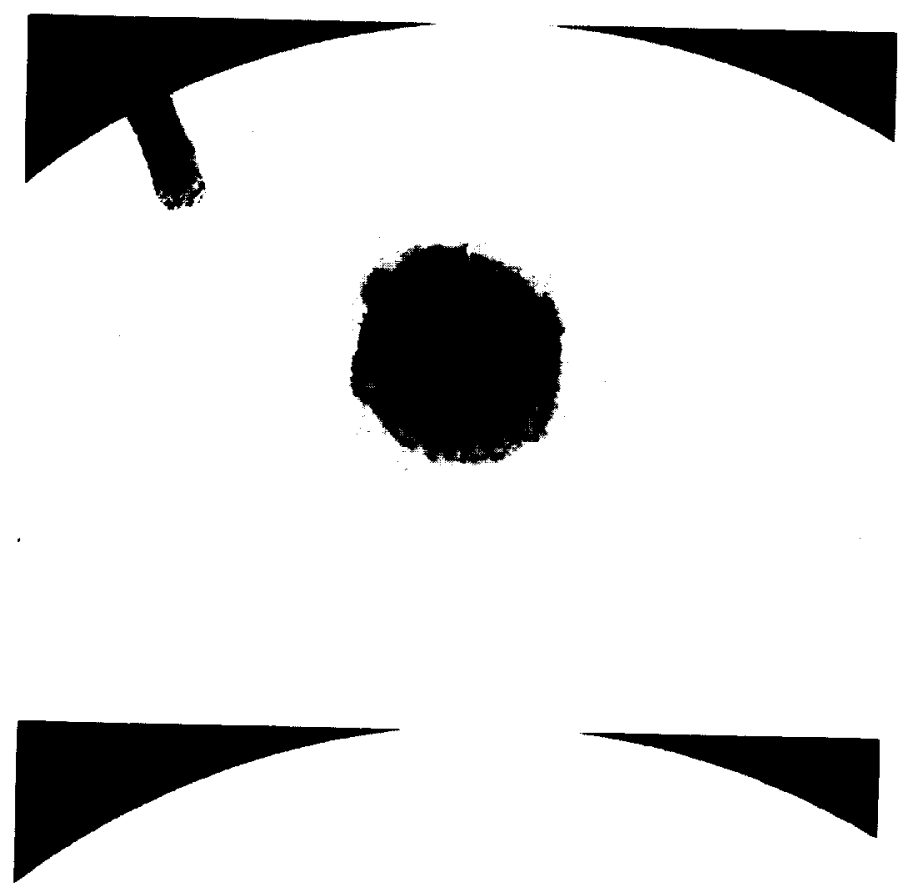

REAR

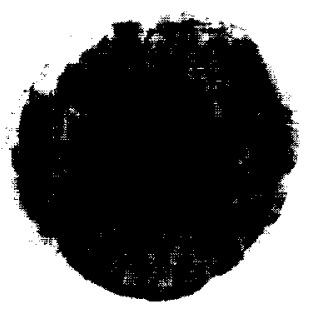

CROSS-SECTION

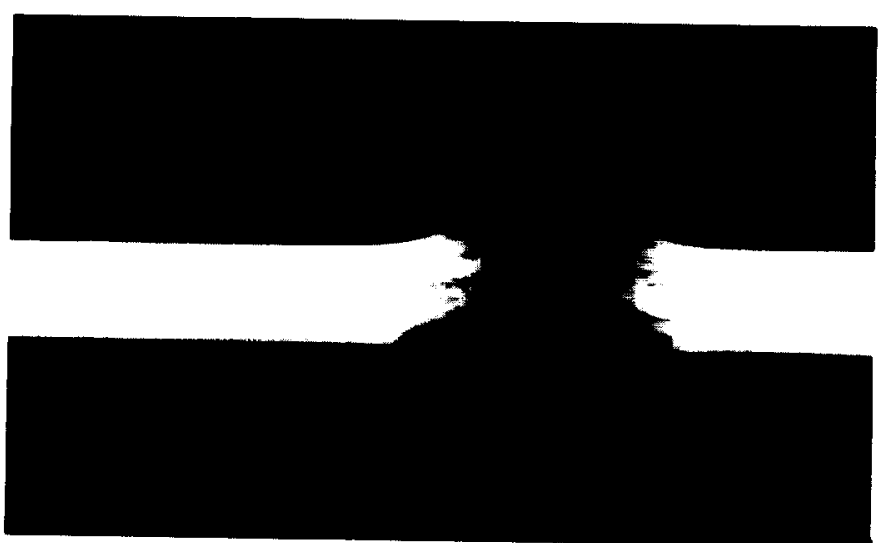





\section{SHOT \# 3590}

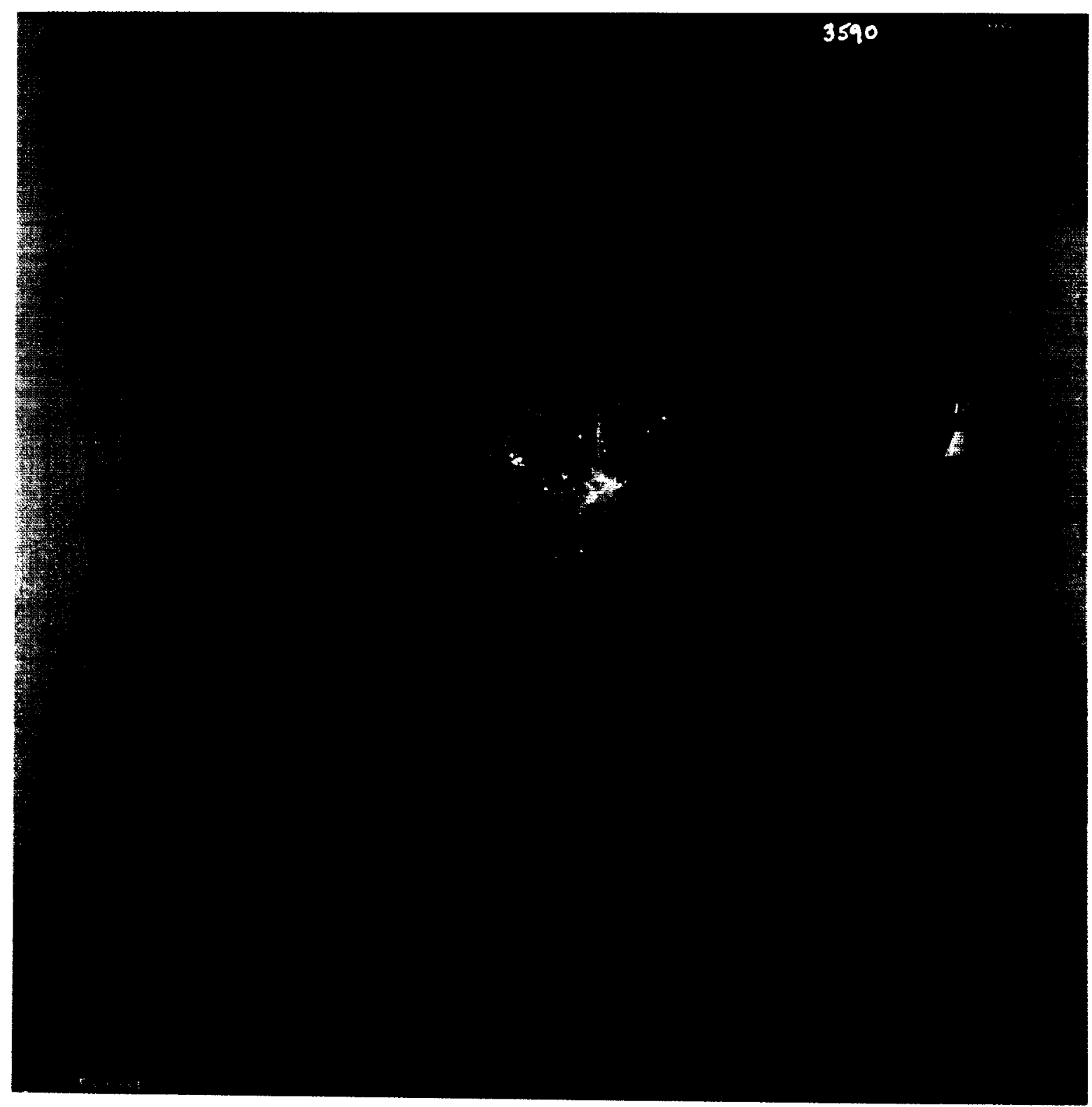



SHOT \# 3578

PROJECTILE: SL

$$
\begin{aligned}
\mathrm{D}_{\mathrm{p}} & =3175 \mu \mathrm{m} \\
\mathrm{V} & =2.25 \mathrm{~km} / \mathrm{s}
\end{aligned}
$$

TARGET: Teflon

$$
\begin{aligned}
\mathrm{T} & =3110 \mu \mathrm{m} \\
\mathrm{D}_{\mathrm{p}} / \mathrm{T} & =1.02
\end{aligned}
$$

\section{FRONT}

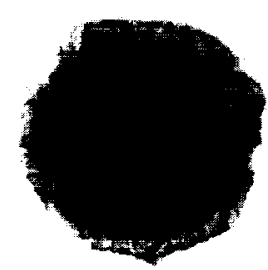

REAR
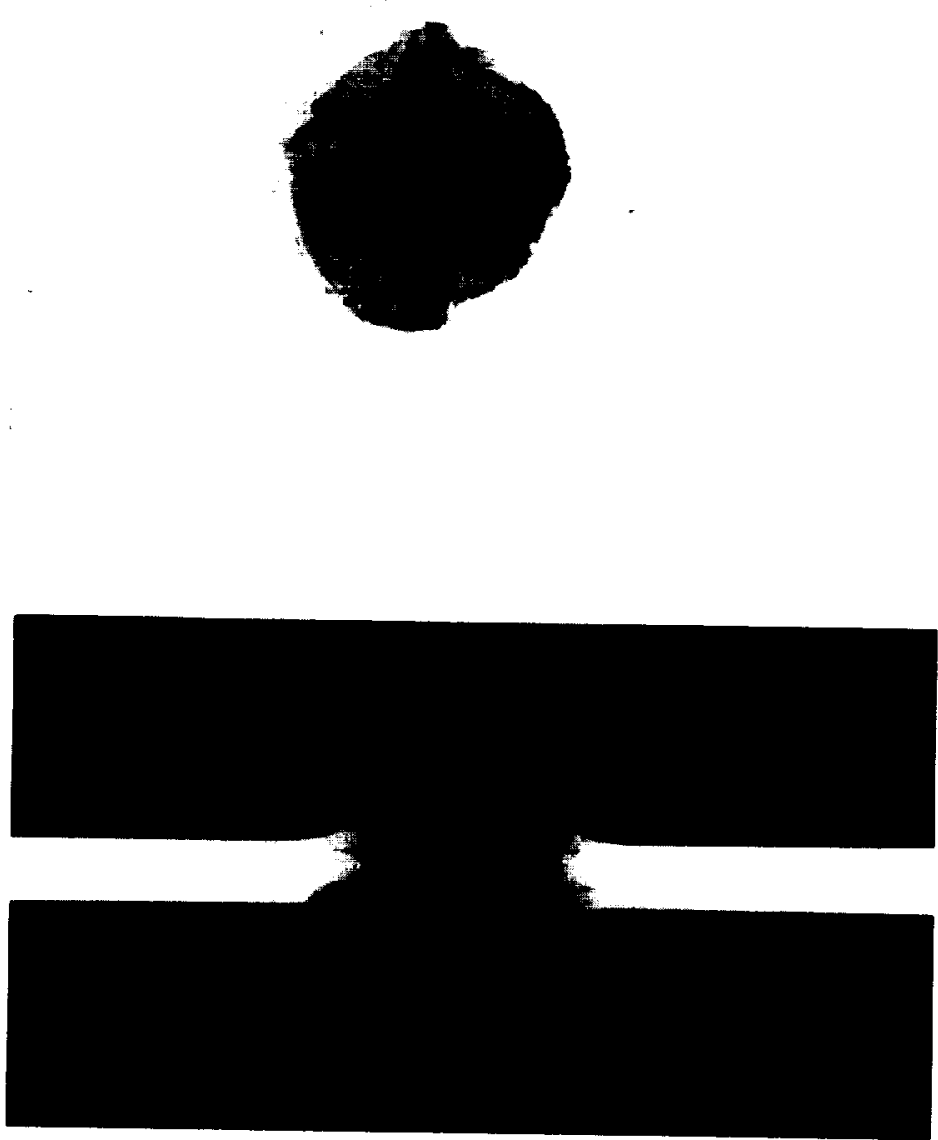

SHOT \# 3578

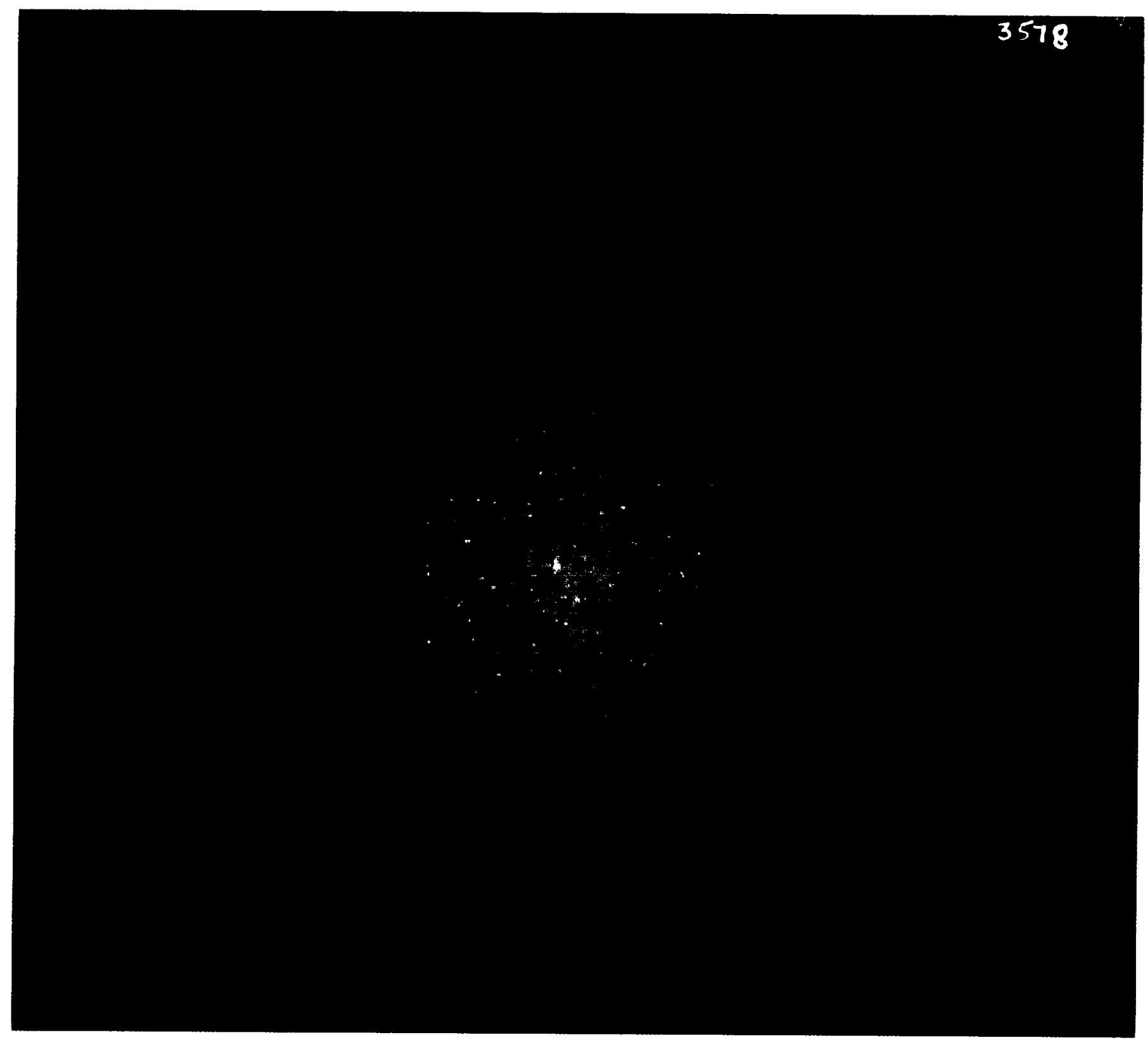





\section{SHOT \# 3586}

PROJECTILE: SL

$$
\begin{aligned}
D_{p} & =3175 \mu \mathrm{m} \\
V & =2.20 \mathrm{~km} / \mathrm{s}
\end{aligned}
$$

\section{TARGET: Teflon}

$$
\begin{aligned}
T & =815 \mu \mathrm{m} \\
\mathrm{D}_{\mathrm{p}} / \mathrm{T} & =3.90
\end{aligned}
$$

FRONT

REAR
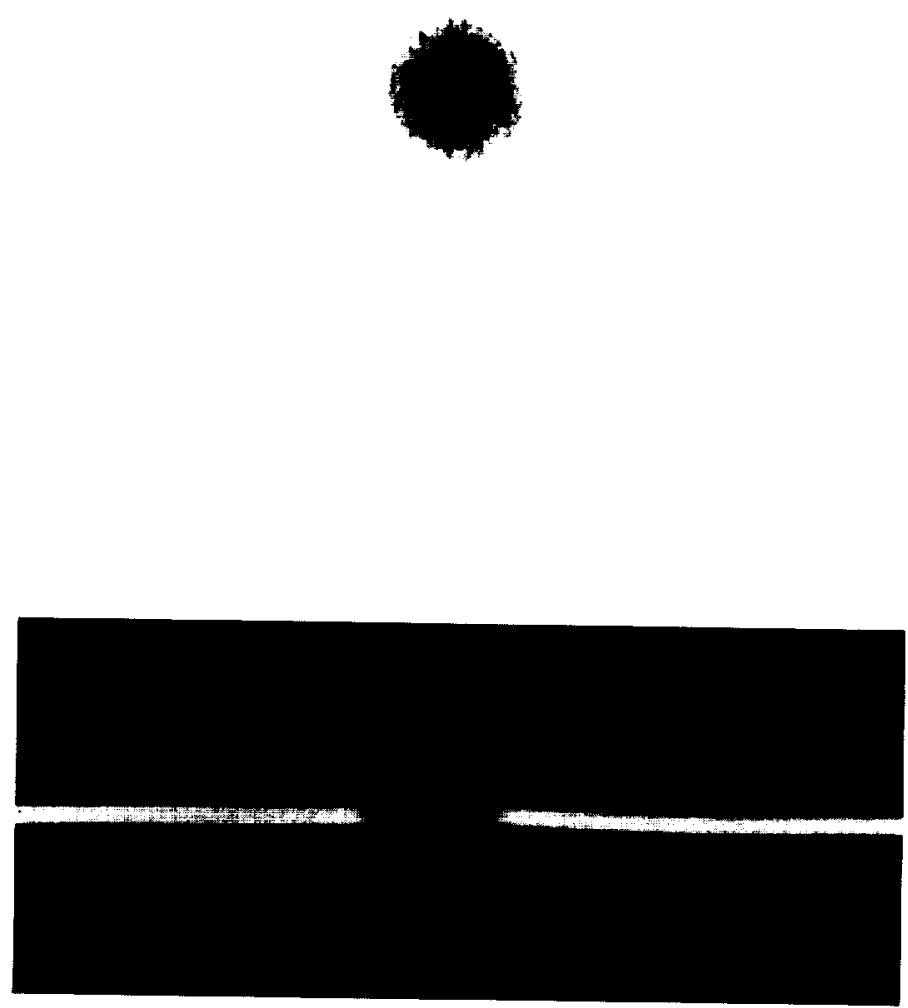

SHOT \# 3586

$*$ 



\section{SHOT \# 3585}

PROJECTILE: SL

$$
\begin{aligned}
\mathrm{D}_{\mathrm{p}} & =3175 \mu \mathrm{m} \\
\mathrm{V} & =2.27 \mathrm{~km} / \mathrm{s}
\end{aligned}
$$

TARGET: Teflon

$\mathrm{T}=500 \mu \mathrm{m}$

$\mathrm{D}_{\mathrm{p}} / \mathrm{T}=6.35$ 

SHOT \# 3585

3585 

PROJECTILE: SL

$D_{p}=3175 \mu \mathrm{m}$

$\mathrm{V}=2.33 \mathrm{~km} / \mathrm{s}$

\section{TARGET: Teflon}

$T=250 \mu \mathrm{m}$

$\mathrm{D}_{\mathrm{p}} / \mathrm{T}=12.70$

\section{FRONT}

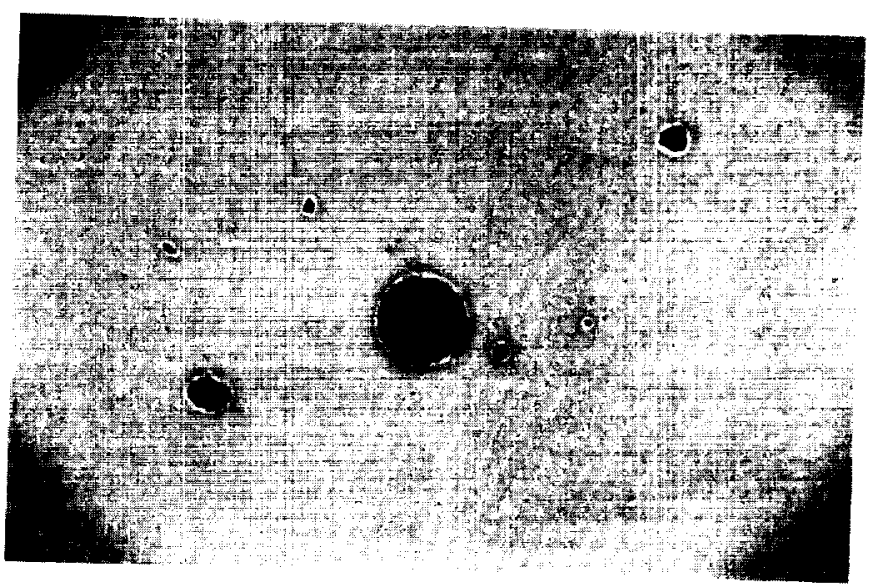

REAR

\section{CROSS-SECTION}





\section{SHOT \# 3584}

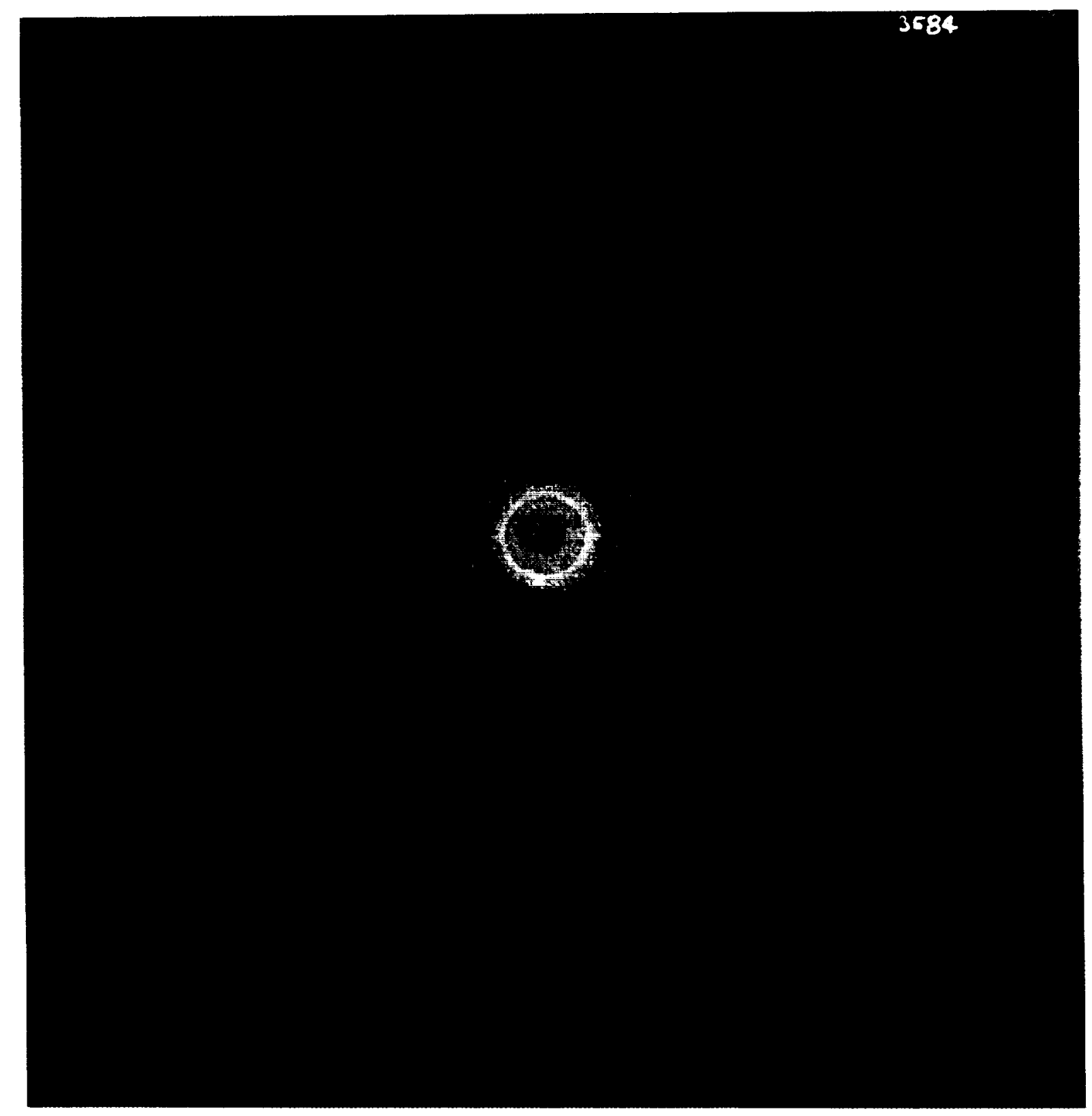





\section{SHOT \# 3583}

PROJECTILE: SL

$$
\begin{aligned}
\mathrm{D}_{\mathrm{p}} & =3175 \mu \mathrm{m} \\
\mathrm{V} & =2.30 \mathrm{~km} / \mathrm{s}
\end{aligned}
$$

TARGET: Teflon

$$
\begin{aligned}
\mathrm{T} & =100 \mu \mathrm{m} \\
\mathrm{D}_{\mathbf{p}} / \mathrm{T} & =31.75
\end{aligned}
$$

\section{REAR}

\section{CROSS-SECTION}



SHOT \# 3583 



\section{SHOT \# 3582}

\section{PROJECTILE: SL}

$$
\begin{aligned}
\mathrm{D}_{\mathrm{p}} & =3175 \mu \mathrm{m} \\
\mathrm{V} & =2.28 \mathrm{~km} / \mathrm{s}
\end{aligned}
$$

TARGET: Teflon

$$
\begin{aligned}
T & =50 \mu \mathrm{m} \\
\mathrm{D}_{\mathrm{p}} / \mathrm{T} & =63.50
\end{aligned}
$$

FRONT

\section{REAR}

\section{CROSS-SECTION}





\section{SHOT \# 3582}

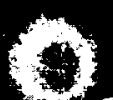

$8+$

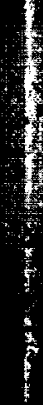



PROJECTLE: SL

SHOT \# 3581

$$
\begin{aligned}
D_{p} & =3175 \mu \mathrm{m} \\
V & =2.31 \mathrm{~km} / \mathrm{s}
\end{aligned}
$$

TARGET: Teflon

$$
\begin{aligned}
T & =25 \mu \mathrm{m} \\
\mathrm{D}_{\mathrm{p}} / \mathrm{T} & =127.00
\end{aligned}
$$

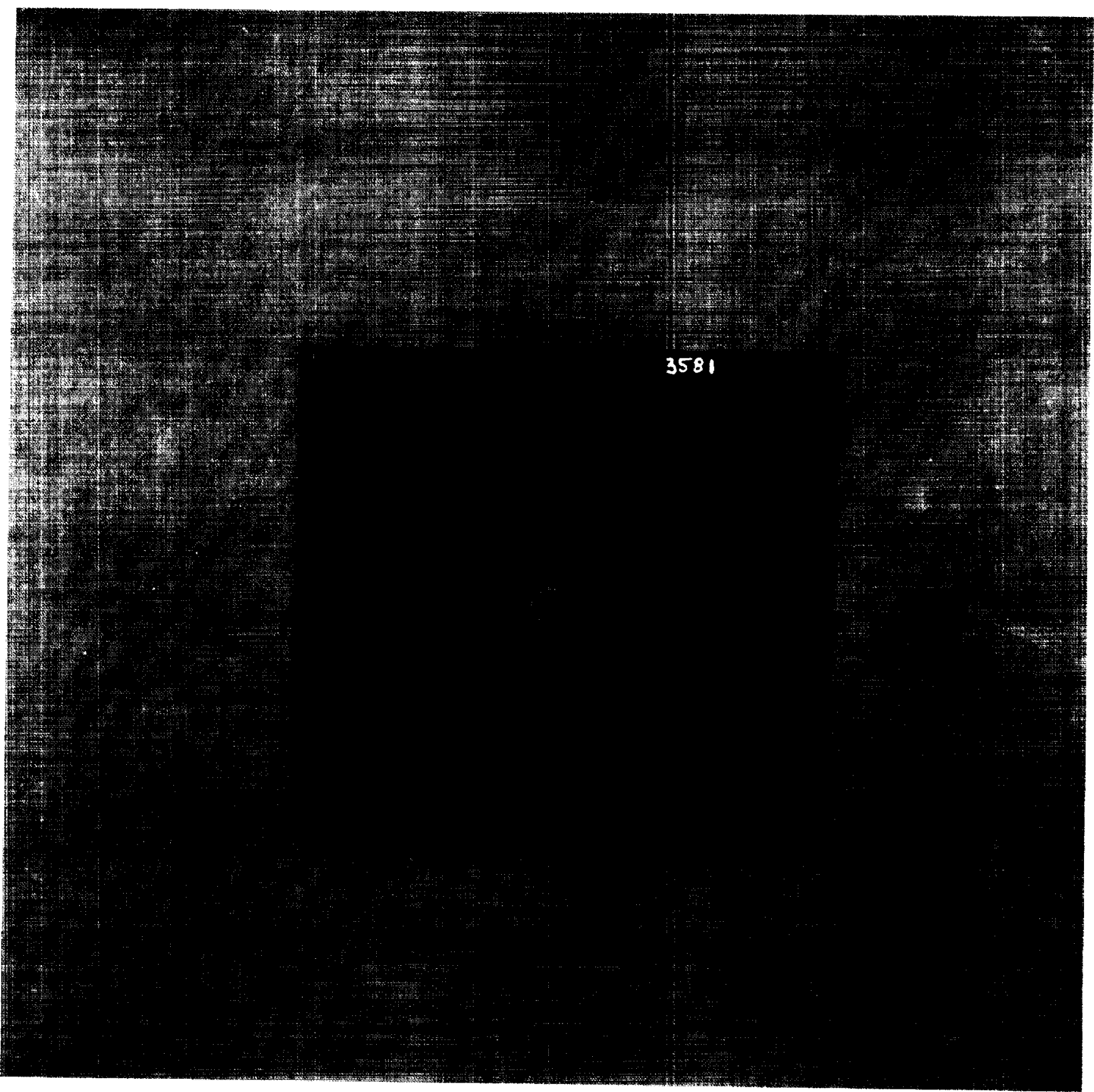



PROJECTILE: SL

$$
\begin{aligned}
\mathrm{D}_{\mathrm{p}} & =3175 \mu \mathrm{m} \\
\mathrm{V} & =2.32 \mathrm{~km} / \mathrm{s}
\end{aligned}
$$

TARGET: Teflon

$$
\begin{aligned}
\mathrm{T} & =12 \mu \mathrm{m} \\
\mathrm{D}_{\mathbf{p}} / \mathrm{T} & =264.58
\end{aligned}
$$



PROJECTILE: SL

$$
\begin{aligned}
\mathrm{D}_{\mathrm{p}} & =3175 \mu \mathrm{m} \\
\mathrm{V} & =2.23 \mathrm{~km} / \mathrm{s}
\end{aligned}
$$

TARGET: Teflon

$$
\begin{aligned}
\mathrm{T} & =6 \mu \mathrm{m} \\
\mathrm{D}_{\mathrm{p}} / \mathrm{T} & =529.17
\end{aligned}
$$



PROJECTILE: Soda Lime

$\mathrm{D}_{\mathrm{p}}=3175 \mu \mathrm{m}$

$\mathrm{V}=3.98 \mathrm{~km} / \mathrm{s}$

TARGET: Teflon

$$
\begin{aligned}
\mathrm{T} & =16850 \mu \mathrm{m} \\
\mathrm{D}_{\mathrm{p}} / \mathrm{T} & =0.19
\end{aligned}
$$

FRONT

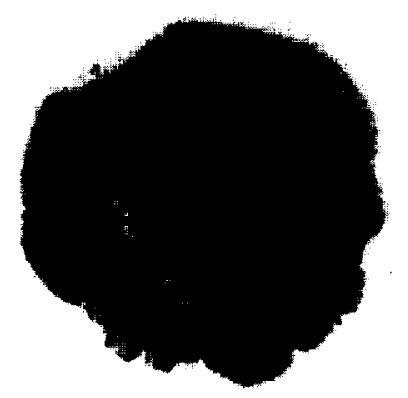

REAR

CROSS-SECTION
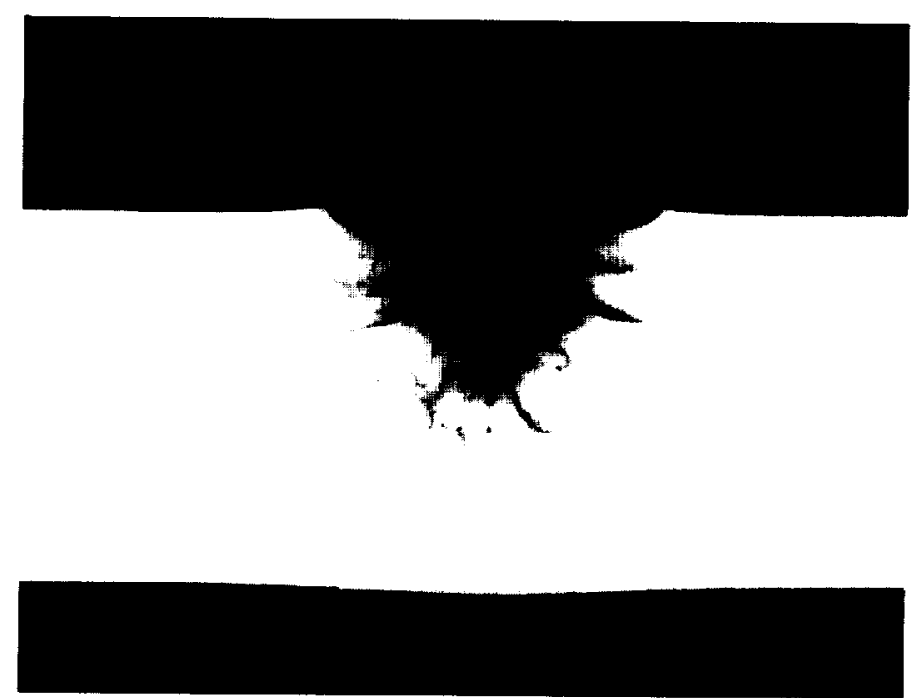
PROJECTILE: Soda Lime

$\mathrm{D}_{\mathrm{p}}=3175 \mu \mathrm{m}$

$\mathrm{V}=4.32 \mathrm{~km} / \mathrm{s}$

TARGET: Teflon

$$
\begin{aligned}
T & =11049 \mu \mathrm{m} \\
\mathrm{D}_{\mathrm{p}} / \mathrm{T} & =0.29
\end{aligned}
$$

FRONT

REAR

CROSS-SECTION
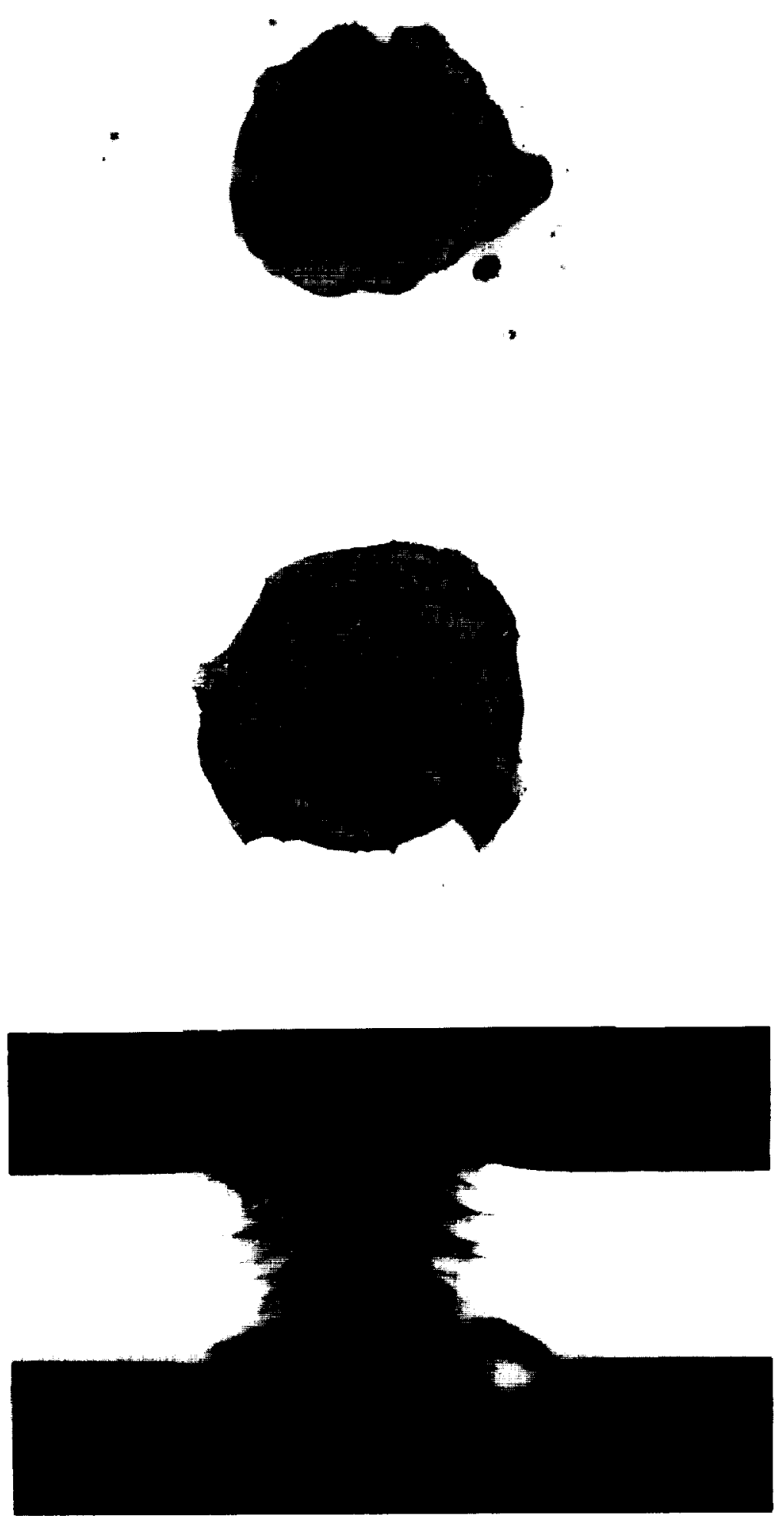


\section{Page Intentionally Left Blank}


SHOT \# 90

PROJECTILE: Soda Lime

$\mathrm{D}_{\mathrm{p}}=3175 \mu \mathrm{m}$

TARGET: Teflon

$\begin{aligned} \mathrm{T} & =7950 \mu \mathrm{m} \\ \mathrm{D}_{\mathbf{p}} / \mathrm{T} & =0.40\end{aligned}$

FRONT

REAR

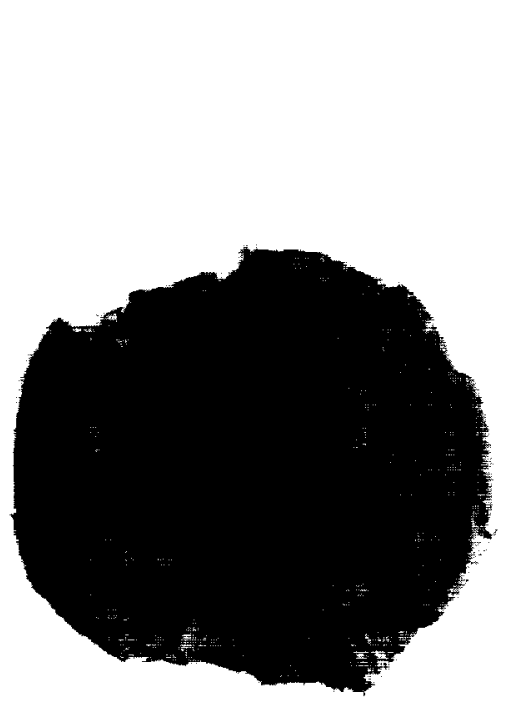

CROSS-SECTION

A48

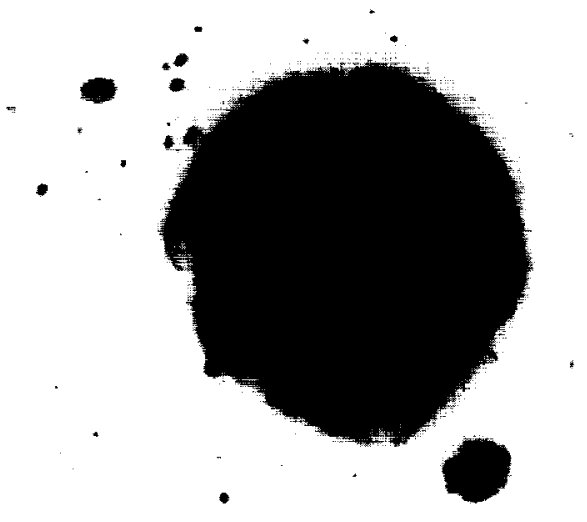




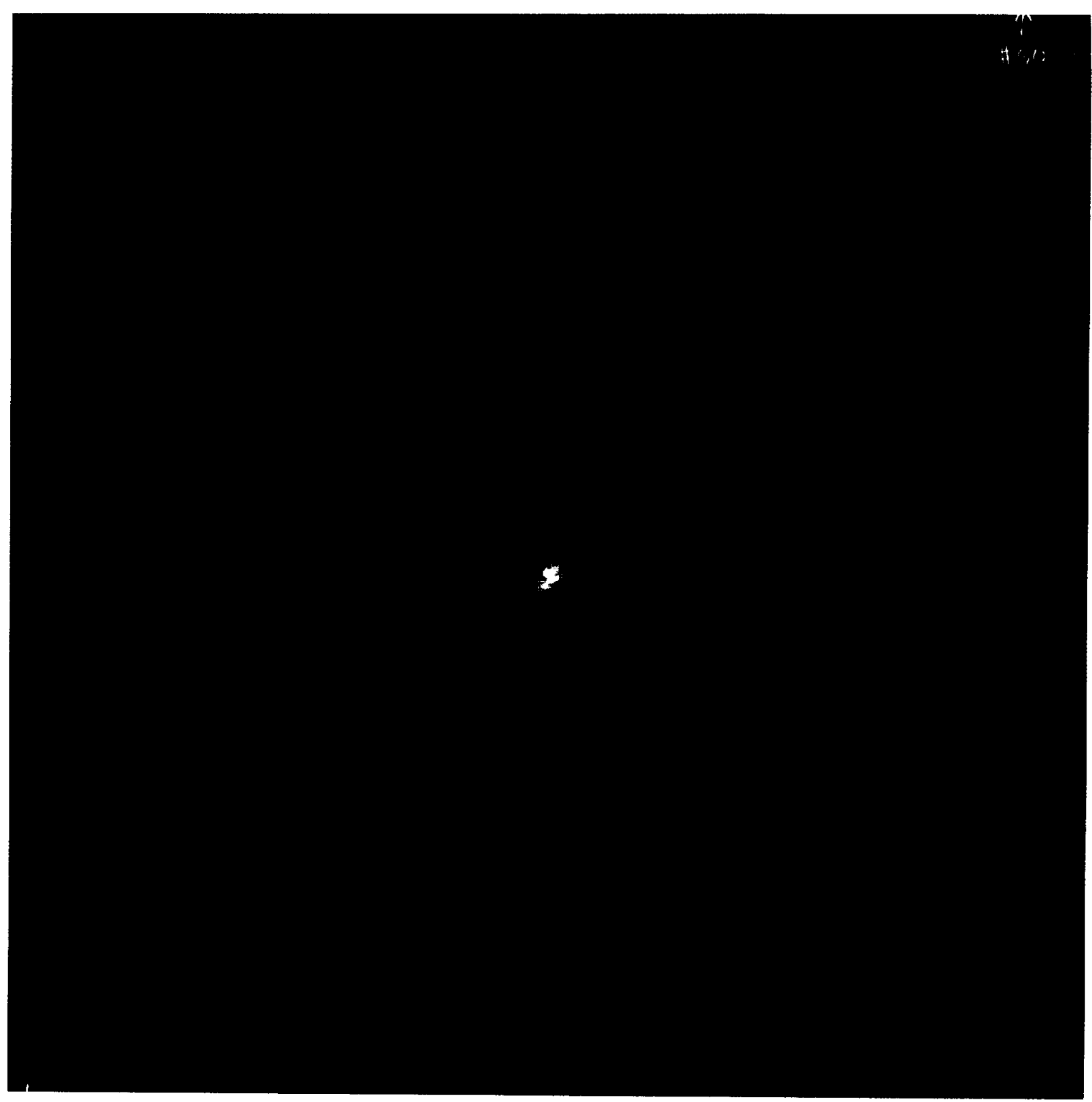



SHOT \# 83

PROJECTILE: Soda Lime

$\mathrm{D}_{\mathrm{p}}=3175 \mu \mathrm{m}$

$\mathrm{V}=4.17 \mathrm{~km} / \mathrm{s}$

TARGET: Teflon

$\mathrm{T}=7950 \mu \mathrm{m}$

$D_{p} / T=0.40$

FRONT

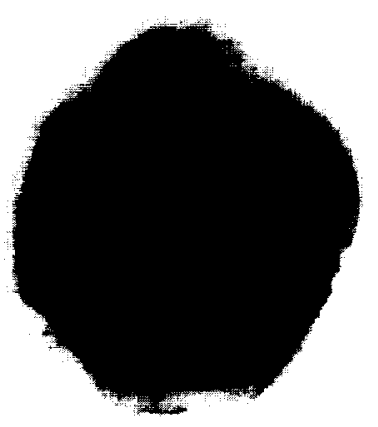

REAR

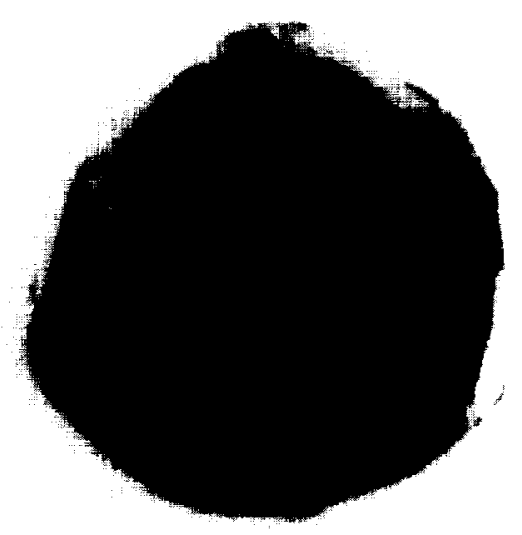

CROSS-SECTION

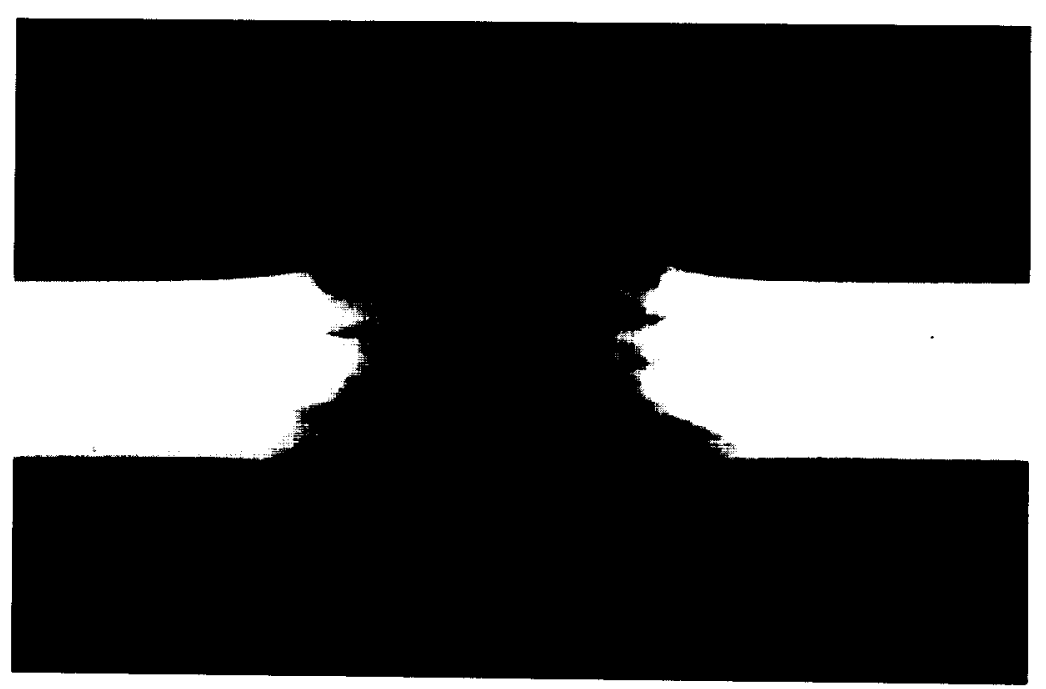



SHOT \# 83

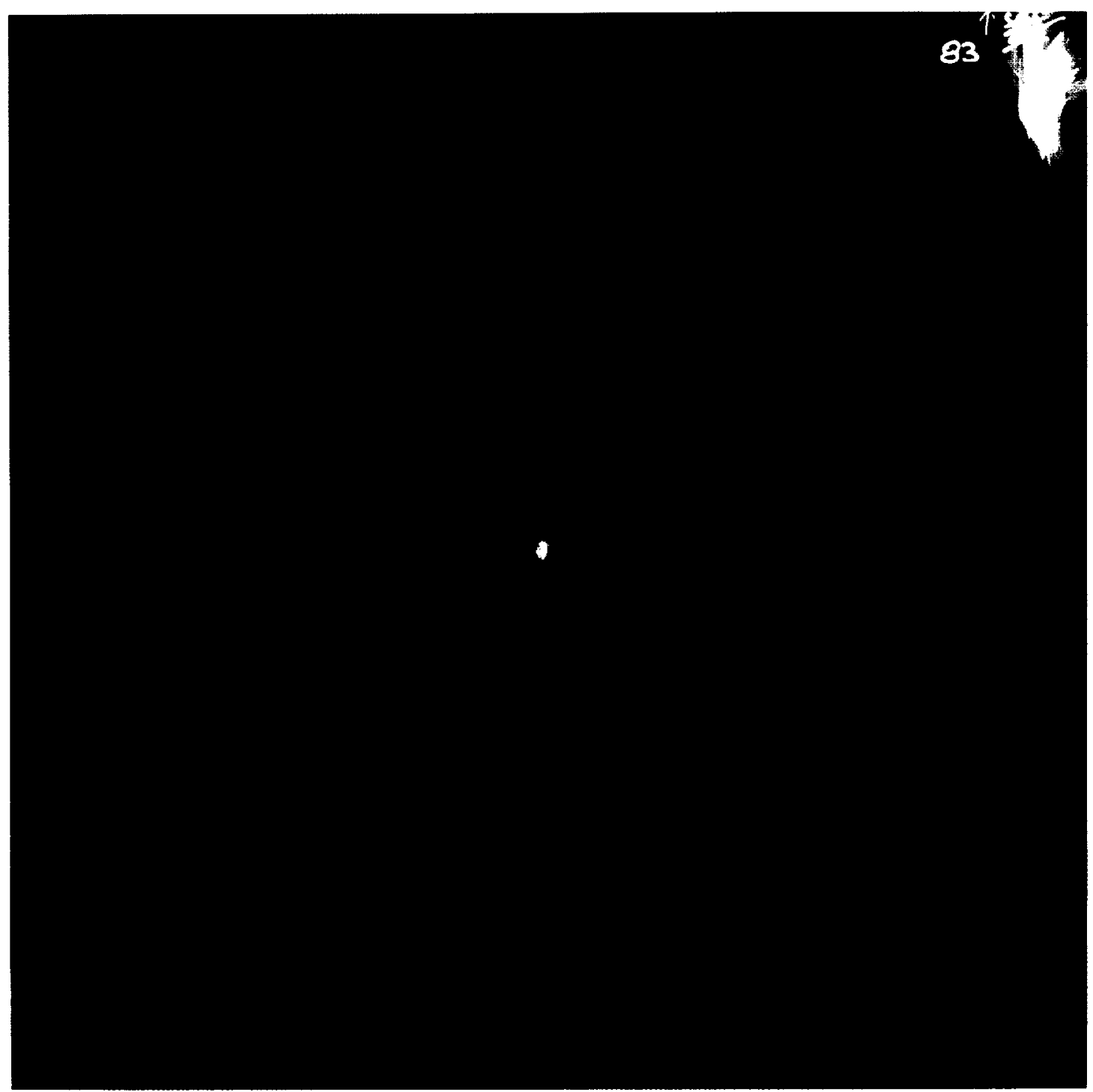



SHOT \# 78

PROJECTILE: Soda Lime

$\begin{aligned} D_{\mathrm{p}} & =3175 \mu \mathrm{m} \\ \mathrm{V} & =4.12 \mathrm{~km} / \mathrm{s}\end{aligned}$

TARGET: Teflon

$\begin{aligned} \mathrm{T} & =2985 \mu \mathrm{m} \\ \mathrm{D}_{\mathrm{p}} / \mathrm{T} & =1.06\end{aligned}$

FRONT

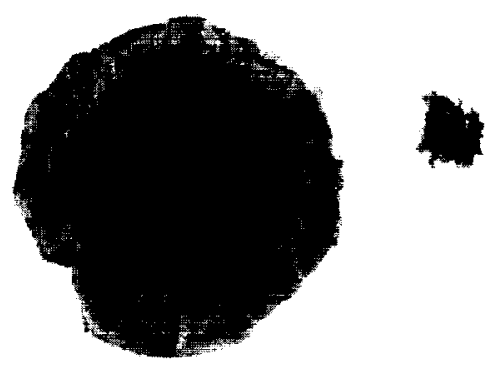

REAR

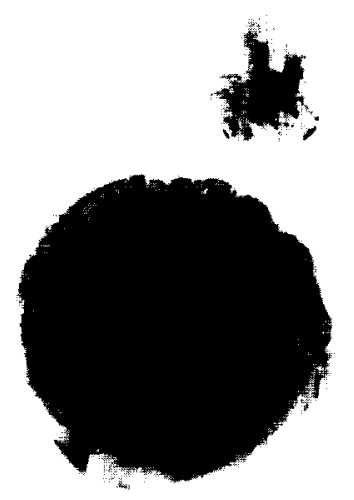

CROSS-SECTION

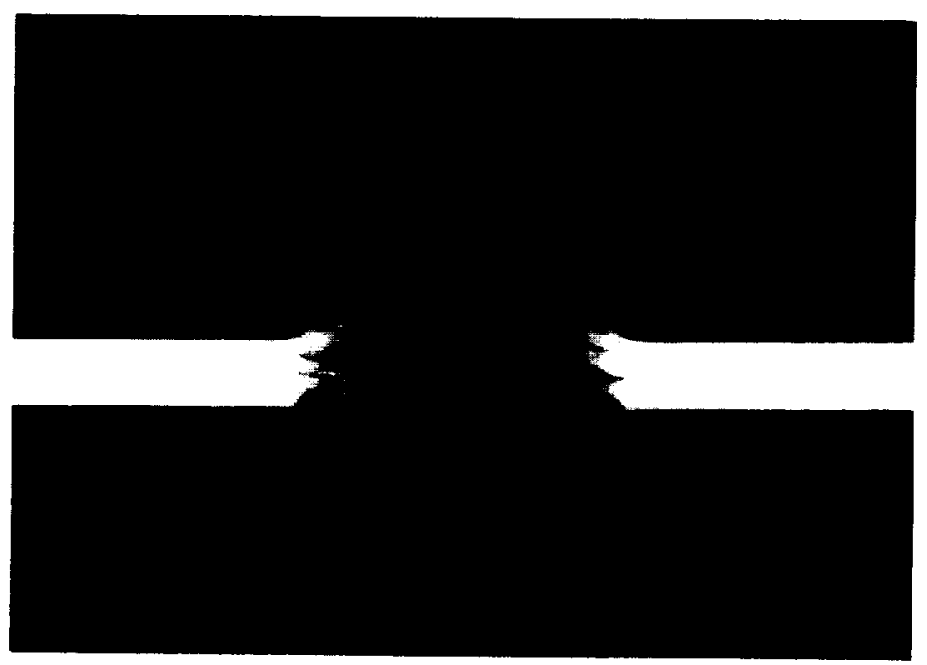





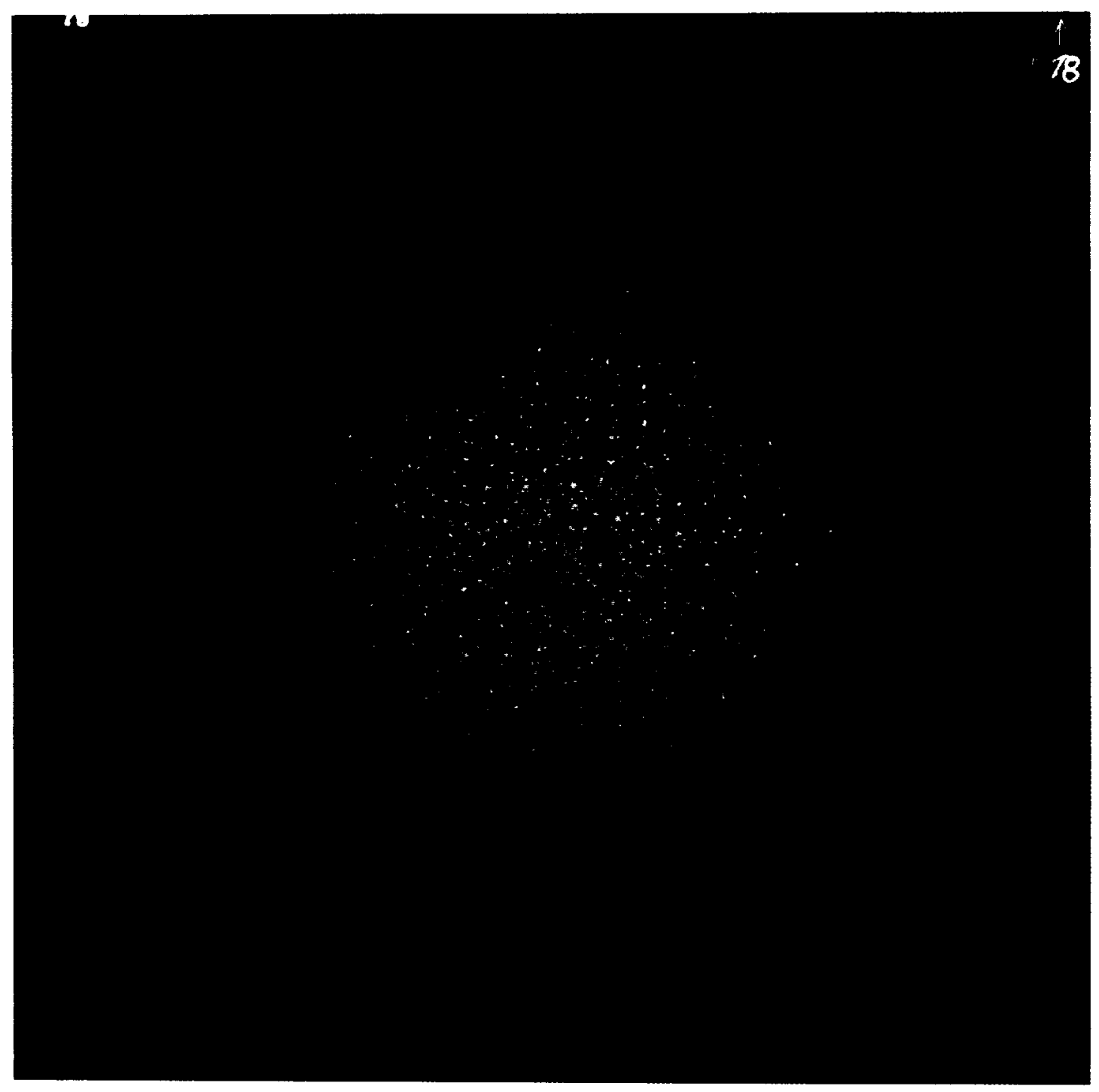



SHOT \# 80

PROJECTILE: Soda Lime

$\mathrm{D}_{\mathrm{p}}=3175 \mu \mathrm{m}$

$\mathrm{V}=4.19 \mathrm{~km} / \mathrm{s}$

TARGET: Teflon

$\mathrm{T}=2920 \mu \mathrm{m}$

$\mathrm{D}_{\mathrm{p}} / \mathrm{T}=1.09$

FRONT

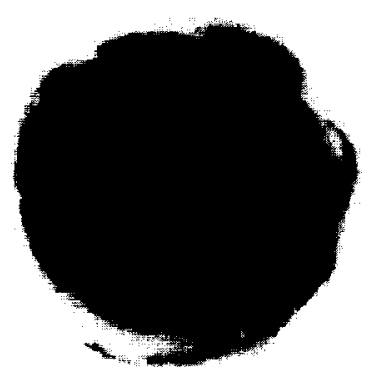

REAR

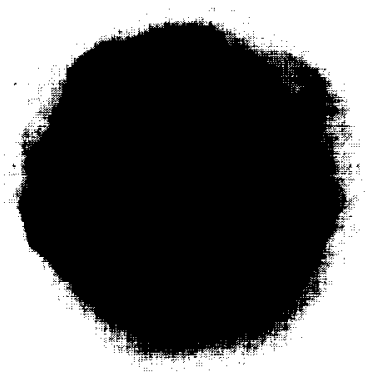

CROSS-SECTION

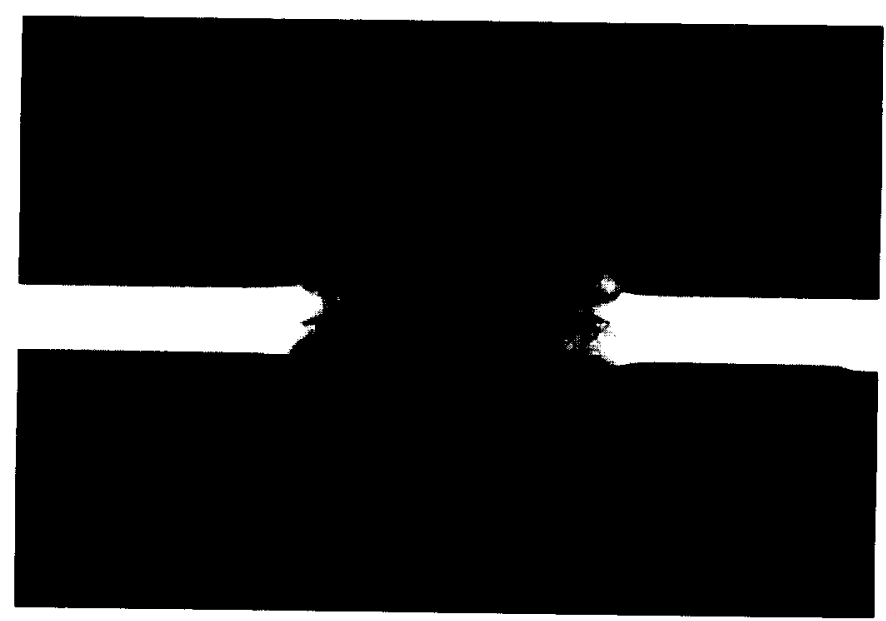



SHOT \# 80

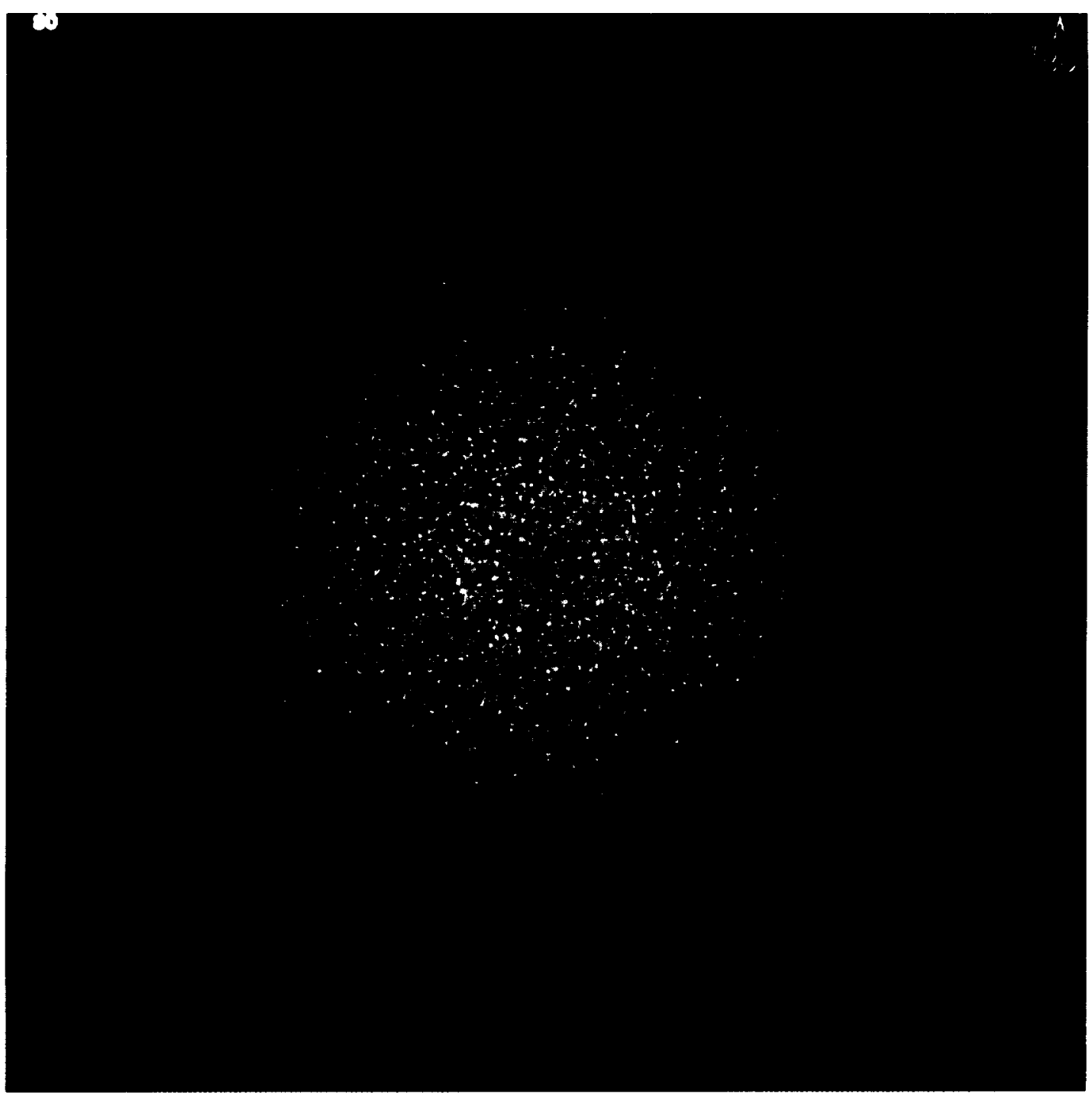



SHOT \# 81

PROJECTILE: Soda Lime

$\mathrm{D}_{\mathrm{p}}=3175 \mu \mathrm{m}$

$\mathrm{V}=3.76 \mathrm{~km} / \mathrm{s}$

TARGET: Teflon

$\begin{aligned} T & =2019 \mu \mathrm{m}\end{aligned}$

$\mathrm{D}_{\mathrm{p}} / \mathrm{T}=1.57$

FRONT

REAR

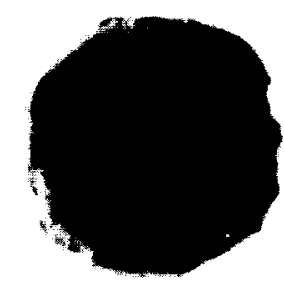

CROSS-SECTION

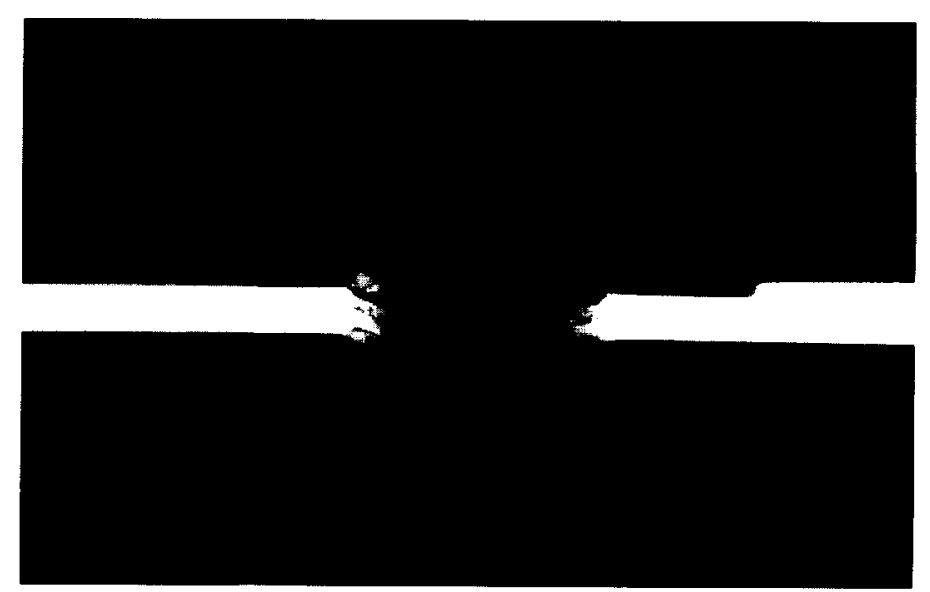



SHOT \# 81 


SHOT \# 84

PROJECTILE: Soda Lime

$$
\begin{aligned}
\mathrm{D}_{\mathrm{p}} & =3175 \mu \mathrm{m} \\
\mathrm{V} & =4.03 \mathrm{~km} / \mathrm{s}
\end{aligned}
$$

TARGET: Teflon

$$
\begin{aligned}
\mathrm{T} & =500 \mu \mathrm{m} \\
\mathrm{D}_{\mathrm{p}} / \mathrm{T} & =6.35
\end{aligned}
$$
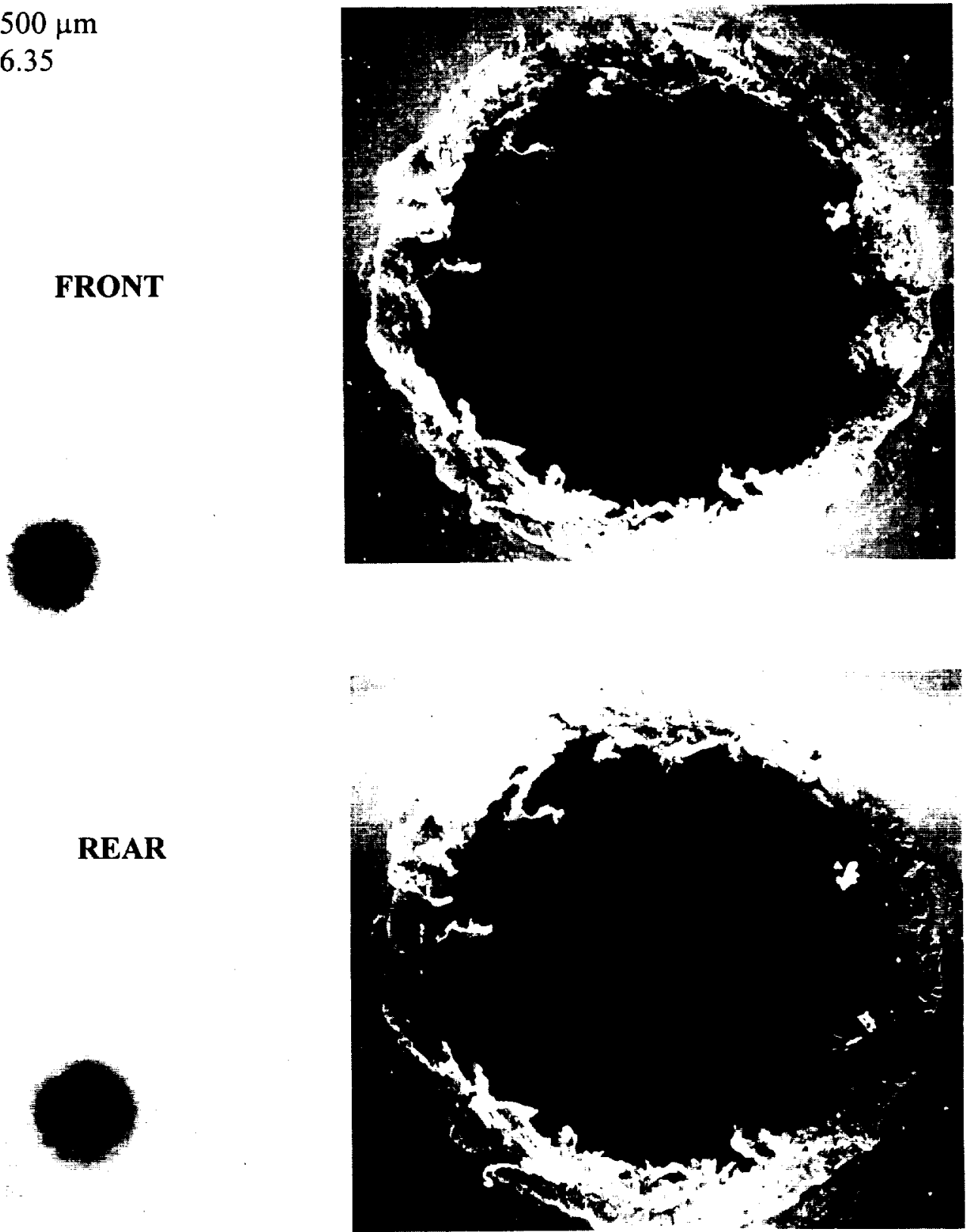

CROSS-SECTION 
SHOT \# 84

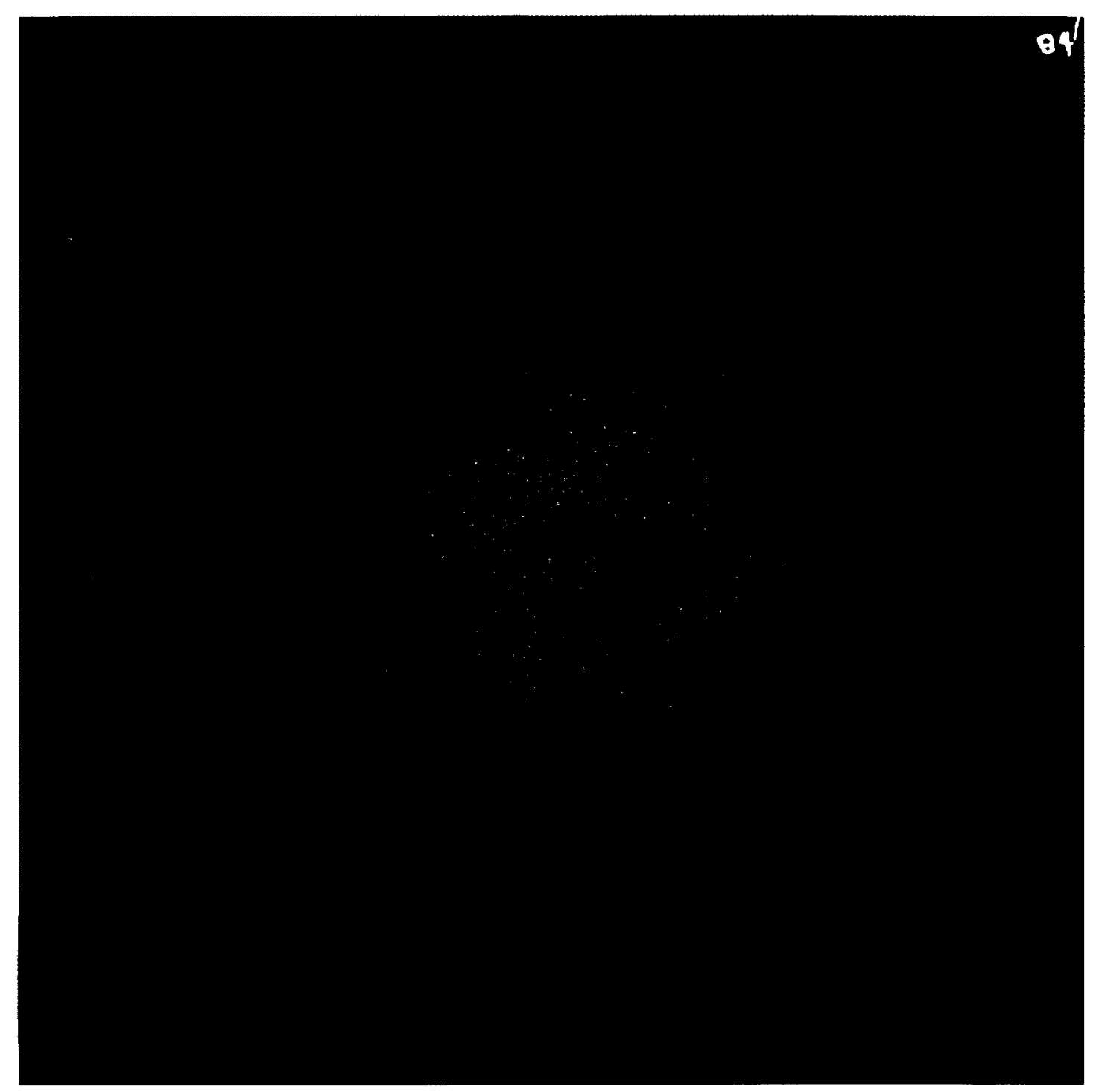




SHOT \# 85

PROJECTILE: Soda Lime

$$
\begin{aligned}
\mathrm{D}_{\mathrm{p}} & =3175 \mu \mathrm{m} \\
\mathrm{V} & =4.12 \mathrm{~km} / \mathrm{s}
\end{aligned}
$$

\section{TARGET: Teflon}

$$
\begin{aligned}
\mathrm{T} & =250 \mu \mathrm{m} \\
\mathrm{D}_{\mathrm{p}} / \mathrm{T} & =12.70
\end{aligned}
$$
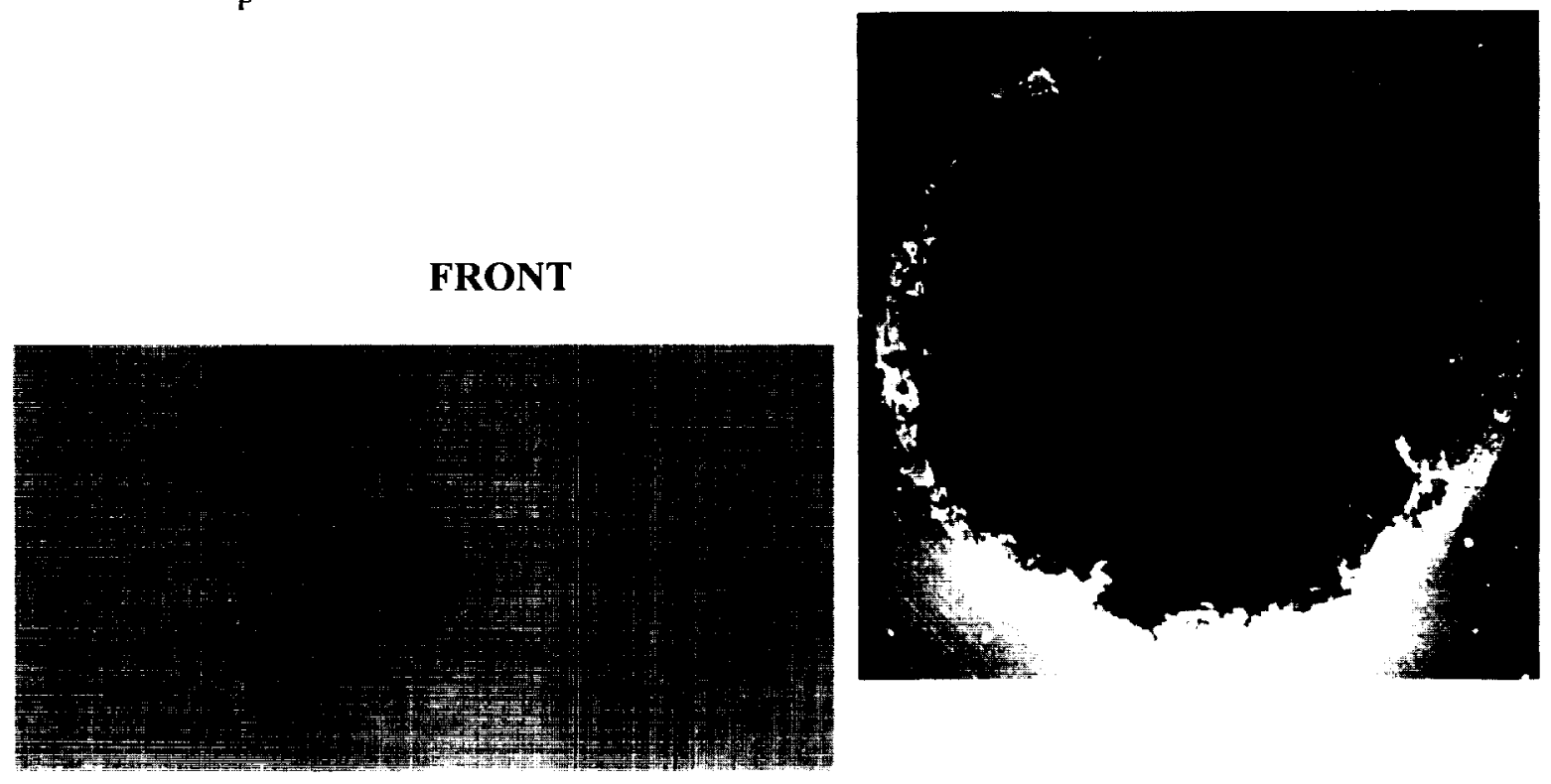

REAR

\section{CROSS-SECTION}




\section{SHOT \# 85}

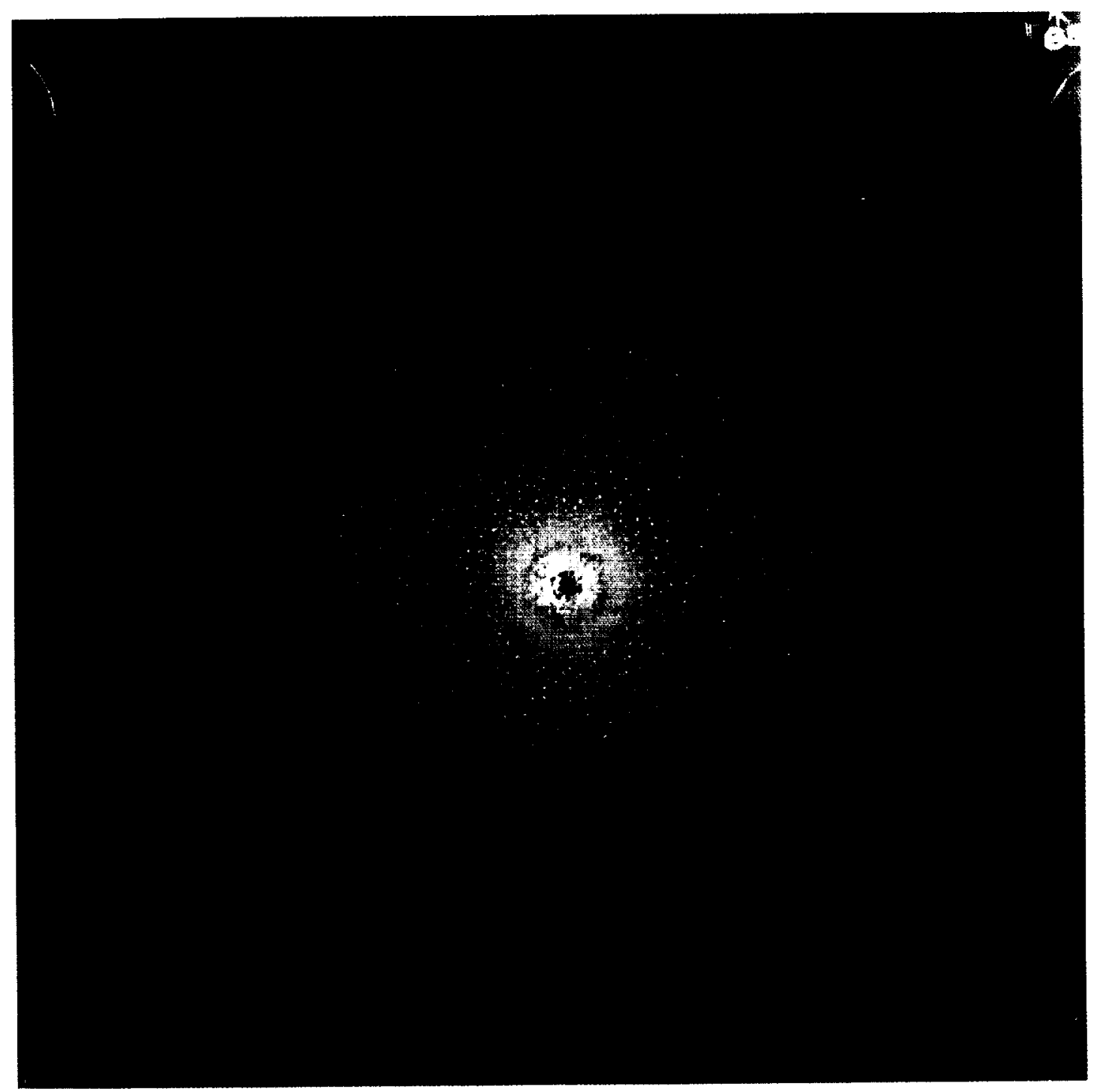




SHOT \# 86

PROJECTILE: Soda Lime

$$
\begin{aligned}
\mathrm{D}_{\mathrm{p}} & =3175 \mu \mathrm{m} \\
\mathrm{V} & =4.16 \mathrm{~km} / \mathrm{s}
\end{aligned}
$$

TARGET: Teflon

$$
\begin{aligned}
\mathrm{T} & =100 \mu \mathrm{m} \\
\mathrm{D}_{\mathrm{p}} / \mathrm{T} & =\mathbf{3 1 . 7 5}
\end{aligned}
$$

FRONT

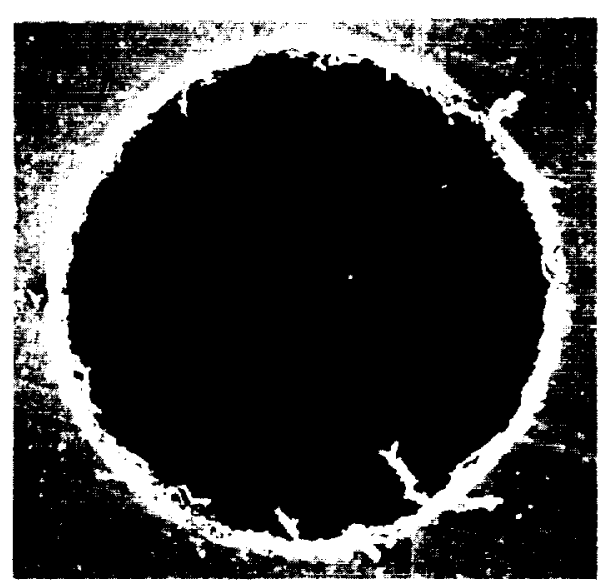

REAR

\section{CROSS-SECTION}




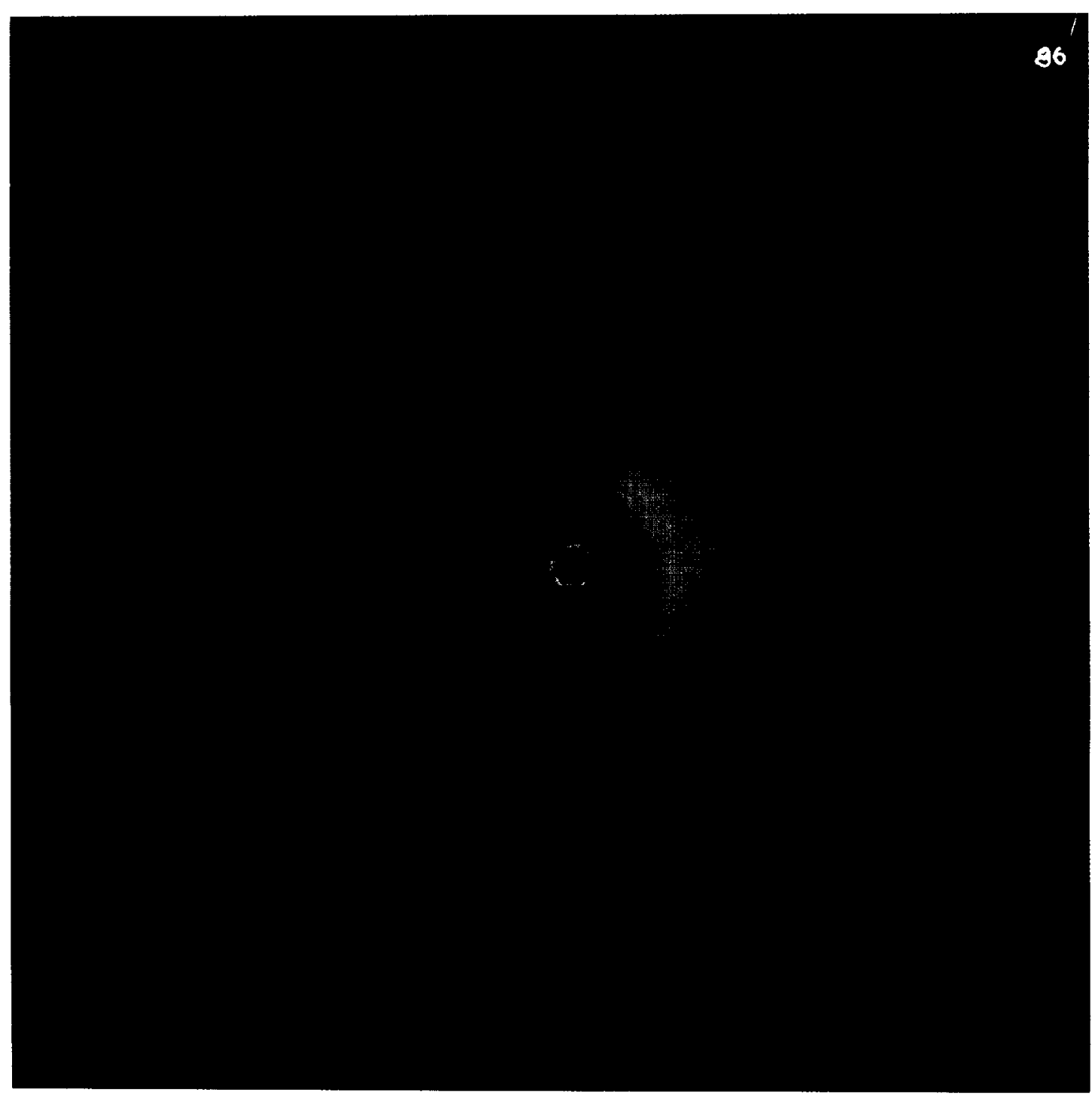



SHOT \# 87

PROJECTILE: Soda Lime

$$
\begin{aligned}
D_{p} & =3175 \mu \mathrm{m} \\
V & =4.12 \mathrm{~km} / \mathrm{s}
\end{aligned}
$$

\section{TARGET: Teflon}

$$
\mathrm{T}=6 \mu \mathrm{m}
$$

$D_{p} / T=529.17$

\section{FRONT}

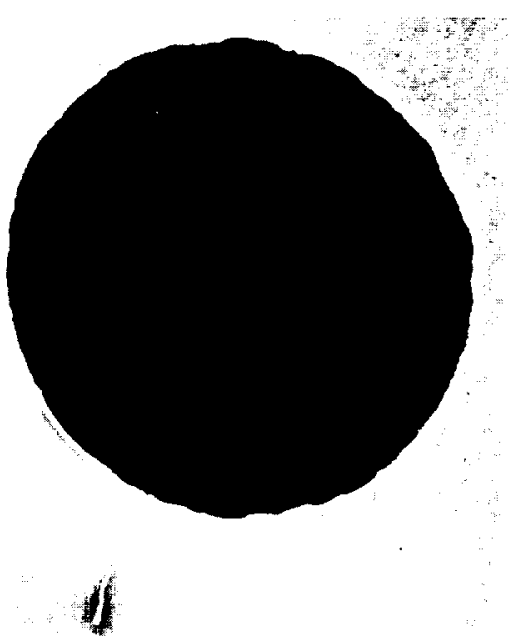

REAR

\section{CROSS-SECTION}


$\therefore \quad, \quad \therefore$ 


\section{SHOT \# 87}

O 



\section{Page Intentionally Left Blank}


$\vdots$

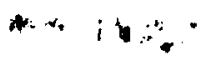

、

" 
PROJECTLE: Soda Lime

$$
\begin{aligned}
\mathrm{D}_{\mathrm{p}} & =3175 \mu \mathrm{m} \\
\mathrm{V} & =5.87 \mathrm{~km} / \mathrm{s}
\end{aligned}
$$

\section{TARGET: Teflon}

$$
\begin{aligned}
\mathrm{T} & =15875 \mu \mathrm{m} \\
\mathrm{D}_{\mathrm{p}} / \mathrm{T} & =0.20
\end{aligned}
$$

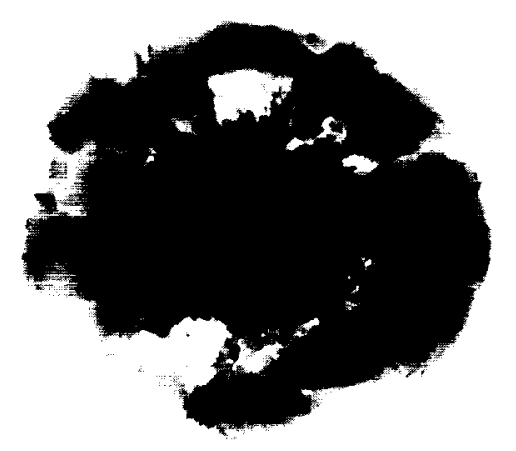

REAR

\section{CROSS-SECTION}


SHOT \# 433

PROJECTILE: Soda Lime

$$
\begin{aligned}
D_{p} & =3175 \mu \mathrm{m} \\
V & =5.90 \mathrm{~km} / \mathrm{s}
\end{aligned}
$$

TARGET: Teflon

$T=12700 \mu \mathrm{m}$

$D_{p} / T=0.25$

FRONT

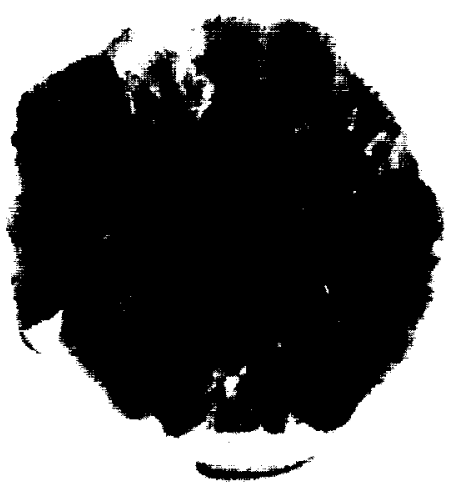

REAR 
SHOT \# 433

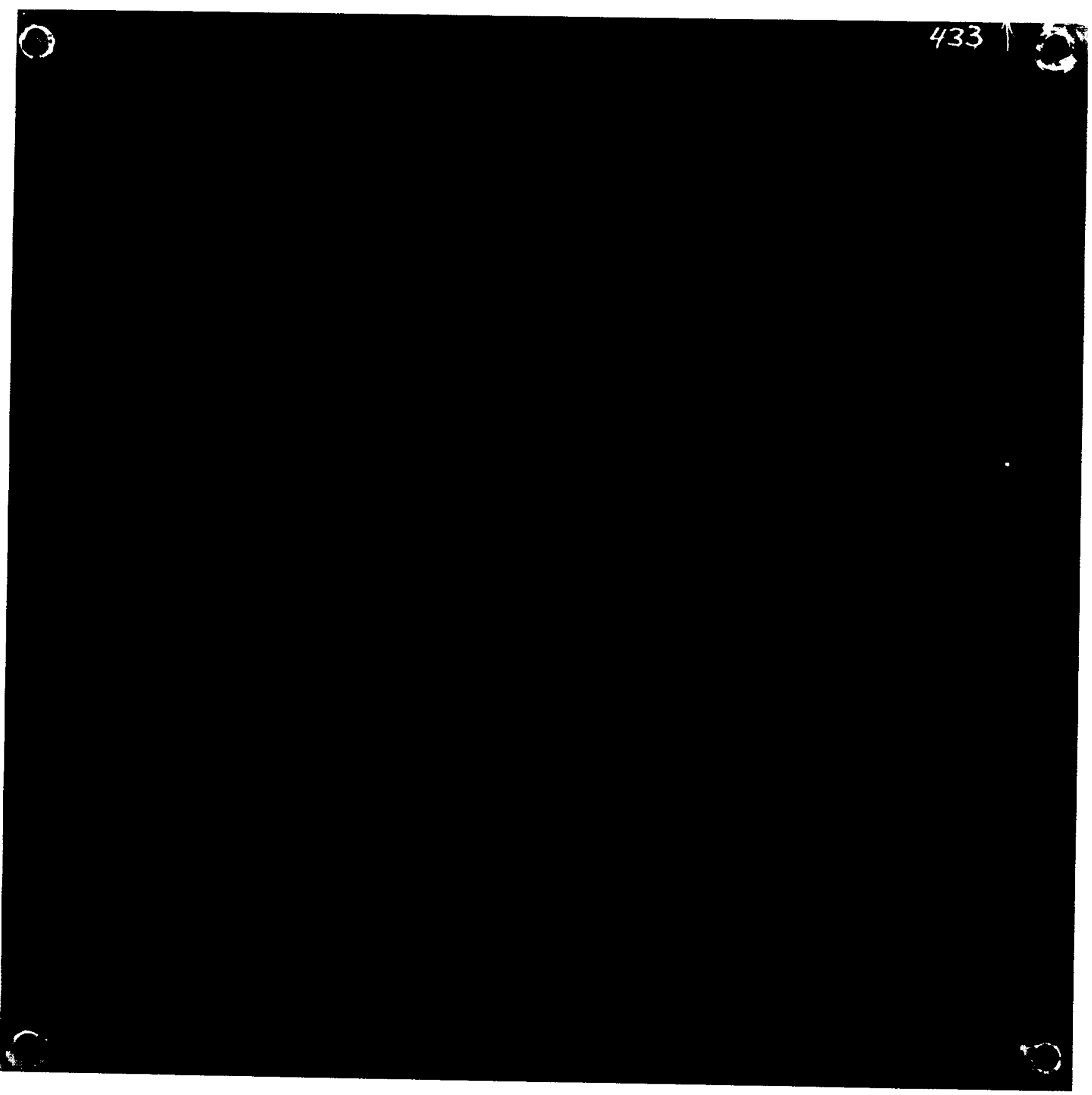


SHOT \# 432

PROJECTILE: Soda Lime

$$
\begin{aligned}
D_{p} & =3175 \mu \mathrm{m} \\
V & =6.04 \mathrm{~km} / \mathrm{s}
\end{aligned}
$$

TARGET: Teflon

$$
\begin{aligned}
\mathrm{T} & =9590 \mu \mathrm{m} \\
\mathrm{D}_{\mathrm{p}} / \mathrm{T} & =0.33
\end{aligned}
$$

FRONT

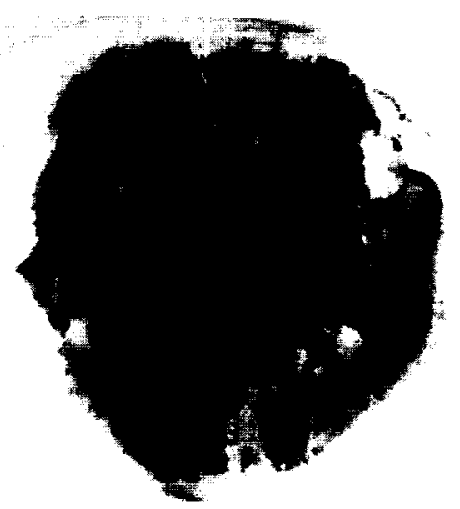

REAR

\section{CROSS-SECTION}



SHOT \# $\mathbf{4 3 2}$

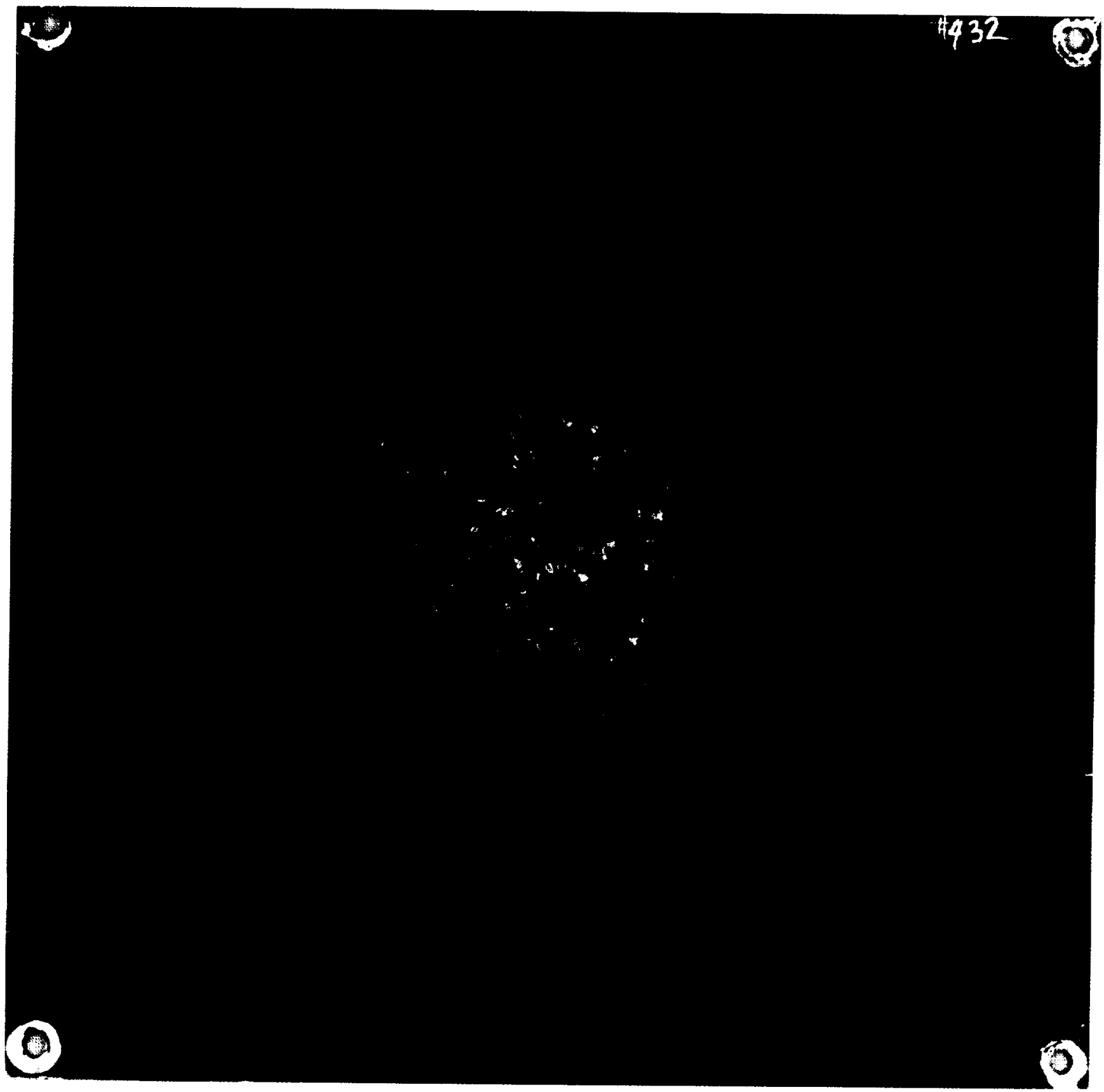




SHOT \# 429

PROJECTILE: Soda Lime

$$
\begin{aligned}
\mathrm{D}_{\mathrm{p}} & =3175 \mu \mathrm{m} \\
\mathrm{V} & =5.97 \mathrm{~km} / \mathrm{s}
\end{aligned}
$$

TARGET: Teflon

$$
\begin{aligned}
\mathrm{T} & =2920 \mu \mathrm{m} \\
\mathrm{D}_{\mathrm{p}} / \mathrm{T} & =1.09
\end{aligned}
$$

FRONT

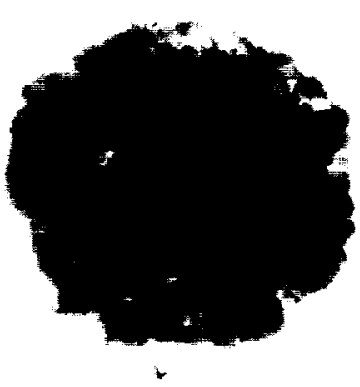

REAR

\section{CROSS-SECTION}


SHOT \# 429

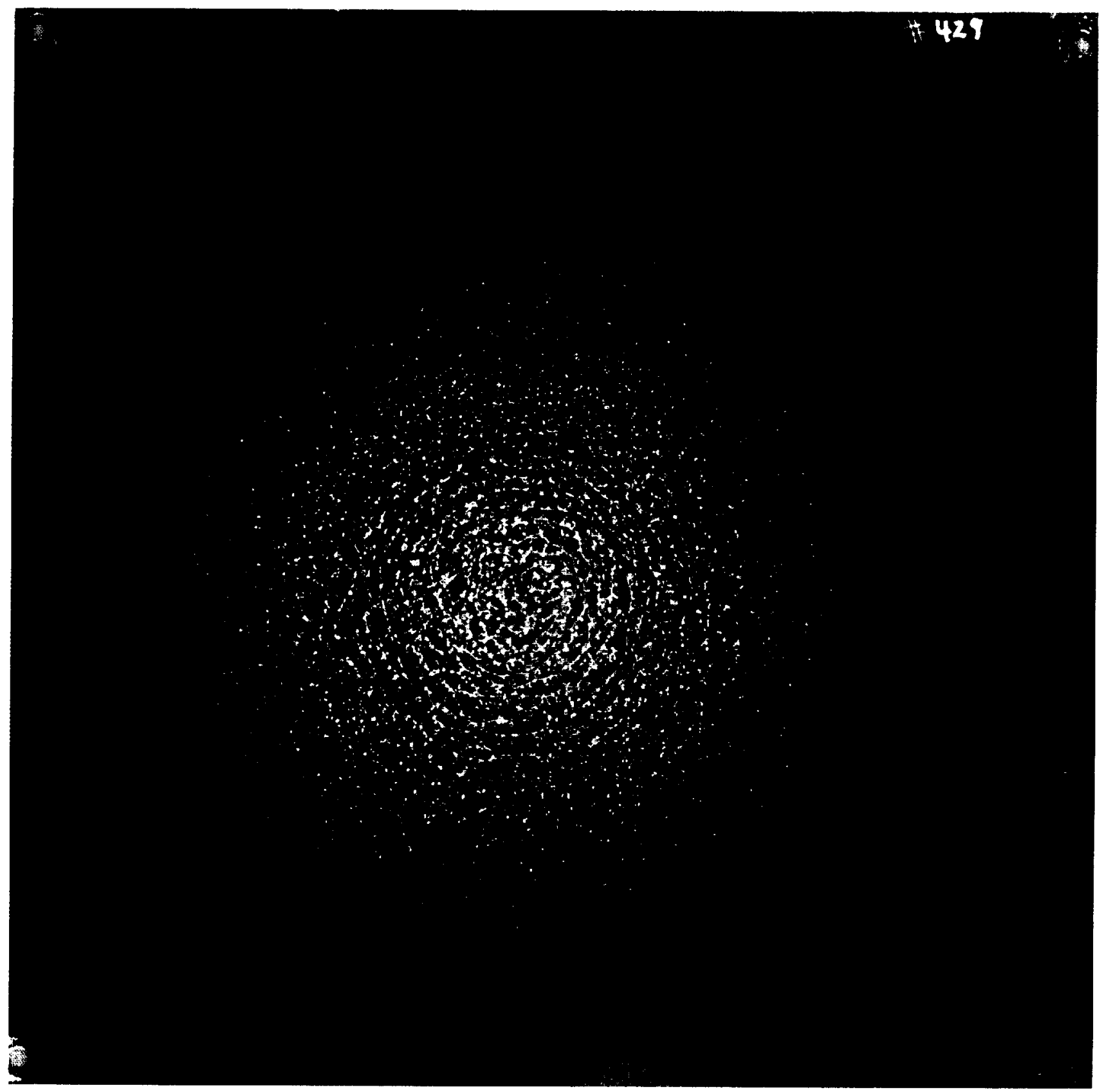



SHOT \# 428

PROJECTILE: Soda Lime

$$
\begin{aligned}
\mathrm{D}_{\mathrm{p}} & =3175 \mu \mathrm{m} \\
\mathrm{V} & =5.86 \mathrm{~km} / \mathrm{s}
\end{aligned}
$$

TARGET: Teflon

$$
\begin{aligned}
\mathrm{T} & =1588 \mu \mathrm{m} \\
\mathrm{D}_{\mathbf{p}} / \mathrm{T} & =2.00
\end{aligned}
$$

FRONT

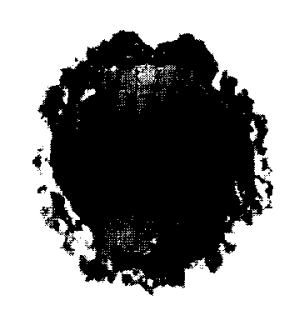

REAR

CROSS-SECTION 



\section{SHOT \# 428}

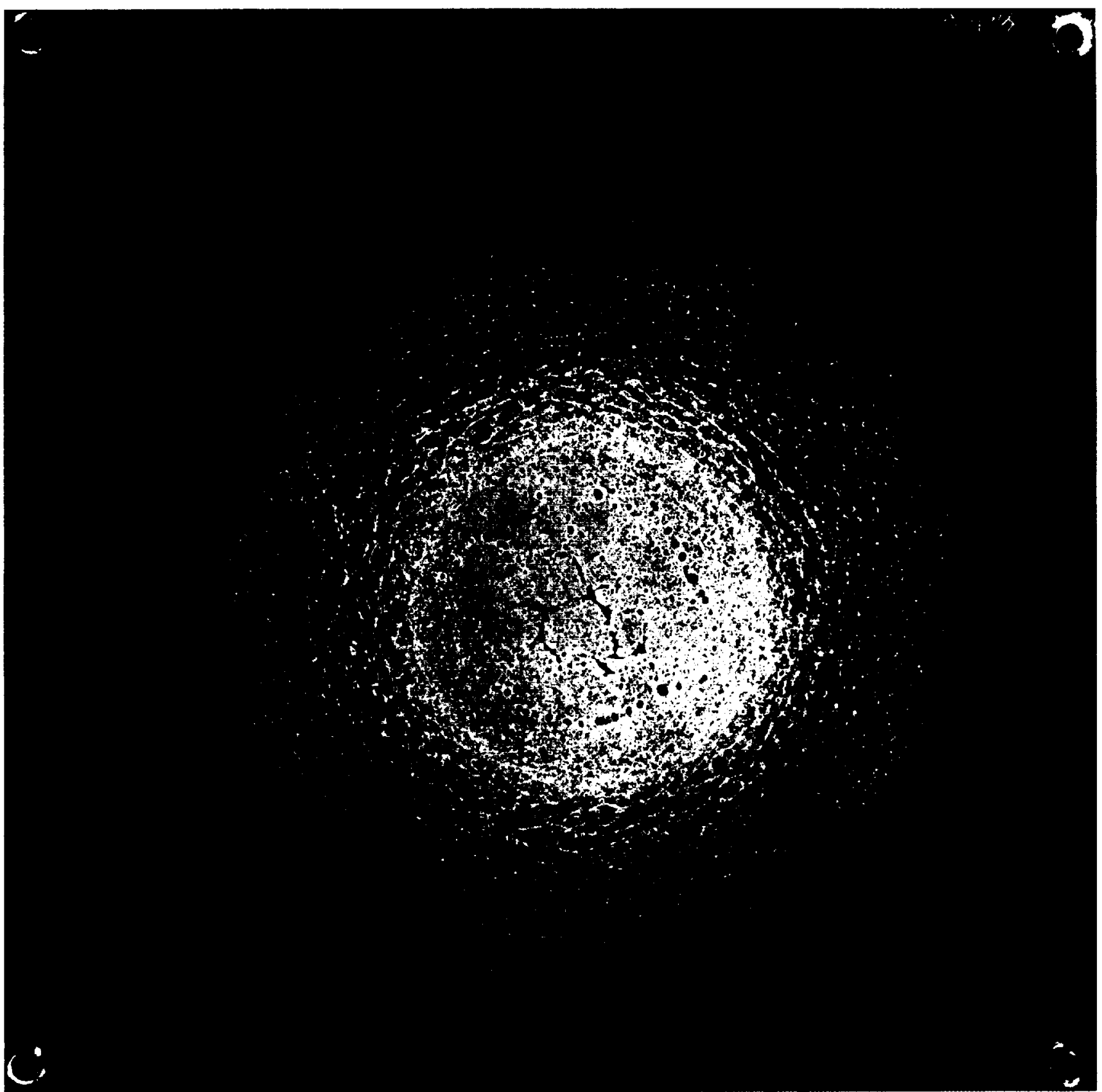



SHOT \# 495

PROJECTILE: Soda Lime

$\begin{aligned} \mathrm{D}_{\mathrm{p}} & =3175 \mu \mathrm{m} \\ \mathrm{V} & =6.04 \mathrm{~km} / \mathrm{s}\end{aligned}$

TARGET: Teflon

$\mathrm{T}=787 \mu \mathrm{m}$

$\mathrm{D}_{\mathrm{p}} / \mathrm{T}=4.03$

FRONT

REAR

CROSS-SECTION 
SHOT \# 495

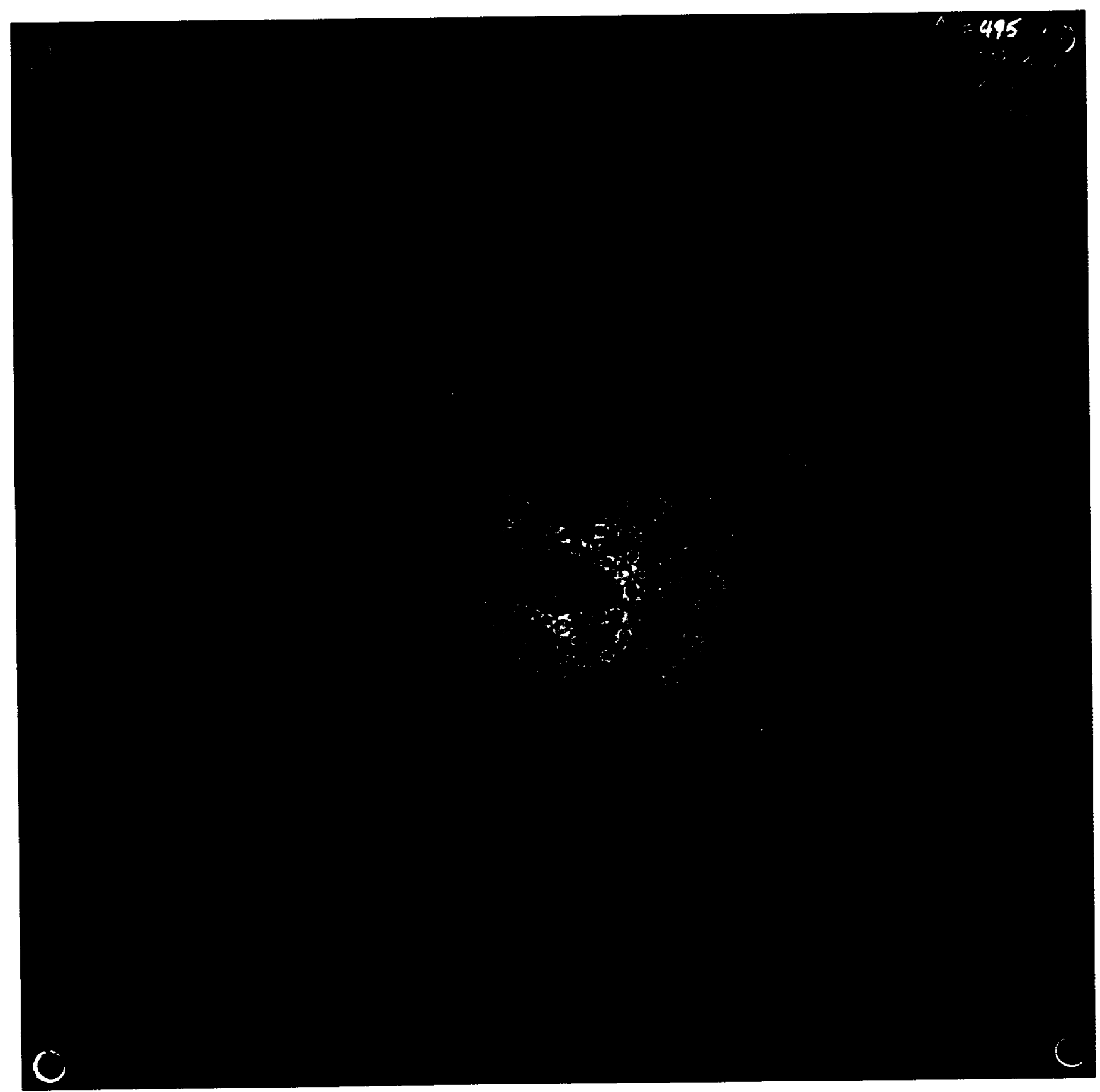





\section{SHOT \# 497}

PROJECTILE: Soda Lime

$\begin{aligned} \mathrm{D}_{\mathrm{p}} & =3175 \mu \mathrm{m} \\ \mathrm{V} & =6.07 \mathrm{~km} / \mathrm{s}\end{aligned}$

TARGET: Teflon

$$
\begin{aligned}
\mathrm{T} & =533 \mu \mathrm{m} \\
\mathrm{D}_{\mathrm{p}} / \mathrm{T} & =5.96
\end{aligned}
$$

\section{CROSS-SECTION}



SHOT \# 497

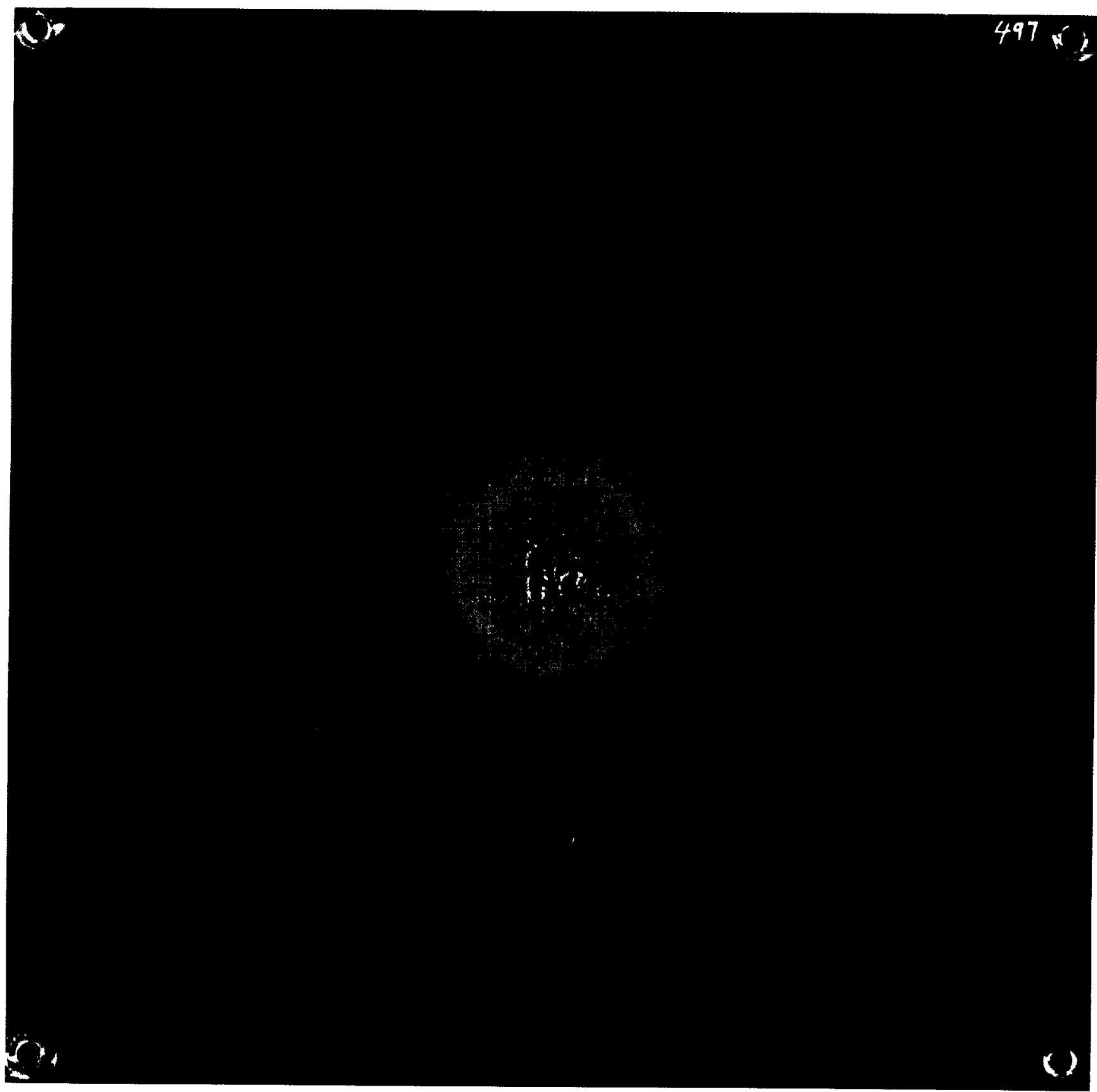



SHOT \# 501

PROJECTILE: Soda Lime

$D_{p}=3175 \mu \mathrm{m}$

$\mathrm{V}=5.96 \mathrm{~km} / \mathrm{s}$

\section{TARGET: Teflon}

$\mathrm{T}=254 \mu \mathrm{m}$

$\mathrm{D}_{\mathrm{p}} / \mathrm{T}=12.50$

FRONT

REAR

CROSS-SECTION 

SHOT \# 501

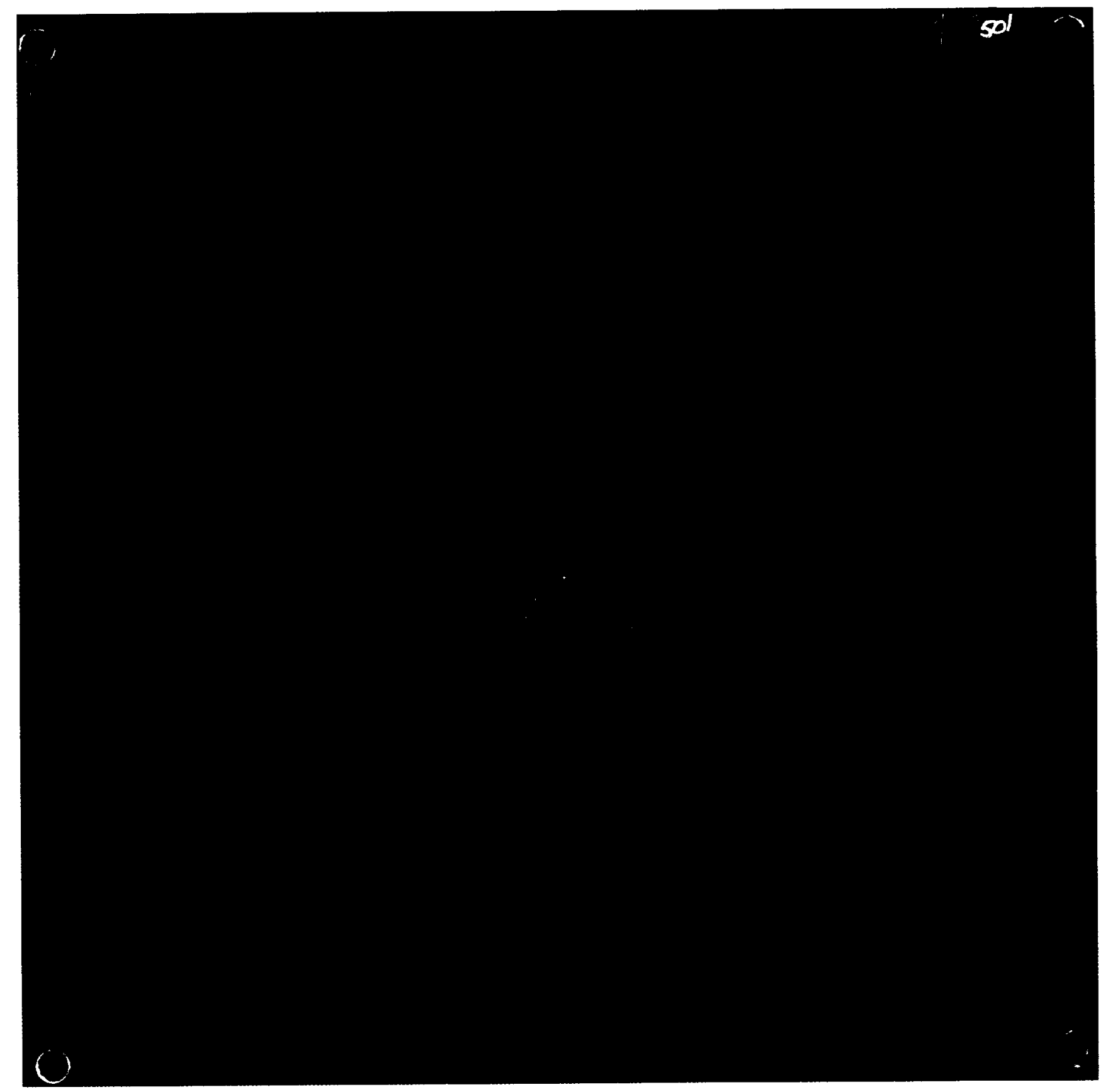






\section{SHOT \# 505}

PROJECTILE: Soda Lime

$$
\begin{aligned}
\mathrm{D}_{\mathrm{p}} & =3175 \mu \mathrm{m} \\
\mathrm{V} & =5.98 \mathrm{~km} / \mathrm{s}
\end{aligned}
$$

TARGET: Teflon

$$
\mathrm{T}=127 \mu \mathrm{m}
$$

$\mathrm{D}_{\mathrm{p}} / \mathrm{T}=25.00$

FRONT

REAR

\section{CROSS-SECTION}




\section{SHOT \# 505}

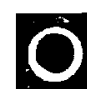

It 505

(1)

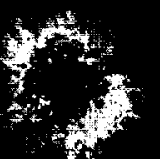

11 




\section{Page Intentionally Left Blank}


PROJECTILE: Soda Lime

$$
\begin{aligned}
\mathrm{D}_{\mathrm{p}} & =3175 \mu \mathrm{m} \\
\mathrm{V} & =6.36 \mathrm{~km} / \mathrm{s}
\end{aligned}
$$

TARGET: Teflon

$$
\begin{aligned}
\mathrm{T} & =23160 \mu \mathrm{m} \\
\mathrm{D}_{\mathrm{p}} / \mathrm{T} & =0.14
\end{aligned}
$$

FRONT
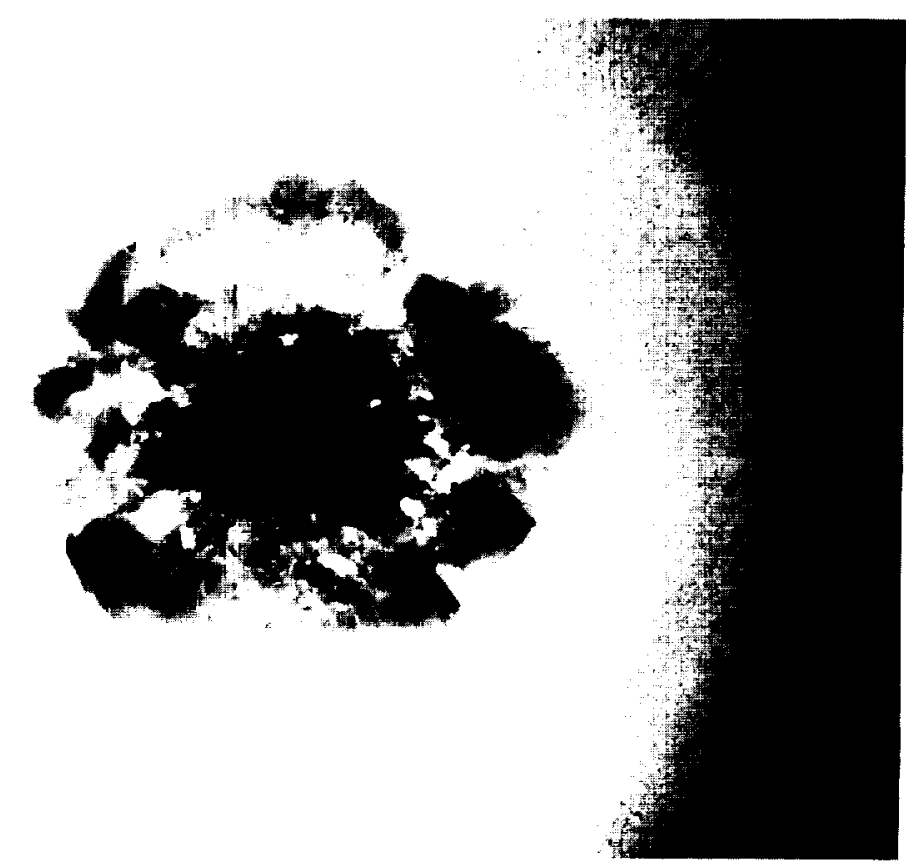

REAR

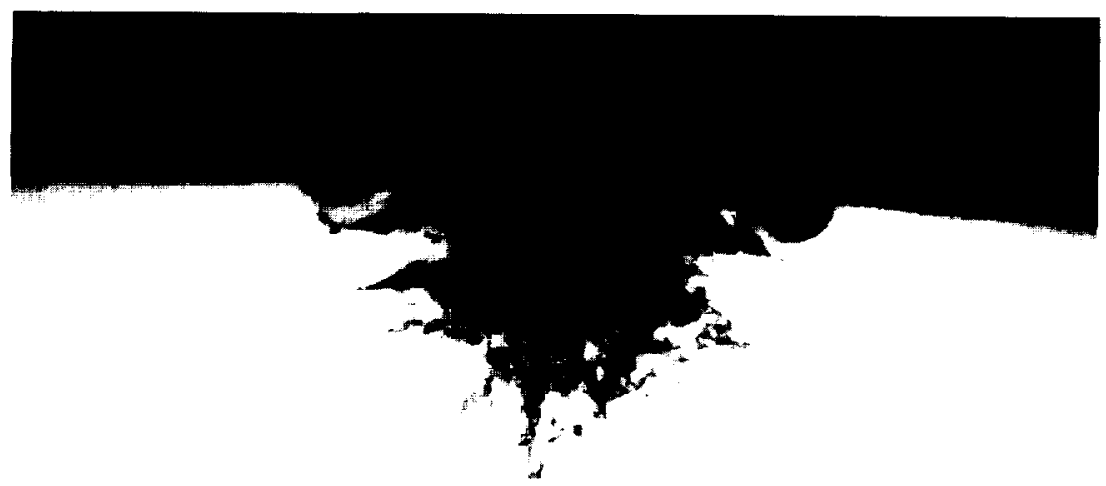

CROSS-SECTION

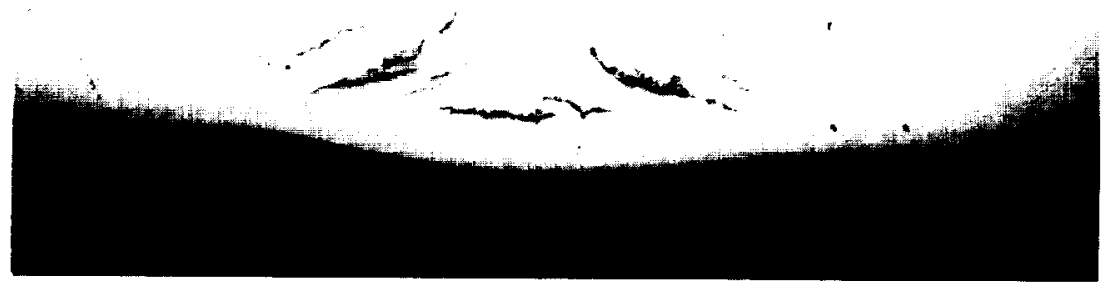


PROJECTILE: Soda Lime

$D_{p}=3175 \mu \mathrm{m}$

$\mathrm{V}=6.40 \mathrm{~km} / \mathrm{s}$

TARGET: Teflon

$$
\begin{aligned}
\mathrm{T} & =21270 \mu \mathrm{m} \\
\mathrm{D}_{\mathrm{p}} / \mathrm{T} & =0.15
\end{aligned}
$$

\section{FRONT}

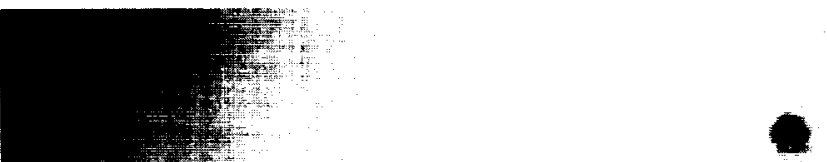

REAR
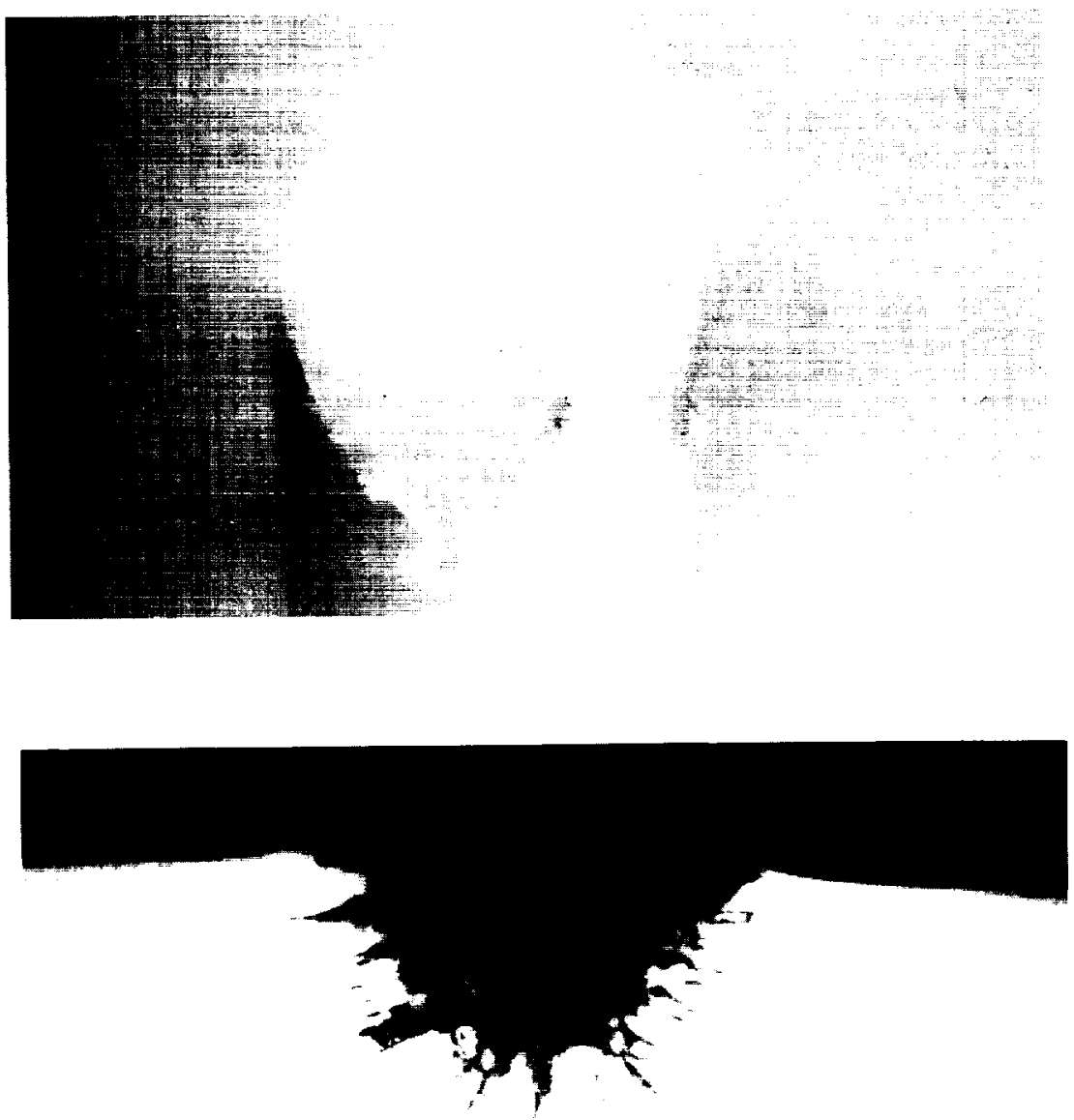

CROSS-SECTION

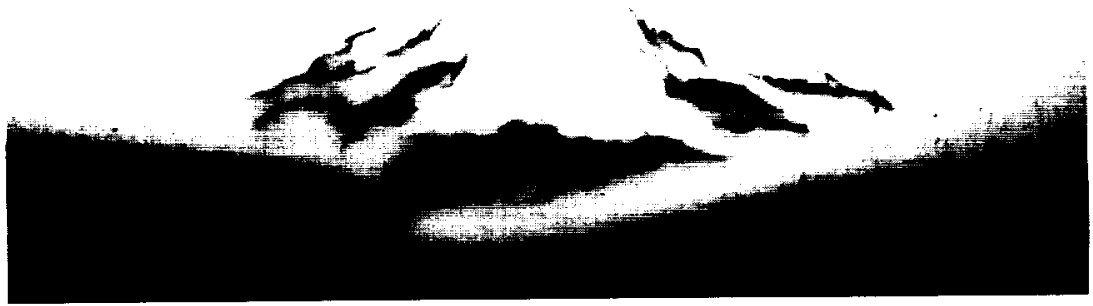


SHOT \# 26

PROJECTILE: Soda Lime $\mathrm{D}_{\mathrm{p}}=3175 \mu \mathrm{m}$

$\mathrm{V}=6.31 \mathrm{~km} / \mathrm{s}$

TARGET: Teflon

$$
\begin{aligned}
\mathrm{T} & =19130 \mu \mathrm{m} \\
\mathrm{D}_{\mathrm{p}} / \mathrm{T} & =0.17
\end{aligned}
$$

FRONT
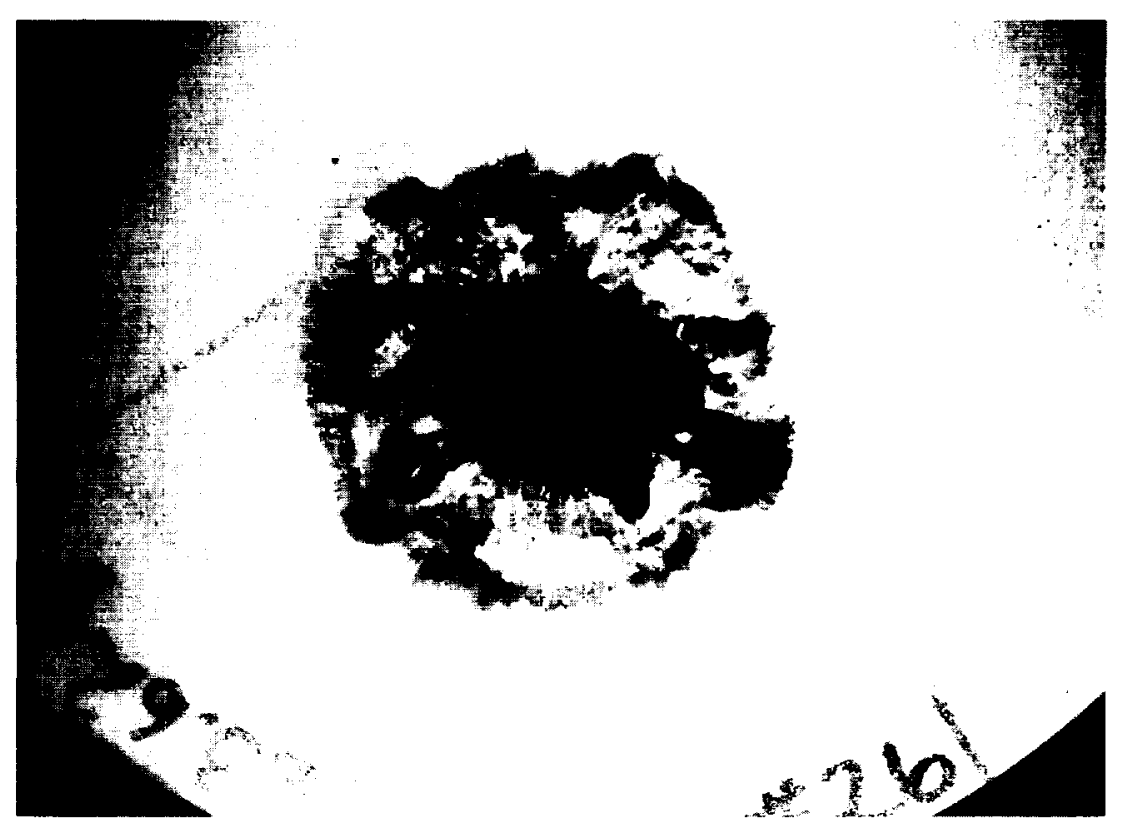

REAR

CROSS-SECTION

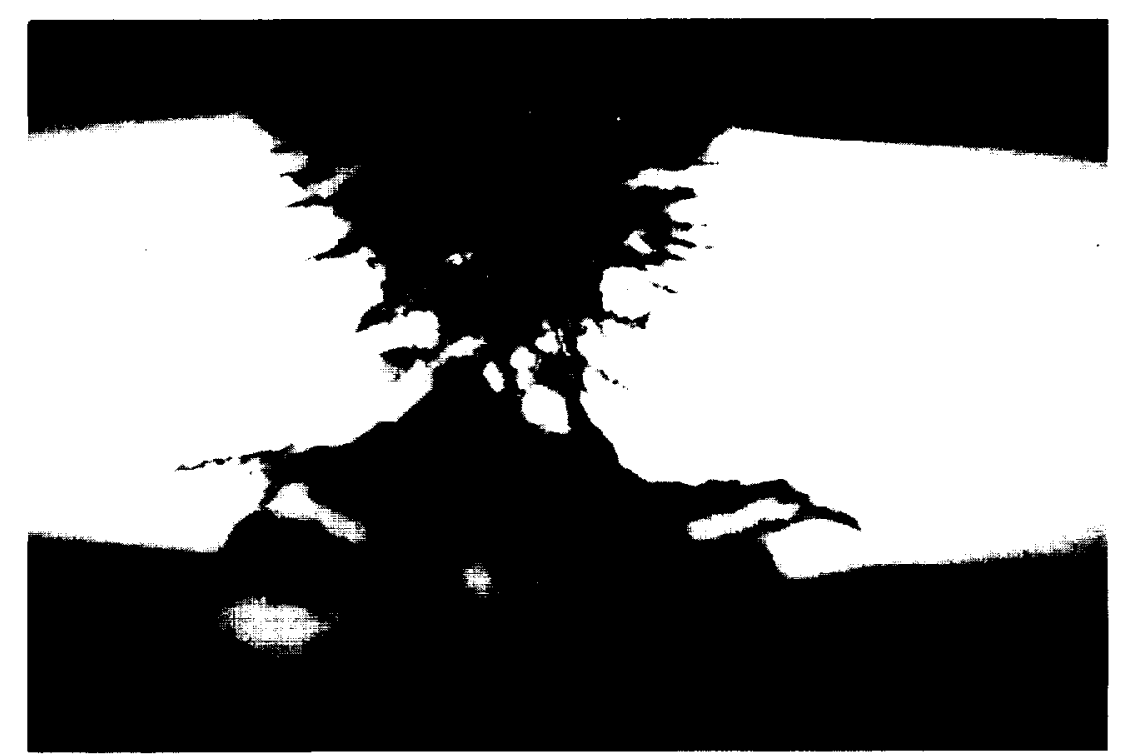


SHOT \# 20

PROJECTILE: Soda Lime

$\mathrm{D}_{\mathrm{p}}=3175 \mu \mathrm{m}$

$\mathrm{V}=6.60 \mathrm{~km} / \mathrm{s}$

TARGET: Teflon

$\begin{aligned} \mathrm{T} & =17463 \mu \mathrm{m} \\ \mathrm{D}_{\mathrm{p}} / \mathrm{T} & =0.18\end{aligned}$

FRONT

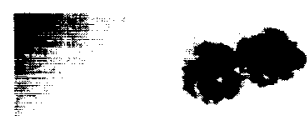

1
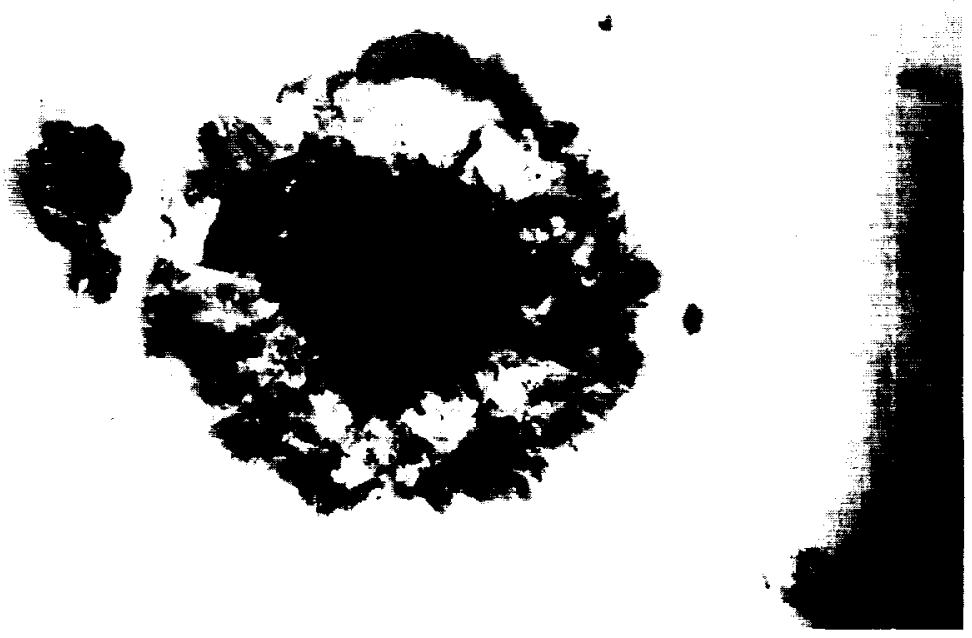

REAR

CROSS-SECTION
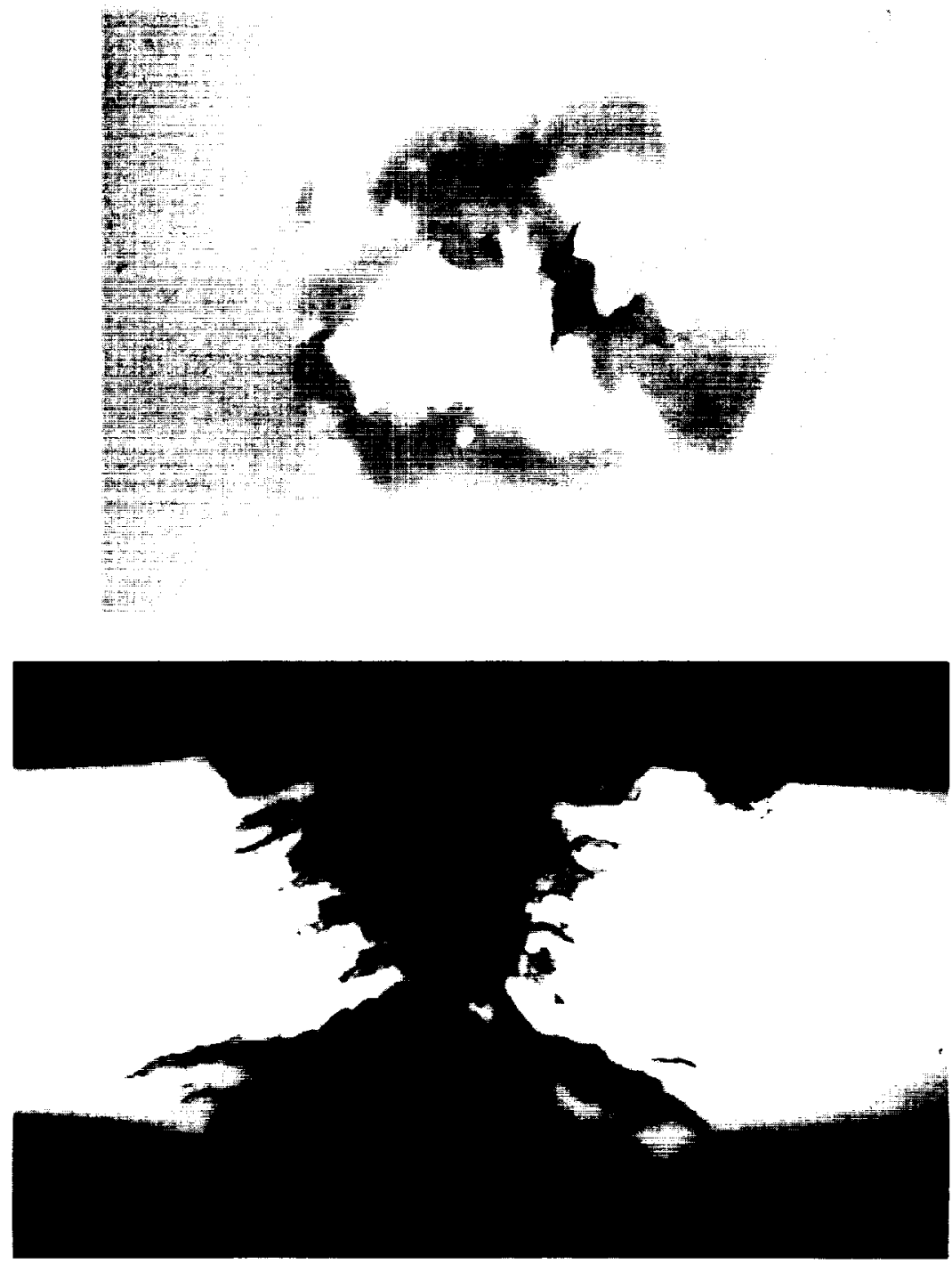


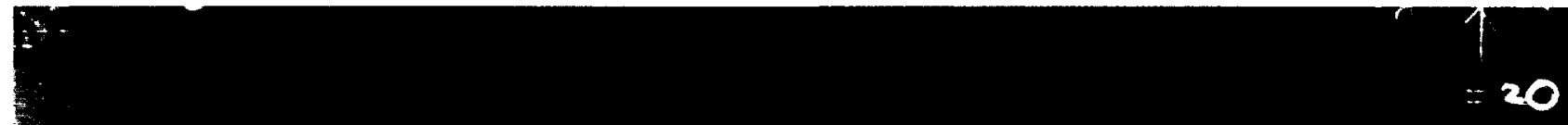




PROJECTILE: Soda Lime

$\mathrm{D}_{\mathrm{p}}=3175 \mu \mathrm{m}$

$\mathrm{V}=6.41 \mathrm{~km} / \mathrm{s}$

TARGET: Teflon

$$
\begin{aligned}
\mathrm{T} & =14275 \mu \mathrm{m} \\
\mathrm{D}_{\mathrm{p}} / \mathrm{T} & =0.22
\end{aligned}
$$

\section{FRONT}

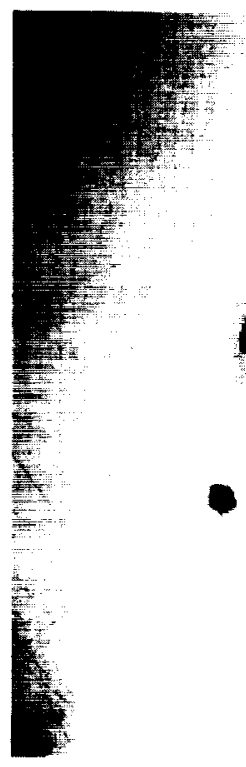

REAR

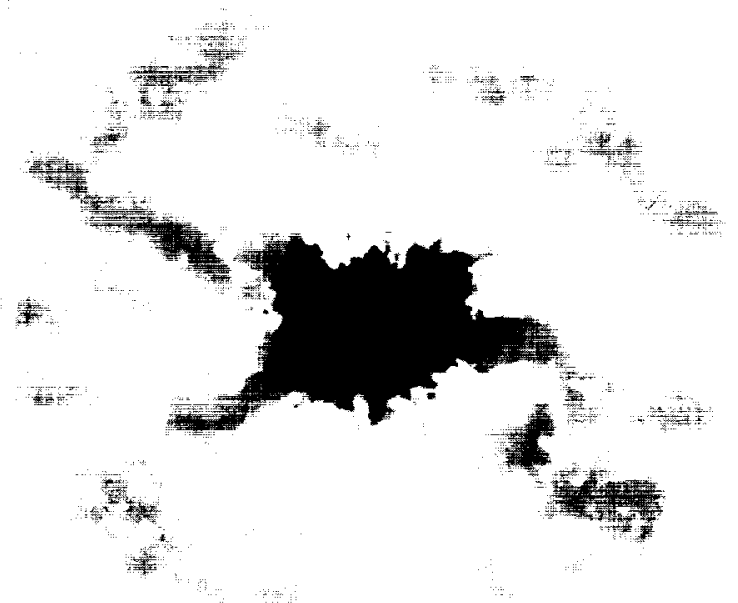

CROSS-SECTION

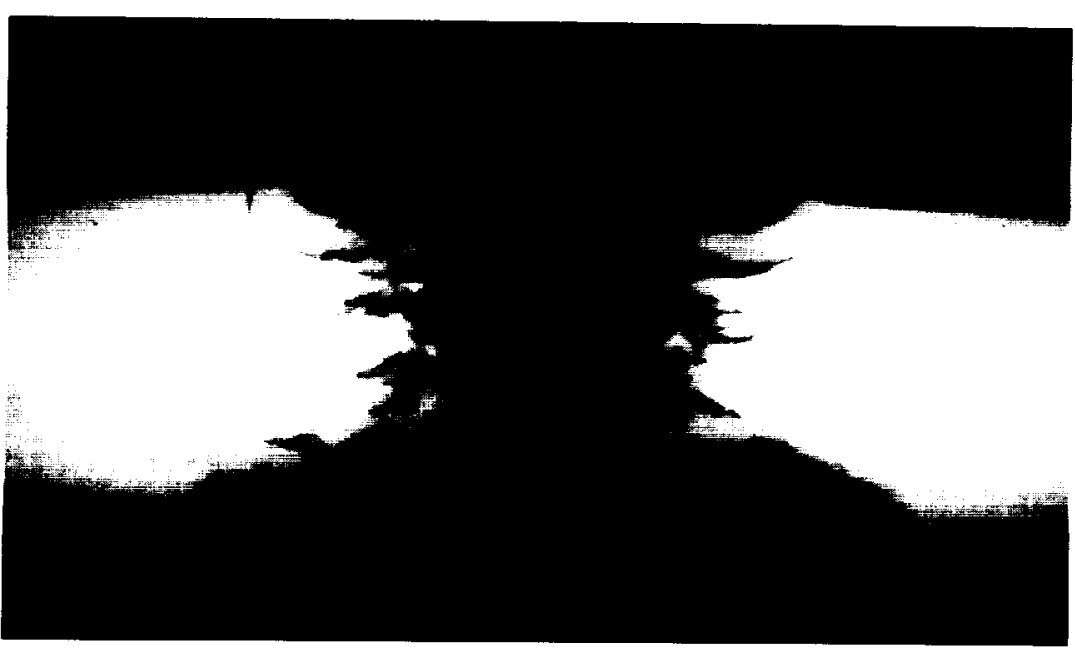




\section{Page Intentionally Left Blank}




SHOT \# 13

PROJECTILE: Soda Lime

$D_{p}=3175 \mu \mathrm{m}$

$\mathrm{V}=6.55 \mathrm{~km} / \mathrm{s}$

TARGET: Teflon

$\begin{aligned} \mathrm{T} & =12650 \mu \mathrm{m} \\ \mathrm{D}_{\mathrm{p}} / \mathrm{T} & =0.25\end{aligned}$

FRONT

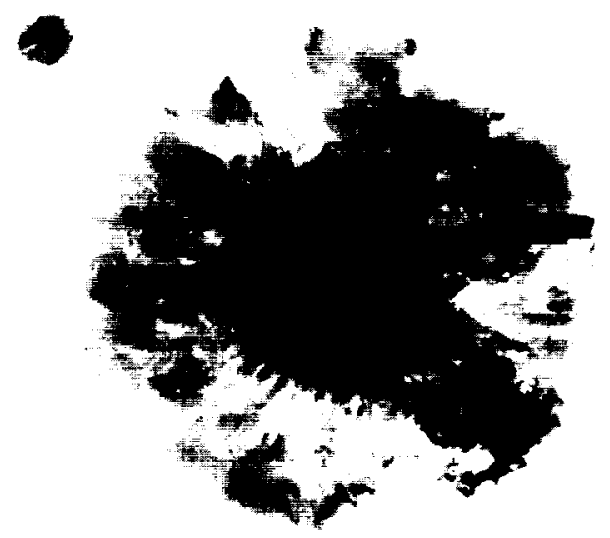

REAR

CROSS-SECTION

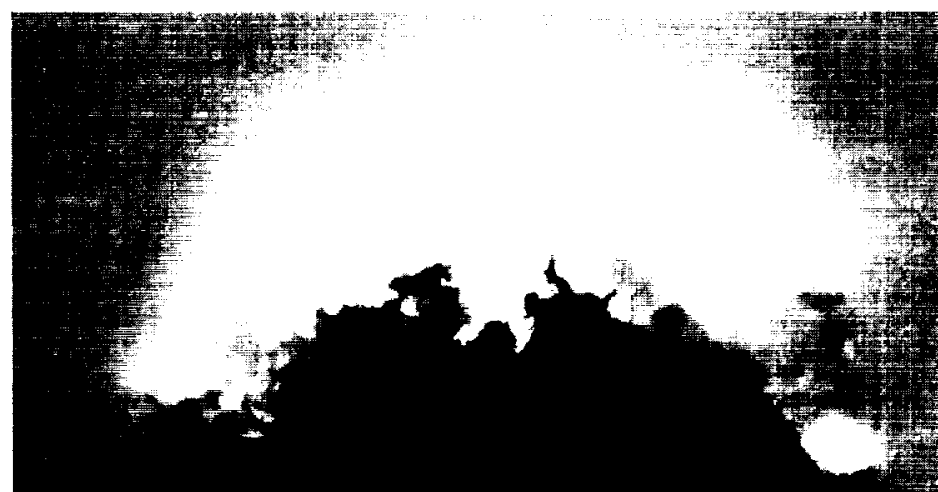

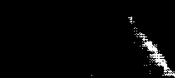
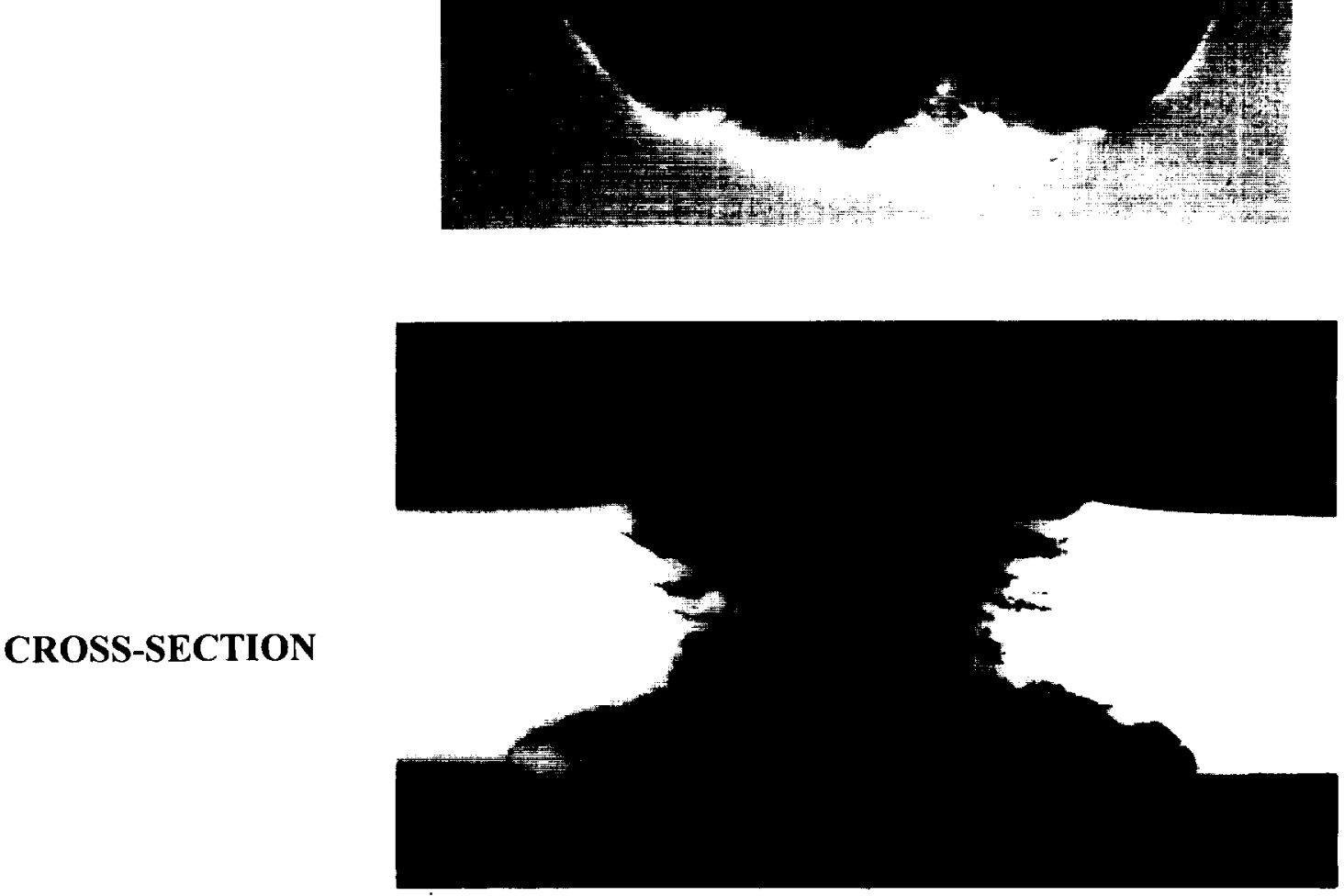
SHOT \# 13
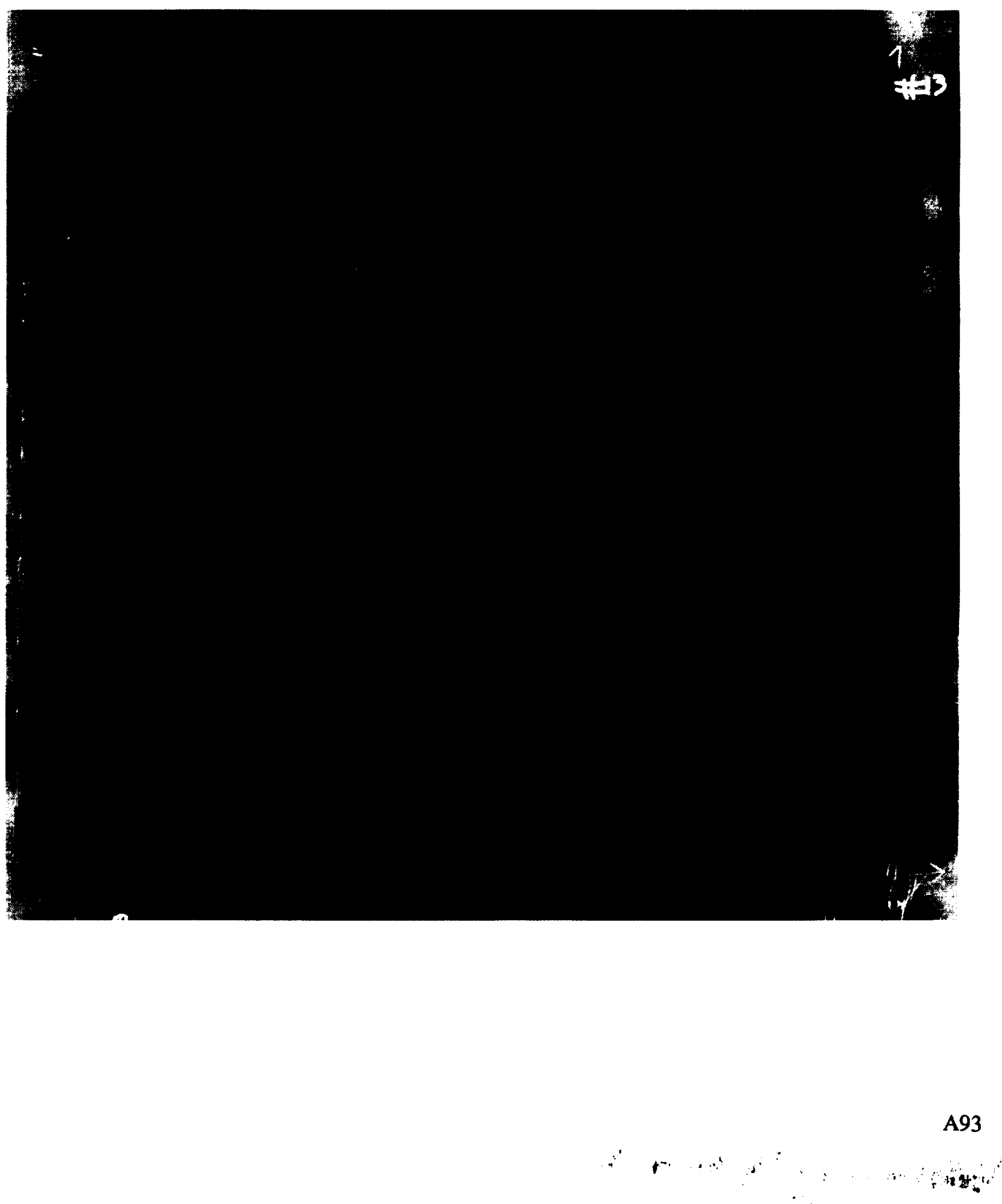


SHOT \# 12

PROJECTILE: Soda Lime

$$
\begin{aligned}
\mathrm{D}_{\mathrm{p}} & =3175 \mu \mathrm{m} \\
\mathrm{V} & =6.62 \mathrm{~km} / \mathrm{s}
\end{aligned}
$$

TARGET: Teflon

$$
\begin{aligned}
\mathrm{T} & =11050 \mu \mathrm{m} \\
\mathrm{D}_{\mathrm{p}} / \mathrm{T} & =0.29
\end{aligned}
$$

FRONT

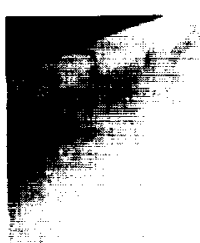

REAR

CROSS-SECTION
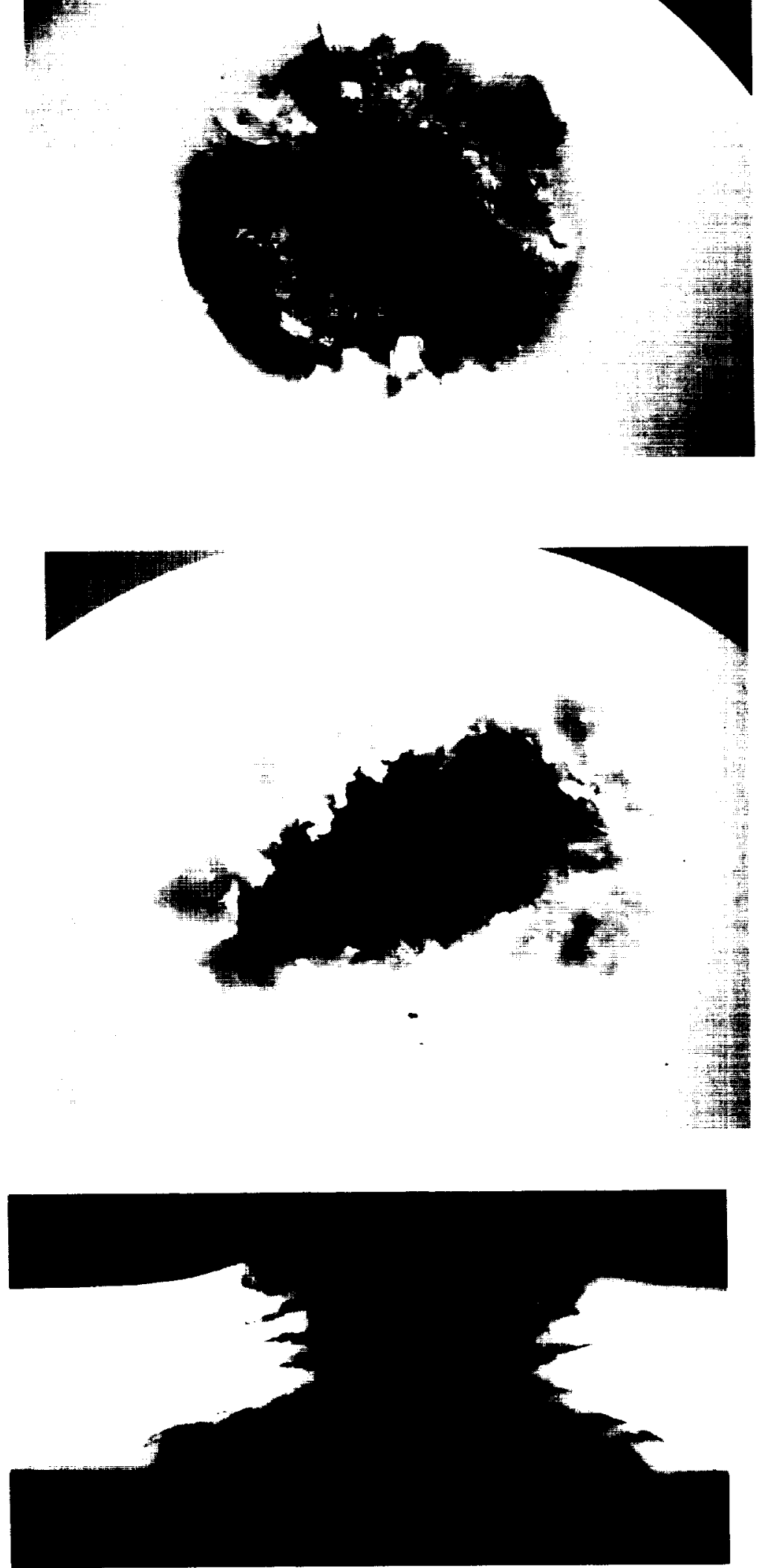
SHOT \# 12 


SHOT \# 23

PROJECTILE: Soda Lime

$\mathrm{D}_{\mathrm{p}}=3175 \mu \mathrm{m}$

$\mathrm{V}=6.39 \mathrm{~km} / \mathrm{s}$

TARGET: Teflon

$\begin{aligned} \mathrm{T} & =9360 \mu \mathrm{m} \\ \mathrm{D}_{\mathrm{p}} / \mathrm{T} & =0.34\end{aligned}$

FRONT

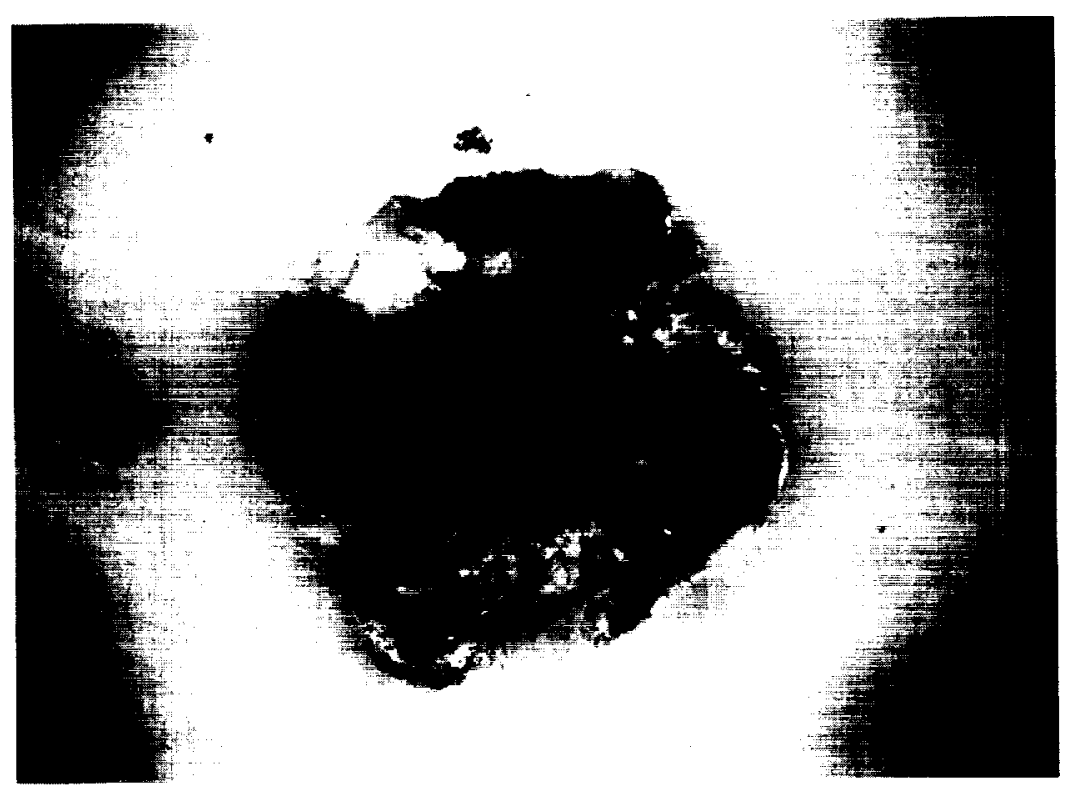

REAR

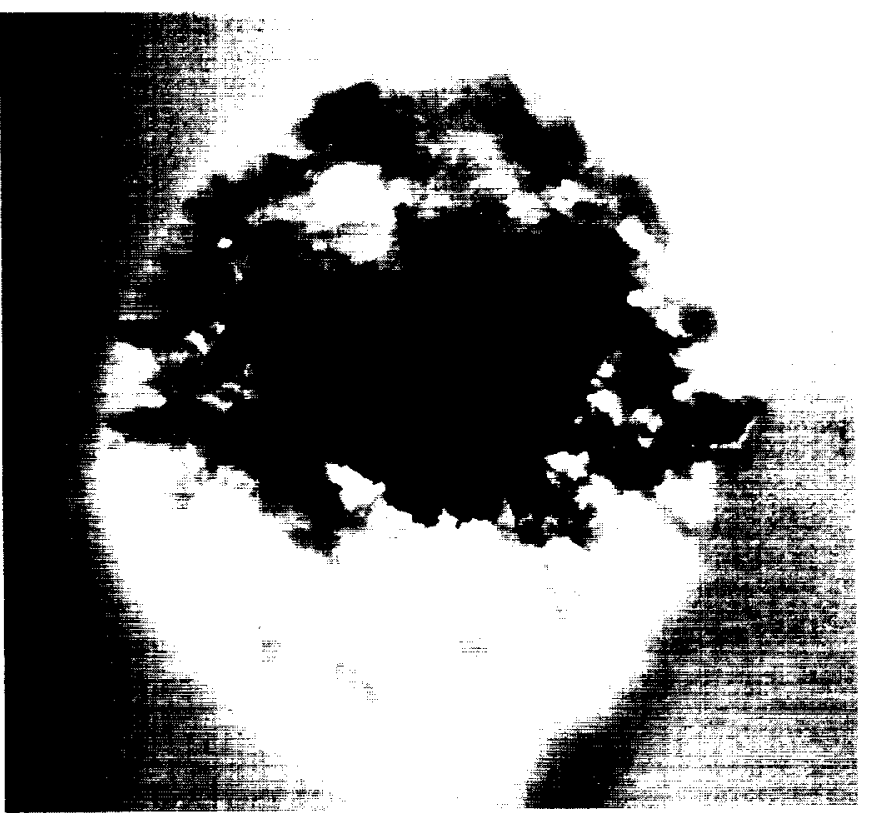

CROSS-SECTION 
SHOT \# 23 




\section{SHOT \# 19}

PROJECTILE: Soda Lime

$\mathrm{D}_{\mathrm{p}}=3175 \mu \mathrm{m}$

$\mathrm{V}=6.41 \mathrm{~km} / \mathrm{s}$

TARGET: Teflon

$$
\begin{aligned}
\mathrm{T} & =7670 \mu \mathrm{m} \\
\mathrm{D}_{\mathrm{p}} / \mathrm{T} & =0.41
\end{aligned}
$$

FRONT

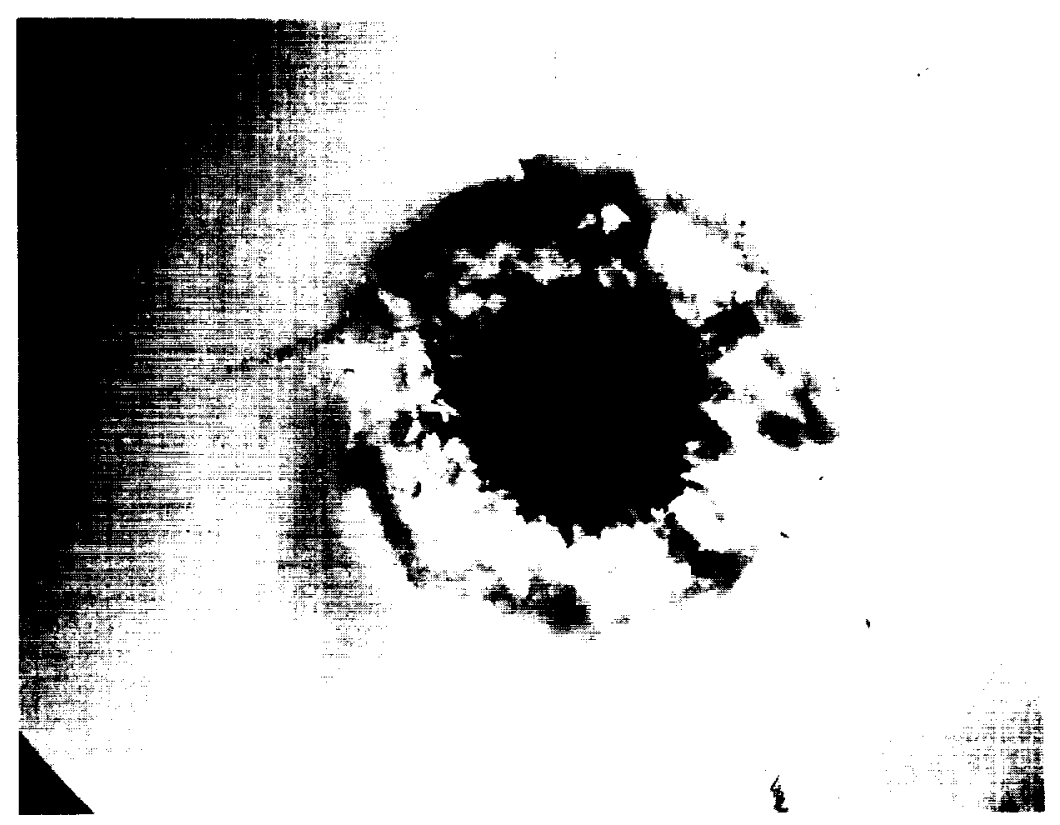

REAR
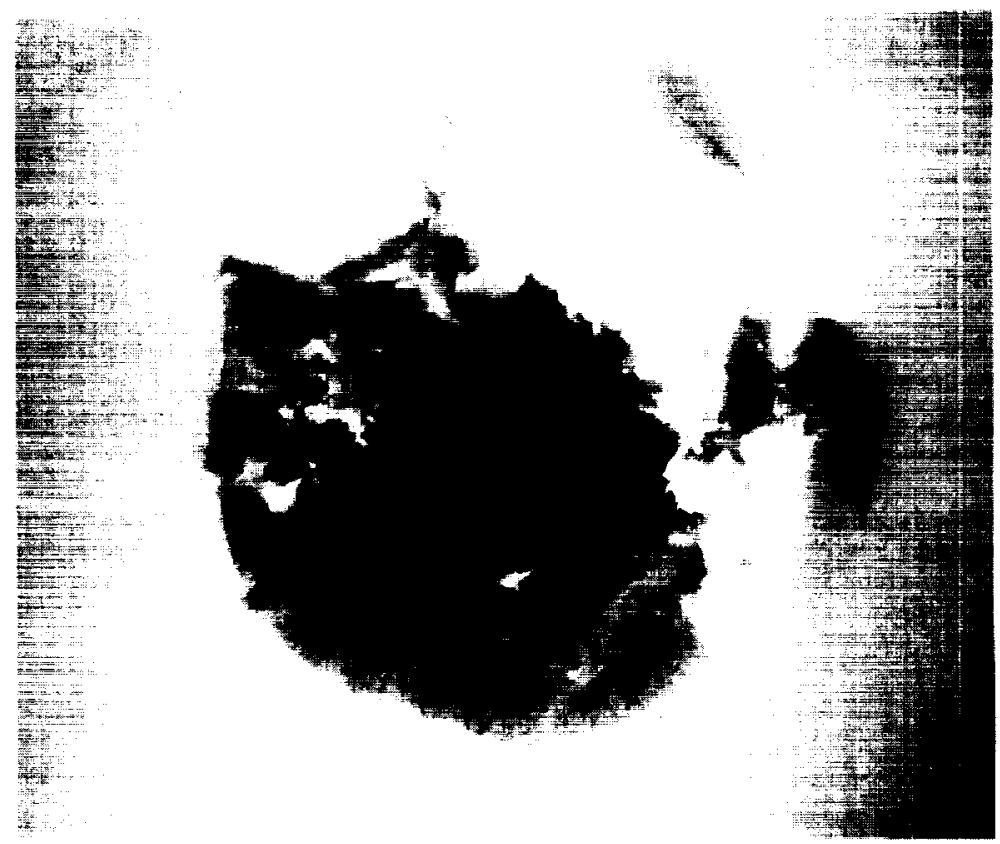

CROSS-SECTION

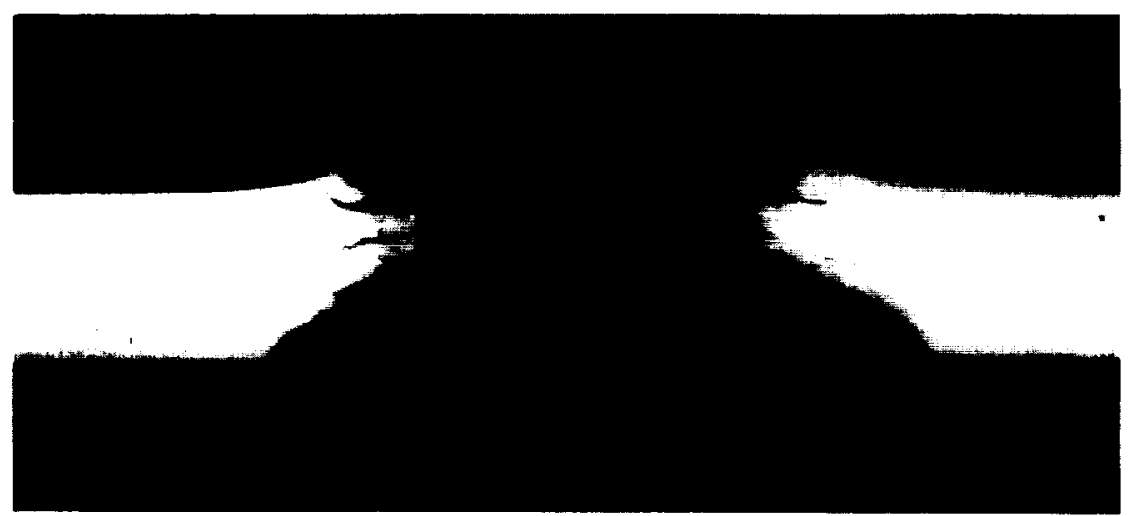


SHOT \# 19

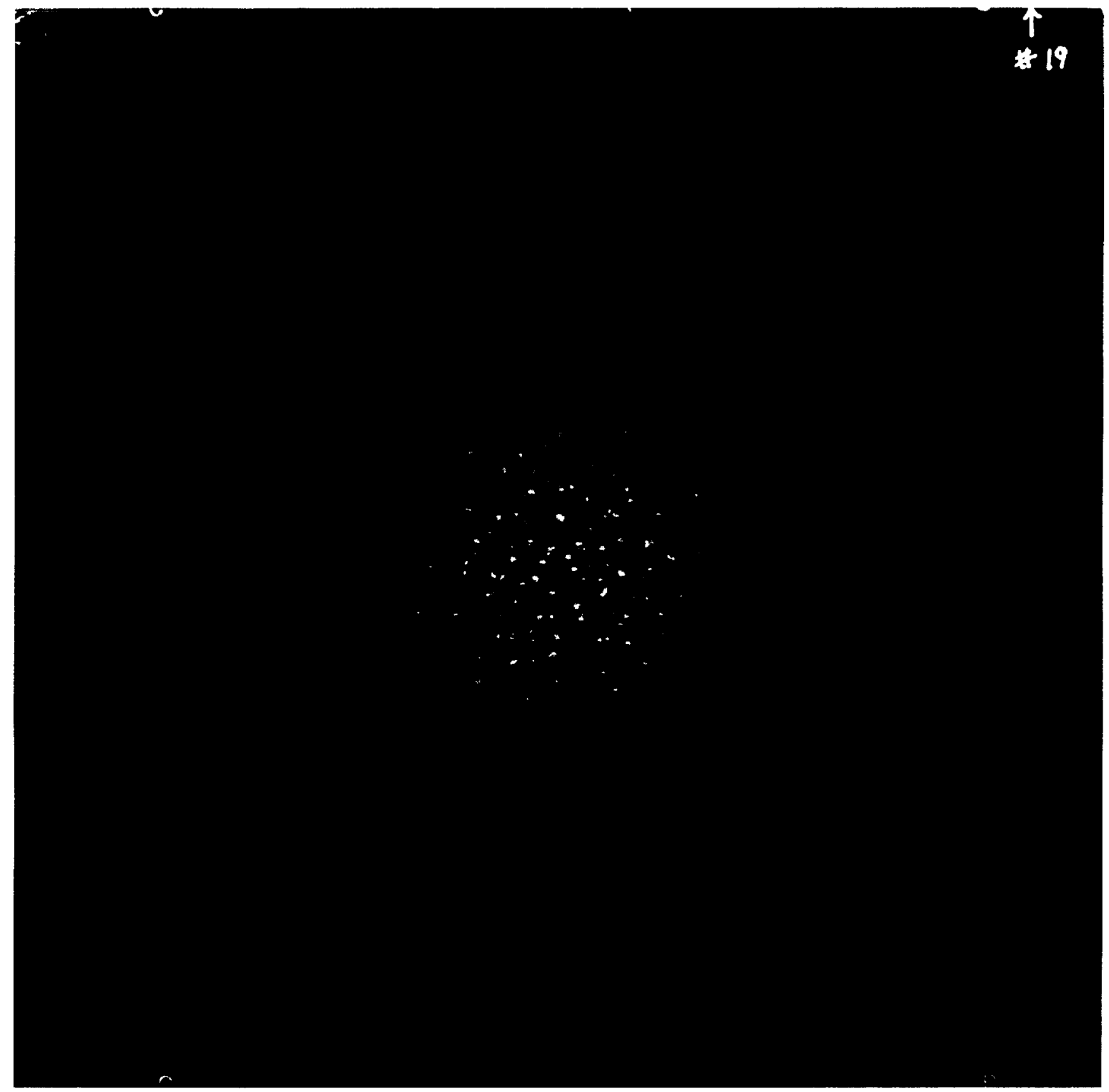






\section{SHOT \# 31}

PROJECTILE: Soda Lime

$$
\begin{aligned}
\mathrm{D}_{\mathrm{p}} & =3175 \mu \mathrm{m} \\
\mathrm{V} & =6.49 \mathrm{~km} / \mathrm{s}
\end{aligned}
$$

\section{TARGET: Teflon}

$$
\begin{aligned}
\mathrm{T} & =6820 \mu \mathrm{m} \\
\mathrm{D}_{\mathrm{p}} / \mathrm{T} & =0.47
\end{aligned}
$$

FRONT

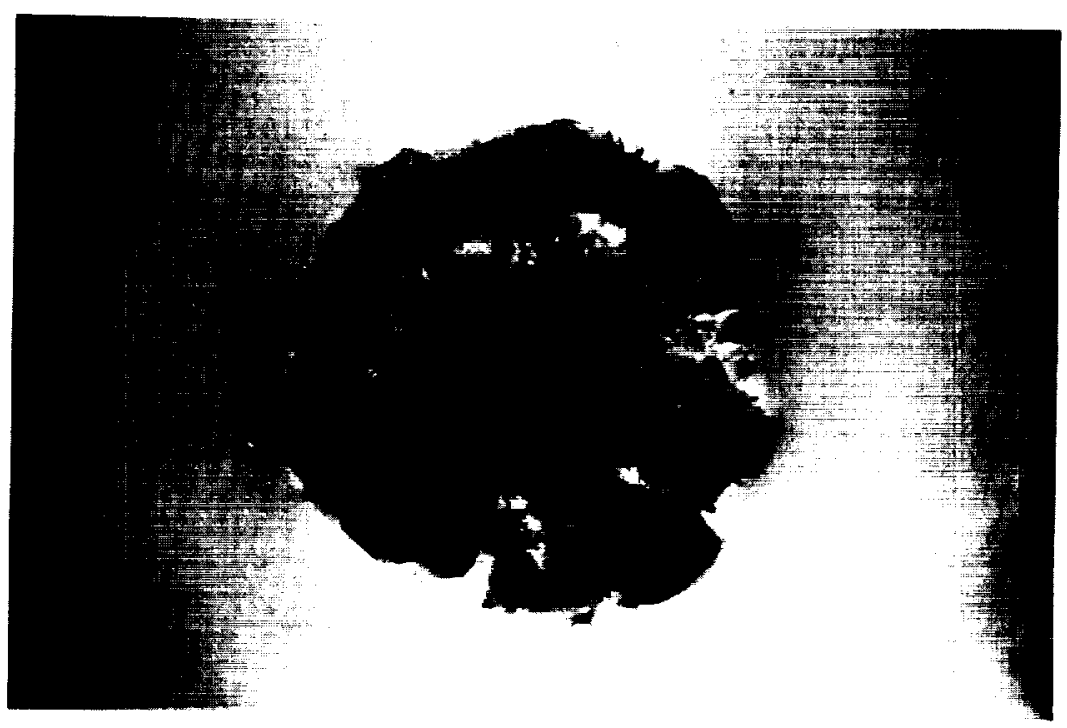

REAR

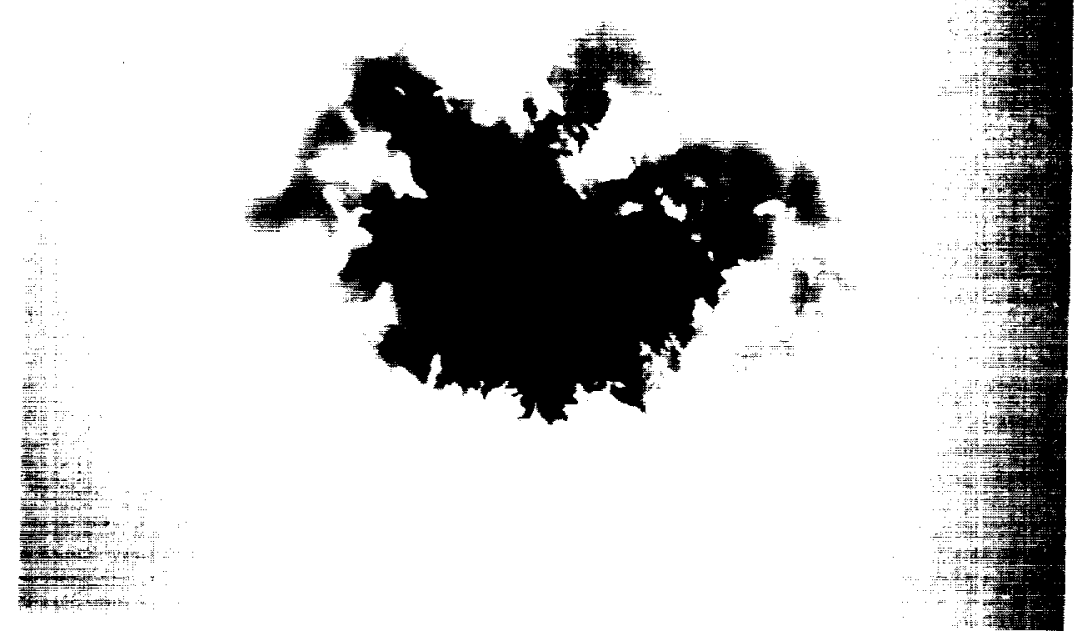

CROSS-SECTION

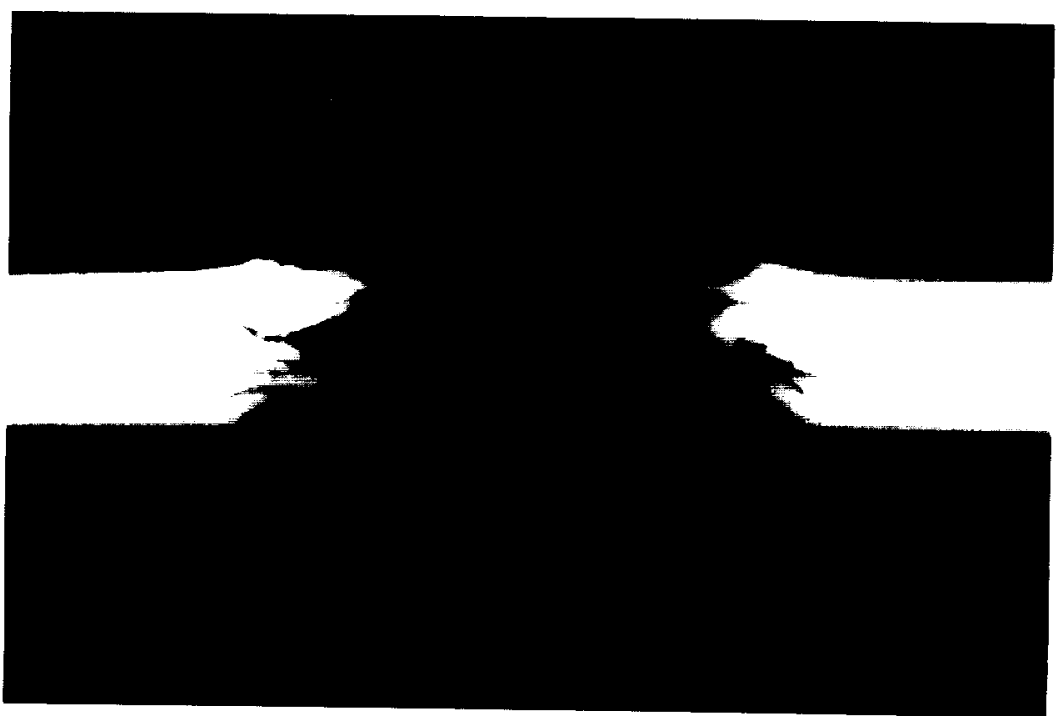


SHOT \# 31

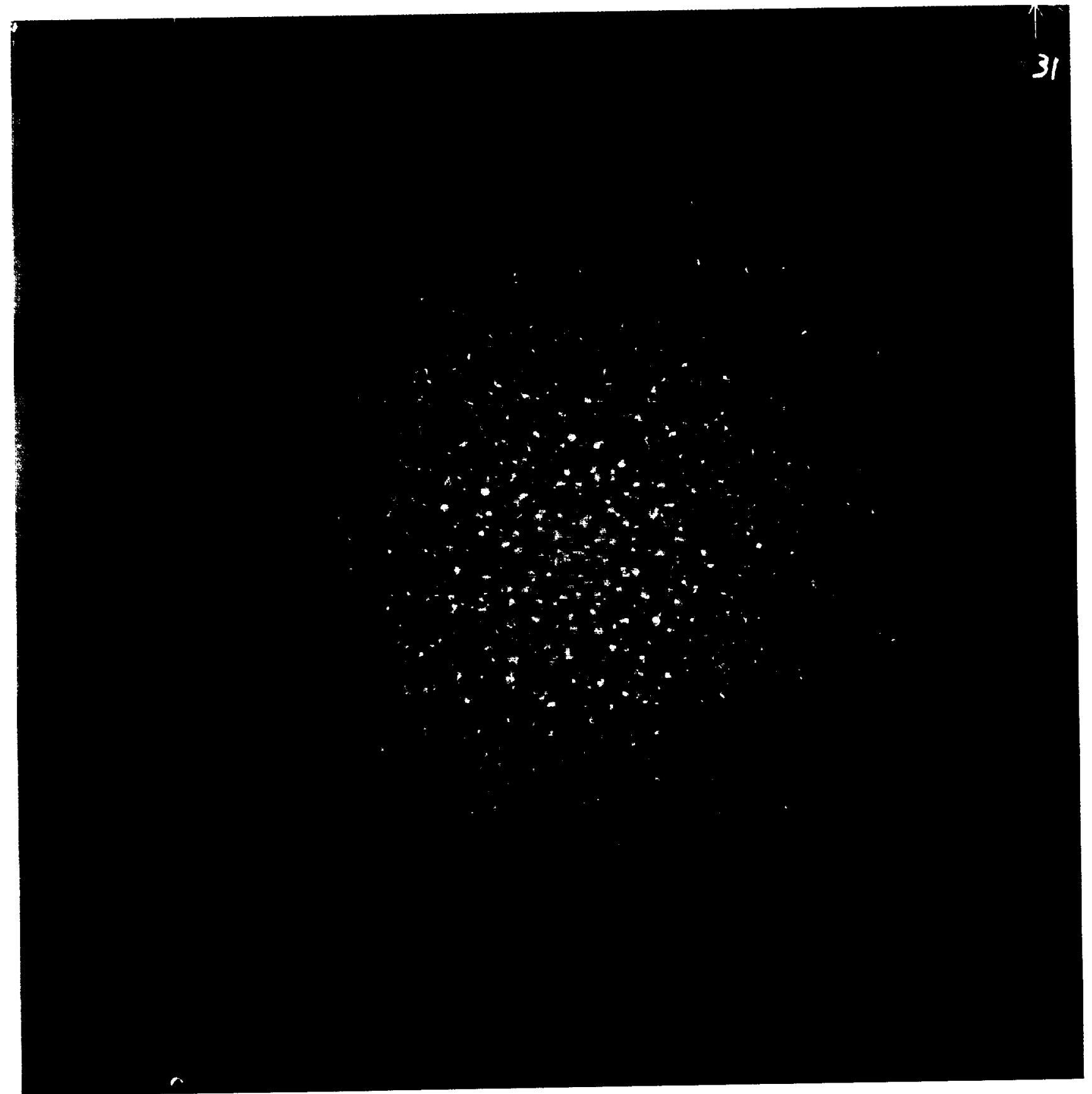




SHOT \# 32

PROJECTILE: Soda Lime

$\mathrm{D}_{\mathrm{p}}=3175 \mu \mathrm{m}$

$\mathrm{V}=6.17 \mathrm{~km} / \mathrm{s}$

TARGET: Teflon

$\begin{aligned} \mathrm{T} & =6130 \mu \mathrm{m} \\ \mathrm{D}_{\mathrm{p}} / \mathrm{T} & =0.52\end{aligned}$

FRONT

REAR

CROSS-SECTION
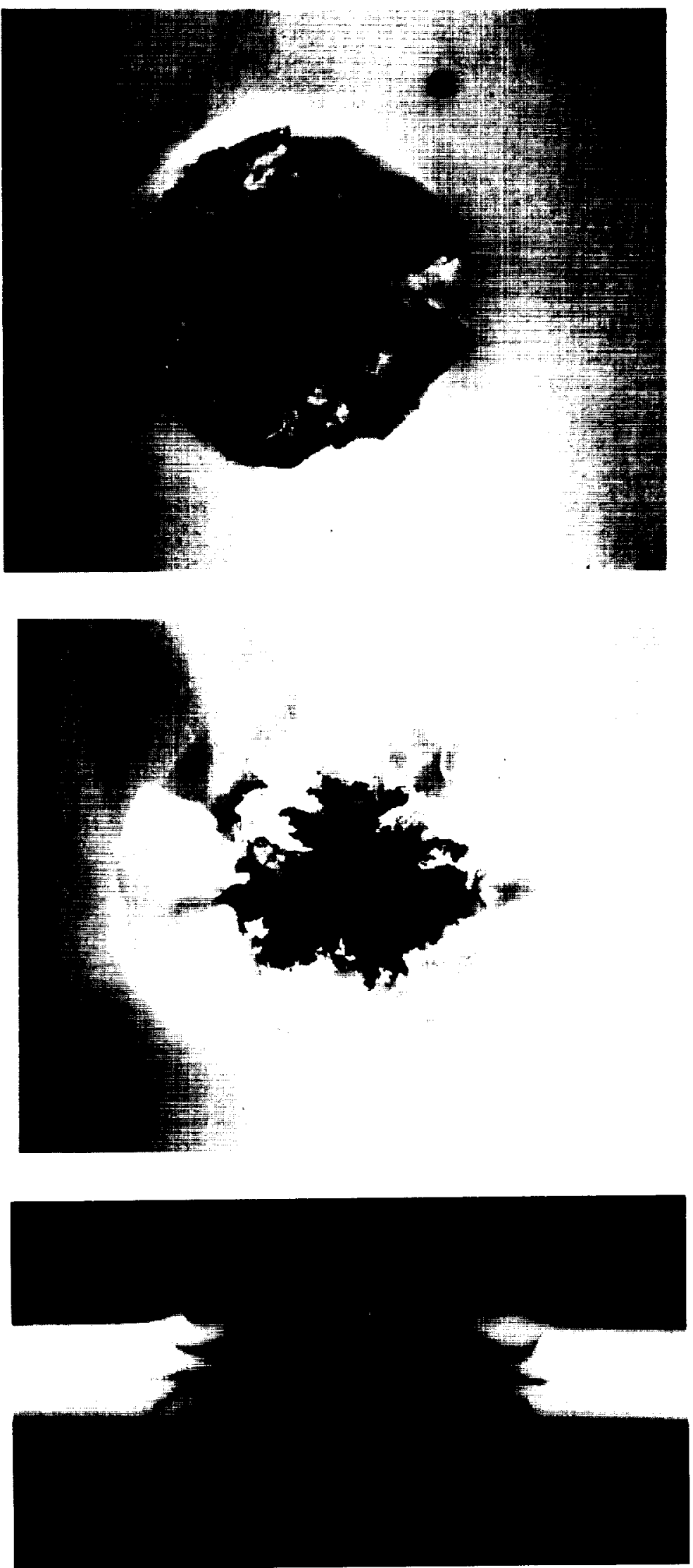
SHOT \# 32

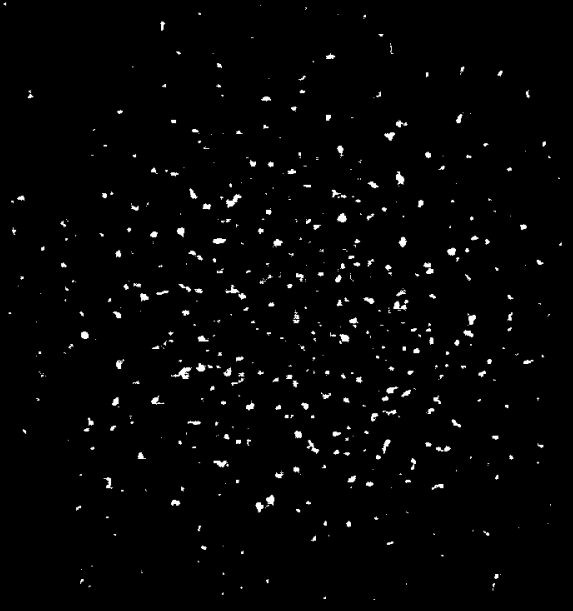




SHOT \# 17

PROJECTILE: Soda Lime

$\begin{aligned} \mathrm{D}_{\mathrm{p}} & =3175 \mu \mathrm{m} \\ \mathrm{V} & =6.31 \mathrm{~km} / \mathrm{s}\end{aligned}$

TARGET: Teflon

$\begin{aligned} \mathrm{T} & =4950 \mu \mathrm{m} \\ \mathrm{D}_{\mathrm{p}} / \mathrm{T} & =0.64\end{aligned}$

FRONT

REAR

CROSS-SECTION

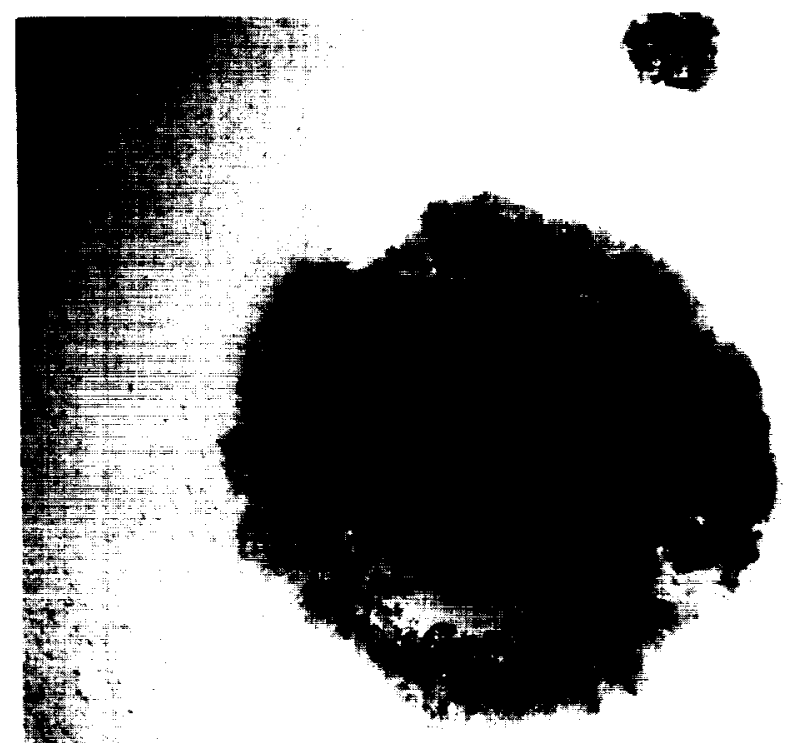

, 1 .

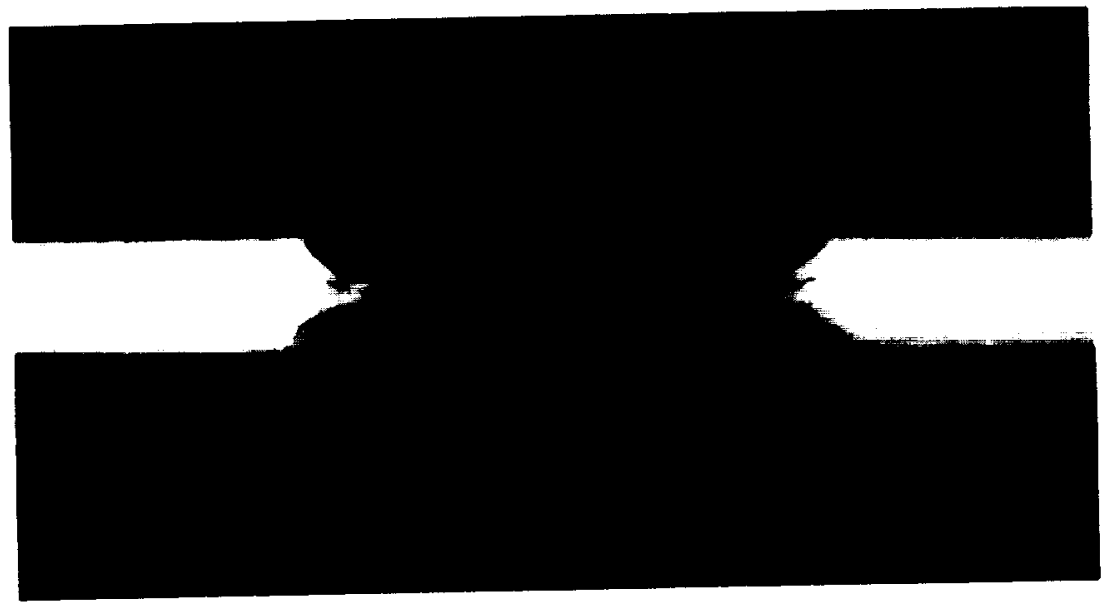


SHOT \# 17

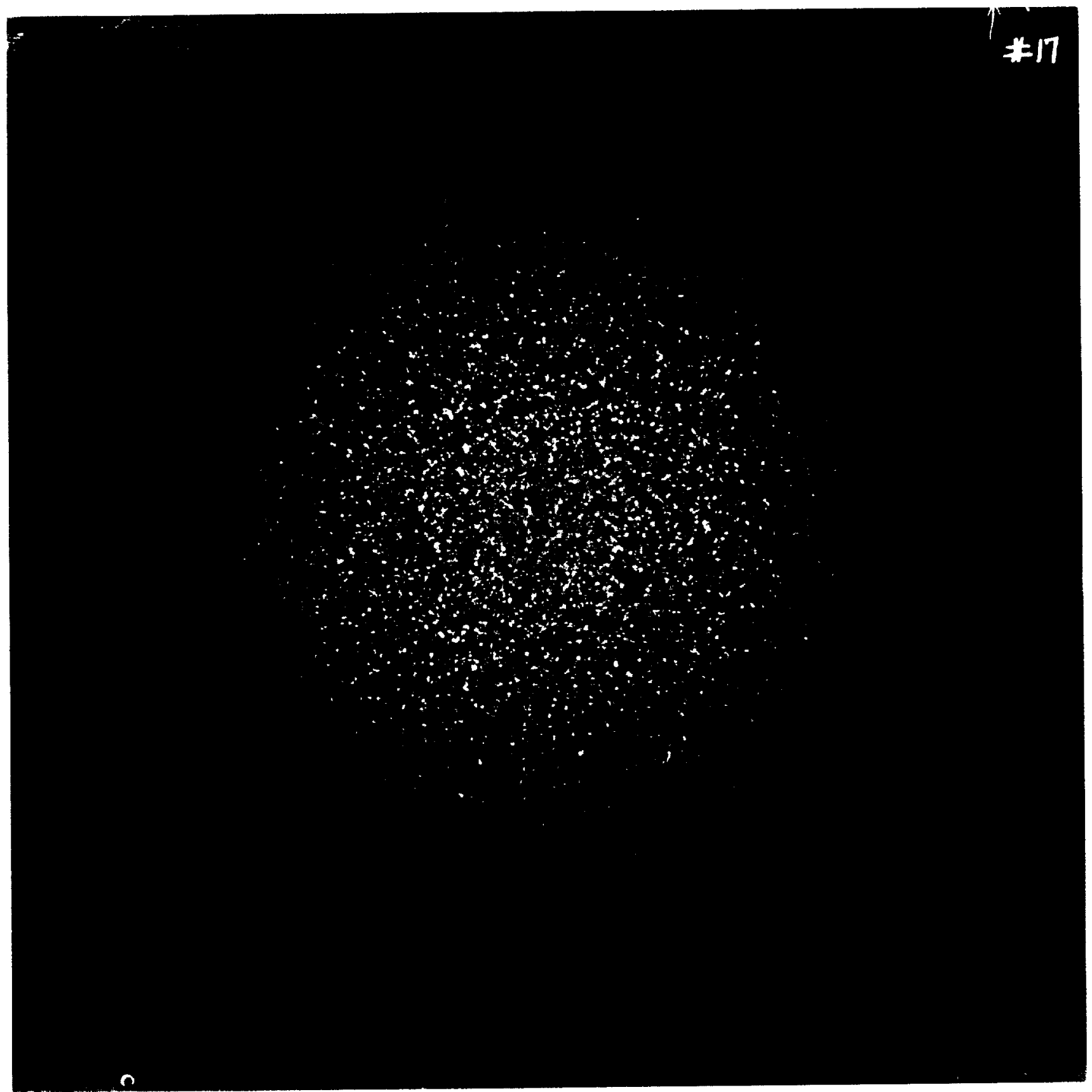




SHOT \# 29

PROJECTILE: Soda Lime

$\begin{aligned} \mathrm{D}_{\mathrm{p}} & =3175 \mu \mathrm{m} \\ \mathrm{V} & =6.37 \mathrm{~km} / \mathrm{s}\end{aligned}$

TARGET: Teflon

$\begin{aligned} \mathrm{T} & =4150 \mu \mathrm{m} \\ \mathrm{D}_{\mathrm{p}} / \mathrm{T} & =0.77\end{aligned}$

FRONT

REAR

CROSS-SECTION
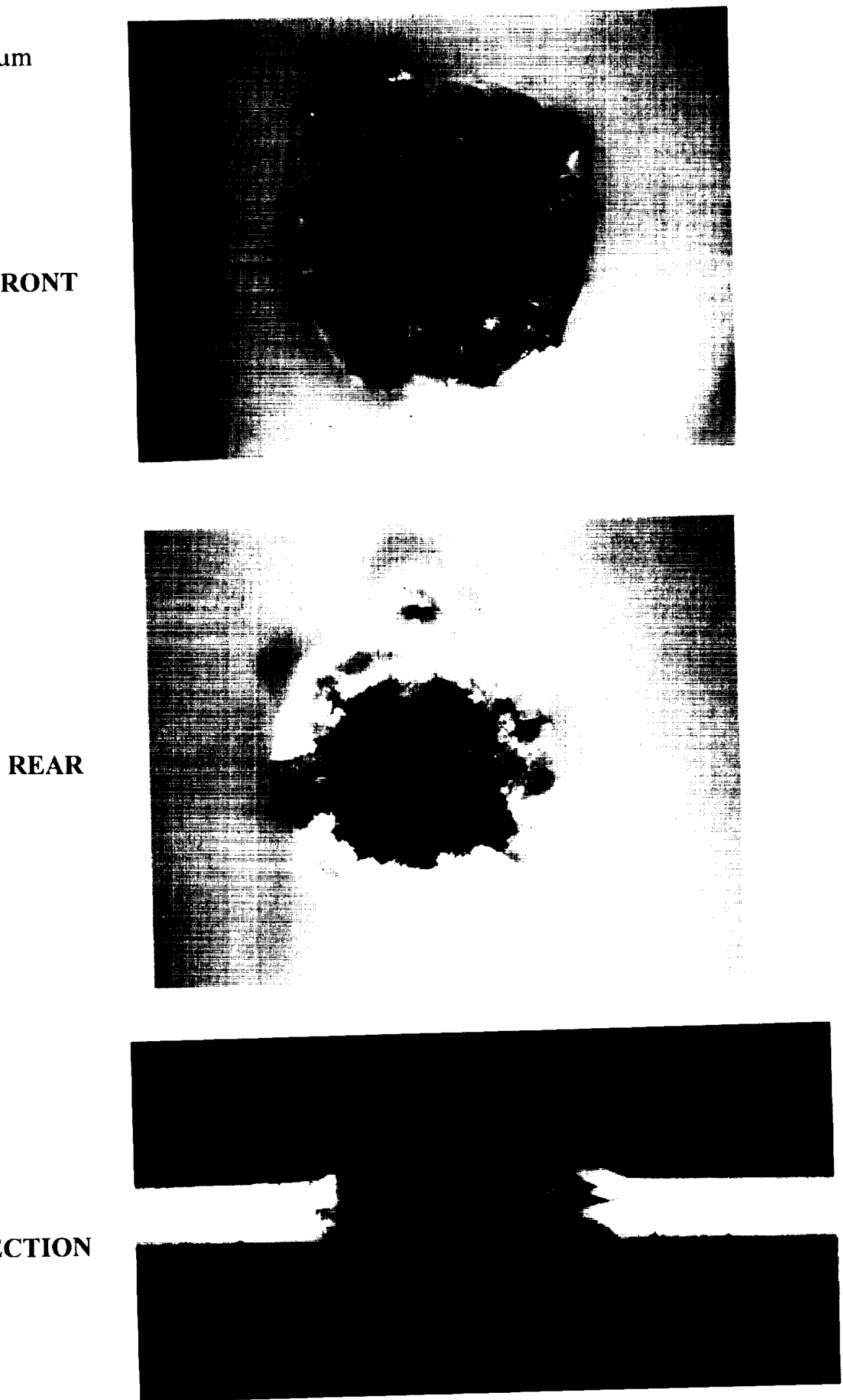
SHOT \# 29 


SHOT \# 28

PROJECTILE: Soda Lime

$\begin{aligned} \mathrm{D}_{\mathbf{p}} & =3175 \mu \mathrm{m} \\ \mathrm{V} & =6.22 \mathrm{~km} / \mathrm{s}\end{aligned}$

TARGET: Teflon

$\begin{aligned} \mathrm{T} & =3650 \mu \mathrm{m} \\ \mathrm{D}_{\mathrm{p}} / \mathrm{T} & =0.87\end{aligned}$

FRONT

REAR

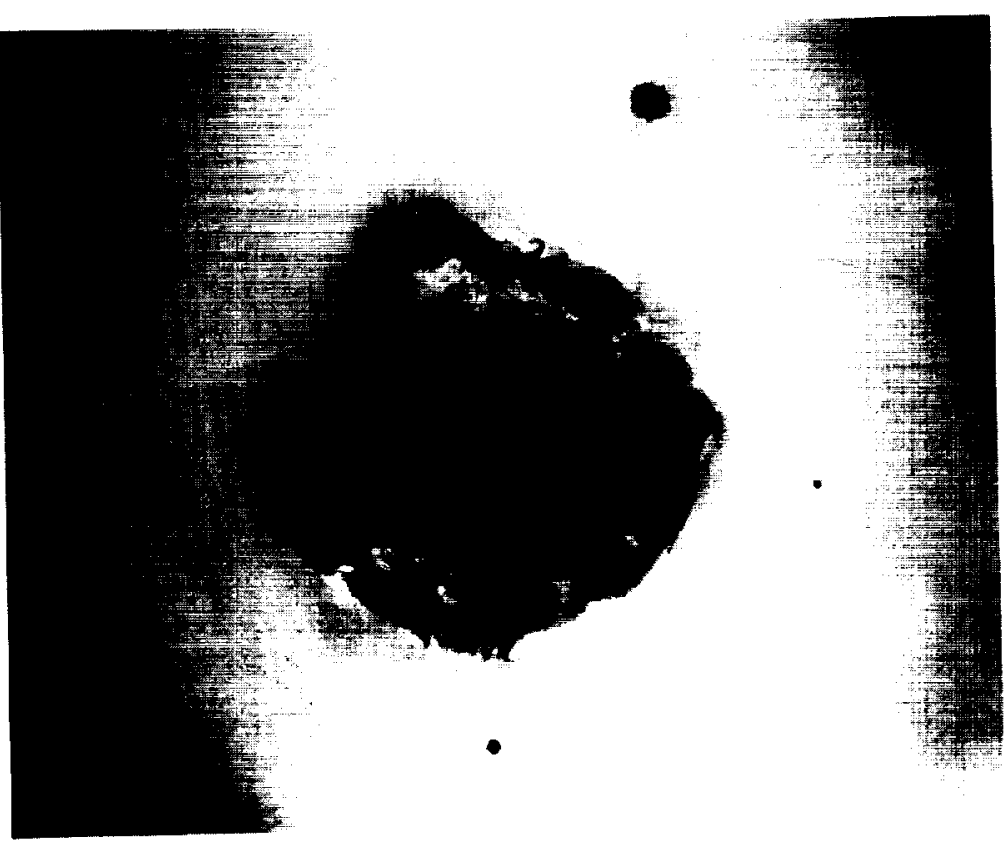

CROSS-SECTION
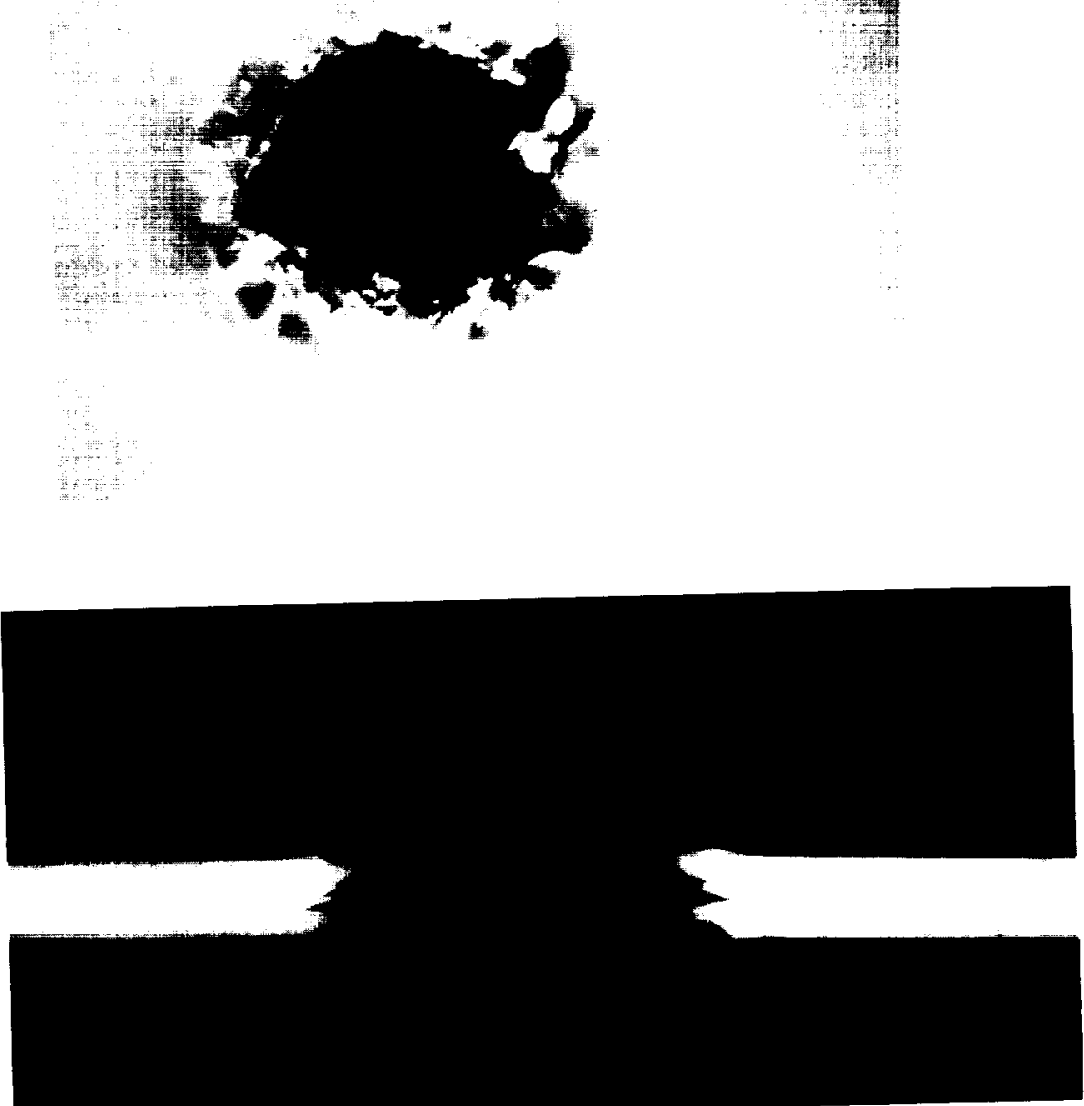
SHOT \# 28 


SHOT \# 18

PROJECTILE: Soda Lime

$\mathrm{D}_{\mathrm{p}}=3175 \mu \mathrm{m}$

$\mathrm{V}=6.56 \mathrm{~km} / \mathrm{s}$

TARGET: Teflon

$\mathrm{T}=3250 \mu \mathrm{m}$

$\mathrm{D}_{\mathrm{p}} / \mathrm{T}=0.98$

FRONT

REAR

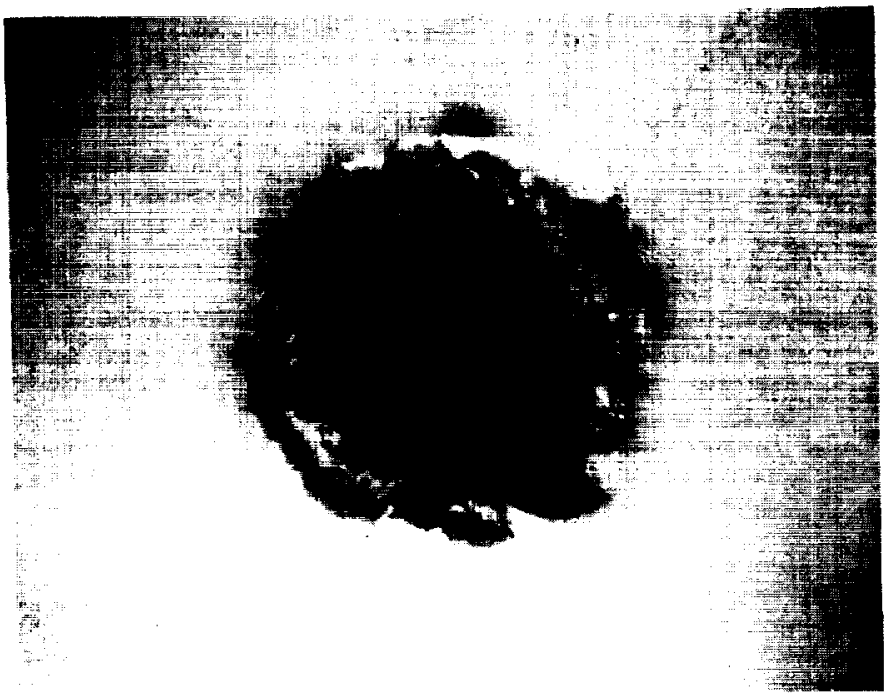

$\frac{1}{4}$

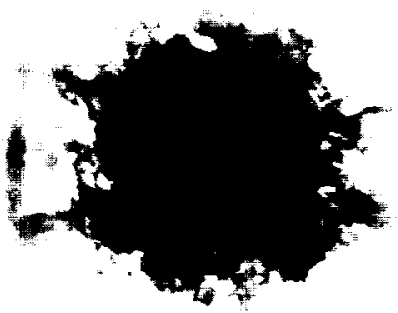

CROSS-SECTION

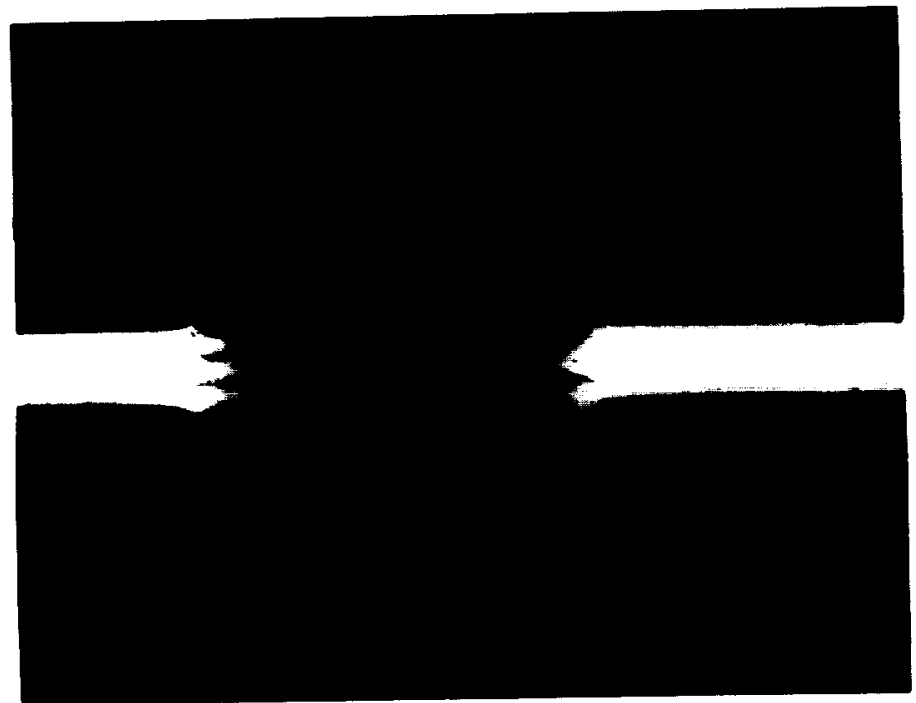


SHOT \# 18

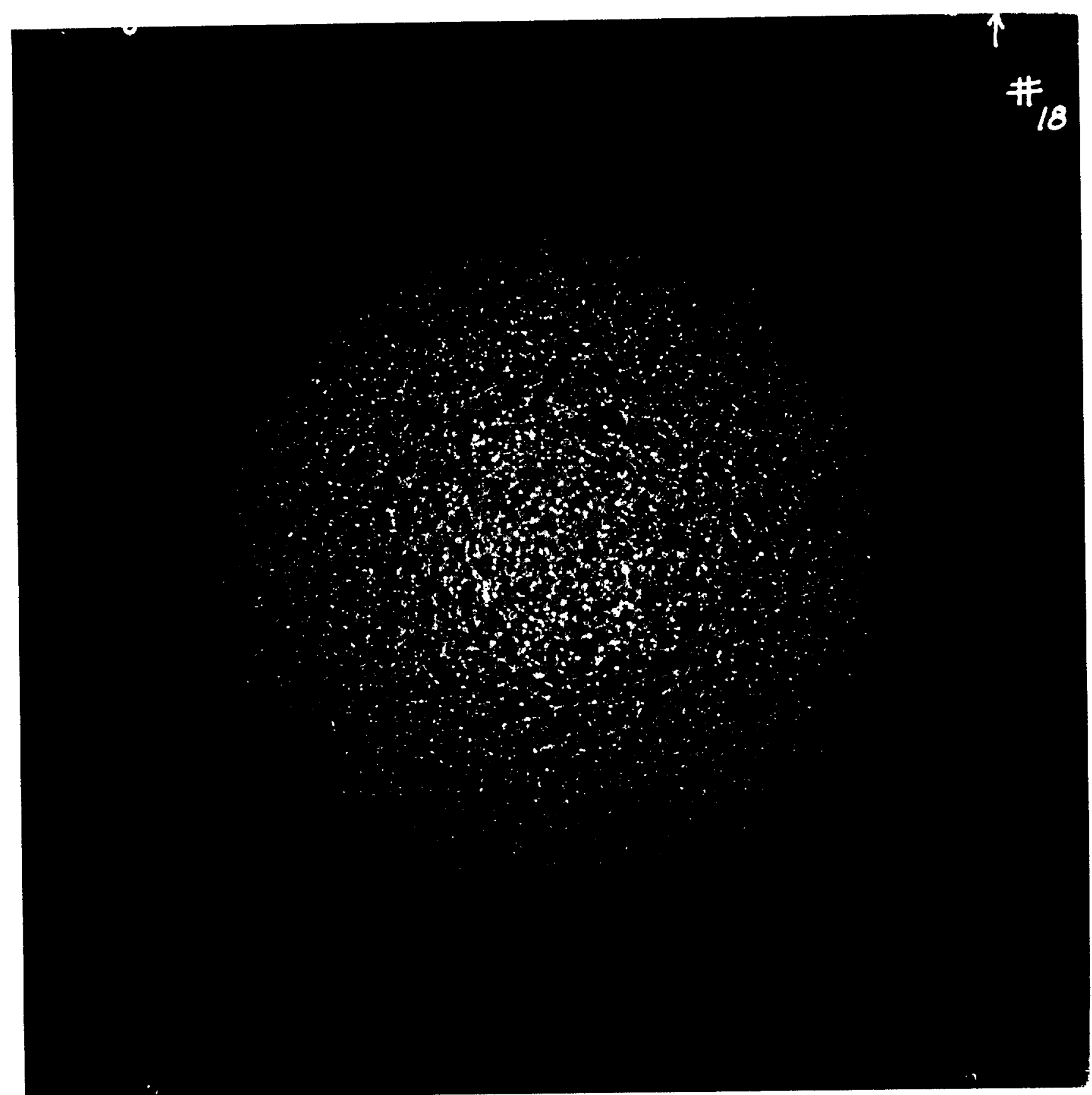




SHOT \# 34

PROJECTILE: Soda Lime

$\mathrm{D}_{\mathrm{p}}=3175 \mu \mathrm{m}$

$\mathrm{V}=6.25 \mathrm{~km} / \mathrm{s}$

TARGET: Teflon

$\mathrm{T}=1640 \mu \mathrm{m}$

$\mathrm{D}_{\mathrm{p}} / \mathrm{T}=1.94$

FRONT

REAR

CROSS-SECTION

A112 
SHOT \# 34

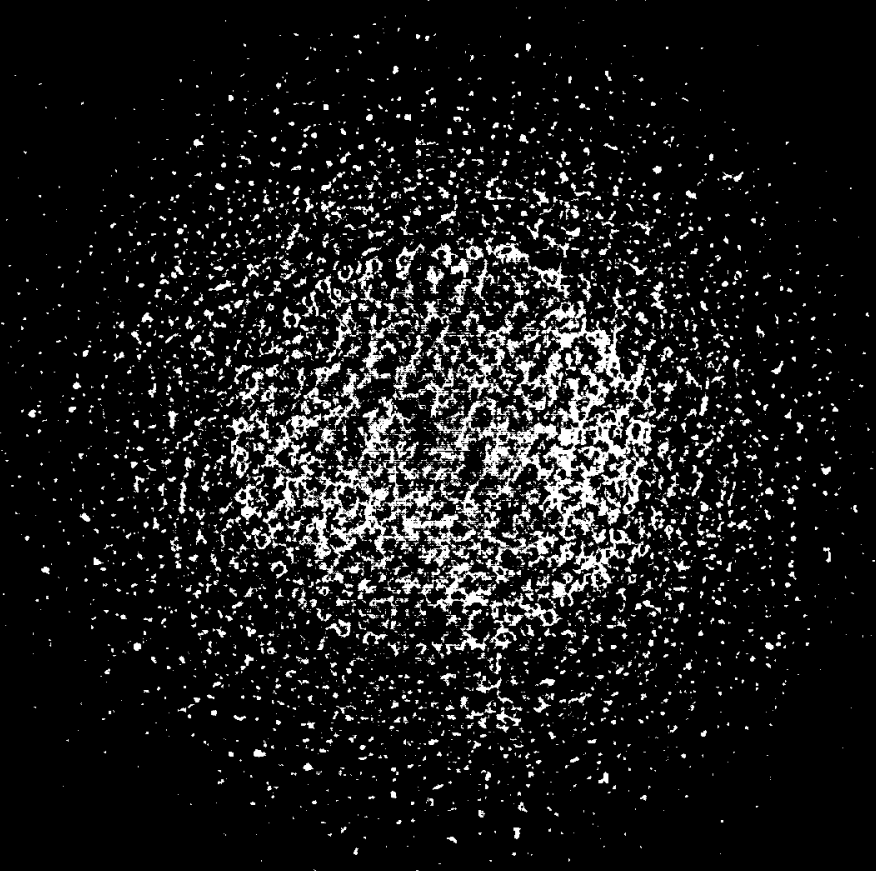


$-$ 

SHOT \# 35

PROJECTILE: Soda Lime

$$
\begin{aligned}
\mathrm{D}_{\mathrm{p}} & =3175 \mu \mathrm{m} \\
\mathrm{V} & =6.32 \mathrm{~km} / \mathrm{s}
\end{aligned}
$$

TARGET: Teflon

$$
\begin{aligned}
\mathrm{T} & =800 \mu \mathrm{m} \\
\mathrm{D}_{\mathrm{p}} / \mathrm{T} & =3.97
\end{aligned}
$$

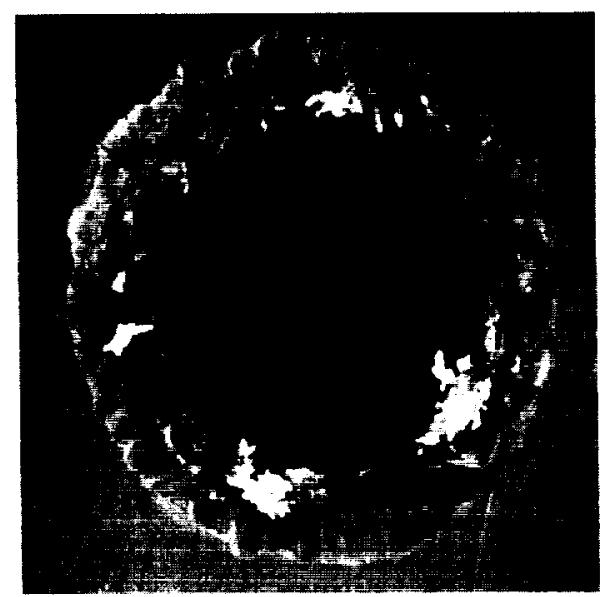

REAR 
SHOT \# 35 


SHOT \# 36

PROJECTILE: Soda Lime

$$
\begin{aligned}
\mathrm{D}_{\mathrm{p}} & =3175 \mu \mathrm{m} \\
\mathrm{V} & =6.35 \mathrm{~km} / \mathrm{s}
\end{aligned}
$$

TARGET: Teflon

$$
\begin{aligned}
\mathrm{T} & =520 \mu \mathrm{m} \\
\mathrm{D}_{\mathrm{p}} / \mathrm{T} & =6.11
\end{aligned}
$$

\section{FRONT}

REAR

CROSS-SECTION 
SHOT \# 36

1136 


PROJECTILE: Soda Lime

$\mathrm{D}_{\mathrm{p}}=3175 \mu \mathrm{m}$

$\mathrm{V}=6.46 \mathrm{~km} / \mathrm{s}$

TARGET: Teflon

$\begin{aligned} \mathrm{T} & =230 \mu \mathrm{m} \\ \mathrm{D}_{\mathrm{p}} / \mathrm{T} & =13.80\end{aligned}$

FRONT

REAR

CROSS-SECTION

A118

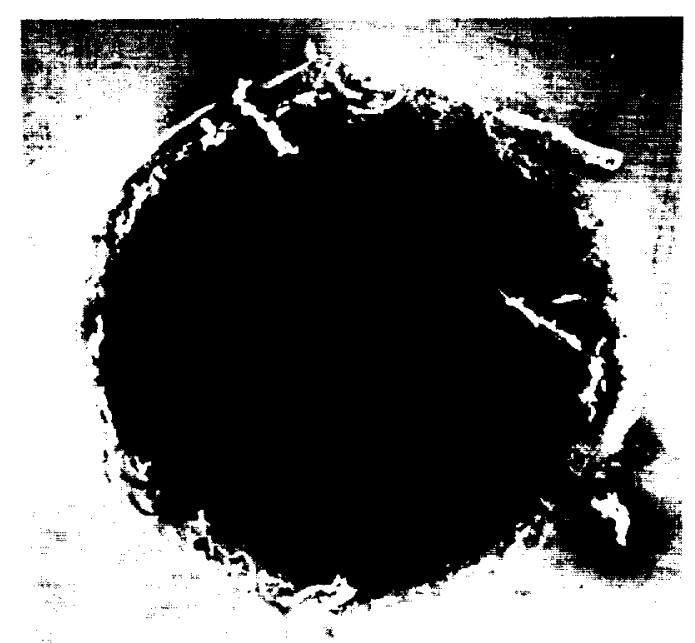


SHOT \# 37 


SHOT \# 38

PROJECTILE: Soda Lime

$\begin{aligned} \mathrm{D}_{\mathrm{p}} & =3175 \mu \mathrm{m} \\ \mathrm{V} & =6.37 \mathrm{~km} / \mathrm{s}\end{aligned}$

TARGET: Teflon

$\mathrm{T}=80 \mu \mathrm{m}$

$\mathrm{D}_{\mathrm{p}} / \mathrm{T}=39.69$

\section{FRONT}

REAR

CROSS-SECTION 
SHOT \# 38 


SHOT \# 40

PROJECTILE: Soda Lime

$\mathrm{D}_{\mathrm{p}}=3175 \mu \mathrm{m}$

$\mathrm{V}=6.31 \mathrm{~km} / \mathrm{s}$

TARGET: Teflon

$\mathrm{T}=40 \mu \mathrm{m}$

$\mathrm{D}_{\mathrm{p}} / \mathrm{T}=79.38$

FRONT

REAR

CROSS-SECTION 
SHOT \# 40

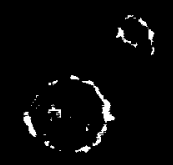




SHOT \# 42

PROJECTILE: Soda Lime

$\mathrm{D}_{\mathrm{p}}=3175 \mu \mathrm{m}$

$\mathrm{V}=6.32 \mathrm{~km} / \mathrm{s}$

TARGET: Teflon

$\mathrm{T}=20 \mu \mathrm{m}$

$\mathrm{D}_{\mathrm{p}} / \mathrm{T}=158.75$

FRONT

REAR

CROSS-SECTION 
SHOT \# 42

$x \neq 42$

. 


SHOT \# 43

PROJECTILE: Soda Lime

$$
\begin{aligned}
\mathrm{D}_{\mathrm{p}} & =3175 \mu \mathrm{m} \\
\mathrm{V} & =6.31 \mathrm{~km} / \mathrm{s}
\end{aligned}
$$

TARGET: Teflon

$$
\begin{aligned}
\mathrm{T} & =10 \mu \mathrm{m} \\
\mathrm{D}_{\mathrm{p}} / \mathrm{T} & =317.50
\end{aligned}
$$

FRONT

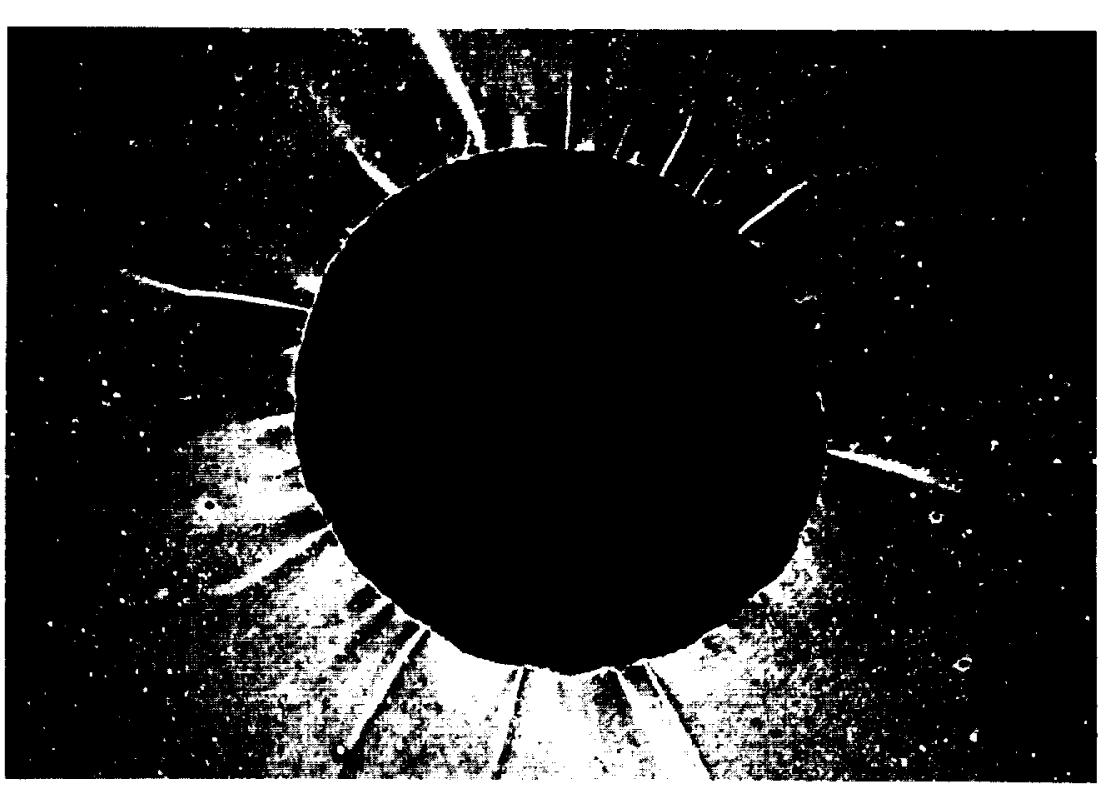

REAR 
SHOT \# 43

43

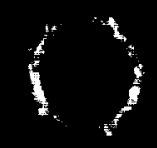




SHOT \# 44

PROJECTILE: Soda Lime

$\mathrm{D}_{\mathrm{p}}=3175 \mu \mathrm{m}$

$\mathrm{V}=6.33 \mathrm{~km} / \mathrm{s}$

TARGET: Teflon

$\mathrm{T}=6 \mu \mathrm{m}$

$\mathrm{D}_{\mathrm{p}} / \mathrm{T}=529.17$

FRONT

REAR

CROSS-SECTION 


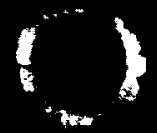






\section{Page Intentionally Left Blank}


PROJECTILE: Soda Lime

$$
\begin{aligned}
\mathrm{D}_{\mathrm{p}} & =3175 \mu \mathrm{m} \\
\mathrm{V} & =7.00 \mathrm{~km} / \mathrm{s}
\end{aligned}
$$

\section{TARGET: Teflon}

$$
\begin{aligned}
\mathrm{T} & =17983 \mu \mathrm{m} \\
\mathrm{D}_{\mathrm{p}} / \mathrm{T} & =0.18
\end{aligned}
$$

\section{FRONT}

\section{REAR}

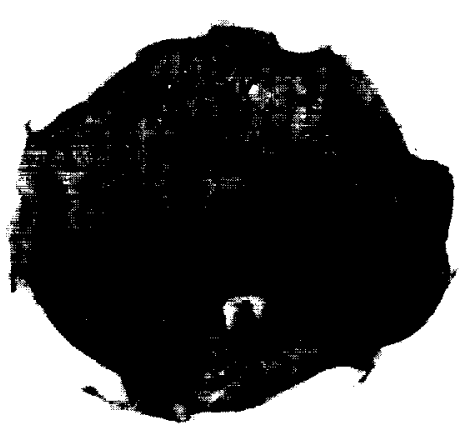

CROSS-SECTION

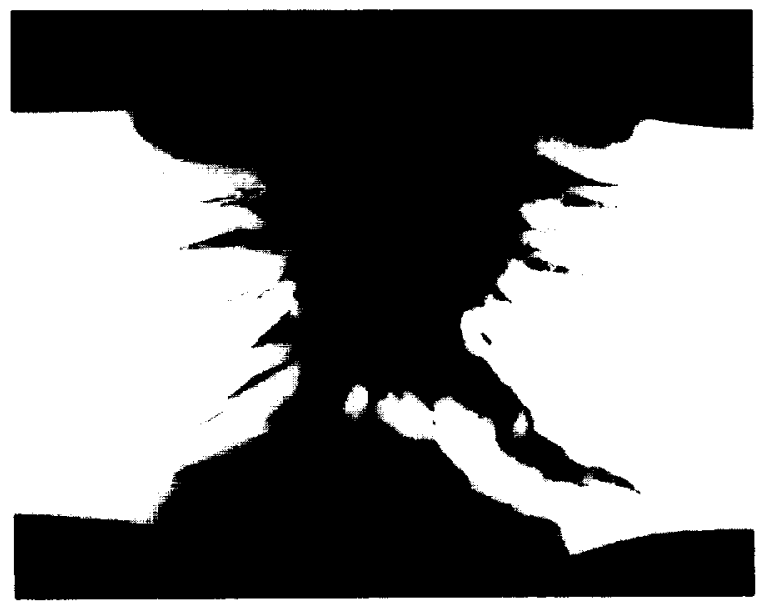


SHOT \# 109

PROJECTILE: Soda Lime

$$
\begin{aligned}
\mathrm{D}_{\mathrm{p}} & =3175 \mu \mathrm{m} \\
\mathrm{V} & =7.09 \mathrm{~km} / \mathrm{s}
\end{aligned}
$$

\section{TARGET: Teflon}

$$
\begin{aligned}
\mathrm{T} & =12929 \mu \mathrm{m} \\
\mathrm{D}_{\mathrm{p}} / \mathrm{T} & =0.25
\end{aligned}
$$

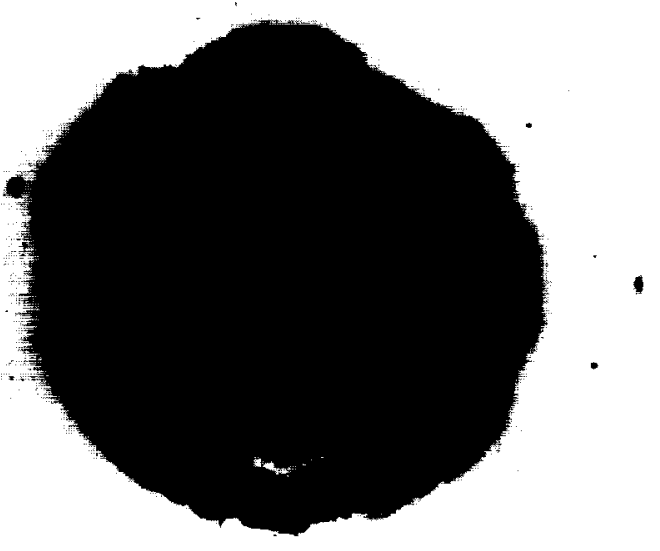

REAR

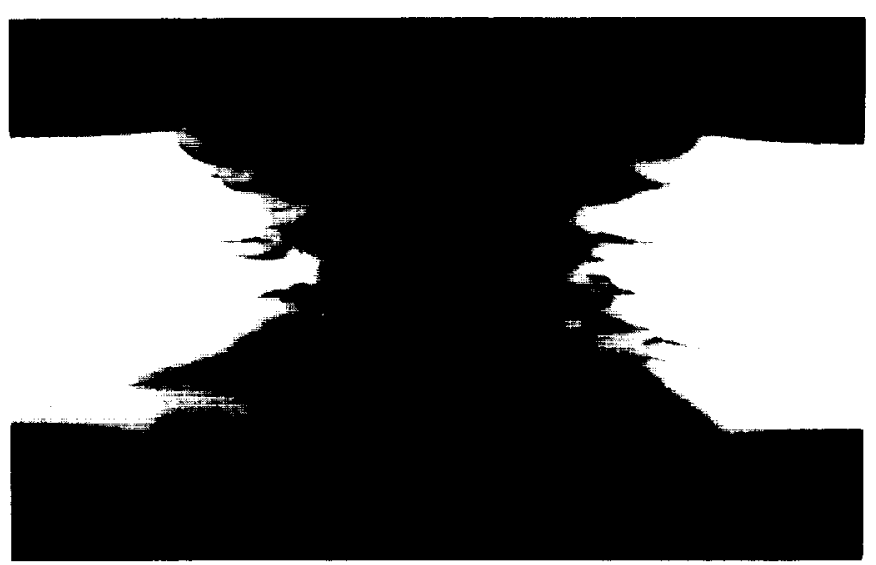


SHOT \# 109

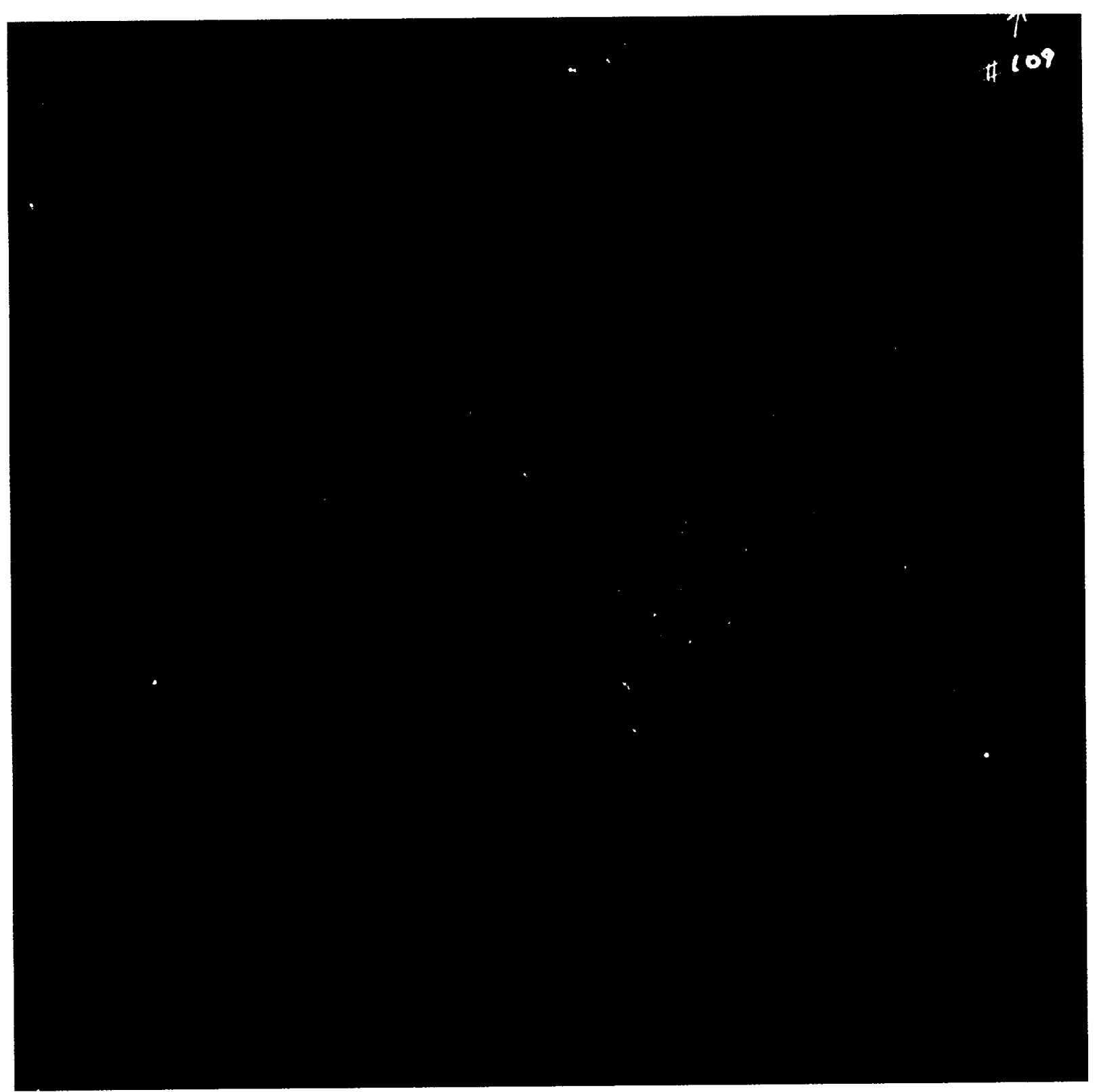




SHOT \# 110

PROJECTILE: Soda Lime

$\begin{aligned} \mathrm{D}_{\mathrm{p}} & =3175 \mu \mathrm{m} \\ \mathrm{V} & =6.94 \mathrm{~km} / \mathrm{s}\end{aligned}$

TARGET: Teflon

$\mathrm{T}=6400 \mu \mathrm{m}$

$\mathrm{D}_{\mathrm{p}} / \mathrm{T}=0.50$

FRONT

REAR

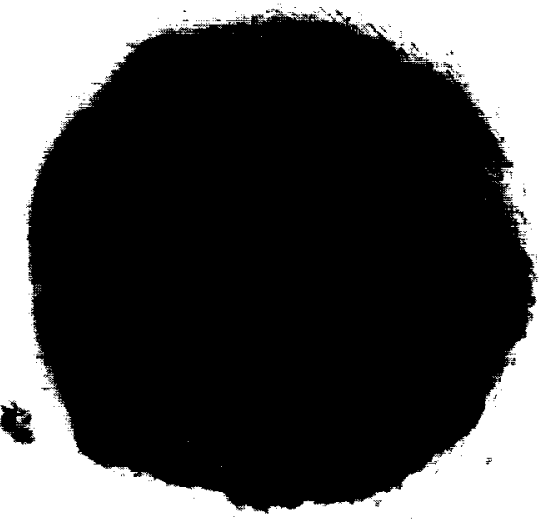

CROSS-SECTION
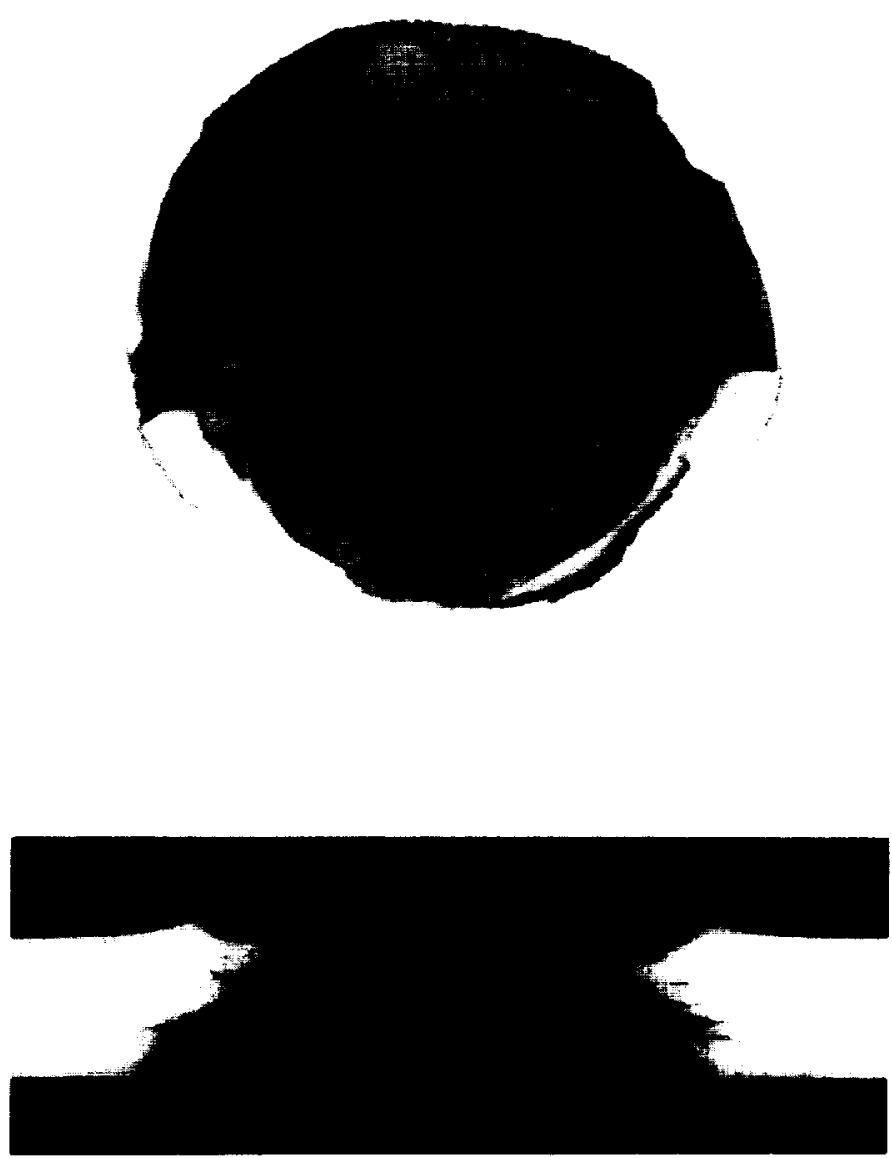
SHOT \# 110 


SHOT \# 111

PROJECTILE: Soda Lime

$$
\begin{aligned}
\mathrm{D}_{\mathrm{p}} & =3175 \mu \mathrm{m} \\
\mathrm{V} & =6.80 \mathrm{~km} / \mathrm{s}
\end{aligned}
$$

TARGET: Teflon

$$
\begin{aligned}
\mathrm{T} & =3226 \mu \mathrm{m} \\
\mathrm{D}_{\mathrm{p}} / \mathrm{T} & =0.98
\end{aligned}
$$

FRONT

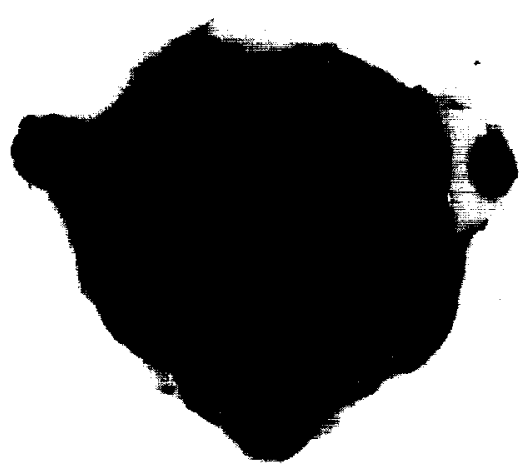

REAR

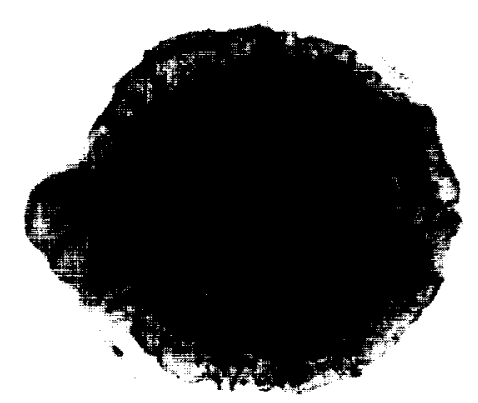

CROSS-SECTION

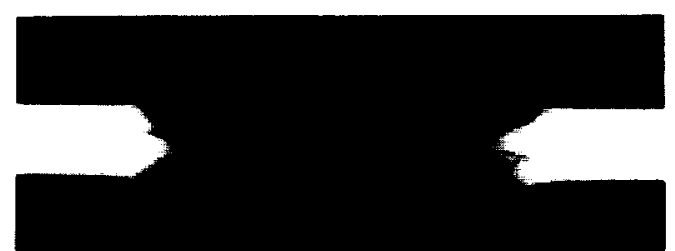


SHOT \# 111 


SHOT \# 112

PROJECTILE: Soda Lime

$D_{p}=3175 \mu \mathrm{m}$

$\mathrm{V}=7.09 \mathrm{~km} / \mathrm{s}$

TARGET: Teflon

$$
\begin{aligned}
\mathrm{T} & =500 \mu \mathrm{m} \\
\mathrm{D}_{\mathrm{p}} / \mathrm{T} & =6.35
\end{aligned}
$$

FRONT

REAR

\section{CROSS-SECTION}


SHOT \# 112

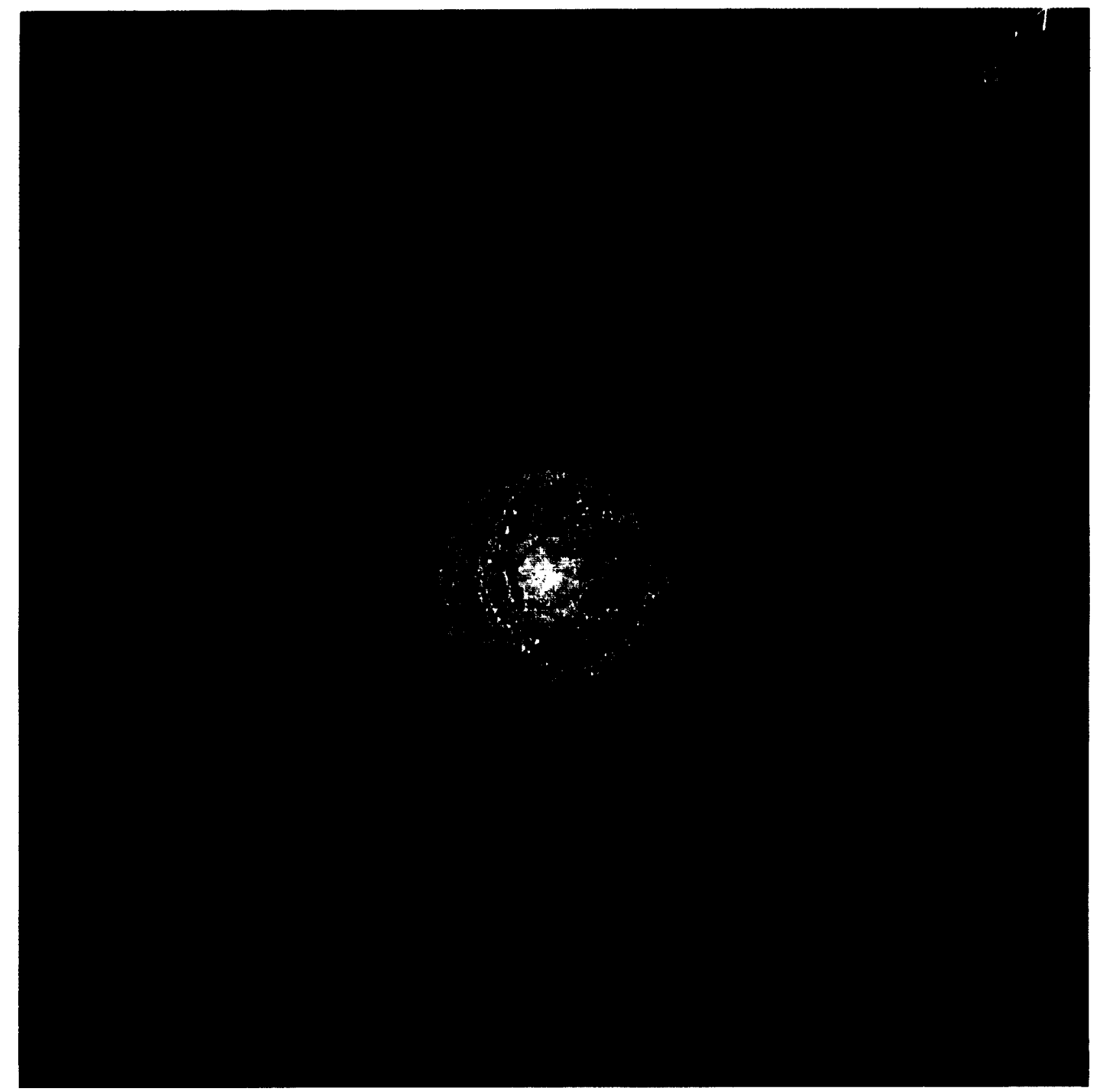






\section{SHOT \# 114}

PROJECTILE: Soda Lime

$$
\begin{aligned}
\mathrm{D}_{\mathrm{p}} & =3175 \mu \mathrm{m} \\
\mathrm{V} & =6.94 \mathrm{~km} / \mathrm{s}
\end{aligned}
$$

TARGET: Teflon

$$
\begin{aligned}
\mathrm{T} & =6 \mu \mathrm{m} \\
\mathrm{D}_{\mathrm{p}} / \mathrm{T} & =529.17
\end{aligned}
$$

FRONT

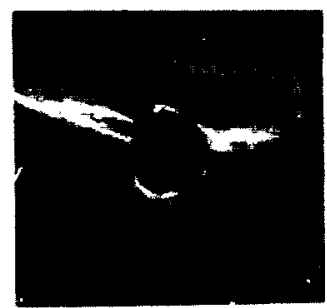

REAR 
SHOT \# 114

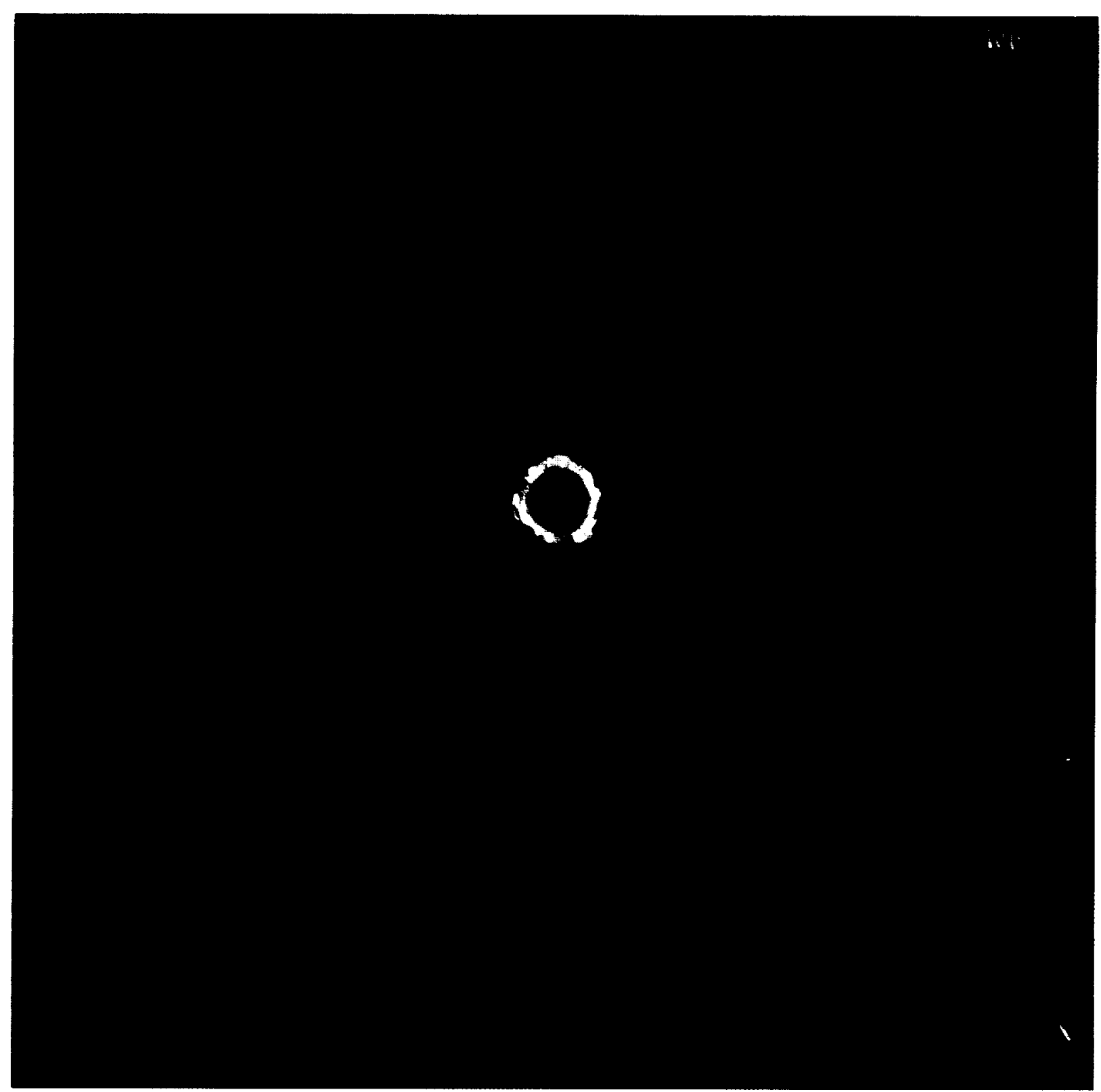

A141 



\section{Page Intentionally Left Blank}


$+4$

in 
Table 1. Experimental Matrix.

\section{manar not ruma:}

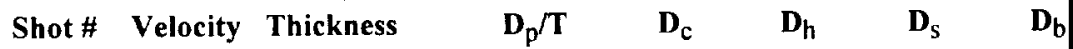
$(\mathrm{km} / \mathrm{s}) \quad(\mu \mathrm{m})$

\begin{tabular}{|c|c|c|c|c|c|c|c|}
\hline \multicolumn{8}{|c|}{ CRATERS } \\
\hline 3705 & 1.04 & 14351 & 0.221 & 2650 & & 6160 & \\
\hline 3708 & 1.61 & 15850 & 0.200 & 3310 & & 8980 & \\
\hline 3709 & 1.99 & 20890 & 0.152 & 4270 & & 10370 & \\
\hline 3591 & 2.35 & 19020 & 0.167 & 4920 & & 10410 & \\
\hline 3706 & 2.64 & 25400 & 0.125 & 5570 & & 11840 & \\
\hline 1313 & 3.02 & 19355 & 0.164 & 5120 & & 12620 & \\
\hline 1312 & 3.45 & 26512 & 0.120 & 5320 & & 13210 & \\
\hline 74 & 3.98 & 16850 & 0.188 & 6930 & & 16350 & \\
\hline 91 & 4.49 & 24400 & 0.130 & 7540 & & 16590 & \\
\hline 71 & 4.54 & 19010 & 0.167 & 8730 & & 16050 & \\
\hline 70 & 5.09 & 19152 & 0.166 & 7460 & & 18510 & \\
\hline 1315 & 5.37 & 26710 & 0.119 & 7120 & & 20030 & \\
\hline 69 & 5.44 & 19020 & 0.167 & 8920 & & 19430 & \\
\hline 1316 & 5.46 & 25146 & 0.126 & 7950 & & 20760 & \\
\hline 68 & 5.84 & 18959 & 0.167 & 8340 & & 20730 & \\
\hline 435 & 6.12 & 19050 & 0.167 & 10700 & & 20840 & \\
\hline 95 & 6.30 & 25600 & 0.124 & 9780 & & 21390 & \\
\hline 21 & 6.44 & 25550 & 0.124 & 12330 & & 21890 & \\
\hline 103 & 6.53 & 24190 & 0.131 & 10730 & & 22360 & \\
\hline 107 & 6.91 & 24790 & 0.128 & 11230 & & 22400 & \\
\hline \multicolumn{8}{|c|}{$2.3 \mathrm{~km} / \mathrm{s}$} \\
\hline 3592 & 2.32 & 12920 & 0.246 & 4420 & & 11140 & \\
\hline 3589 & 2.38 & 9580 & 0.331 & 4300 & 4300 & 10800 & 11510 \\
\hline 3588 & 2.31 & 6770 & 0.469 & & & & \\
\hline 3587 & 2.34 & 6450 & 0.492 & 4620 & 3780 & 11260 & 14320 \\
\hline 3590 & 2.44 & 4610 & 0.689 & & 4930 & 10070 & 12610 \\
\hline 3578 & 2.25 & 3110 & 1.021 & & 6750 & 10740 & 13090 \\
\hline 3586 & 2.20 & 815 & 3.896 & & 3930 & 6080 & 6300 \\
\hline 3585 & 2.27 & 500 & 6.350 & & 4150 & 5000 & 5100 \\
\hline 3584 & 2.33 & 250 & 12.700 & & 3850 & 3900 & 3900 \\
\hline 3583 & 2.30 & 100 & 31.750 & & 3425 & & \\
\hline 3582 & 2.28 & 50 & 63.500 & & 3350 & & \\
\hline 3581 & 2.31 & 25 & 127.000 & & 3300 & & \\
\hline 3580 & 2.32 & 12 & 264.583 & & 3175 & & \\
\hline 3579 & 2.23 & 6 & 529.167 & & 3175 & & \\
\hline \multicolumn{8}{|c|}{$4.0 \mathrm{~km} / \mathrm{s}$} \\
\hline 74 & 3.98 & 16850 & 0.188 & 6930 & & 16350 & \\
\hline 89 & 4.32 & 11049 & 0.287 & 7170 & 3850 & 17430 & 19680 \\
\hline 90 & 4.13 & 7950 & 0.399 & & 6430 & 15950 & 21660 \\
\hline 83 & 4.17 & 7950 & 0.399 & & 6850 & 15340 & 21040 \\
\hline 79 & 4.04 & 5004 & 0.634 & & 6360 & 12670 & 15890 \\
\hline 78 & 4.12 & 2985 & 1.064 & & & & \\
\hline 80 & 4.19 & 2920 & 1.087 & & 9170 & 14760 & 14510 \\
\hline 81 & 3.76 & 2019 & 1.573 & & 7100 & 11675 & 11300 \\
\hline 84 & 4.03 & 500 & 6.350 & & 4800 & 5600 & \\
\hline 85 & 4.12 & 250 & 12.700 & & 3500 & 3600 & \\
\hline 86 & 4.16 & 100 & 31.750 & & 4000 & 4300 & \\
\hline 87 & 4.12 & 6 & 529.167 & & 3200 & & \\
\hline
\end{tabular}


Table 1. (continued)

\begin{tabular}{|c|c|c|c|c|c|c|c|}
\hline Shot \# & $\begin{array}{c}\text { Velocity } \\
(\mathrm{km} / \mathrm{s})\end{array}$ & $\begin{array}{c}\text { Target } \\
\text { Thickness } \\
(\mu \mathrm{m})\end{array}$ & $\mathrm{D}_{\mathrm{p}} / \mathrm{T}$ & $\mathbf{D}_{\mathrm{c}}$ & $\mathbf{D}_{\mathrm{h}}$ & $\mathbf{D}_{\mathrm{s}}$ & $\mathbf{D}_{\mathrm{b}}$ \\
\hline \multicolumn{8}{|c|}{$6.0 \mathrm{~km} / \mathrm{s}$} \\
\hline 434 & 5.87 & 15875 & 0.200 & 11350 & & 21630 & \\
\hline 433 & 5.90 & 12700 & 0.250 & 9960 & 6700 & 19090 & 23560 \\
\hline 432 & 6.04 & 9590 & 0.331 & & 10470 & 19450 & 23620 \\
\hline 430 & 5.98 & 4670 & 0.680 & & 11610 & 19930 & 19040 \\
\hline 429 & 5.97 & 2920 & 1.087 & & 9780 & 16000 & 16190 \\
\hline 428 & 5.86 & 1588 & 1.999 & & 9180 & 10630 & 10380 \\
\hline 495 & 6.04 & 787 & 4.034 & & 5860 & 6780 & 6880 \\
\hline 497 & 6.07 & 533 & 5.957 & & 5620 & 5800 & 5770 \\
\hline 501 & 5.96 & 254 & 12.500 & & 4140 & & \\
\hline 504 & 6.02 & 127 & 25.000 & & 3610 & & \\
\hline 505 & 5.98 & 127 & 25.000 & & 3350 & & \\
\hline \multicolumn{8}{|c|}{$6.3 \mathrm{~km} / \mathrm{s}$} \\
\hline 25 & 6.36 & 23160 & 0.137 & 10660 & & 23190 & \\
\hline 22 & 6.40 & 21270 & 0.149 & 9940 & & 21540 & \\
\hline 26 & 6.31 & 19130 & 0.166 & 9850 & & 21960 & 25070 \\
\hline 20 & 6.60 & 17463 & 0.182 & 9780 & 2150 & 21350 & 23100 \\
\hline 11 & 6.41 & 14275 & 0.222 & 9850 & 7000 & 23790 & 30460 \\
\hline 13 & 6.55 & 12650 & 0.251 & & 8560 & 21770 & 32490 \\
\hline 12 & 6.62 & 11050 & 0.287 & & 9070 & 21570 & 29520 \\
\hline 23 & 6.39 & 9360 & 0.339 & & 8970 & 23410 & 27740 \\
\hline 19 & 6.41 & 7670 & 0.414 & & 11010 & 22450 & 30300 \\
\hline 31 & 6.49 & 6820 & 0.466 & & 10400 & 21450 & 24720 \\
\hline 27 & 6.32 & 6200 & 0.512 & & 15380 & & \\
\hline 32 & 6.17 & 6130 & 0.518 & & 11280 & 21200 & 23620 \\
\hline 17 & 6.31 & 4950 & 0.641 & & 15120 & 23460 & 24150 \\
\hline 29 & 6.37 & 4150 & 0.765 & & 12970 & 19010 & 20300 \\
\hline 28 & 6.22 & 3650 & 0.870 & & 11480 & 16780 & 18380 \\
\hline 18 & 6.56 & 3250 & 0.977 & & 10910 & 17780 & 18850 \\
\hline 34 & 6.25 & 1640 & 1.936 & & 8500 & & \\
\hline 35 & 6.32 & 800 & 3.969 & & 6000 & & \\
\hline 36 & 6.35 & 520 & 6.106 & & 5500 & & \\
\hline 37 & 6.46 & 230 & 13,804 & & 4300 & & \\
\hline 113 & 6.29 & 100 & 31.750 & & 3650 & & \\
\hline 38 & 6.37 & 80 & 39.688 & & 3600 & & \\
\hline 40 & 6.31 & 40 & 79.375 & & 3350 & & \\
\hline 42 & 6.32 & 20 & 158.750 & & 3400 & & \\
\hline 43 & 6.31 & 10 & 317.500 & & 3300 & & \\
\hline 44 & 6.33 & 6 & 529.167 & & 3300 & & \\
\hline \multicolumn{8}{|c|}{$7.0 \mathrm{~km} / \mathrm{s}$} \\
\hline 108 & 7.00 & 17983 & 0.177 & 11820 & & 23430 & 19420 \\
\hline 109 & 7.09 & 12929 & 0.246 & 11970 & 7070 & 23020 & 26310 \\
\hline 110 & 6.94 & 6400 & 0.496 & 13510 & 12480 & 22760 & 28050 \\
\hline 111 & 6.80 & 3226 & 0.984 & & 11690 & 18340 & 16800 \\
\hline 112 & 7.09 & 500 & 6.350 & & 5600 & 6675 & 6500 \\
\hline 114 & 6.94 & 6 & 529.167 & & 3500 & & \\
\hline
\end{tabular}


Table 2. Numerical listing of all experimental shots included in this study.

\begin{tabular}{|c|c|c|c|}
\hline Shot & Purpose & $\mathrm{D}_{\mathrm{p}} \sqrt{\mathrm{T}}$ & Page \\
\hline 11 & Penetration@6.3 km/s & 0.222 & A90 \\
\hline 12 & Penetration@6.3 km/s & 0.287 & A94 \\
\hline 13 & Penetration@6.3 km/s & 0.251 & $\mathbf{A 9 2}$ \\
\hline 17 & Penetration $@ 6.3 \mathrm{~km} / \mathrm{s}$ & 0.641 & A104 \\
\hline 18 & Penetration@6.3 km/s & 0.977 & A110 \\
\hline 19 & Penetration@6.3 km/s & 0.414 & A98 \\
\hline 20 & Penetration@6.3 km/s & 0.182 & A88 \\
\hline 21 & Crater@6.3 km/s & 0.124 & A18 \\
\hline 22 & Crater@6.3 km/s & 0.149 & A86 \\
\hline 23 & Penetration@6 $6.3 \mathrm{~km} / \mathrm{s}$ & 0.339 & A96 \\
\hline 25 & Crater@6.3 km/s & 0.137 & A85 \\
\hline 26 & Crater $@ 6.3 \mathrm{~km} / \mathrm{s}$ & 0.166 & A87 \\
\hline 27 & Penetration @6.3 km/s & 0.512 & $\mathbf{N P}$ \\
\hline 28 & Penetration@6.3 km/s & 0.870 & A108 \\
\hline 29 & Penetration@6.3 km/s & 0.765 & A106 \\
\hline 31 & Penetration @6.3 km/s & 0.466 & $\mathbf{A} 100$ \\
\hline 32 & Penetration@6.3 km/s & 0.518 & A102 \\
\hline 34 & Penetration@6.3 km/s & 1.936 & A112 \\
\hline 35 & Penetration @6.3 km/s & 3.969 & A114 \\
\hline 36 & Penetration@6.3 km/s & 6.106 & A116 \\
\hline 37 & Penetration@6.3 km/s & 13.804 & A118 \\
\hline 38 & Penetration@6.3km/s & 39.688 & $\mathbf{A 1 2 0}$ \\
\hline 40 & Penetration@6.3 km/s & 79.375 & A122 \\
\hline 42 & Penetration $@ 6.3 \mathrm{~km} / \mathrm{s}$ & 158.750 & A124 \\
\hline 43 & Penetration $@ 6.3 \mathrm{~km} / \mathrm{s}$ & 317.500 & A126 \\
\hline 44 & Penetration@6.3 km/s & 529.167 & A128 \\
\hline 68 & Crater@ $9.84 \mathrm{~km} / \mathrm{s}$ & 0.167 & A15 \\
\hline 69 & Crater@ $5.44 \mathrm{~km} / \mathrm{s}$ & 0.167 & A13 \\
\hline 70 & Crater@ $5.09 \mathrm{~km} / \mathrm{s}$ & 0.166 & A11 \\
\hline 71 & Crater@ $4.54 \mathrm{~km} / \mathrm{s}$ & 0.167 & $\mathbf{A 1 0}$ \\
\hline 74 & Crater $@ 3.98 \mathrm{~km} / \mathrm{s}$ & 0.188 & $A 8 \& A 45$ \\
\hline 78 & Penetration@ $9 \mathrm{~km} / \mathrm{s}$ & 1.064 & A52 \\
\hline 79 & Penetration@ @ km/s & 0.634 & $\mathbf{N P}$ \\
\hline 80 & Penetration@ $9 \mathrm{~km} / \mathrm{s}$ & 1.087 & A54 \\
\hline 81 & Penetration @ $4 \mathrm{~km} / \mathrm{s}$ & 1.573 & A56 \\
\hline 83 & Penetration @ $4 \mathrm{~km} / \mathrm{s}$ & 0.399 & A50 \\
\hline 84 & Penetration@ 4 km/s & 6.350 & A58 \\
\hline 85 & Penetration@ $9 \mathrm{~km} / \mathrm{s}$ & 12.700 & A60 \\
\hline 86 & Penetration@ $4 \mathrm{~km} / \mathrm{s}$ & 31.750 & A62 \\
\hline 87 & Penetration $@ 4 \mathrm{~km} / \mathrm{s}$ & 529.167 & A64 \\
\hline 89 & Penetration@ $9 \mathrm{~km} / \mathrm{s}$ & 0.287 & A46 \\
\hline 90 & Penetration@ $9 \mathrm{~km} / \mathrm{s}$ & 0.399 & A48 \\
\hline 91 & Crater @ $4.49 \mathrm{~km} / \mathrm{s}$ & 0.125 & A9 \\
\hline 95 & Crater@6.30 km/s & 0.124 & A17 \\
\hline
\end{tabular}

\begin{tabular}{|c|c|c|c|}
\hline Shot & Purpose & $\mathrm{D}_{\mathrm{p}} / \mathrm{T}$ & Page \\
\hline 103 & Crater@6.53 km/s & 0.131 & A19 \\
\hline 107 & Crater@6.91 km/s & 0.128 & $\mathbf{A} 20$ \\
\hline 108 & Crater@ $7.00 \mathrm{~km} / \mathrm{s}$ & 0.177 & A131 \\
\hline 109 & Penetration @ $7 \mathrm{~km} / \mathrm{s}$ & 0.246 & A132 \\
\hline 110 & Penetration@ 9 km/s & 0.496 & A134 \\
\hline 111 & Penetration@7 km/s & 0.984 & A136 \\
\hline 112 & Penetration@7 km/s & 6.350 & A138 \\
\hline 113 & Penetration@6.3km/s & 31.750 & $\mathbf{N P}$ \\
\hline 114 & Penetration@ @ $7 \mathrm{~km} / \mathrm{s}$ & 529.167 & A140 \\
\hline 428 & Penetration@6 km/s & 1.999 & A74 \\
\hline 429 & Penetration@6 km/s & 1.087 & $\mathbf{A 7 2}$ \\
\hline 430 & Penetration@6 km/s & 0.680 & $\mathbf{N P}$ \\
\hline 432 & Penetration@6 km/s & 0.331 & A 70 \\
\hline 433 & Penetration@6 km/s & 0.250 & A68 \\
\hline 434 & Crater@ @ 5.87 km/s & 0.200 & $\mathbf{A 6 7}$ \\
\hline 435 & Crater@ $6.12 \mathrm{~km} / \mathrm{s}$ & 0.167 & A16 \\
\hline 495 & Penetration@6 km/s & 4.034 & A76 \\
\hline 497 & Penetration@6km/s & 5.957 & A78 \\
\hline 501 & Penetration@6km/s & 12.500 & $\mathbf{A 8 0}$ \\
\hline 504 & Penetration@6 km/s & 25.000 & $\mathbf{N P}$ \\
\hline 505 & Penetration@6 km/s & 25.000 & A82 \\
\hline 1312 & Crater @ $3.45 \mathrm{~km} / \mathrm{s}$ & 0.120 & A7 \\
\hline 1313 & Crater@3.02 km/s & 0.164 & A6 \\
\hline 1315 & Crater@ $5.37 \mathrm{~km} / \mathrm{s}$ & 0.119 & A12 \\
\hline 1316 & Crater@ @5.46 km/s & 0.126 & A14 \\
\hline 3578 & Penetration $@ 2.3 \mathrm{~km} / \mathrm{s}$ & 1.021 & $\mathbf{A} 30$ \\
\hline 3579 & Penetration@ $2.3 \mathrm{~km} / \mathrm{s}$ & 529.167 & A44 \\
\hline 3580 & Penetration $@ 2.3 \mathrm{~km} / \mathrm{s}$ & 264.583 & A43 \\
\hline 3581 & Penetration @ $2.3 \mathrm{~km} / \mathrm{s}$ & 127.000 & $\mathbf{A 4 2}$ \\
\hline 3582 & Penetration@ $2.3 \mathrm{~km} / \mathrm{s}$ & 63.500 & $\mathbf{A 4 0}$ \\
\hline 3583 & Penetration@2.3 km/s & 31.750 & A38 \\
\hline 3584 & Penetration@2.3 km/s & 12.700 & A36 \\
\hline 3585 & Penetration@ $2.3 \mathrm{~km} / \mathrm{s}$ & 6.350 & A34 \\
\hline 3586 & Penetration@ $2.3 \mathrm{~km} / \mathrm{s}$ & 3.896 & $\mathbf{A 3 2}$ \\
\hline 3587 & Penetration@ @ 2.3 km/s & 0.492 & A26 \\
\hline 3588 & Penetration@ $2.3 \mathrm{~km} / \mathrm{s}$ & 0.469 & A24 \\
\hline 3589 & Penetration @ $2.3 \mathrm{~km} / \mathrm{s}$ & 0.331 & A22 \\
\hline 3590 & Penetration@ @ $2.3 \mathrm{~km} / \mathrm{s}$ & 0.689 & A28 \\
\hline 3591 & Crater $@ 2.3 \mathrm{~km} / \mathrm{s}$ & 0.167 & A4 \\
\hline 3592 & Crater $@ 2.3 \mathrm{~km} / \mathrm{s}$ & 0.246 & A21 \\
\hline 3705 & Crater@ $1.04 \mathrm{~km} / \mathrm{s}$ & 0.221 & A1 \\
\hline 3706 & Crater $@ 2.64 \mathrm{~km} / \mathrm{s}$ & 0.125 & A5 \\
\hline 3708 & Crater@1.61 km/s & 0.200 & A2 \\
\hline 3709 & Crater@1.99km/s & 0.152 & A3 \\
\hline
\end{tabular}

NP $=$ Not Pictured 


\section{REPORT DOCUMENTATION PAGE}

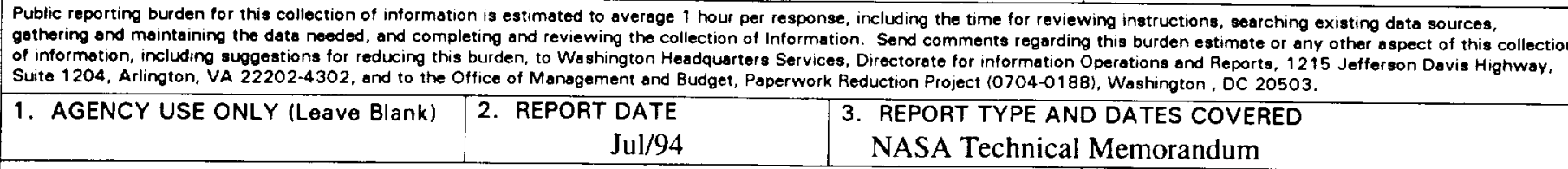

4. TITLE AND SUBTITLE

5. FUNDING NUMBERS

Cratering and Penetration Experiments in Teflon Targets at Velocities from 1 to $7 \mathrm{~km} / \mathrm{s}$

6. AUTHOR(S)

Friedrich Horz, Mark Cintala, Ronald P. Bernhard*, Frank Cardenas*, William Davidson*, Gerald Haynes*, Thomas H. See*, Jerry Winkler*, Jeffrey Knight**

\section{PERFORMING ORGANIZATION NAME(S) AND ADDRESS(ES)}

NASA Lyndon B. Johnson Space Center

Houston, Texas 77058

9. SPONSORING/MONITORING AGENCY NAME(S) AND ADDRESS(ES)

National Aeronautics and Space Administration

Washington, DC 20546-0001
8. PERFORMING ORGANIZATION REPORT NUMBERS

S-771

10. SPONSORING/MONITORING AGENCY REPORT NUMBER

TM-104797

11. SUPPLEMENTARY NOTES

*Lockheed Engineering and Sciences Company, Houston, Texas

**University of Houston, Houston, Texas

12a. DISTRIBUTION/AVAILABILITY STATEMENT

Unclassified/Unlimited

12b. DISTRIBUTION CODE

Available from NASA Center for AeroSpace Information

800 Elkridge Landing Road

Linthicum Heights, MD 21090-2934

(301) 621-0390

Subject category: 24

13. ABSTRACT (Maximum 200 words)

Impact experiments in Teflon targets were conducted to reproduce craters and penetration holes in thermal protective blankets that were exposed to space for 5.7 years on board the long duration exposure facility. The objective was to understand the relationships between projectile size and the resulting crater or penetration-hole diameter over a wide range of impact velocities. Powder propellant and light-gas guns were used to launch soda-lime glass spheres of $3.175 \mathrm{~mm}\left(1 / 8^{\prime \prime}\right)$ nominal diameter (Dp) into pure Teflon targets at velocities ranging from 1 to $7 \mathrm{~km} / \mathrm{s}$. Target thickness (T) was varied over more than three orders of magnitude from infinite halfspace targets $(\mathrm{Dp} / \mathrm{T}<0.1)$ to very thin films $(\mathrm{Dp} / \mathrm{T}>100)$.

Cratering and penetration of massive Teflon targets is dominated by brittle failure and the development of extensive spall zones at the target's front and, if penetrated, the target's rear side. Mass removal by spallation at the back side of Teflon targets may be so severe that the absolute penetration-hole diameter (Dh) can become larger than that of a standard crater (Dc) at relative target thicknesses of $\mathrm{Dp} / \mathrm{T}=0.6-0.9$. The crater diameter in infinite halfspace Teflon targets increases -- at otherwise constant impact conditions -- with encounter velocity by a factor of $V 0.44$. In contrast, the penetration-hole size in very thin foils $(\mathrm{Dp} / \mathrm{T}>50)$ is essentially unaffected by impact velocity. Penetrations at target thicknesses intermediate to these extremes will scale with variable exponents of $V$. Our experimental matrix is sufficiently systematic and complete, up to 7 $\mathrm{km} / \mathrm{s}$, to make reasonable recommendations for the velocity scaling of Teflon craters and penetrations. We specifically suggest that cratering behavior and associated equations apply to all impacts in which the shock-pulse duration of the projectile (tp) is shorter than that of the target (It).

\section{SUBJECT TERMS}

projectile cratering; impact damage; hypervelocity impact; Teflon; thermal protection

15. NUMBER OF PAGES 317 \begin{tabular}{l|l} 
17. SECURITY CLASSIFICATION & $\begin{array}{l}\text { 18. SECURITY CLASSIFICATION } \\
\text { OF REPORT }\end{array}$ \\
OF THIS PAGE
\end{tabular}

Unclassified Unclassified

NSN 7540-01-280-5500

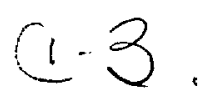

16. PRICE CODE

20. LIMITATION OF ABSTRACT OF ABSTRACT Unclassified Unlimited

Standard Form 298 (Rev 2-89) Prescribed by ANSI Std. 239-18 298.102 

